\title{
USING TECHNOLOGY FOR GLOBAL RECRUITMENT Why HR/OB Scholars Need IS Knowledge?
}



USING TECHNOLOGY FOR GLOBAL RECRUITMENT Why HR/OB Scholars Need IS Knowledge? 


\section{Graduation Committee}

Prof. Dr. Ramses Wessel (dean), University of Twente, the Netherlands

Prof. Dr. Celeste Wilderom (promoter), University of Twente, the Netherlands

Prof. Dr. Rolf van Dick, University of Frankfurt, Germany

Prof. Dr. Jos van Hillegersberg, University of Twente, the Netherlands

Prof. Dr. Gordon Hunter, University of Lethbridge, Canada

Prof. Dr. Jan-Kees Looise, University of Twente, the Netherlands

Prof. Dr. Bart Nieuwenhuis, University of Twente, the Netherlands

Prof. Dr. Tom W. Kent, University of Charleston, SC, USA

Prof. Dr. Roland Mueller, Berlin School of Economics and Law, Germany

Prof. Dr. Dennis Muntslag, University of Twente, the Netherlands

Prof. Dr. David J. Teece, University of California, Berkeley, USA

Dr. Tanya Bondarouk, University of Twente, the Netherlands

Dr. Svetlana Khapova, VU University Amsterdam, the Netherlands

Dr. Pramila Rao, Marymount University, USA

Dr. Mary Tate, Victoria University of Wellington, New Zealand

Copyright (C) 2012. All rights reserved.

ISBN: 978-90-365-3384-3

DOI: 10.3990/1.9789036533843

Email: elfi.furtmueller@amc.or.at 


\title{
USING TECHNOLOGY FOR GLOBAL RECRUITMENT Why HR/OB Scholars Need IS Knowledge?
}

\author{
DISSERTATION \\ to obtain \\ the degree of doctor at the University of Twente, \\ on the authority of the rector magnificus, \\ Prof.dr. H. Brinksma, \\ on account of the decision of the graduation committee, \\ to be publicly defended \\ on $22^{\text {nd }}$ June, 2012 at $04: 45 \mathrm{PM}$
}

By

Elfi Furtmueller

Born on $15^{\text {th }}$ May, 1978

Wels, Austria 
This dissertation has been approved by:

Prof. Dr. Celeste Wilderom (promotor) 


\section{TABLE OF CONTENTS}

\section{Chapter 1}

Preface

Introduction and Overview

\section{Chapter 2}

Electronic Human Resource Management: Four Decades of Empirical Evidence

\section{Chapter 3}

A Review of the e-Recruiting Literature

\section{Chapter 4}

Managing Recruitment and Selection in the Digital Age: E-HRM and Resumes

\section{Chapter 5}

Designing E-HRM Systems: The Service-dominant Logic

\section{Chapter 6}

IT Professionals' Preferred Modes of Being Recruited in the Contemporary Economy

\section{Chapter 7}

Sustainable e-Recruiting Services: How to Motivate Applicants to Stay Connected Throughout their Careers?

\section{Chapter 8}

Utilizing the Lead User Method for Promoting Innovation in e-Recruiting Services

Design

\section{Chapter 9}

Globalizing e-HRM Services: Localization versus Standardization of HRM Practices

\section{Chapter 10}

Synthesis \& What Future Online Career Services Research Needs to Solve 



\section{CHAPTER 1}

\section{Preface}

Coming from a background in Organizational Behaviour (OB) and Human Resource Management (HRM) to an Information Systems (IS) department at the University of Twente in the Netherlands, I found a vibrant environment and colleagues with rich and diverse knowledge on designing, implementing and effectively managing information technology. Working amidst Information Systems, Computer Science and Human Resources researchers motivated me to recognize the tension between HRM/OB and IS research and think about means to bring these two disciplines fruitfully together.

Research fields have their own scholarly communities, conferences and journals, and during my PhD journey I was frequently challenged to position myself as either an HRM/OB or an IS researcher when presenting research results to diverse audiences. I quickly learned that HRM/OB and IS scholars have very different mindsets about how to effectively use information systems to automate human resource departments.

It appeared an exciting and risky endeavor to find a home for my research ideas. After having presented earlier research findings at various international technical conferences (AOIR, BIS, DrupalCon, ECIS, HICSS, ICEIS, ICIS), I realized the need to catch up and learn new theories and methods to effectively navigate between these two different research communities. Fortunately, I received strong support from the Department of Information Systems and Change Management. Soon after I began this line of research I had the good fortune to also come into contact with staff from the Department of Operations, Organization and Human Resources Management. I absorbed their focus on related e-HRM research areas which enabled me to present my initial study results at the European Workshop of e-HRM and contribute to a Handbook on the Transformation of HRM.

All of the above has finally come together in this dissertation ${ }^{1}$. While the ink was still wet I attended the 2011 Academy of Management Meetings in San Antonio, Texas, where I

\footnotetext{
${ }^{1}$ I did not include all articles which I produced together with my colleagues in the past years. Readers who are interested in additional articles which emerged from this stream of research are referred to my publication list at the end of this book.
} 
had the opportunity to discuss e-HRM and my e-Recruiting research with some Human Resource Management scholars. These conversations and presentations I attended reinforced my thesis' conviction about living on the edge - about the deep need to continue building all sorts of bridges between technical and social sciences researchers. At the conference I was excited to meet several respected scholars who publish widely in the field of online recruitment. While the term e-Recruitment became common sense to me when I was employed in an information systems department where everything becomes "e" (e-learning, eservices, e-business, e-architecture, e-health, e-government, e-modeling, etc.), it was curious that the term "e-Recruitment" (obviously different from the term online recruiting) and the link to information systems research appeared strange to some of the HRM scholars. Recruiting using online channels seems to appear more closely related to the human resources ontological mindset.

High tech with a human touch reflects the mission of the University of Twente and this dissertation reflects the various mindsets of strategic managers, users, system analysts, designers and developers of e-Recruiting services. In particular, I aim to add value to the literature on designing and innovating sustainable e-Recruiting services or, as IS researchers would put it: requirements for next generation (global) e-Recruiting services. I did not set out to engage in analyzing implementations of recruiting software in organizations and all the things that can go wrong during such implementations, since there is already superb research available on implementation (such as SAP HR/3) and organizational change (e.g. Kossek et al., 1994; Bondarouk et al., 2009; Heikkilä \& Smale, 2010).

Rather, I seek to contribute to the scholarly discussion on designing global recruiting services and architectures, since sourcing new staff in our progressively flat world is increasingly done on a global basis. 


\section{Introduction and Overview}

The early digitalization of personnel departments was marked by a generation of scholarly efforts to understand and explain the multiple reasons underlying the adoption of Human Resource Information Systems (HRIS) (Mayer, 1971; Tomeski \& Lazarus, 1974; DeSanctis, 1986). A new generation of inquirers has emerged who have recognized its power of potentially transforming human resourcing tasks (Ruel et al., 2004; Bondarouk \& Ruel, 2009; Marler, 2009) and accordingly displaced the term HRIS with that of e-HRM (Electronic Human Resource Management). Whereas HRIS are primarily intended to reduce HR departments' administrative burden, e-HRM promises strategic service improvements and role changes of HR professionals (Lawler \& Mohrman, 2003).

Within e-HRM research, the study of automating organizations' recruiting services (referred to e-Recruiting, online recruiting, web-based-recruiting) is the most studied subfield. Unlike traditional recruitment methods for tapping the labor pool, it exploits digital means and resources such as the intranet and its panoply of desktop and mobile technologies to support the recruiting process. A contemporary survey of global human resource departments reveals that nearly all Fortune 500 companies use some form of e-Recruiting (Lee, 2005; CedarCrestone, 2011), making it one of the most widely practiced e-business application in organizations (Lee, 2011).

Academics engaged in e-Recruitment research largely belong to two disciplines: (1) human resource management, and (2) information systems. Bringing the virtues of the best explanatory theories of these two domains together is challenging, mirroring the real life difficulty of persuading traditional personnel departments of the genuine working value of computerized information systems. It cannot be stressed enough how deep-seated is the loyalty to older timeworn normal means of recruitment - where face-to-face contact and recruiters' individual evaluation of applicants' skills (e.g. pre-screening, selection interviews, assessment centers) were long seen as an integral part of a recruiter's job (Gardner et al., 2003). Recruiters are of course still important in the overall recruitment process because they perform a fundamental role in articulating information about the job and the hiring organization (Carless \& Wintle, 2007). That being said, e-Recruitment should help recruiters to take the matching of employees and employers to the next level (Jones et al., 2002). For example, organizations that use corporate career sections can provide applicants with patently superior information about the organization, its culture, the job and career perspectives (Stone et al., 2006). 
Modern organizations survive increasing competition and globalization by adopting the cost and time savings of IT, striving to improve recruiters' ability to handle job postings and job applications by minimizing paperwork and automating key recruiting activities (Furtmueller et al., 2010). Nearly two decades after the sudden emergence of the world wide web the vast majority of larger organizations routinely use e-Recruiting as the primary method for job-searching and recruiting activity (Lee, 2011). E-Recruitment has radically changed the heart and pace and radius of both recruitment processes and the way applicants search and apply for jobs. No one alive in 1992 would have been able to comprehend the truly incommensurable ways recruiters today publish job ads and communicate interactively with applicants. In this new world of online applications and video interviews, it is not at all surprising many personnel departments fear downsizing (administrative) HR staff, resist quick acceptance of information systems, and are challenged by failed organizational change initiatives.

The advantages of our new connected world are by no means taken for granted or obvious to everyone. Utilizing the potential of e-HRM is very often acutely constrained by the complexities of people dynamics such as managing user acceptance when adapting new eHRM systems (Grant et al., 2009). Problematical communication and misunderstanding between human resource personnel with IT staff that is transparent to everyone has been found to prevent successful e-HRM implementations (Wilson-Evered \& Hartel, 2009). A further more opaque obstacle was documented by Gardner et al. (2003) who found that in practice the implementation of e-HRM, rather than freeing up time for HR practitioners, simply led to the replacement of administrative duties with technology-related work. In brief, it did not reach the intended goal of improving HRM services. Other studies report numerous cases where HR professionals were unsuccessful in using technology to initiate and support strategic decisions (Dery \& Wailes, 2005), or e-HRM technology was primarily used to simply support routine administrative HR tasks (Ball, 2001; Haines \& Lafleur, 2008; Hussain et al. 2007).

However some companies after years of experimenting with it have abandoned eRecruiting, and retreated back to traditional recruiting techniques such as newspaper ads (Lee, 2011). These companies typically suffered from ineffective storage and sorting of huge volumes of digital job applications, the cost of which they determined offset the expected cost savings (Furtmueller et al., 2011). For instance, Chapman and Webster's (2003) report that only $25 \%$ of organizations using e-Recruitment regard its implementation as successful. Given the widespread ambivalence and well founded fears of stakeholders who grasp the 
overriding significance of their decisions to go digital in their everyday organizational recruitment, it is manifest that far more understanding on how to design effective e-Recruiting services from the various users' perspectives is needed so as to wisely transform traditional recruitment to e-Recruitment (Galanaki, 2002; Singh \& Finn, 2003; Ruel et al., 2004).

Organizations are now aware that electronic staffing activities need to be integrated seamlessly along the entire recruiting process in order to take full advantage of emerging technologies. In the research literature it is well established that IT is not an autonomous island and does not per se generate value (Peppard \& Ward, 2004). To the contrary, keen observers have found that investments in IT require complementary investments in a host of non-IT processes, structures and organizational resources to generate value (Melville, 2004); there is no doubt whatsoever that the effects of IT resources on performance parameters result from a continuous interplay with other complementary resources (Teece et al., 1997).

When investments in technology are made naively - without a corresponding evolution in the organizational skills and routines, the result might be a significant productivity loss. The potential value of IT is subject to being overcompensated by negative influences due to a profound mismatch of long-standing organizational practices and the IT structure implemented (Brynjolfsson \& Hitt, 2000).

Overcoming barriers to IT adoption in recruiting thus requires a deeper understanding of the requirements of e-Recruiting systems. Poorly designed and ineffective recruiting services discourage job applicants from submitting and updating profiles (Lee, 2011). Recruiters were found who were frustrated about wasting their time on "digital applicants" in outdated resume profile databases (Furtmueller et al., 2010).

Consequently, this thesis takes a service engineering approach by studying the diverse needs of end-users (applicants, recruiters, employee branding professionals), system designers, and developers as well as managers of e-Recruiting systems, in order to innovate and make e-Recruiting services more dynamic and thus sustainable. 
Chapter 2 opens with a critical survey of the past four decades research literature concerned with the digitalization of e-HRM personnel services.

Chapter 3 presents an overview of current state-of the art academic e-Recruiting literature. Research into e-Recruiting represents the most studied functional area within eHRM literature.

Chapter 4 delineates the requirements of digital resume forms and emphasizes the basic differences between print and digital resume content. Challenges in categorizing digital resume data and digital matching between resumes and job advertisements are identified. Data was systematically gathered during interviews with recruiters and content analysis of 40 e-Recruiting sites.

Chapter 5 continues this line of research and uses a service engineering lens to focus on the sustainable design of personnel services. I try to map out how personnel departments, challenged to adapt to our connected universe, can use IT as a service to support strategically important business processes and decisions. Special emphasis is placed on one particular path that was carved out - a design science project carried out over seven years that used a service engineering life-cycle to design, develop, implement and evaluate a leading e-Recruiting system. It includes a discussion of the simplest effective conceptual ontology for digital resume content, classifying staffing processes for the automatic extraction of relevant metadata for applicant selection, and a workflow for resume searching, maintenance and extension of e-Recruiting services.

Chapter 6 describes an empirical study that shows the relevance of e-Recruitment in the contemporary economy. I argue recruiters who are in the know should steer their recruiting practices with applicants' preferred communication modes. In an effort to study the behaviour of those searching for jobs, I discuss why certain traditional and recently emerging web 2.0 recruitment practices are from the applicants' perspective seen as either attractive or unattractive.

In Chapter $7 \mathrm{I}$ aim to make a contribution to the scholarship on requirements analysis in the context of sustainable e-Recruiting services. Since most e-Recruiting services suffer from outdated applicant profiles because they receive little or no user return as soon as 
applicants have found a new job, this study explores how to motivate applicants to keep their profiles up-to-date and stay connected with one specific recruiting portal throughout their careers. Based on in-depth open ended interviews with applicants, system analysts and programmers of an e-Recruiting service for engineers, I show how differently these three stakeholders interpret system requirements for long-term usage. I proceed to sketch the implications for more sustainable e-Recruiting applications, design and development.

Chapter 8 uses the Lead User (LU) Method (von Hippel, 1986) to derive innovations for e-Recruiting services. I discovered that applicants in the process of searching jobs are frequently in uncertain, changing stages of their life, and that they would greatly benefit from services that enhance their self-esteem. The menu of service ideas presented in this chapter tries to enrich online career services offerings. The most innovative but technically difficult to realize service idea identified in this study is an applicants' market value. In the future, applicants should be able to compare how well they match (based on their resume data) with a specific job description, in comparison to other users, friends, potential applicants in a certain region or an organization's complete applicant database.

In Chapter 9 I discuss strategies for globalizing e-HRM systems. A case study is presented of experience with a local IT group tasked with implementing a global e-HRM strategy. Besides the standard implementation challenges reported in previous literature, I identified systemic problems resulting from a tension between an arbitrage strategy for HRM management, and an aggregation strategy for e-HRM management. The results imply that the heterachy model of strategy (Chakravarthy \& Henderson, 2007) is difficult to enact at a global IT level.

Chapter 10 assumes the dedicated reader is prepared for the homestretch, and offers them a penetrating synthesis of the state-of-the-art knowledge on e-Recruiting services. This dissertation has shown that e-Recruiting systems frequently suffer from sustainability issues, involving ineffective resume storage, problematic sorting of large volumes of digital applications and communication problems among HRM and IS scholars and practitioners. Against this background I close by outlining a future research agenda to solve the prevalent sustainability issues of online career services. 


\title{
CHAPTER 2 \\ e-HRM Effectiveness Research: \\ Four Decades of Empirical Evidence ${ }^{2}$
}

\begin{abstract}
This paper reviews four decades of e-HRM (Electronic Human Resource Management) academic literature. Such a review is timely and relevant since e-HRM is one of the most implemented applications in organizations (Lee, 2011). The analysis of 299 articles reveals that one stream of e-HRM literature, dominated by IT-oriented scholars, investigates the essential factors to consider when implementing e-HRM technology. A second stream, dominated by organizational (and pure HRM) scholars, focuses on studying the consequences of e-HRM systems. The authors synthesize and discuss the full range of empirically studied factors, aiming to heighten awareness about the impact of e-HRM systems on management decisions and their consequences for organizations and employees. While technological factors were assumed to be most relevant for effectively automating personnel departments in the 70's and 80's, it was subsequently recognized that managing people and organizational factors was of vital importance for successful implementations. Next to positive operational consequences of e-HRM systems, relational and transformational consequences continue to gain importance. This review shows how e-HRM research is evolving from merely declaring assumptions towards enhancing the rigor of its conceptual and empirical basis.
\end{abstract}

Keywords: e-HRM, HRIS, Literature Review, Implementation, Consequences.

\footnotetext{
2 This paper was selected as keynote presentation at the International HRM Conference: Innovation, Creativity and e-HRM, Nottingham Business School, UK, March 28-29, 2012.

This paper was accepted for presentation at the Academy of Management Meetings in Boston, USA, Aug 3-7, 2012 and was selected into the Best Paper Proceedings in the Human Resource Management Division.
}

A revised version is under consideration for the Annual Review Issue in the Journal of Management. 


\section{Introduction}

E-HRM has been a diverse research topic, beginning with the witnessing of its birth in an article on Electronic Data Processing Personnel Systems by Mayer (1971). For four decades organizations have increasingly implemented e-HRM technology in the hope of achieving administrative and strategic benefits (Kovach et al., 2002; Strohmeier, 2009; CedarCrestone, 2011). E-HRM promises to provide cost reduction, service improvements, and reorientation of HR professionals to become more strategic (see also Ruel et al. 2007). Recently e-HRM was defined by Bondarouk and Ruel (2009) as an umbrella term "covering all possible integration mechanisms and contents between HRM and Information Technologies, aiming at creating value within and across organizations for targeted employees and management" ( $p$. 507).

The e-HRM literature covers a broad range of research fields and issues. It is commonplace to differentiate between operational, relational and transformational consequences of e-HRM (Lepak \& Snell, 1998; Reddick, 2009). Operational consequences represent efficiency and effectiveness gains leading to cost savings. Relational consequences mirror service improvements for internal and external HR clients. Finally, transformational consequences are reflected in strategic re-orientation and change management, including restructuring HR service delivery, increased usage of service centers, and outsourcing and business partnering (Ruël et al. 2004; Strohmeier, 2007; Reddick, 2009; Martin \& Reddington, 2010). While the tone of the literature is basically optimistic about the potential of e-HRM (Ball, 2001; Bondarouk \& Ruël, 2009; Haines \& Lafleur, 2008; Kovach et al. 2002; Ngai \& Wat, 2006; Ruta, 2005; Strohmeier, 2009), researchers increasingly question the advantages of automating personnel affairs and call for more empirical studies.

Further, there is substantial accumulated knowledge about which factors to consider when implementing e-HRM. At the same time, personnel departments still experience difficulties with implementing new technologies, and e-HRM results are not always as positive as commonly assumed. To put it differently, e-HRM projects continue to report failures (e.g. Tansley et al. 2001; Smale \& Heikkilä, 2009; Martin \& Reddington, 2010), and were found to achieve less than expected (Chapman \& Webster, 2003). For example, Gardner et al. (2003) discovered that rather than freeing up time for HR practitioners, the implementation of e-HRM in practice led to the replacement of administrative duties with technology-related ones. In brief, it did not improve HRM services. Other studies show that HR professionals were unsuccessful in using technology to initiate and support strategic 
decisions (Dery \& Wailes, 2005); e-HRM technology was primarily used to simply support routine administrative HR tasks (Ball, 2001; Haines \& Lafleur, 2008; Hussain et al. 2007); and line managers reported contradictory results when using e-HRM (Reddington \& Hyde, 2008). In addition, utilizing the potential of e-HRM was constrained by the complexities of people dynamics such as managing user acceptance when adapting new e-HRM systems (Grant et al., 2009).

One provocative explanation for e-HRM drifting from anticipated benefits is that consequences depend on how scholars viewed its context. Although positive outcomes are steadily reported (e.g. Bondarouk \& Ruël, 2008), organizations are not entirely conscious of the critical factors that lead either to e-HRM success or failure. Likewise, studies tend to report overlapping, as well as contradictory results. Some authors claim user involvement during development and implementation is of great importance for success (Kossek et al., 1994) while others argue the evidence for this is weak (Haines \& Petit, 1997). While some authors (Haines \& Petit, 1997; Hussain et al., 2007) claim the size of an organization to be insignificant, others describe it as a determining factor (Ball, 2001; Haines \& Lafleur, 2008; Strohmeier \& Kabst, 2009). Likewise, for the importance of training: evidence in favor of training is recognized (Alleyne et al., 2007; Panayotopoulou et al., 2007; Martin \& Reddington, 2010), as well as evidence against it (Ruël et al., 2007). Some research advises HR professionals to increase technical knowledge and skills to enable effective e-HRM implementations (Hempel, 2004), and other findings show just the opposite (Bell et al., 2006).

A vast volume of papers continue to be published from the point of view of Human Resources Management (HRM), Information Technology (IT) and other disciplines, and scholars should find an in depth synthesis invaluable. They and practitioners will clearly benefit from a reliable inquiry on the full range of prevailing contradictions in e-HRM research, and a careful overview of those factors which are merely assumed versus those empirically proven to impact e-HRM implementation. This review integrates the most relevant academic literature typically found scattered across the research fields of information systems, human resource management, psychology, and management. It has now been five years since Strohmeier (2007) observed the field lacks a leading paradigm, and this paper aims to fill this gap by systematically analyzing 40 years of empirical research to identify key factors of implementing e-HRM in organizations, and deriving an overview of e-HRM consequences.

The paper is structured as follows. First, we describe how we sampled the literature, how we searched, selected and analyzed. Then we provide a chronological overview of the 
varied factors influencing e-HRM implementation and e-HRM consequences. Third, we synthesize salient findings and areas of divergence in the literature, and point to the critical implications of this review for new research paths on e-HRM effectiveness.

\section{Literature Review Methodology}

As e-HRM research is fed by various disciplines, we comprehensively searched for relevant journal articles in Human Resources Management, Organizational Behaviour, Psychology, Management, Information Technology, and Computer Science research fields. The primary information source was a database search on ISI Web of Science and Scopus. In order to find the articles, an initial list of search words was reviewed by experienced e-HRM scholars. Lengthy discussion finally led to a reduced list of 20 search terms such as 'e-HRM', 'electronic HRM', 'digital HRM', 'virtual HRM', 'web (based) HRM', 'online HRM', 'HRIS', 'HRIT' and 'Computer Based Human Resource Management' (Table 1). It was understood by everyone that in practice full phrases of the abbreviated terms would be used as search terms. This procedure resulted in 4,960 hits on Scopus and 1,689 hits on Web of Science.

Table 1

Literature Search Terms

\begin{tabular}{lll}
\hline & \multicolumn{2}{l}{ Number of results } \\
Search Query & Web of & Scopus \\
\hline e-HRM & Science & \\
eHRM & 8 & 30 \\
e-HR & 6 & 10 \\
Electronic HRM & 39 & 71 \\
Electronic Human Resource Management & 16 & 39 \\
Online HRM & 62 & 402 \\
Online Human Resource Management & 6 & 15 \\
Web HRM & 26 & 158 \\
Web Human Resource Management & 9 & 20 \\
Web based HRM & 99 & 387 \\
Web based Human Resource Management & 5 & 12 \\
HRIS & 61 & 132 \\
Human Resource Information Systems & 136 & 39 \\
HRIT & 689 & 1847 \\
Human Resource Information Technology & 3 & 1 \\
Virtual HRM & 397 & 1193 \\
Virtual Human Resource Management & 8 & 9 \\
Digital HRM & 55 & 84 \\
Digital Human Resource Management & 5 & 4 \\
Computer Based Human Resource Information Systems & 28 & 112 \\
Total: & 1689 & 395 \\
& Grand total: & 4649 \\
\hline
\end{tabular}


First, duplicates were removed. Then, we kept only those articles with e-HRM as their main research focus. Functional fields of single HRM applications such as e-Recruitment or elearning were thus categorically excluded. Three researchers independently reviewed the titles and abstracts of all the identified e-HRM publications (1970-2010). They made an initial selection of 299 relevant articles, compressing basic information about each article organized in a spreadsheet, including an abstract, the full article citation and a link to the article itself. We critically examined the article information for relevance to the literature review by asking the following questions when reading each article: 'does the article empirically report on implementation factors or consequences of e-HRM?' and 'what is the likely impact of the article (author's importance in the field, frequently of citation, a journal's impact rating?').

At this stage, we adapted the technique outlined by Wolfswinkel et al. (2012) to verify inter-coder reliability. In a first comparison among three researchers, an article overlap of 0.72 was achieved. A preliminary sample of 109 articles was established which was then reexamined using a forward and backward search for relevant articles. Each of the three reviewers carefully read all of the articles and sorted out an exclusive list of only those which presented concrete empirical findings. Purely conceptual and theoretical papers were put aside. After resolving conflicting interpretations for judging the relevance of an article and filtering out non-empirical texts, the final sample in this review comprised 69 articles (see Appendix 1). Of these two are from the 70's, four from the 80's; twelve from the 90's and 51 were published after 2000. Our collective very rough first impression of these 69 articles was that they fell into three basic classes: 37 quantitative, 20 qualitative and 12 mixed method papers.

In order to identify key factors when implementing e-HRM in organizations and derive an overview of e-HRM consequences, the analysis began with a variant of 'open coding' (Strauss \& Corbin, 1990) of the publications. First, we read and scanned the articles for empirical data on implementation and consequences. Potentially relevant factors were highlighted, noted in a list and annotated in the article margins. We then re-read the articles to control for having overlooked material and determine whether the factors highlighted during the first reading were still highly relevant. The procedure was exhaustive, continuing until no new factors emerged. Next, we started to categorize e-HRM implementation factors and eHRM consequences using mind maps software. These mind maps complimented our evolving analysis and significantly helped us to identify, label, categorize and re-label categories reflecting the full range of factors and sub-factors in the universe. The challenge was to be able to freshly observe and learn from the plurality of factors encountered. 


\section{Four Decades of E-HRM Research}

The literature analyses we conducted revealed that one stream of e-HRM literature investigates factors that should be considered when implementing e-HRM technology, and is dominated by IT-oriented scholars. A second stream focuses on studying the consequences of e-HRM systems, and is dominated by organizational (and 'pure' HRM) scholars. We present and discuss these factors to clarify the issue of e-HRM impact on management decisions, actions and consequences for organizations and employees (see table 2).

Table 2

E-HRM Implementation Factors and Consequences $(1970-2010)^{3}$

\begin{tabular}{|c|c|c|c|c|c|}
\hline \multicolumn{6}{|c|}{ Implementation } \\
\hline $\begin{array}{l}- \\
- \\
-\end{array}$ & $\begin{array}{l}\text { Technology factors } \\
\text { Current IT Architecture } \\
\text { Digitalizing HR Data } \\
\text { Technology Project } \\
\text { Management }\end{array}$ & - & $\begin{array}{l}\text { Organizational factors } \\
\text { Demographics (age, size, } \\
\text { sector) Organ. Knowledge and } \\
\text { Skills } \\
\text { Organizational Policies and } \\
\text { Practices } \\
\text { Project Management } \\
\text { Resources }\end{array}$ & $\begin{array}{l}- \\
- \\
- \\
-\end{array}$ & $\begin{array}{l}\text { People factors } \\
\text { Communication Qualities } \\
\text { Employee Demographics } \\
\text { Employee and Management } \\
\text { Attitudes (Support and } \\
\text { Commitment) } \\
\text { Employee and Management } \\
\text { Involvement } \\
\text { Employee and Management } \\
\text { Skills vs. Training Needs } \\
\text { Organizational Culture and } \\
\text { Leadership } \\
\text { Psychological Factors }\end{array}$ \\
\hline \multicolumn{6}{|c|}{ Consequences } \\
\hline $\begin{array}{l}- \\
- \\
-\end{array}$ & $\begin{array}{l}\text { Operational Consequences } \\
\text { HR Cost Savings } \\
\text { HR Efficiency } \\
\text { HR Effectiveness }\end{array}$ & $\begin{array}{l}- \\
- \\
- \\
- \\
-\end{array}$ & $\begin{array}{l}\text { Relational Consequences } \\
\text { HR Attitude Management } \\
\text { HR Communications } \\
\text { HR Relationship Management } \\
\text { HR Status } \\
\text { HR Service Improvements }\end{array}$ & $\begin{array}{l}- \\
- \\
- \\
-\end{array}$ & $\begin{array}{l}\text { Transformational Consequences } \\
\text { HR Globalization } \\
\text { HR Knowledge Management } \\
\text { HR Planning } \\
\text { HR Strategic Change } \\
\text { Management }\end{array}$ \\
\hline
\end{tabular}

A consistent finding about the forty years from 1970 to 2010 is that all the implementation factors identified could be categorized into technological, organizational and people factors. Technology factors include requirements of the new or existing technology. Organizational factors reflect the 'hard' organizational characteristics and people factors refer to the 'soft' or individual factors influencing e-HRM implementations. Effective technical implementation of e-HRM does not necessarily imply organizational e-HRM effectiveness. For e-HRM to be

\footnotetext{
${ }^{3}$ See appendix 2 for a detailed overview of the identified implementation factors. See appendix 3 for detailed consequences.
} 
effective, employees who must use these systems need to accept the new technology, i.e., become convinced about their value and be trained for effective usage. We delineate empirically verified consequences of e-HRM in line with prior definitions, calling them operational, relational and transformational consequences (Lepak \& Snell, 1998; Reddick, 2009). The following discussion describes the identified e-HRM implementation factors and consequences that have emerged.

\section{E-HRM Research in 1970 - 1989}

In the early years research into the effectiveness of HRIS was barely addressed as a substantive topic (DeSanctis, 1986). Scholars were still conceptualizing and processing the new HRIS phenomenon. Authors did not yet use the term e-HRM but referred to Human Resource Information Systems or HRIS (e.g. Mathys \& LaVan, 1982), Computerized Information Systems in Personnel (Tomeski \& Lazarus, 1974) or Personnel Systems (Mayer, 1971) for describing computerized HR support.

One stream of research focused on studying the status quo of HRIS in organizations by analyzing which areas are being automated (Mayer, 1971; Tomeski \& Lazarus, 1974; Mathys \& LaVan, 1982; Lederer, 1984; Magnus \& Grossman, 1985). A second stream investigated factors influencing HRIS implementation, what information technology researchers refer to as the factors influencing the adoption of technology (DeSanctis, 1986; Taylor \& Davis, 1989). Reporting requirements to the government (e.g. pursuant to the Equal Employment Opportunity Act (1965) in the USA) and growth in organizational size were major pressures for computerization (Hennessey, 1979). Additionally, the rapidly growing sector of white collar work and the knowledge and skills that come with these changes (DeSanctis, 1986) forced organizations to grasp their accelerating dependency on highly skilled managerial and technical personnel (Hennessey, 1979).

These initial systems supported administrative HR tasks without electronic internetbased technology. Payroll systems (e.g. Lederer, 1984), employee records (Magnus \& Grossman, 1985), compensation and benefits administration (Magnus \& Grossman, 1985), government reporting (DeSanctis, 1986) and skill databases (Hennessey, 1979) were the first to be automated. 


\section{Implementation factors (1970 - 1989)}

DeSanctis (1986) and Taylor and Davis (1989), recognized information technology scholars in the late 80 's, were the first to empirically study factors for effectively implementing personnel information systems. With regard to technology factors, personnel departments sought to gain more understanding on the reliability and output of HRIS, challenges of integrating and aligning previous systems and the duration of computerization. While Magnus and Grossman (1985) studied factors such as customizing HRIS software, Lederer (1984) warned that modification can lead to system errors. Scholars advised managers to analyze organizational needs and clarify required technology characteristics prior to modifying or implementing new systems (Magnus \& Grossman, 1985). Current computer capability in an organization was reported to directly influence the extent of computerization of personnel departments (Mayer, 1971). If computerization appeared overly time consuming and the output unreliable, HRIS implementation were typically prevented, paused or even stopped (Tomeski \& Lazarus, 1974).

Most organizational implementation factors studied in the 70's ad 80's relate to organizational size (Mayer, 1971) and sector (Mayer, 1971; Tomeski \& Lazarus, 1974). Organizational size was found to be positively related to computerization, since the administrative burden increases with an increase in personnel (Mayer, 1971) and computers were seen as a potential solution. Lack of planning from the corporate level to the divisional level was reported to negatively impact the coordination between personnel and IT departments, making HRIS implementation difficult. The growing consensus was that effective implementations require close alignment of HR, IT and corporate goals (DeSanctis, 1986).

Taylor and Davis in 1989 observed that violating ethical concerns impacts employees' attitudes and beliefs and can have legal ramifications, leading to the call for efforts to securing privacy when implementing HRIS. Knowledge of which personal information is stored in HRIS and the possibility to verify its accuracy were required to mitigate dysfunctional attitudes of employees towards HRIS usage (Taylor \& Davis, 1989). Shortages in technical personnel were seen as a key obstacle to the computerization of the typical personnel department (Magnus \& Grossman, 1985). Organizations with only modest budgets (Magnus \& Grossman, 1985) or relatively high internal costs (Mayer, 1971) were less likely to adopt a digitalized personnel system. 
In respect to people factors, Mayer (1971) reported lack of top management support as the most limiting factor for successful HRIS implementation. Other negative factors included lack of priority given to HRIS (Tomeski \& Lazarus, 1974), incongruence between needs of IT and personnel department (Magnus \& Grossman, 1985) and difficulties of personnel departments in communicating with computer technicians (Tomeski \& Lazarus, 1974). In this context, Magnus and Grossman (1985) showed that needs incongruence puts a serious limitation on effective implementations. Mayer (1971) confirmed that advocates of HRIS had to go up to higher managerial levels than was the case in other functional areas. Technology usage in personnel departments was often not perceived by top management as important. In retrospect, they clearly had an extraordinary blind spot in seeing computerizing as expensive and the suggested benefits exaggerated (Mayer, 1971). Human resources managers found it hard to justify the costs for a new technology. On the employee level, DeSanctis (1986) showed that involving users during systems development positively influenced satisfaction in personnel departments. She suggested that the larger the organizational investment in HRIS and the greater the system's influence, the more it was valued by the organization.

\section{Consequences of HRIS implementations (1970 - 1989)}

Scholars in the 1970's and 1980's rarely studied the consequences of implementations, being concerned rather with exploring the factors causing the rise of computerized personnel departments. It was recognized by scholars that measures of HRIS effectiveness were lacking and they called for the development of instruments to evaluate human resources efforts (Mathys \& LaVan, 1982). Mayer had early on (1971) claimed more research was needed in order to identify the true cost-benefits tradeoffs of technology. Most research depended on surveys and merely summarized findings and percentages, failing to offer a deeper analysis of tested relationships. The only exception is the study of DeSanctis (1986) who empirically verified operational consequences: cost savings, effectiveness and efficiency gains.

Initial warnings of "dehumanizing the personnel department" were counteracted by positive experiences in payroll and record-keeping applications (Mayer, 1971). Tomeski and Lazarus (1974) reported faster reporting capability, improved accuracy of reports, and freeing personnel staff for more important tasks. Researchers alluded to such reports of increased efficiency and effectiveness in stating their positive expectations for the future usage of HRIS. 


\section{E-HRM Research in 1990 - 1999}

We continue using the term 'HRIS' in reviewing the 90's since the term e-HRM had not yet emerged. We observed an increase in empirical articles: in the 90 's $41 \%$ were empirical, compared to $19 \%$ of articles in the 70 's and 80 's. Organizations in the 90 's were gradually convinced about the necessity of reducing labor intensive administration by automating personnel affairs. In general, positive consequences developed at the everyday operational level: increased accuracy of data, time and cost savings. Organizations also began to have a growing awareness and appreciation of the broader possible benefits of computer systems in performing HR duties. For instance, Kossek et al. (1994) documented strategic, next to administrative, roles of HRIS.

On a theoretical notion, scholars started to study e-HRM using a wide spectrum of approaches: the Technology Acceptance Model (Davis, 1989); Organization Contingency Models, Stakeholder Theory, and Organizational Commitment Theory. Nevertheless, there was scant published research on the relationships between implementation factors and HRIS effectiveness. Relationships continued to be studied using quantitative survey research or anecdotal evidence from qualitative studies. The rare exceptions are the studies of Sturman et al. (1996), Haines and Petit (1997) and Eddy et al. (1999). We will now turn to a more detailed account of these empirically studied implementation factors.

\section{Implementation factors (1990 - 1999)}

In the 90's several key technology factors were identified as influencing HRIS implementations: data integrity, system usefulness, system integration, and in-house development versus using external HRIS software. Comparing mainframe-based and personal computer-based applications shows that the first group is related to a centralized (standardized) HR, and the second to a decentralized HR management tailored to individual users requiring higher integration efforts. Accordingly, current technology used in an organization affects the amount of integration efforts (Broderick \& Boudreau, 1992). Similarly, Hannon et al. (1996) reported standardization of HR processes as an important factor when implementing HRIS. Whether in-house- or outsourcing development is more beneficial depends on a particular organization's concrete needs, future expectations and risk orientations.

A research tradition emerged where a growing number of organizational characteristics potentially impacting implementation success were studied. Concerning 
organizational policies and practices, restricted access and possibilities for employees to edit personal information were found to impact user acceptance of digitalized data (Eddy et al., 1999). While organization and HR, IS and HRIS departmental age showed insignificant relationships to system usage, Mathieson (1993) observed that larger organizations were more likely to implement HRIS. However, early system adoption by itself does not automatically positively influence the acceptance or usage of individual users (Haines and Petit, 1997). The most prevalent IT usage in personnel departments in the 90's was in the massively important and visible financial service, real estate and hospitality sectors. Delays in computerizing personnel departments (Kossek et al., 1994) in this period resulted from budget limitations due to the economic recession (Martinsons, 1994) and unforeseen costs during implementations.

Regarding people factors, Kossek et al. (1994) reported diagnosing and managing power dynamics, organizational culture and communication between HR and other functions as important determinants of successful implementations. Effective implementations require exceptional cooperation between diverse business units which hitherto operated independently. These units frequently had different priorities different perceptions of new systems. For instance, top management showed high resistance as they did not perceive HRIS systems having value for their own careers. In their view the new systems would only provide benefits for clerical and not strategic tasks. Further, Haines and Petit (1997) detected a negative relationship between the amount of employee experience in their present position and user satisfaction $(\mathrm{r}=-0,16 ; \mathrm{p}<0,05)$. The more familiar people were with work practices in their current position, the more they resisted using new systems (i.e. a new HRIS).

Other people factors studied in the 90's are employee and management skills versus trainings needs and user involvement. Hannon et al. (1996) claimed HR professionals are usually able to solve micro-level problems (data entry, editing, and retrieval), but usually lack a more macro viewpoint and the technical skills requisite to using HRIS for reports or analysis. Training typically plays a crucial role in achieving a more sophisticated use of systems, whereas in-house training was found to enhance satisfaction, self-training was found to diminish it. Accordingly, organizations are well advised to train employees in-house in preference to requiring self-training.

While lack of top management support continued to constraint HRIS implementations, HR, financial and IT executives and staff more and more have supported the automation of personnel affairs (Hannon et al., 1996). 


\section{Consequences of HRIS implementations (1990 - 1999)}

Operational consequences continued to be explored and were empirically validated in the literature: HR effectiveness, efficiency gains, cost and time savings (Kossek et al., 1994, Sturman et al., 1996). The consensus was that more HR work could be accomplished with fewer personnel. Martinsons (1994) showed that HRIS usage freed professionals for superior tasks. Hannon et al. (1996) further documented that uniformity of personnel data enabled divisional and corporate reporting requirements.

Besides operational benefits, increasingly relational consequences were acknowledged: HR service improvements, HR professionals' status as information brokers, and new communication channels with HR (Kossek et al., 1994). For instance, HR directors evaluated applicants who used the internet for applications more positively than those using a fax, in terms of progressiveness, creativity and innovativeness (Eddy et al., 1999). Hannon et al. (1996) also acknowledged a negative relational consequence of automation: dependence on external vendors. The latter occurred either when systems were bought off-the-shelf or were developed outside; this caused practical dependency on external firms for maintenance, support and system extension. Transformational consequences were noted in the form of HR globalization: integration of decentralized units and consistency of HR practices (Broderick \& Boudreau, 1992).

\section{E-HRM Research in 2000 - 2010}

Research on e-HRM has grown significantly in comparison to prior decades. Scholars undertook joint efforts to understand the phenomenon and its multilevel implications within and across organizations. Several special issues on e-HRM appeared in international academic journals between 2004 and 2010 (Human Resource Management, 2004 and 2008; Journal of Managerial Psychology, 2009; International Journal of Human Resource Management, 2009; International Journal of Technology and Human Interaction, 2010; International Journal of Training and Development, 2010; Human Resource Management Review, forthcoming; German Journal of Human Resource Research, forthcoming; European Journal of International Management, forthcoming).

Finally, the term e-HRM was coined and the field differentiated in the academic literature from HRIS (Ruël et al., 2004). Whereas HRIS are primarily intended to reduce HR departments' administrative burden, e-HRM promises strategic service improvements and

\footnotetext{
${ }^{4}$ In June 2011, Emerald Publishing group asked its members to propose new journals aimed at publishing research on eHRM and its functional areas.
} 
role changes of HR professionals (Lawler \& Mohrman, 2003). Heikkilä and Smale (2010) add to this description: e-HRM changes the face-to-face nature of interactions between $\mathrm{HR}$ professionals, line managers and employees into technology-mediated ones. Research further shifted from technologies targeting HR staff to technologies aimed at internal customers. Florkowski and Olivas-Luján (2006) showed that by the year 2000 the number of applications for internal customers (i.e. employees and managers) exceeded those targeted at HR staff. Users of e-HRM systems are thus increasingly people outside of HR departments. Along with the shifting focus from HRIS to e-HRM, scholars increasingly identified relational and transformational consequences.

Theoretically, e-HRM studies built on IT, organization, and sociological literature using structuration, enactment, contingency, configurational perspectives and media richness theory. Contrary to our expectations, rigorous empirical studies of e-HRM effectiveness are still scant, and research is dominated by exploratory case studies.

\section{Implementation factors (2000 - 2010)}

Integrating vendor and organizational software continues to be difficult and expensive, yet technology is no longer seen as the most difficult factor (Chapman and Webster, 2003; Teo et al., 2007). Instead, managing people factors surfaced as most essential for successful e-HRM implementations. This indicates an amplified awareness of the human aspect in computerizing personnel departments.

Technology factors ever more incorporate organizations globalization requirements (e.g. international staffing). Organizations need to make decisions about the level of standardization of HR practices across subsidiaries, determining the degree HR practices should be adapted to local demands (Hustad \& Munkvold, 2005).

In the last decade company size was the most frequently studied of organizational implementation factor: larger companies were more likely to implement e-HRM (Ngai \& Wat, 2006). However, while implementation is more widespread among large organizations Strohmeier \& Kabst (2009) describe larger companies as earlier adopters), successful implementation is more widespread among small organizations (Chapman \& Webster, 2003). Not surprisingly, organizations dependent upon high telecommuting adopt e-HRM more frequently (Strohmeier \& Kabst, 2009). More research is needed to discover which factors mediate or moderate the relationship between organizational size and implementation success.

Crucially, e-HRM implementations should be termed an HR rather than an IT project, given that HR staff holds knowledge of HR processes. In this context, Panayotopoulou et al. 
(2007) argued that close collaboration between departments (principally HR and IT) is critical. In a study closely related to this emphasis upon developing a shared vision between HR and IT managers (Tansley \& Newell, 2007). Tansley and Watson (2000) reported using cross-functional project teams with representatives from HR and IS, mapping of HR processes and identification of HR needs as impacting implementation success.

Regarding people factors, the most studied in the last decade center around organizational culture, leadership and psychological variables (Panayotopoulou et al., 2007). In general, IT-friendly cultures reported greater implementation success. Visionary, supporting and encouraging leaders (i.e. transformational leader) who advocate e-HRM implementations were found to contribute to the acceptance of new systems (Tansley \& Watson, 2000; Hustad \& Munkvold, 2005). Psychological factors impacting e-HRM implementation that have been empirically explored include the level of trust among project teams members (Tansley \& Watson, 2000), group morale, workplace distress (Wilson-Evered \& Härtel, 2009) and security and privacy fears (Reddick, 2009). Olivas-Luján et al. (2007) investigated employees' different mindsets towards e-HRM, finding that employees resisted accepting new systems if they thought it would increase their personal workload after implementations.

Stakeholder commitment to organizations' long-term goals supported by e-HRM strategizing has become progressively relevant (Olivas-Luján et al., 2007). Thus communication about intended e-HRM use is important (Beulen, 2009); organizations should actively collect feedback from users who are impacted in their jobs by new technology before, during and after implementations (Alleyne et al. 2007). Implementation success is positively impacted (Cronin et al., 2006) by internal marketing such as sending information to stakeholders about the functionality of new systems, positive word of mouth and appointing a system advocate who keeps users enthusiastic about the new systems. As in past decades, training HR professionals in using new systems reinforces successful implementation (Panayotopoulou et al., 2007; Martin \& Reddington, 2010).

\section{Consequences of e-HRM implementation (2000 - 2010)}

Initially, e-HRM promised to lead to efficiency gains, and most researchers in the past decade advocated e-HRM's strong contribution to the bottom line (Svoboda \& Schröder, 2001; Jones et al., 2001; Chapman \& Webster, 2003; Ruël et al, 2004; Buckley et al., 2004; Panayotopoulou et al. 2007; Olivas-Lujan et al., 2007; Beulen, 2009; Oiry, 2009). However, 
there were serious disagreement among researchers, e.g. Reddick (2009) did not find support for operational cost savings and only Buckley et al. (2004) provided numerical data for cost savings due to e-HRM.

The research focus of scholars first shifted from operational (70's and 80's) to relational consequences ( 80 's), and then to transformational consequences of e-HRM in the last decade (Marler, 2009). In our view, this transformation in perspective is attributable to organizations changing from HRIS to e-HRM, whereas applications are targeted to a greater extent to internal customers. Since HR professionals started to budget and spend more time on transformational activities (Gardner et al., 2003) they progressively focus more on their mission (Reddick, 2009). As they become more are more engaged in organizational change activities they are increasingly seen as business partners (Haines \& Lafleur, 2008), and their competence is directed to business issues (Bell et al., 2006), supporting risk management, innovation (Ruël et al., 2004) and scanning (Guechtouli, 2010). E-HRM enabled professionals to implement HR strategic decisions (Cronin et al., 2006) and to positively affect HR planning (Beulen, 2009). Literature continues to emphasize the strategic potential of e-HRM to support the long term strategy evolution of an organization by transforming HR from merely administrative to strategic partners (Reddick, 2009; Bell et al., 2006; Panayotopoulou et al., 2007).

Very large organizations exploit information from e-HRM for sophisticated analysis and advanced reporting. For employee planning, e-HRM plays an instrumental role in storing, aligning and managing employee data, while simultaneously providing a flexible platform for employees to follow training and development needs. Ball (2001) discovered that organizational size impacts the type of information stored in e-HRM systems, the way it used and the volume of additional applications. Organizations with more than 500 employees tend to store and analyze more data, and there is an enhanced expectation it will contribute to the achievement of strategic goals.

Concerning the role of knowledge in organizations, we found support for increased knowledge creation, capture, transfer and use due to e-HRM (Reddick, 2009). Ruël et al. (2004) reported that a more open culture was the positive consequence of an implementation. Hustad and Munkvold (2005), in a case study at Ericsson on the implementation of a competence management system, showed how staff with similar knowledge became aware of each other.

Employee attraction and retention was found to be indirectly influenced by e-HRM, presumably because using e-HRM was reported to positively shape company image. 
Organizations using the latest technology were viewed as modern and progressive by employees (Panayotopoulou et al., 2007). Ruël et al. (2004) illustrated how e-HRM also enhanced visibility of career paths which enabled employees to better choose their own, and how this could increase a company's image (Neary, 2002). In large companies, e-HRM provided a transparent and flexible internal labor market (Ruël et al., 2004), facilitating identification of (global) company talent (Neary, 2002).

Relational consequences were detected in the form of improved communication, cooperation, relationships and HR service improvements. Reddick (2009) observed how eHRM improves employee awareness, appreciation and use of HR programs. Hussain et al. (2007) verified positive attitudes of HR professionals who perceived e-HRM as a crucial and enabling technology. E-HRM was reported as beneficial to employee satisfaction (Panayotopoulou et al., 2007; Voermans \& van Veldhoven, 2007). Recent literature reveals an augmented service satisfaction with the HR department (Lukaszewski et al., 2008), and satisfaction related to HR processes (Cronin et al., 2006). Local adaption of e-HRM was even found to affect employee retention. Beulen (2009) documented how employees working in different cultures had different e-HRM preferences, and it was essential to adjust to these needs to retain talented employees.

Surprisingly, rigorous empirical studies are still scarce (Florkowski \& Olivas-Luján, 2006). Most factors and consequences of e-HRM were identified in case studies and do not yield 'hard' evidence. The identified relationships imply the field of e-HRM requires much more theoretical and methodological grounding before it will become a mature research tradition.

\section{Discussion}

This review synthesized empirical e-HRM studies scattered throughout HRM, organizational behaviour, psychology, and management and information systems literature in order to guide e-HRM scholars from these different disciplines. By outlining the historical development of factors influencing e-HRM implementation and consequences, important changes over time otherwise typically unrecognized are illustrated. Let's summarize the major e-HRM research themes during the last 40 years and review key changes along the path (see table 4). 


\section{Table 4 \\ Major E-HRM Research Themes (1970-2000)}

1970-1989

- IT-oriented research
1990-1999

- Human Resource Management Organizational Behavior, Management and Psychologyoriented research

\section{0-2010}

Human Resource Management Organizational Behavior, (International) Management and Psychology-oriented research

\begin{tabular}{|c|c|c|c|}
\hline- & $\begin{array}{l}\text { Conceptualizing HRIS } \\
\text { phenomenon }\end{array}$ & $\begin{array}{l}\text { - Various terms for } \\
\text { computerization of personnel } \\
\text { departments }\end{array}$ & $\begin{array}{l}\text { - Conceptualizing HRIS vs. } \\
\text { e-HRM }\end{array}$ \\
\hline- & $\begin{array}{l}\text { Mostly large organizations } \\
\text { computerize personnel } \\
\text { departments (early adopters) }\end{array}$ & $\begin{array}{l}\text { - Mostly large organizations } \\
\text { computerize personnel } \\
\text { departments }\end{array}$ & $\begin{array}{l}\text { - Large, medium-size and small } \\
\text { organizations computerize or } \\
\text { outsource personnel affairs } \\
\text { - } \text { Organizations with high }\end{array}$ \\
\hline- & $\begin{array}{l}\text { Pressure for computerization } \\
\text { due to organizational growth } \\
\text { and increase in white collar } \\
\text { work }\end{array}$ & & $\begin{array}{l}\text { telecommuting adopt e-HRM } \\
\text { - Large organizations adopt } \\
\text { earlier, but smaller } \\
\text { organizations report greater e- } \\
\text { HRM success }\end{array}$ \\
\hline- & $\begin{array}{l}\text { Warnings of de-humanizing } \\
\text { personnel departments }\end{array}$ & & $\begin{array}{l}\text { - IT-friendly cultures report } \\
\text { greater implementation success }\end{array}$ \\
\hline- & HR administrative role & - HR relational role & - HR transformational role \\
\hline- & $\begin{array}{l}\text { Focus on development of } \\
\text { applications for internal use } \\
\text { within HR departments }\end{array}$ & $\begin{array}{l}\text { - Focus on development of } \\
\text { applications for internal use } \\
\text { within HR departments }\end{array}$ & $\begin{array}{l}\text { - Focus on development of } \\
\text { applications for line managers } \\
\text { and employees (users outside } \\
\text { HR departments) }\end{array}$ \\
\hline- & $\begin{array}{l}\text { HRIS supports HR department } \\
\text { goals }\end{array}$ & $\begin{array}{l}\text { - HRIS supports HR department } \\
\text { goals }\end{array}$ & $\begin{array}{l}\text { - e-HRM supports long-term } \\
\text { organizational goals }\end{array}$ \\
\hline- & $\begin{array}{l}\text { Lack of top management } \\
\text { support for HRIS }\end{array}$ & $\begin{array}{l}\text { - Lack of top management support } \\
\text { for HRIS } \\
\text { - Increasing support of HR, IT and } \\
\text { Finance executives and } \\
\text { employees }\end{array}$ & $\begin{array}{l}\text { - Increasing support of top } \\
\text { management, HR, IT and } \\
\text { Finance executives } \\
\text { - Decreasing support of line } \\
\text { managers and employees }\end{array}$ \\
\hline- & $\begin{array}{l}\text { Scant empirical research on } \\
\text { implementation factors and } \\
\text { consequences }\end{array}$ & $\begin{array}{l}\text { - Scant empirical research on } \\
\text { implementation factors and } \\
\text { consequences }\end{array}$ & $\begin{array}{l}\text { - Increase in empirical research } \\
\text { on implementation factors and } \\
\text { consequences }\end{array}$ \\
\hline- & $\begin{array}{l}\text { Research focus on } \\
\text { implementation factors, } \\
\text { (enablers, success factors, } \\
\text { constraints) }\end{array}$ & $\begin{array}{l}\text { - Research focus on consequences } \\
\text { (benefits) } \\
\text { - Conceptual and case study } \\
\text { research, survey research } \\
\text { without testing relationships } \\
\end{array}$ & $\begin{array}{l}\text { - Increase in academic e-HRM } \\
\text { literature (special issues in ISI } \\
\text { journals) }\end{array}$ \\
\hline- & $\begin{array}{l}\text { Focus on technology factors for } \\
\text { successful implementations }\end{array}$ & $\begin{array}{l}\text { - Focus on organizational factors } \\
\text { for successful implementations }\end{array}$ & $\begin{array}{l}\text { - Focus on people factors for } \\
\text { successful implementations }\end{array}$ \\
\hline \multirow[t]{2}{*}{-} & $\begin{array}{l}\text { HRIS consequences: focus on } \\
\text { operational cost savings, } \\
\text { efficiency and effectiveness } \\
\text { gains }\end{array}$ & $\begin{array}{l}\text { - HRIS consequences: focus on } \\
\text { operational and increasingly } \\
\text { relational consequences (HR } \\
\text { Service Improvements, HR } \\
\text { Relationship Management, HR } \\
\text { Status }\end{array}$ & $\begin{array}{l}\text { - e-HRM consequences: focus on } \\
\text { transformational consequences } \\
\text { (HR Globalization, HR } \\
\text { Strategic Change Management, } \\
\text { HR Knowledge Management, } \\
\text { HR Planning) next to } \\
\text { operational and relational } \\
\text { consequences }\end{array}$ \\
\hline & & $\begin{array}{l}\text { - Theoretical lens: Technology } \\
\text { Acceptance Model, Organization } \\
\text { Contingency Models, } \\
\text { Stakeholder Theory, } \\
\text { Organizational Commitment }\end{array}$ & $\begin{array}{l}\text { - Theoretical lens: Media } \\
\text { Richness Theory, Structuration, } \\
\text { Enactment, Contingency, } \\
\text { Configurational, International } \\
\text { HRM and Change Management }\end{array}$ \\
\hline
\end{tabular}


Theory

- In-house development, technical integration of systems, centralizing, interfacing, customizing data
- In-house vs. outsourcing development decision making, integrating systems, usability, standardization
- Global vs. local development and integration of systems: compatibility across subsidiaries, local adaption of eHRM, language standardization

- Training HRIS skills supports effective implementation
- Training e-HRM, intranet, knowledge management, leadership and strategic planning skills support effective implementation

While researchers in the 70's and 80's in the main focused on understanding factors for successfully implementing e-HRM technology, in the past decade research on relational and transformational consequences of e-HRM has intensified. A finding evident throughout the past 40 years is that all identified implementation factors involve either technological, organizational or people requirements.

In the last decade we observed a significant increase in the relevance of "people factors' for successful implementations. Although technological and organizational factors are necessary prerequisites, increasingly people factors - notably the mindsets within a certain organizational culture and supportive leadership - determine HRM effectiveness. In view of that trend Ruël et al. (2004) observed that effectively implementing e-HRM in an organization requires a change in employees' mindsets, since it requires them to do their work differently. Since e-HRM affects an organization as a whole, management and employee support and commitment are essential.

The analysis of e-HRM consequences revealed a clear development. Whereas scholars from the 70's and 80's report only operational consequences, they subsequently increasingly explored both relational and transformational consequences. This development appears closely linked to the shift in practices from HRIS (automating HR department) towards eHRM (automating services for employees and managers). Florkowski and Olivas-Luján (2006) documented how by 2000 the number of personnel applications developed for employees and managers exceeded those of HR staff. While HRIS partly relieved the administrative burden of HR professionals, allowing them to spend more time on other tasks (e.g. relational tasks), with the arrival of e-HRM they lost even more operational tasks. Accordingly, the jobs of HR professionals underwent an evolution from being in main administrative (70's and 80 's) to being relational (90's), and then to a distinctly strategic transformational role. 
Reflecting upon e-HRM goals discussed at the outset of this paper, namely cost savings, improved HR services and strategic reorientation of the HR department, we found support for most of these goals in the analyzed literature. However, scholars have placed increasingly opposed findings into the archives. For example, an important mixed contribution among researchers emerged in the last decade: e-HRM might on the one hand decrease administrative burden of HR professionals (Reddick, 2009), while on the other hand increase the burden of employees and line managers (Martin \& Reddington, 2010). Chapman and Webster (2003) reported higher time investments by HR staff to filter and respond to applicants due to the growing amount of digital applications, while Buckley et al. (2004) illustrated more efficient screening processes because of e-HRM. Reddick (2009) found no support for an increased volume of HR work, while Ruël et al. (2004) found efficiency gains in the form of a decrease in administrative burden. Reddick (2009) did not find support for reduced levels of bureaucracy, elimination of paperwork or reduced HR labor force. Initially, the promise of e-HRM was to reduce bureaucracy, yet the necessary organizational policies and processes needed to be in place to realize this potential.

In order to gain support, e-HRM advocates need to quantify how automating personnel affairs improves business operations for different stakeholders. It is essential to take into account the trade-offs for local adoption or standardization and integration of systems, and that organizations need to define the specific goals they aim to achieve with e-HRM before starting an implementation. The underlying complexity of this state of affairs is evident in a study by Bondarouk et al. (2009) who document that line managers and employees have different goals for e-HRM use. It is clear future research must take a multi-stakeholder perspective to accurately explore HRM effectiveness in real life. For HR professionals to accept new technologies they need to know how to effectively work with them and become convinced about the value of new systems (Hempel, 2004). The classic formats of traditional HR education and all that it involves often falls short in increasing technical expertise:

"HR is placed in a position of having to catch up with these (technology) innovations, and since the HR department is not driving these organizational and work-design changes, an additional layer of complexity is added. HR professionals will need a broader understanding of both the operational and strategic side of the business in order to effectively support these innovations" (Hempel, 2004. p. 166).

While Hannon et al. (1996) reported HR professionals' lack of technical knowledge and skill as problematic, Kossek et al. (1994) showed that user's higher technical skill level can have a 
negative impact. Due to the typical long development periods, by the time systems were finally up and running they barely represented the latest technology valued by highly skilled users. Overall, users with more developed computer skills seemed to use systems earlier, but at the same time were generally less positive about doing so.

One would normally expect that developing a system inside an organization would create positive attachment of users, but Haines and Petit (1997) showed that in-house development of e-HRM had no effect on user satisfaction. Earlier Kossek et al. (1994) had argued that user involvement is important for successful implementations and enhances user satisfaction. The vital issue appears to be an employee's experience in their present position, variations of which were found to negatively influence the level of satisfaction with a new system (Haines \& Petit, 1997). It is likely the longer employees are working in the current position, the more resistant they become towards adapting to new technology. Using an international management lens, a certain degree of resistance can be routinely always expected in global e-HRM projects since subsidies are often used to making own choices regarding HR practices. The transformational potential lies in the integration of distributed HR information across different units and subsidies, and organizations should thus map all HR processes as a coherent whole to enable strategic global implementations (Tansley et al., 2001).

Taking into account environmental contingencies, we found three factors outside the direct control of organizations impacting the implementation of e-HRM. First, a lower degree of e-HRM adoption can be expected in organizations operating in sectors with high union presence. Haines and Lafleur (2008) found that union presence negatively impacts IT usage. Second, a country's economic relative development influences implementation success (Strohmeier \& Kabst, 2009). For instance, Olivas-Luján et al. (2007) noted that most companies in Mexico continue to lag technologically and economically in automating personnel departments. Finally, country culture was shown to influence e-HRM implementations (Smale \& Heikkilä, 2009); cultures that legitimate and support hierarchical layers manifest respect towards managers (Olivas-Luján et al., 2007). When managers decide to implement new e-HRM systems in such cultures they are likely to experience less employee resistance.

E-HRM advocates who have followed our deliberation on management practice should now have a solid foundation of insights into the range of factors impacting e-HRM effectiveness. Organizations can use the analyses to anticipate and weigh the relative importance of contingencies for implementing e-HRM. By comparing current practices in 
organizations with those in the past, one can better evaluate if adoption is feasible, if targeted goals can be achieved and what measures can be taken to enhance the chances for successful e-HRM implementation.

The field of HRM is still criticized for not contributing added value to business operations. We have shown here how e-HRM can add to human resource effectiveness, contribute to organizational goals and has the potential to enhance an organizations' competitive advantage by means of a strategic reorientation of the HR department. The resource-based view of the firm states that organizations with unique internal resources - that competitors find difficult to imitate - can have a significant competitive advantage (Barney, 1989). An e-HRM system used to its full potential is, in our view, such a unique organizational resource. When we began our research we expected to find an increase of research rigor, of precision and accuracy, in the empirical literature. It turned out that more theory-driven and evidence-based e-HRM studies are still needed in this still immature research field.

\section{Positioning e-HRM Research}

Literature on e-HRM continues to grow and the field has distinguished itself as a unique research area. The relevance of e-HRM is evidenced in special journal issues, conferences, and academic publishers inviting the human resource management community to establish dedicated journals aimed at publishing e-HRM research. There are essentially four fundamental reasons to consider research on e-HRM as distinct from research on human resource management or information systems.

First, concerning reach, e-HRM potentially impacts everyone in an organization inasmuch as they are registered with personnel data, and they need to update their information

Second, the information stored in e-HRM systems concerns sensitive personnel data. When organizations fail to use personnel data in a safe and confidential manner, it can have serious (legal) consequences.

Third, e-HRM can enhance the service of the HR-department and even transform them into a strategic business unit. This change impacts HR and other professionals' work practices and job requirements (e.g. technical HR skills).

Fourth, the traditional HR-department is often seen narrowly as an administrative support unit. Thus the business case for implementing e-HRM systems is not easily built upon an essential need of an organization's survival, and it is harder to gain management support. 
Motivation to implement new technology for managing human resources is further diminished by failed IT implementations of new software in other functional units.

In order to gain support, e-HRM advocates need to quantify how e-HRM will improve business operations for different stakeholders, and persuasively show the strategic organizational benefits of using technology for managing human resources. Since implementations often fail due to rising and unexpected costs, management prior to computerizing personnel departments needs to strictly canvass organizational needs and carefully define costs.

\section{Conclusion}

This review synthesizes and describes the progress of e-HRM effectiveness research from 1970 to 2010 . We traced the rough path of a growing archive of reports on empirically studied implementation factors and e-HRM consequences. Over the decades more specific e-HRM goals emerged such as improved HR service provision and the strategic reorientation of HR departments (Marler, 2009). Unquestionably, e-HRM has the potential to simplify and enrich; steer and support; and shorten and speed up the pursuit of organizational and employee goal accomplishment. How it is introduced in specific firms and other organizational units seems crucial for fulfilling the promise. This is especially true because e-HRM entails a changemanagement type of paradox, requiring us to continuously ask the question; if HRM is supposed to aid or support employees doing well for the organization, how routinizing part of that process (through e-HRM) might enrich those organizational life everyday contexts even more, and why?

In other words, we found hardly any generic factor that can be held responsible for all implementations of e-HRM in organizations. Rather, it is people factors (such as innovative and visionary leaders promoting e-HRM, trust, change management, confidence with technology skills, communication about system usefulness) that were reported as most relevant for successful implementations in the last decade. More theorizing is necessary on this complex issue before new empirical research on this generic issue may bear fruit. Let's address some of the limitations of this review and suggest directions for future research.

This literature review solely analyzed studies based on factors that were empirically investigated. There may well be many other relevant implementation factors and consequences which did not receive research attention in the past. We limited our sample to general e-HRM research and did not specifically search literature in functional human 
resources areas such as e-Recruitment and e-learning. Although some of the analyzed articles investigated these areas, our review focused on e-HRM in general. Given the increasing complexity in e-HRM theory and practice, a 'multi-functional e-HRM approach' is clearly needed. Future research should examine the identified factors and consequences in relation to distinct functional HRM areas. At present it is extremely difficult to say whether the identified factors influence all types of e-HRM applications. This of course is also a limitation of this study since we selected solely articles on e-HRM. It is essential to establish a theoretical framework for the various e-HRM applications. Further, we did not examine the archives for the rich body of literature on a host of other IT-implementations. For instance, literature on ERP (Enterprise Resource Planning) would no doubt be especially useful to understand e-HRM implementation effectiveness. Scholars should continue to investigate IT literatures and assess if the factors presented in this review can be meaningfully extended and validated in practice.

Although we identified relevant factors, these were mostly discussed in the literature as success factors or enablers when positive, or barriers and constraints when negative; at no point did we strive to explain the procedures used to benefit from the positive factors or remedy the barriers. Based on the theory underlying the set of papers, we could not provide a full explanatory account how the identified factors contribute to e-HRM success. For example, for the factor 'internal marketing' it would be interesting to investigate which contents or format of communication are most effective in achieving successful e-HRM implementations.

Further, none of the studies distinguished between various implementation phases. Considering 'user involvement', one could ask: 'is user involvement necessary in a phase prior to the implementation, during the implementation process or especially at the end?'

Research on environmental factors impinging on e-HRM appeared scant. Although these factors are often hard to influence by an organization, it is crucial to clarify which have implications for organizations planning to implement e-HRM. Future research should pay attention to potential mediators or moderators affecting implementation and consequences. Organizational size, type of e-HRM, sector and employees' demographics are basic conditions to explicitly consider. It would be also interesting to study the differential effects of internet applications versus intranet applications, since both may have other consequences. For instance, the use of internet-based applications in personnel systems may threaten the privacy of personnel data. 
Since effectiveness is a multidimensional concept, e-HRM effectiveness may depend on various organizational, departmental, professional and individual goals (i.e. cost and time savings, improvement of HR services, strategic re-orientation of HR department). While Strohmeier and Kabst (2009) emphasized that e-HRM implementation is a multilevel phenomenon best studied at the individual and organizational level, implementation was typically alluded to only in a general sense in the analyzed literature. Future research should pay attention to the various levels of analysis in order to find out which factors are most important for individuals, teams, other groups/stakeholders, subsidiaries or organizations as a whole. We do hope this paper will stimulate more of such research. 


\section{References}

Alleyne, C., Kakabadse, A. \& Kakabadse, N. 2007. Using the HR intranet - An exploratory analysis of its impact on managerial satisfaction with the HR function. Personnel Review, 36(1-2): 295-310.

Ball, K.S. 2001. The use of human resource information systems: A survey. Personnel Review, 30(5-6): 677- 693.

Bell, B.S., Lee, S.W. \& Yeung, S.K. 2006. The impact of e-HR on professional competence in HRM: Implications for the development of HR professionals. Human Resource Management, 45(3): 295-308.

Beulen, E. 2009. The contribution of a global service provider's Human Resources Information System (HRIS) to staff retention in emerging markets: Comparing issues and implications in six developing countries. Information Technology \& People, 22(3): 270288.

Bondarouk, T.V., Ruel, H. \& van der Heijden, B. 2009. E-HRM effectiveness in a public sector organization: a multi-stakeholder perspective. International Journal of Human Resource Management, 20(3): 578-590.

Bondarouk, T.V. \& Ruël, H.J.M. 2009. Electronic Human Resource Management: challenges in the digital era. International Journal of Human Resource Management, 20(3): 505514.

Broderick, R. \& Boudreau, J.W. 1991. The Evolution of Computer Use in Human-Resource Management. Interviews with 10 Leaders. Human Resource Management, 30(4): 485508.

Buckley, P., Minette, K., Joy, D. \& Michaels, J. 2004. The use of an automated employment recruiting and screening system for temporary professional employees: A case study. Human Resource Management, 43(2-3): 233-241.

Chapman, D.S. \& Webster, J. 2003. The use of technologies in the recruiting, screening, and selection processes for job candidates. International Journal of Selection and Assessment, 11(2-3): 113-120.

CedarCrestone. 2011-2012. HR Systems Survey: HR Technologies, Deployment Approaches, Value, and Metrics. 14th Annual Edition.

Cronin, B., Morath, R., Curtin, P. \& Heil, M. 2006. Public sector use of technology in managing human resources. Human Resource Management Review, 16(3): 416-430.

Davis, F.D. 1989. Perceived usefulness, perceived ease of use, and user acceptance of information technology. MIS Quarterly, 13: 319-339.

Dery, K. \& Wailes, N. 2005. Necessary but not Sufficient: Strategic HRM and ERPs', Strategic Change, 14(5): 265-272.

DeSanctis, G. 1986. Human-Resource Information-Systems: A Current Assessment. MIS Quarterly, 10(1): 15-27.

Eddy, E.R., Stone, D.L. \& Stone-Romero, E.F. 1999. The effects of information management policies on reactions to human resource information systems: An integration of privacy and procedural justice perspectives. Personnel Psychology, 52(3): 335-358.

Florkowski, G.W. \& Olivas-Lujan, M.R. 2006. The diffusion of human-resource informationtechnology innovations in US and non-US firms. Personnel Review, 35(6): 684-710.

Gardner, S.D., Lepak, D.P. \& Bartol, K.M. 2003. Virtual HR: The impact of information technology on the human resource professional. Journal of Vocational Behavior, 63(2): 159-179.

Guechtouli, M. 2010. e-HRM's impact on an environment scanning process: How can technology support selection of information. International Journal of Technology and Human Interaction, 6(3): 53-66. 
Haines, V.Y. \& Lafleur, G. 2008. Information technology usage and human resource roles and effectiveness. Human Resource Management, 47(3): 525-540.

Haines, V.Y. \& Petit, A. 1997. Conditions for successful human resource information systems. Human Resource Management, 36(2): 261-275.

Hannon, J., Jelf, G. \& Brandes, D. 1996. Human resource information systems: Operational issues and strategic considerations in a global environment. International Journal of Human Resource Management, 7(1): 245-269.

Heikkilä, J.P. \& Smale, A. 2010. The effects of 'language standardization' on acceptance and use of e-HRM systems in foreign subsidiaries. Journal of World Business, 46(2): 135266.

Hempel, P.S. 2004. Preparing the HR profession for technology and information work. Human Resource Management, 43(2-3): 163-177.

Hennessey, H.W. 1979. Computer applications in Human Resource Information Systems. Human Resource Planning, 2(4): 205-213.

Hussain, Z., Wallace, J. \& Cornelius, N.E. 2007. The use and impact of human resource information systems on human resource management professionals. Information and Management, 44(1): 74-89.

Hustad, E. \& Munkvold, B.E. 2005. IT-supported competence management: A case study at Ericsson. Information Systems Management, 22(2): 78-88.

Jones, J.W., Brasher, E.E. \& Huff, J.W. 2002. Innovations in integrity-based personnel selection: Building a technology assessment. International Journal of Selection and Assessment, 10(1-2): 87-97.

Kossek, E.E., Young, W., Gash, D.C. \& Nichol, V. 1994. Waiting for innovation in the Human-Resources Department: Godot implements a Human-Resource InformationSystem. Human Resource Management, 33(1): 135-159.

Lederer, A.L. 1984. Planning and developing a human resources information system. Personnel Administrator, 61(3): 14-27.

Lee. I. 2011. Modeling the benefit of e-Recruiting process integration. Decision Support Systems, 51(1): 230-239.

Lepak, D.P. \& Snell, S.A. 1998. Virtual HR: Strategic human resource management in the 21st century. Human Resource Management Review, 8(3): 215-234.

Lukaszewski, K.M., Stone, D.L. \& Stone-Romero, E.F. 2008. The effects of the ability to coose the type of Human Resources System on perceptions of invasion of privacy and system satisfaction. Journal of Business and Psychology, 23(3-4): 73-86.

Kovach, K.A., Hughes, A.A., Fagan, P. \& Maggitti, P.G. 2002. Administrative and strategic advantages of HRIS. Employment Relations Today, 29(2): 43-48.

Lawler, E.E. \& Mohrman, S.A. 2003. HR as a Strategic Partner: What Does it Take to Make It Happen? Human Resource Planning, 26(3):15-24.

Magnus, M. \& Grossman, M. 1985. Computers and the personnel department. Personnel Journal, 64(4): 42-48.

Marler, J. 2009. Making human resources strategic by going to the Net: Reality or myth? International Journal of Human Resource Management, 20: 515-527.

Martin, G. \& Reddington, M. 2010. Theorizing the links between e-HR and strategic HRM: A model, case illustration and reflections. International Journal of Human Resource Management, 21(10): 1553-1574.

Martinsons, M.G. 1994. Benchmarking Human-Resource Information-Systems in Canada and Hong-Kong. Information \& Management, 26(6): 305-316.

Martinsons, M.G. \& Chong, P.K.C. 1999. The influence of human factors and specialist involvement on information systems success. Human Relations, 52(1):123-152. 
Mathieson, K. 1993.Variations in Users Definitions of an Information-System. Information \& Management, 24(4): 227-234.

Mathys, N. \& LaVan, H. 1982. A survey of the human resource information systems (HRIS) of major companies. Human Resource Planning, 5(2): 83-90.

Mayer, S.J. 1971. EDP Personnel Systems - What Areas Are Being Automated. Personnel, 48(4): 29-36.

Neary, B. 2002. Creating a company-wide, on-line, performance management system: a case study at TRW Inc. Human Resource Management, 41: 491-498.

Ngai, E.W.T. \& Wat, F.K.T. 2006. Human resource information systems: a review and empirical analysis. Personnel Review, 35(3): 297-314.

Oiry, E. 2009. Electronic human resource management: organizational responses to role conflicts created by e- learning. International Journal of Training and Development, 13(2): 111-123.

Olivas-Lujan, M.R., Ramirez, J. \& Zapata-Cantu, L. 2007. e-HRM in Mexico: adapting innovations for global competitiveness. International Journal of Manpower, 28(5): 418434.

Panayotopoulou, L., Vakola, M. \& Galanaki, E. 2007. E-HR adoption and the role of HRM: evidence from Greece. Personnel Review, 36(1-2): 277-294.

Reddick, C.G. 2009. Human Resources Information Systems in Texas City Governments: Scope and Perception of its Effectiveness. Public Personnel Management, 38(4): 19-34.

Reddington, M. \& Hyde, C. 2008. The Impact of e-HR on Line Managers and Employees in the UK: Benefits, Problems, and Prospects. In: Technology, Outsourcing and Transforming HR: Potentials, Problems, and Guidance for Practitioners. (Ed.) M.G., Reddington \& H. Alexander, 35-59. Oxford: Butterworth-Heinemann/Elsevier.

Ruel, H., Bondarouk, T. \& Looise, J.K. 2004. E-HRM: Innovation or Irritation : An Explorative Empirical Study in Five Large Companies on Web-based HRM. Management Revue, 15(3): 364-381.

Ruël, H.J.M., Bondarouk, T.V. \& Van der Velde, M. 2007. The Contribution of e-HRM to HRM Effectiveness. Employee Relations, 29(3): 280-291.

Ruta, C.D. 2009. HR portal alignment for the creation and development of intellectual capital. International Journal of Human Resource Management, 20(3): 562-577.

Smale, A. \& Heikkilä, J.P. 2009. IT-Based integration of HRM in a foreign MNC subsidiary: A micro-political perspective. Handbook of Research on E-Transformation and Human Resources Management Technologies: Organizational Outcomes and Challenges, 153-170.

Strauss, A.L. \& Corbin, J. 1990. Basics of qualitative research: Grounded theory procedures and techniques. Newbury Park, CA: Sage.

Strohmeier, S. 2007. Research in e-HRM: review and implications. Human Resource Management Review, 17(1): 19-37.

Strohmeier, S. 2009. Concepts of e-HRM Consequences: A Categorization, Review and Suggestion. International Journal of Human Resource Management, 20(3): 528 - 543

Strohmeier, S. \& Kabst, R. 2009. Organizational adoption of e-HRM in Europe An empirical exploration of major adoption factors. Journal of Managerial Psychology, 24(6): 482501.

Sturman, M.C., Hannon, J.M. \& Milkovich, G.T. 1996. Computerized decision aids for flexible benefits decisions: The effects of an expert system and decision support system on employee intentions and satisfaction with benefits. Personnel Psychology, 49(4): 883908. 
Svoboda, M. \& Schroder, S. 2001. Transforming human resources in the new economy: Developing the next generation of global HR managers at Deutsche Bank AG. Human Resource Management, 40(3): 261-273.

Tansley, C. \& Newell, S. 2007. A knowledge-based view of agenda-formation in the development of human resource information systems. Management Learning, 38(1): 95119.

Tansley, C., Newell, S. \& Williams, H. 2001. Effecting HRM-style practices through an integrated human resource information system - An e-greenfield site? Personnel Review, 30(3): 351-370.

Tansley, C. \& Watson, T. 2000. Strategic exchange in the development of Human Resource Information Systems (HRIS). New Technology Work and Employment, 15(2): 108-122.

Taylor, G.S. \& Davis, J.S. 1989. Individual Privacy and Computer-Based Human-Resource Information Systems. Journal of Business Ethics, 8(7): 569-576.

Teo, T.S.H., Lim, G.S. \& Fedric, S.A. 2007. The adoption and diffusion of human resources information systems in Singapore. Asia Pacific Journal of Human Resources, 45(1): 4462.

Tomeski, E.A. \& Lazarus, H. 1974. Computerized Information Systems in Personnel. Academy of Management Journal, 17(1): 168-172.

Voermans, M. \& Van Veldhoven, M. 2007. Attitude towards E-HRM: an empirical study at Philips. Personnel Review, 36(5-6), 887-902.

Wilson-Evered, E. \& Hartel, C.E.J. 2009. Measuring attitudes to HRIS implementation: A field study to inform implementation methodology. Asia Pacific Journal of Human Resources, 47(3): 374-384. 


\section{Appendix 1 \\ Analysed e-HRM literature}

\begin{tabular}{|c|c|c|c|}
\hline $\mathrm{Nr}$ & Year & Author & Method \\
\hline 1 & 1971 & Mayer & Quantitative \\
\hline 2 & 1974 & $\begin{array}{l}\text { Tomeski } \\
\& \text { Lazarus }\end{array}$ & Quantitative \\
\hline 3 & 1982 & $\begin{array}{l}\text { Mathys } \\
\& \text { LaVan }\end{array}$ & Quantitative \\
\hline 4 & 1985 & $\begin{array}{l}\text { Magnus } \\
\& \text { Grossman }\end{array}$ & Quantitative \\
\hline 5 & 1986 & DeSanctis & Quantitative \\
\hline 6 & 1989 & Taylor \& Davis & Quantitative \\
\hline 7 & 1992 & $\begin{array}{l}\text { Broderick } \\
\& \text { Boudreau }\end{array}$ & Qualitative \\
\hline 8 & 1993 & Mathieson. & Quantitative \\
\hline 9 & 1994 & Kossek et al. & Qualitative \\
\hline
\end{tabular}

Sample

375 major US corporations

12 federal departments, 22 states, 15 counties, 24 cities, 17 private organizations

75 private sector companies (37 manufacturing, 5 Retail \& Wholesale, 14 Finance, 9 Utilities, 10 Transportation

1000 US personnel journal subscribers. The majority work in manufacturing, finance or health services. Their titles include: $\mathrm{CEO} /$ owner/partner/corporate officer/vice president (15\%), director (22.9\%), manager (39.5\%), administration/supervisor/officer (14.3\%) and specialist/analyst/ assistant or consultant $(8.3 \%)$

171 members of the Association of Human Resource System Professionals. All major industries are represented in the sample, including manufacturing, banking, insurance, transportation, communications, construction, retailing, education, and services. The typical respondent was a "manager of HRIS," but the survey was completed as well by vice presidents, directors, supervisors within personnel, and managers of compensation and benefits 223 business management undergraduates participated in the study; 100 (45\%) female and $123(55 \%)$ male

Case studies of 10 Fortune 500 companies considered 'leaders' in HRIS usage (exploratory interviews with top HR Manager, HRIS Manager, Representatives from HRIS staff, Information Systems, Finance or other areas who regularly worked with the HRIS

Survey of 78 users of a university HRIS

Longitudinal case study. Data were collected at two different times spanning several years. Surveys, interviews, and reviews of company documents were used. $26 \%$ were from corporate, $74 \%$ from field locations. 23\% were managers and 77\% were HRM professionals or staff. $72 \%$ were experienced users

\begin{tabular}{|c|c|c|c|}
\hline 10 & 1994 & Martinsons & Quantitative \\
\hline 11 & 1996 & Hannon et al. & Mixed \\
\hline & & & Method \\
\hline 12 & 1996 & Sturman et al. & Quantitative \\
\hline 1 & 1997 & Haines & Quantitative \\
\hline & & $\&$ Petit & \\
\hline
\end{tabular}
118 Canadian respondents, 361 Hong Kong respondents

14 US-based MNCs. 14 telephone interviews and 11 in-depth interviews with executives

Experimental design in a field setting. 80 employees of a Fortune 500 company. Random assignment to 3 conditions

141997 Powell \& Dent- Quantitative Survey of 152 members of the Canadian Association of Human Resource Systems Professionals (CHRSP). They were users who interact directly with a computer-based HRIS to do their work 65 surveys of CEOs and senior executives in the retail industry

161999 Eddy et al. Quantitative

Survey on the perceptions of job-search methods of 32 HRM professionals in top 100 privately owned companies in Georgia

171999 Martinsons Quantitative 124 employed persons enrolled in an MBA course. Experimental design

Field study of 67 questionnaires of professionals responsible for HRM on the enterprise-level in East and South-East Asia. A second follow-up questionnaire was conducted with the managers whose department most directly affected by the new computer systems (61 of earlier 67)

$181999 \quad$ Elliott \&

Quantitative 154 questionnaires of HRM professionals in public $(n=77)$ and private $(\mathrm{n}=77)$ sector companies

$192000 \quad$ Tansley Mixed Two year ethnographic/case study (observations, 10 interviews, document analysis, field notes). Covered HRM and IS managers working on a three year global HRIS project for an American corporation (60 countries, 80,000 employees) active in different 

\& Schröder Ball

\section{Tansley et al.}

2002 Jones et al. \& Friedman \& Weiss

Chapman \& Webster

Potosky \& Bobko

Buckley et al.

Mixed

Method

Singh $\&$ Point

Hustad \& Munkvold

Bell et al.

Cronin et al.

Florkowski \& Olivas-Lujan

Mixed

Method

Mixed

Method

Mixed

Method

Mixed

Method
Qualitative

Quantitative

Quantitative

Qualitative

Qualitative

Quantitative

Qualitative

Quantitative

Qualitative

Quantitative

Qualitative

Qualitative

Quantitative on the diffusion of HRIT. Specifically it was questioned whether the diffusion was caused by internal forces or external forces, or was hybrid

Quantitative

Surveys, interviews, observations of 60 Malaysian employees in manufacturing SME's (more than 250 employees). 21\% were public limited companies 700 employees of Ericsson (mainly Norwegian branch). Two third were working in $R \& D$ departments. Semi-structured interviews and document analysis over 5 months

Interviews were conducted with HR representatives from 19 Fortune 500 companies to examine the linkage between electronic human resources (e-HR) and the reshaping of professional competence in HRM

Benchmarking study: interviews with $20 \mathrm{HR}$ professionals working in federal agencies

Survey of 147 HRM practitioners in Hong Kong 
Mixed

Method

Hussain et al.

Mixed

Method

42

2008 Ngai et al

Quantitative

43 et al.

Method

Newell

Olivas-Lujan et Qualitative al.

\section{Voermans \&} van Veldhoven Teo et al.

492008 Beulen

Bondarouk \& Ruël

Haines \&

Lafleur al.

Bondarouk et al.

\section{Qualitative}

\section{Qualitative}

Quantitative

Quantitative

Qualitative

Qualitative

Quantitative

Quantitative

Mixed Method
Case study of a customer service division in a major telecommunications organization which had developed and implemented a company-wide HRM intranet. The sample consisted of HR managers and HR customers

Survey of 101 HRM professionals and interviews with 11 senior executives (to whom the HRM professionals reported) working in small, medium and large UK organizations

Survey of 147 HRM practitioners in Hong Kong on their perceptions of the importance of the internet for effective HRM Research on e-HRM adoption in Greece by means of focus groups and 76 questionnaires. For the focus groups 3 HRM managers from the following sectors were included: manufacturing, banking and telecommunications

On-line questionnaire with 100 operational employees, managers and HR professionals in the Dutch ministry of internal affairs

Ethnographic narrative study of an IS and HR manager working in a North-American owned corporation (more than 80,000 employees) during the agenda setting stage of a global HRIS implementation. Over a two-year period the researchers observed 12 global HRIS team meetings. The meetings were about the design, specification and procurement of a $\$ 15$ million HRIS with a global data warehouse and country-specific integrated employee databases

Case studies of 4 large Mexican owned firms from 4 different sectors (food and beverages, financial and commercial services, production and distribution of construction materials, information technology and BPO (business process outsourcing)). Semistructured interviews with Senior HR managers, line managers and employees were conducted

Online questionnaires of 99 managers and 257 employees of Philips Electronics, Netherlands

Questionnaire with 110 companies in Singapore

Case study with 16 HRM executives at Accenture on the way HRIS supports them in their HRM tasks

3 case studies (structured interviews, field notes and document analysis) of a hospital, an insurance company and a university. 83 interviews were conducted with managerial employees responsible for strategic policymaking in the companies, members of the IT project teams and system end-users

Survey research of 210 senior HRM executives at leading Canadian corporations

2 experimental studies. Using a $2 \times 2$ experimental design the researchers examined the effects of (a) ability to choose the type of HRM system to which data would be disclosed (choice vs. no choice), and (b) type of information disclosed (medical vs. nonmedical) on invasiveness and service satisfaction. Study 1 used 71 and Study 2 used 68 employed participants

Case study of 16 HRM executives and managers at Accenture. The interviewed worked at the company's Argentina, Brazil, China, India, Latvia and Slovakia branches. The purpose was to explore how HRIS supported Accenture's efforts in retention management 21 interviews about the adaptation of a career development tool were conducted at the Ministry of Interior and Kingdom Relations in the Netherlands: 10 with line managers and 11 with employees.

Case study of a leading international consulting firm focused on the implementation of an advanced HRM portal and the way it contributes to intellectual capital creation, maintenance and leverage

Case study (semi-structured interviews, internal publications, media reports, and other published sources) of HRM unit 
managers of 20 multinational companies in the United Kingdom (6), Continental Europe (6), Asia-Pacific (5) and the United States (2). Also a survey with 263 HRM Managers. Hypotheses were tested using Structural Equation Modelling

\& Kabst

On the basis of a literature review the authors derived factors affecting the adoption of online recruitment. Then 14 semistructured interviews were held with UK HRM managers in order to validate the factors. The factors were then used to conduct a survey with 439 HR managers and directors to investigate which were associated with vacancies advertised via the corporate website or commercial job boards

$\begin{array}{llll} & & \& \text { Kabst } & \\ 59 & 2009 & \begin{array}{l}\text { Imperatori } \\ \& \text { Bissola }\end{array} & \text { Quantitative } \\ 60 & 2009 & \text { Oiry } & \text { Qualitative }\end{array}$

Large scale survey with senior HRM managers in 2,336 organizations in 23 European countries to examine which general and contextual factors influence cross-national organizational adoption of e-HRM

Experiment with 1,078 undergraduate students attending Organizational Design, HRM and Organizational Behaviour courses at Catholic University in Milan

$602009 \quad$ Oiry

Four case studies of the French banking sector on role conflicts arising from e-learning. 15 interviews were conducted: 4 with training managers, 4 with e-learning project managers, 1 with union representative, 1 direct manager, 2 employees who had undergone the training, 2 members of training department and 1 expert in the development of e-learning in France

612009 Payne et al. Quantitative

Quasi-experimental study on employee reaction to the use of an online performance appraisal (PA) system conducted with the traditional paper-and-pencil (P\&P) approach. Reactions of a group of 83 employees evaluated with the P\&P approach and 152 employees evaluated with the online system were compared

Survey of 88 US Human Resource Directors employed in the public sector. Scope and perception of HRIS effectiveness

632009 Smale Qualitative A longitudinal in-depth case study on the integration of a global e\& Heikkilä HRM system in Finland. Qualitative data was collected via interviews with key HR personnel and managers, which was complemented by company documentation of negotiation between HQ and subsidiaries during the IT-based integration of HRM \& Hartel Survey with HR staff and line managers in five hospital districts directly involved in the implementation of $\mathrm{HR} /$ payroll integrated HRIS (34 respondents) and an automated system (26 respondents) Focus on key determinants of successful information systems implementation

$652010 \quad$ Barut \& Dogerlioglu

Quantitative Survey with HR professionals ( $81 \%$ HR managers or directors) in 31 organizations

Focus on success factors and consequences of HRIS implementation

$66 \quad 2010 \quad$ Guechtouli

Qualitative

Case study in an organization with more than 5000 employees. Describes the way an IT system supports environmental scanning procedures. Interviews were conducted with 5 managers. , Company documents were also analyzed

$672010 \quad$ Martin Mixed \& Reddington Method

Case study of an e-HRM implementation in two strategic business units of a UK-based global oilfield services provider. There were two stages of data collection: 1) survey with 41 line managers, 2) 9 in-depth interviews with line managers

$682010 \begin{aligned} & \text { Olivas-Lujan } \\ & \text { \& Florkowski }\end{aligned} \quad$ Quantitative

Web-based survey of 136 US and Canadian firms on the influence of IT governance arrangements on the intensity of e-HRM usage. 116 interviewees had positions in HRM and 60\% worked in higher management

$692010 \quad$ Heikkilä

\& Smale

Qualitative

18 in depth-interviews with subsidiary HR managers from two European MNCs about the effects of language standardization on the acceptance and use of e-HRM systems 


\section{Implementation factors: Part 1 - Technology implementation factors (1970-2010)}

\begin{tabular}{|c|c|c|c|}
\hline & 1970-1989 & 1990-1999 & $2000-2010$ \\
\hline $\begin{array}{l}\text { Current IT } \\
\text { Architecture }\end{array}$ & $\begin{array}{l}\text { Current applications (Mayer, } \\
\text { 1971) } \\
\text { Decisions about HRIS } \\
\text { characteristics e.g., number } \\
\text { of applications (DeSanctis, } \\
\text { 1986) } \\
\text { Computer output reliability, } \\
\text { accuracy of personnel data } \\
\text { (Tomeski \& Lazarus, 1974) }\end{array}$ & $\begin{array}{l}\text { Applications that meet business unit needs } \\
\text { (Broderick \& Boudreau, 1992) } \\
\text { Current applications versus those planned } \\
\text { (Haines \& Petit, 1997) } \\
\text { Ease of use and usefulness (Haines \& Petit, } \\
\text { 1997) } \\
\text { Subsystems modification (Kossek et al., } \\
\text { 1994) } \\
\text { Digital data reliability (Kossek et al., 1994) } \\
\text { Widespread system access for employees } \\
\text { (Broderick \& Boudreau, 1992) } \\
\text { Types of HRIS technology: mainframe vs. } \\
\text { pc-based (Broderick \& Boudreau, 1992) } \\
\text { Online applications (Haines \& Petit, 1997) }\end{array}$ & $\begin{array}{l}\text { Current applications, IT infrastructure, (Hooi, 2006; Reddick, 2009), availability of } \\
\text { computers in organization (Ruel et al., 2004) } \\
\text { Quality of e-HRM application, content and design (Bondarouk et al., 2009; Ruel et } \\
\text { al., 2007) } \\
\text { Ease of use, usefulness (Ruta, 2009) and usability (Voermans \& van Veldhoven, } \\
\text { 2007) } \\
\text { Manager self-service applications (Beulen, 2009) } \\
\text { Option of keyword searches in personnel information systems (Chapman \& } \\
\text { Webster, 2003) } \\
\text { IT usage in organization (Haines \& Lafleur, 2008) } \\
\text { Clarity and ease of use of information structure (Ruel et al., 2004) } \\
\text { Reliable technology (Chapman \& Webster, 2003) }\end{array}$ \\
\hline $\begin{array}{l}\text { Digitalizing HR } \\
\text { Data }\end{array}$ & $\begin{array}{l}\text { Centralization of records } \\
\text { (Magnus \& Grossman, 1985) } \\
\text { Integration (Magnus \& } \\
\text { Grossman, 1985) } \\
\text { Customizing HRIS (Magnus } \\
\text { \& Grossman, 1985) } \\
\text { Interfacing with corporate } \\
\text { headquarter (Magnus \& } \\
\text { Grossman, 1985) }\end{array}$ & $\begin{array}{l}\text { Subsystems integration (Kossek et al., } \\
\text { 1994) } \\
\text { Current systems architecture (Kossek et al., } \\
\text { 1994) } \\
\text { Incorporating personnel data in HR } \\
\text { database (Broderick \& Boudreau, 1992) } \\
\text { Patched updating (Hannon et al., 1996) } \\
\text { Quantity of data/information to be } \\
\text { integrated (Broderick \& Boudreau, 1992) }\end{array}$ & $\begin{array}{l}\text { Compatibility across departments ( (Teo et al., 2007; Parry \& Wilson, 2009) } \\
\text { Alignment across subsidiaries (Morris, et al., 2009) } \\
\text { Local adaption of HRIS (Beulen, 2009; Smale \& Heikkila, 2009) } \\
\text { Global integration of applications (Beulen, 2009) } \\
\text { Language standardization (Heikkila \& Smale, 2010) } \\
\text { Integrating vendor software with in-house software (Chapman \& Webster, 2003) } \\
\text { Customizing personnel systems (Cronin et al., 2009) intranet (Alleyne et al., 2007) } \\
\text { HR portal configuration throughout organization (Ruta, 2009) }\end{array}$ \\
\hline $\begin{array}{l}\text { Technology } \\
\text { Project } \\
\text { Management }\end{array}$ & $\begin{array}{l}\text { Time management for } \\
\text { computerization (Tomeski \& } \\
\text { Lazarus, 1974) } \\
\text { Selecting software (Magnus } \\
\text { \& Grossman, 1985) }\end{array}$ & $\begin{array}{l}\text { Decision to outsource development } \\
\text { (Hannon et al., 1996) } \\
\text { Documentation (Haines \& Petit, 1997) }\end{array}$ & $\begin{array}{l}\text { Decision for in-house development vs. adapting commercial applications (Chapman } \\
\& \text { Webster, 2003) } \\
\text { Mapping HR processes prior to system implementation (Cronin et al., 2006) }\end{array}$ \\
\hline
\end{tabular}




\section{Appendix 2 (Continued) \\ Implementation factors: Part 2 - Organizational implementation factors (1970-2010)}

\begin{tabular}{|c|c|c|c|}
\hline & $1970-1989$ & 1990-1999 & 2000-2010 \\
\hline Demographics & $\begin{array}{l}\text { Organizational size (Mayer, 1971) } \\
\text { Sector (Tomeski \& Lazarus, 1974) }\end{array}$ & $\begin{array}{l}\text { Organizational size (Haines \& Petit, 1997) } \\
\text { Departmental size of HR, IS, HRIS (Haines } \\
\text { \& Petit, 1997) } \\
\text { Sector (Martinsons, 1994) } \\
\text { Age of HRIS department (Haines \& Petit, } \\
\text { 1997) }\end{array}$ & $\begin{array}{l}\text { Organizational size (Chapman \& Webster, 2003; Ngai \& Wat, 2006; Teo } \\
\text { et al., 2007; Strohmayer \& Kabst, 2009; Ball 2001) } \\
\text { Sector (Olivas-Lujan et al., 2007; Panayotopoulou et al., 2007; } \\
\text { Strohmayer \& Kabst, 2009) } \\
\text { Sector characteristics and culture (Panayotopoulou et al., 2007) } \\
\text { Organizational subsidy/branch (Voermans \& Veldhoven, 2007) }\end{array}$ \\
\hline Resources & $\begin{array}{l}\text { Shortages of personnel and time } \\
\text { (Magnus \& Grossman, 1985) } \\
\text { Budget limitations (Mayer, 1971; } \\
\text { Magnus \& Grossman, 1985) } \\
\text { Unforeseen costs (Mayer, 1971) }\end{array}$ & $\begin{array}{l}\text { Shortages in personnel (Martinsons, 1994) } \\
\text { Budget limitations during a recession } \\
\text { (Martinsons, 1994) } \\
\text { Concerns about economic and operational } \\
\text { feasibility (Kossek et al., 1994) } \\
\text { Unforeseen (rising) costs during } \\
\text { implementation (Kossek et al., 1994) }\end{array}$ & $\begin{array}{l}\text { Financial resources (Hool, 2006) } \\
\text { Organizations' financial situation (Hustad \& Munkvold, 2005) } \\
\text { Budget limitations ( Reddick, 2009) }\end{array}$ \\
\hline $\begin{array}{l}\text { Organizational } \\
\text { Policies and } \\
\text { Practices }\end{array}$ & Securing privacy (Tylor \& Davis, 1989) & $\begin{array}{l}\text { Standardization of HR processes (Hannon } \\
\text { et al., 1996) } \\
\text { Degree of centralization of HR } \\
\text { management (Broderick \& Boudreau, 1992) } \\
\text { Restricted access (Eddy et al., 1999) } \\
\text { Employee authorization prior to releasing } \\
\text { personal information ((Eddy et al., 1999) }\end{array}$ & $\begin{array}{l}\text { Global standardization (centralization) of HRM practices vs. local } \\
\text { adaption (Hustad \& Munkvold, 2005) } \\
\text { Confidentiality and security of input data (Ruel et al., 2004) } \\
\text { Employment structure: temporary vs., fixed personnel (Strohmayer \& } \\
\text { Kabst, 2009) } \\
\text { HR ICT governance (Olivas-Lujan \& Florkowski, 2010) } \\
\text { Configuration of HRM, degree of formalism (Strohmayer \& Kabst, 2009) } \\
\text { Type of information disclosed (Lukaszewski et al., 2008) } \\
\text { Organizational policies for career development (Bondarouk et al., 2009) }\end{array}$ \\
\hline $\begin{array}{l}\text { Knowledge and } \\
\text { skills }\end{array}$ & $\begin{array}{l}\text { Shortage of technical personnel } \\
\text { (Magnus \& Grossman, 1985) }\end{array}$ & $\begin{array}{l}\text { Shortage of technical expertise (Martinsons, } \\
\text { 1994) } \\
\text { Knowledge of technological developments } \\
\text { (Martinsons, 1994) } \\
\text { Organizations' technology level (Hannon et } \\
\text { al., 1996) } \\
\text { Firm's computer experience (Haines \& } \\
\text { Petit, 1997) }\end{array}$ & $\begin{array}{l}\text { IT expertise (Hooi, 2006), HRIS (Teo et al., 2007) } \\
\text { HR staff capacity to acquire IT skills (Olivas-Lujan \& Florkowski, 2010) } \\
\text { Technical expertise of project team (Bradford Neary, 2002) } \\
\text { Employee's language capabilities (Heikkila \& Smale, 2010) } \\
\text { Expertise in change management (Reddick, 2009) } \\
\text { Lack of awareness of HR system potential (Tansley \& Watson, 2000) }\end{array}$ \\
\hline $\begin{array}{l}\text { Project } \\
\text { Management }\end{array}$ & $\begin{array}{l}\text { Integration of HR plan with corporate } \\
\text { plan }\end{array}$ & $\begin{array}{l}\text { Cooperation among departments } \\
\text { (Broderick \& Boudreau, 1992; Kossek et } \\
\text { al., 1994) } \\
\text { Identification and planning of current and } \\
\text { future organizational needs (Hannon et al., } \\
\text { 1996) } \\
\text { Strategic planning (Hannon et al., 1996; } \\
\text { (Kossek et al., 1994) }\end{array}$ & $\begin{array}{l}\text { Cooperation among departments, especially HR and IT (Panayotopoulou } \\
\text { et al., 2007) } \\
\text { Mapping HR processes (Tansley \& Watson, 2000) } \\
\text { Cross-functional project team (Tansley \& Watson, 2000) } \\
\text { Project in hands of HR department (Tansley \& Watson, 2000) } \\
\text { Clear e-HRM goals and planning (Ruel et al., 2004) } \\
\text { Consulting with external advisors at IT vendors (Tansley \& Watson, } \\
\text { 2000) }\end{array}$ \\
\hline
\end{tabular}




\section{Appendix 2 (Continued) \\ Implementation factors: Part 3 - People implementation factors (1970-2010)}

\begin{tabular}{|c|c|c|c|c|}
\hline & & 1970-1989 & 1990-1999 & $2000-2010$ \\
\hline \multirow{5}{*}{$\frac{0}{2}$} & $\begin{array}{l}\text { Employee and } \\
\text { Management } \\
\text { Attitudes } \\
\text { (support and } \\
\text { commitment) }\end{array}$ & $\begin{array}{l}\text { Lack of top management } \\
\text { support (Tomeski \& } \\
\text { Lazarus, 1974; Magnus \& } \\
\text { Grossman, 1985) } \\
\text { Top management attitude } \\
\text { towards HRIS (Mayer, } \\
\text { 1974) }\end{array}$ & $\begin{array}{l}\text { Lack of top management support (Hannon et al., } \\
\text { 1996) } \\
\text { Support from HR executives and staff (Hannon et al., } \\
\text { 1996) } \\
\text { Support from HR executives and staff (Hannon et al., } \\
\text { 1996) } \\
\text { Support from financial executives and staff (Hannon } \\
\text { et al., 1996) }\end{array}$ & $\begin{array}{l}\text { Lack of CEO or manager support (Reddick, 2009) } \\
\text { Lack of middle or top management support (Tansely \& Watson, 2000) } \\
\text { Commitment from management and employees (Hustad \& Munkvold, 2005) } \\
\text { Top and line management commitment to e-HRM strategy (Olivas-Lujan \& } \\
\text { Florkowski, 2010) } \\
\text { Top management support and priority for e-HRM systems ((Hustad \& } \\
\text { Munkvold, 2005, Teo et al., 2007) } \\
\text { Experienced user support (Voermans \& Veldhoven, 2007) } \\
\text { Support from each business unit (Bradford Neary, 2002) }\end{array}$ \\
\hline & $\begin{array}{l}\text { Employee and } \\
\text { Management } \\
\text { Involvement }\end{array}$ & $\begin{array}{l}\text { User involvement during } \\
\text { systems development } \\
\text { (DeSanctis, 1986) }\end{array}$ & $\begin{array}{l}\text { HR staff and management involvement in design } \\
\text { (Kossek et al., 1994) } \\
\text { Involvement of line management (Kossek et al., } \\
\text { 1994) } \\
\text { Insignificance of user involvement for satisfaction } \\
\text { (Kossek et al., 1994) }\end{array}$ & $\begin{array}{l}\text { HR and IT staff involvement (Tansely \& Watson, 2000) } \\
\text { HR and IT staff involvement from other subsidiaries (Tansely \& Watson, } \\
2000 \text { ) } \\
\text { Failure in not involving stakeholders impacted by new technology (Tansely \& } \\
\text { Watson, 2000) } \\
\text { Customer involvement (Alleyne et al., 2007) }\end{array}$ \\
\hline & $\begin{array}{l}\text { Employee and } \\
\text { Management } \\
\text { Skills versus } \\
\text { Training Needs }\end{array}$ & $\begin{array}{l}\text { Challenge of training } \\
\text { users (Magnus \& } \\
\text { Grossman, 1985) }\end{array}$ & $\begin{array}{l}\text { Providing training and help troubleshooting } \\
\text { (Broderick \& Boudreau, 1992) } \\
\text { Face-to-face training (Kossek et al., 1994) } \\
\text { Training HRIS skills (Kossek et al., 1994) } \\
\text { HR professionals deficient in technical knowledge } \\
\text { (Hannon et al., 1996) } \\
\text { Computer experience (Haines \& Petit, 1997) } \\
\text { In-house training enhances satisfaction (Haines \& } \\
\text { Petit, 1997) }\end{array}$ & $\begin{array}{l}\text { HR professionals' deficiency in IT skills, individual IT competence } \\
\text { (Panayotopoulou et al., 2007) } \\
\text { PC skills of management and employees (Ruel et al., 2004) } \\
\text { Employee languages competence when using e-HRM (Heikkila \& Smale, } \\
2010 \text { ) } \\
\text { HR, manager and employee training (Cronin et al., 2006) } \\
\text { Training HR professionals in e-HRM usage (Panayotopoulou et al., 2007) } \\
\text { Inadequate e-HRM training (Martin \& Reddington, 2010) } \\
\text { E-Learning (Svoboda \& Schröder, 2001) }\end{array}$ \\
\hline & $\begin{array}{l}\text { Employee } \\
\text { Demographics }\end{array}$ & & $\begin{array}{l}\text { Users' age and education insignificant for HRIS } \\
\text { satisfaction (Haines \& Petit, 1997) } \\
\text { Employee experience in present position negatively } \\
\text { impacts satisfaction and usage (Haines \& Petit, 1997) } \\
\text { Self-training negatively impacts HRIS satisfaction } \\
\text { (Haines \& Petit, 1997) }\end{array}$ & $\begin{array}{l}\text { Insignificance of users' age, education, gender, job experience (Voermans \& } \\
\text { Veldhoven, 2007) for usage } \\
\text { HR professionals' age and gender (Gardner et al., 2003) insignificant for } \\
\text { usage }\end{array}$ \\
\hline & $\begin{array}{l}\text { Communication } \\
\text { Difficulties }\end{array}$ & $\begin{array}{l}\text { Difficulties in } \\
\text { communication between } \\
\text { HR and IT (Tomeski \& } \\
\text { Lazarus, 1974) } \\
\text { Incongruence between } \\
\text { HR and IT needs (Magnus } \\
\text { \& Grossman, 1985) }\end{array}$ & $\begin{array}{l}\text { Difficulties in communication between HR and IT } \\
\text { (Kossek et al., 1994) } \\
\text { Managing power dynamics (Kossek et al., 1994) }\end{array}$ & $\begin{array}{l}\text { Communication about e-HRM usefulness (Beulen, 2009) } \\
\text { Lack of information about implications of new e-HRM (Martin \& Reddington, } \\
\text { 2010) } \\
\text { Feedback and evaluation after systems implementation (Alleyne et al., 2007) }\end{array}$ \\
\hline
\end{tabular}


Appendix 2 (Continued)

Implementation factors: Part 3 - People implementation factors (1970-2010)

\begin{tabular}{|c|c|c|}
\hline 1970-1989 & 1990-1999 & 2000-2010 \\
\hline $\begin{array}{l}\text { Organizational } \\
\text { Culture and } \\
\text { Leadership }\end{array}$ & 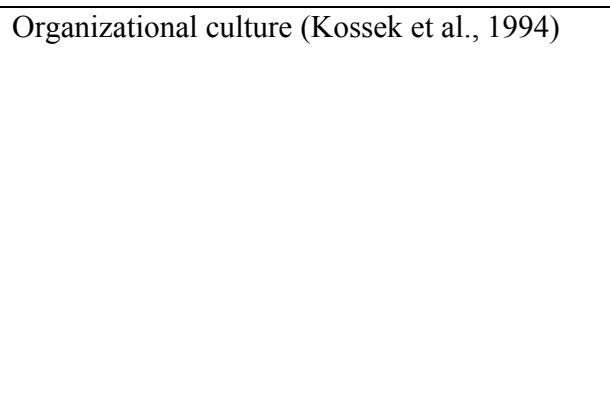 & $\begin{array}{l}\text { Organizational culture (Panayotopoulou et al., 2007, Chapman \& Webster, } \\
\text { 2003) } \\
\text { Organizational image (Chapman \& Webster, 2003) } \\
\text { HR innovation climate (Olivas-Lujan \& Florkowski, 2010) } \\
\text { Subjective norms (Parry \& Wilson,2009) } \\
\text { Openness to new ideas, receptiveness (Martin \& Reddington, 2010) } \\
\text { Change management leadership (Wilson-Evered \& Härtel, 2009) } \\
\text { Visionary leader promoting e-HRM (Tansley \& Watson, 2000) } \\
\text { Presence of system champion (Hustad \& Munkvold, 2005) } \\
\text { Presence of HR technology champion (Olivas-Lujan \& Florkowski, 2010) } \\
\text { Aligning e-HRM, HR and corporate strategy (Tansely \& Watson, 2000) }\end{array}$ \\
\hline $\begin{array}{l}\text { Psychological } \\
\text { factors }\end{array}$ & Staff resistance to change (Kossek et al., 1994) & $\begin{array}{l}\text { Trust between members of e-HRM project team (Tansely \& Watson, 2000) } \\
\text { Staff resistance to change (Reddick, 2009) } \\
\text { Security/privacy fears (Reddick, 2009) } \\
\text { Negative perception of HR staff (Martin \& Reddington, 2010) } \\
\text { Changing mindset of employees and line managers (Ruel et al., 2004) } \\
\text { Employee champion preferences (Voermans \& Veldhoven, 2007) } \\
\text { Strategic preferences and differences among involved parties (Voermans \& } \\
\text { Veldhoven, 2007) } \\
\text { Group morale (Wilson-Evered \& Härtel, 2009) } \\
\text { Workplace distress (Wilson-Evered \& Härtel, 2009) } \\
\text { Job satisfaction (Wilson-Evered \& Härtel, 2009) } \\
\text { Confidence with technology skills (Wilson-Evered \& Härtel, 2009) } \\
\text { Positive and negative beliefs about advantages of new systems (Parry \& } \\
\text { Wilson, 2009) }\end{array}$ \\
\hline
\end{tabular}




\section{Appendix 3}

Consequences of e-HRM (1970-2010) - Part 1: Operational

\begin{tabular}{|c|c|c|c|}
\hline & \begin{tabular}{|c|}
$1970-1989$ \\
\end{tabular} & 1990-1999 & $2000-2010$ \\
\hline HR Efficiency & $\begin{array}{l}\text { Faster reporting (Tomeski } \\
\& \text { Lazarus, 1974) } \\
\text { Freeing HR staff for } \\
\text { important tasks (Tomeski \& } \\
\text { Lazarus, 1974) } \\
\text { Productivity, more HR } \\
\text { work with less HR } \\
\text { personnel (Tomeski \& } \\
\text { Lazarus, 1974) }\end{array}$ & $\begin{array}{l}\text { Faster diagnosis of HR } \\
\text { problems (Broderick \& } \\
\text { Boudreau, 1992) } \\
\text { Freeing HR staff for } \\
\text { important tasks } \\
\text { (Martinsons, 1994) } \\
\text { Time savings (Kossek et al., } \\
\text { Sturman et al., 1996) } \\
\text { Increased automation of HR } \\
\text { duties (Kossek et al., 1994) } \\
\text { Productivity, more HR } \\
\text { work with less HR } \\
\text { personnel (Broderick \& } \\
\text { Boudreau, 1992) }\end{array}$ & $\begin{array}{l}\text { Time savings (Cronin et al., 2006; Panayotopoulou et al., 2007) } \\
\text { Efficient screening systems (Chapman \& Webster, 2003), Buckley et al., 2004) } \\
\text { Increased automation of HR duties (Ruel et al, 2004; Reddick, 2009) } \\
\text { HR operating efficiency (Ruel et al., 2004; Reddick, 2009, Beulen, 2008) } \\
\text { Productivity of HR staff (Reddick, 2009) } \\
\text { Role of HR professionals' administrative competency becomes less important (Bell el al., 2006) } \\
\text { Decrease in administrative burden (Ruel et al, 2004; Reddick, 2009) } \\
\text { Increase of line managers' workload (Martin \& Reddington, 2010) }\end{array}$ \\
\hline HR Effectiveness & $\begin{array}{l}\text { Information processing } \\
\text { (Tomeski \& Lazarus, 1974) } \\
\text { Accuracy of data/reports } \\
\text { (Tomeski \& Lazarus, 1974) }\end{array}$ & $\begin{array}{l}\text { Accuracy of administration } \\
\text { activities (Broderick \& } \\
\text { Boudreau, 1992) } \\
\text { Data uniformity (Hannon et } \\
\text { al., 1996) }\end{array}$ & $\begin{array}{l}\text { Accuracy of data/reports (Reddick, 2009) } \\
\text { Technical HRM effectiveness (Ruel et al., 2007, Haines \& Lafleur, 2008; Ruta, 2009) } \\
\text { Increased number of underqualified applicants (Chapman \& Webster, } 2003 \\
\text { Increased information responsiveness by HR (Gardner et al., 2003) } \\
\text { Greater information autonomy for HR (Gardner et al., 2003) } \\
\text { Flexibility of HR professionals (Reddick, 2009) } \\
\text { Standardization of HR processes (Cronin et al., 2006) } \\
\text { Cheating issues (Chapman \& Webster, 2003) } \\
\text { Training flexibility (Oiry, 2009) } \\
\text { Increased number of minority applications from (Chapman \& Webster, 2003) }\end{array}$ \\
\hline HR Cost Savings & $\begin{array}{l}\text { Cost reduction (Tomeski \& } \\
\text { Lazarus, 1974) }\end{array}$ & $\begin{array}{l}\text { Cost reduction due to } \\
\text { effective administration, } \\
\text { record keeping, outsourcing } \\
\text { (Broderick \& Boudreau, } \\
\text { 1992; Hannon et al., 1996) }\end{array}$ & $\begin{array}{l}\text { Cost reduction (Svoboda \& Schröder, 2001; Jones et al, 2001; (Chapman \& Webster, 2003; Ruel et al, } \\
\text { 2004; Buckley et al, 2004; Panayotopoulou et al., 2007; Olivas-Lujan et al, 2007; Oiry, 2009) } \\
\text { Eliminated paperwork (Reddick, 2009) - no empirical support }\end{array}$ \\
\hline
\end{tabular}




\section{Appendix 3 (Continued) \\ Consequences of e-HRM (1970-2010) - Part 2: Relational}

\begin{tabular}{|c|c|c|c|}
\hline \multirow{24}{*}{$\begin{array}{l}\text { HR Service } \\
\text { Improvements }\end{array}$} & \multirow[t]{7}{*}{ 1970-1989 } & \multirow{7}{*}{$\begin{array}{l}\mathbf{1 9 9 0 - 1 9 9 9} \\
\text { Improved employee } \\
\text { benefits administration } \\
\text { (Sturman et al., 1996) } \\
\text { HR provides centralized } \\
\text { services (Kossek et al., } \\
\text { 1994) }\end{array}$} & \multirow{2}{*}{ 2000-2010 } \\
\hline & & & \\
\hline & & & Improved employee services (Panayotopoulou et al., 2007) \\
\hline & & & Faster responses from HR department (Olivas-Lujan et al, 2007; Reddick, 2009) \\
\hline & & & Improved training and development services (Beulen, 2009; Oiry, 2009) \\
\hline & & & Empowered employees and managers (Reddick, 2009, Beulen, 2009) \\
\hline & & & HR professionals devote more time to IT support activity (Gardner et al., 2003) \\
\hline & & Dependence on software & Improved cooperation (Panayotopoulou et al., 2007) \\
\hline & & vendors, outsourcing & Improved relationships with HR (Alleyne et al., 2007), upper management (Reddick, 2009) \\
\hline & & partners (Hannon et al., & Enhanced team spirit (Svoboda \& Schröder, 2001) \\
\hline & & 1996) & Dehumanized selection processes (Chapman \& Weber, 2003) \\
\hline & Impersonality of & Employee perceptions of & Lack of human contact (Oiry, 2009) \\
\hline & computerization (Mayer, & invasions of privacy (Eddy & HR professionals perception of HR as crucial and enabling technology (Hussein et al., 2007) \\
\hline & 1971) & et al., 1999) & Improved employee awareness, appreciation and use of systems (Reddick, 2009) \\
\hline & Upper management and HR & Employee perceptions of & Employee commitment (Olovas-Lujan et al., 2009) \\
\hline & management satisfaction & fairness (Eddy et al., 1999) & Employee perceptions of invasion of privacy (Lukaszewski et al., 2008) \\
\hline & with HRIS (De Sanctis, & HR directors' positive & Role-conflicts (Oiry, 2009) \\
\hline & 1986) & perception of applicants & Levels of supervisor accountability (Payne et al., 2009) \\
\hline & & doing online applications & Levels of personnel data security (Payne et al., 2009) \\
\hline & & (Hubbard et al., 1997) & Employee and manger satisfaction with HR intranet (Alleyne et al., 2007; (Panayotopoulou et al., \\
\hline & & User satisfaction with HRIS & 2007), e-HR services (Ruel et al., 2004) \\
\hline & & (Sturman et al., 1996; Elliot & Satisfaction with HR processes (Cronin et al., 2006) \\
\hline & & \& Tevavichulda, 1999; & Satisfaction with HR services (Lukaszewski et al., 2008) \\
\hline & & Haines \& Petit, 1997) & Satisfaction with performance appraisals (Payne et al., 2009) \\
\hline \multirow{3}{*}{$\begin{array}{l}\text { HR } \\
\text { Communications }\end{array}$} & & Consistent communication & Improved communication between HR and employees (Ruel et al, 2004; Panayotopoulou et al., 2007) \\
\hline & & of HR policies (Broderick & Employees participating in online discussions (Ruel et al., 2004) \\
\hline & & \& Boudreau, 1992) & Improved employee access to HR information (Panayotopoulou et al., 2007) \\
\hline \multirow[t]{4}{*}{ HR Status } & & HR status and role as & Enhanced professional standing of HR (Hussein et al., 2007) \\
\hline & & information brokers and & HR professionals using external professional links, outsourcing, networking (Gardner et al., 2009) \\
\hline & & decision enablers (Kossek & HR professionals shift from administrative to strategic role (Bell et al., 2006) \\
\hline & & et al., 1994) & Concepts of company image, employer of choice (Panayotopoulou et al., 2007) \\
\hline
\end{tabular}


Appendix 3 (Continued)

Consequences of e-HRM (1970-2010) - Part 3: Transformational

\begin{tabular}{|c|c|c|c|}
\hline \multirow{6}{*}{\multicolumn{2}{|c|}{$\begin{array}{l}\text { HR } \\
\text { Globalization }\end{array}$}} & 1990-1999 & 2000-2010 \\
\hline & & Consistent HR practices & Alignment of HR and corporate strategy ( Ruel et al., 2004) \\
\hline & & throughout the firm & Alignment of HR functions with organizational objectives (Panayotopoulou et al., 2007) \\
\hline & & (Broderick \& Boudreau, & Alignment of corporate and employee goals (Panayotopoulou et al., 2007) \\
\hline & & 1992) & HR replication capability distributed across subsidiaries (Morris et al., 2009) \\
\hline & & Integration of decentralized & Identification of a global talent company (Neary, 2002) \\
\hline \multirow{20}{*}{ 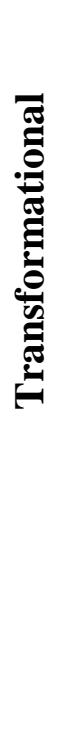 } & & & Making HR a strategic partner (Reddick, 2009) \\
\hline & Strategic Change & & Scope of HR towards strategic management (Reddick, 2009) \\
\hline & Management & & Strategic HRM effectiveness (Ruel et al., 2004; Haines \& Lafleur, 2008) \\
\hline & & & Support of risk taking and innovation (Ruel et al., 2004) \\
\hline & & & HR professionals devoting more time to transformational activities ( Gardner et al., 2003) \\
\hline & & & The role of the HR professional as a strategic business partner (Haines \& Lafleur, 2008; \\
\hline & & & The role of the HR professional as a change agent (Haines \& Lafleur, 2008) \\
\hline & & & Improved strategic information analyses (Ball, 2001) \\
\hline & HR Knowledge & & Knowledge sharing culture (Ruel et al., 2004; Ruta, 2009) \\
\hline & Management & & Increased knowledge management: creation, capture, transfer and use (Reddick, 2009) \\
\hline & & & The development and maintenance of intellectual capital (Ruta, 209) \\
\hline & & & Globally available resources for learning (Svoboda \& Schröder, 2001) \\
\hline & & & The quality of the information base used in performance appraisals and ratings (Payne et al., 2009) \\
\hline & & & Emergence of competency management systems (Hustad \& Munkvold, 2001) \\
\hline & HR Planning & & Improved HR planning (Beulen, 2009) \\
\hline & & & Improved recruiting and retention systems (Reddick, 2009) \\
\hline & & & The reduction employee turnover (Buckley et al., 2009, Beulen 2009) \\
\hline & & & Transparent and flexible internal labor market ( Ruel et al., 2004) \\
\hline & & & Managing and evaluating employees: the role of uniformity and completeness (Neary, 2002) \\
\hline & & & Digitalized planning of employee development (Panayotopoulou et al., 2007) \\
\hline
\end{tabular}




\title{
CHAPTER 3
}

\section{A Review of the E-Recruiting Literature ${ }^{5}$}

\begin{abstract}
In this paper we show how a grounded theory lens aids in the reviewing of a set of carefully selected academic studies on e-Recruiting, being the most studied area within Electronic Human Resource Management. This lens is shown to offer a novel approach to analyze the published studies on e-Recruiting. The increasing diversity in the publications in e-Recruiting research calls for such a systematic synthesis. Applying grounded theory for review purposes aims to point to new interconnections between relevant e-Recruiting variables. In order to advance both e-Recruiting research and practice links between research achievements, gaps and future research directions are delineated. Using grounded theory enabled us to reach across research foci, themes and models. We extended (also graphically) the 11 consecutive eRecruiting process steps of Lee (2007) so as to be applicable as well to the study of commercial recruiting websites. We also show the sequence of events for internet recruiting defined by Bartram (2000) is too narrow, and derive a broader image of e-Recruiting. Beyond synthesis, this grounded theory type review presents fresh insights for more theory-based eRecruiting study.
\end{abstract}

Keywords: e-Recruiting, Grounded Theory Method, Review.

\footnotetext{
${ }^{5}$ A previous version of this paper has been published in the Proceedings of the European Conference of Information Systems, June 7-9, 2010, Pretoria, South Africa.

A revised version of this paper has been conditionally accepted for publication in the European Journal of Information Systems.
} 


\section{Introduction}

Although e-Recruiting is a relatively young research field (Galanaki, 2002), a vast number of publications have already been produced on this topic, particularly in the last decade. Serious reflection on the extant e-Recruiting literature is needed for several reasons. First, various synonyms are used in e-Recruiting research (e-Recruiting, web-based recruiting, internet recruiting, cyber recruiting, online recruiting), which makes the range of the literature opaque. Second, the subject has been studied across many disciplines, such as information systems, marketing, psychology, management and human resources indicating an interdisciplinary nature. Third, the mere large volume of publications calls for such a synthesis. Fourth, no single academic overview or comprehensive reflection on e-Recruiting research has appeared to date. Such research needs to add value by being of theoretical significance; it should thoroughly integrate accumulated insights.

By importing grounded theory procedures the field might become more precisely prepared for new in-depth studies that extend the theoretical repertoire. Although Glaser and Strauss (1967) suggested that data for grounded theory can come from various textual sources such as government documents, newspapers, letters and books, most published grounded theory studies rely only on interviews and observational data. An exception is Lehmann and Fernandez (2007) who include various types of data such as technical reports. As Glaser and Strauss stated:

"We believe that although formal theory can be generated directly from data, it is more desirable and usually necessary, to start the formal theory from a substantive one. The latter not only provides a stimulus to a "good idea" but it also gives an initial decision in developing relevant categories and properties and in choosing modes of integration. Indeed it is difficult to find a grounded formal theory that was not in some way stimulated by substantive theory" (Glaser \& Strauss, 1967; p. 79).

In this paper we invoke grounded theory with the aim of enhancing the scientific rigor of the literature to date. We want to shed light on how the e-Recruiting research stream has developed over time, and how the major codes, concepts and categories in the dispersed literature might interrelate. Applying grounded theory to learning across written perspectives and themes, we want to uncover major achievements and research gaps. We will derive these gaps from the substantive analyses that associate emerging codes, themes and categories used in e-Recruiting research. We discuss several promising avenues of e-Recruiting inquiry, and from our reflection on the literature a grounded definition of e-Recruiting emerges. Since our empirically grounded definition is stated only in later sections of the paper, we provide here 
our basic working definition, based on Galanaki (2002): e-Recruiting is using the internet to recruit through either corporate websites, specialized websites or online advertisement. The paper is organized as follows: First, the search strategy for inclusion of the papers (i.e. the data fit for analysis) is described. Next, the lens and modes of data analyses are depicted. We then present and discuss the major findings, including various new research directions.

\section{Literature Selection}

In order to offer new valuable theorizing about e-Recruiting, we identified all journal publications on the topic and then selected the most scholarly work. In order to gather up the original universe of relevant papers, a systematic search for e-Recruiting literature across the following disciplines was conducted: Information Systems, Computer Science, Human Resources Management, Organizational Behavior, Psychology, Management and related fields. The research databases Scopus, Web of Science, AIS Electronic Library, ACM Digital Library and IEEE Electronic Library were used. The specific search terms used were eRecruiting, e-Recruitment, "web(-based) recruiting/recruitment", "online recruiting/recruitment", "recruiting online/on the internet", "electronic resume" and "ecruiting." This search resulted in 230 articles. There was of course some overlap, particularly between Scopus and Web of Science. The selection criteria for inclusion in our analysis at this stage were two-fold. An article had to be published in a peer-reviewed international journal, and e-Recruiting had to be the major focus of research. Two researchers engaged in removing duplicates by comparing the titles and abstracts. By doing forward and backward citations, comparing impact factors of the publications, and reading the full texts of the selected subsample of 45 highly relevant academic articles, the eventual sample was determined. For a graphical representation of the selection procedure see figure 1, and a listing of the finally selected articles see Appendix A.

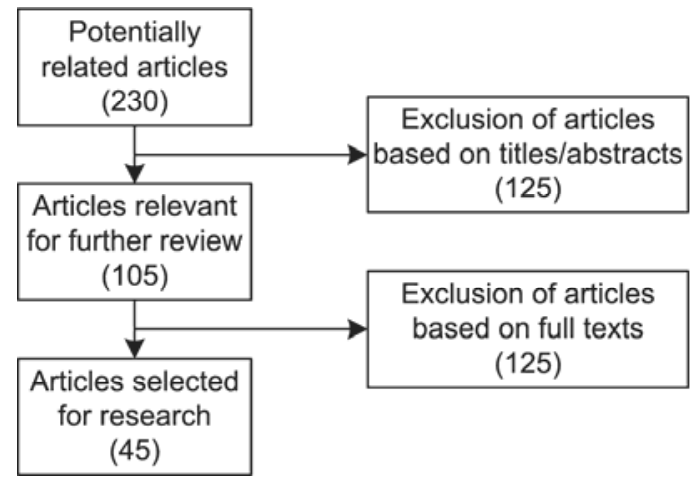

Figure 1

Selection procedure leading to the 45 analyzed e-Recruiting articles 


\section{Lens for and Modes of Data Analyses}

The chosen analytical strategy was introduced by Glaser and Strauss (1967) and adapted as a method by Lehmann and Fernandez (2007). The underlying assumptions of grounded theory are particularly useful to this area because of its neutral starting point, and the way the reading and analysis of the papers continuously influence each other, interrelate the newly acquired insights and build upon the previous steps. Both Glaser and Strauss (1967) and Lehmann and Fernandez (2007) advise the use of various types of data resources. Glaser and Strauss had noted that anything that sheds light on the questions under study can be coded in the same way as interviews or observations. In this study, the 45 journal articles were taken as source. Applying grounded theory on this carefully selected set of articles enables an approach that is comparable to fine-grained qualitative data analyses. Traditional grounded theory studies rely mostly on in-depth interviews with a limited and potentially unrepresentative pool of respondents. In grounded theory use for review purposes, the written content is being analyzed in highly systematic ways while biases in sampling, data collection and code saturation are averaged out. In grounded-theory type reviewing the data is thus more comprehensive while the data analysis is more precise than customary.

The analytical steps taken had four phases: (1) open coding, (2) theoretical coding, (3) comparative analysis, and (4) theory building. A first reading of the literature provided a rough four-fold view of the data: conceptual; qualitative; quantitative and mixed method papers. We structured four tables accordingly; they contain author, title, main purpose and results and suggested future research directions. Depending on the type of research, additional features were summed up (such as attributes of the qualitative articles or sample, procedure and measures of the quantitative articles). Then, with these rough schemas in place, two researchers read and discussed the individual papers and produced through open coding preliminary figures and tables; while reading the articles they both made detailed comments in a codebook. Such theoretical coding enabled the two coders to find 'incidents' in the table and figure representations that were given conceptual labels. The continuous comparing of concepts and categories was used to find salient categories, overlaps, agreements, disagreements, and gaps: in essence everything that stood out in the e-Recruiting data. The main steps of the analytical process, i.e. open coding, theoretical coding, comparative analysis and theory building were intertwined. As other grounded theory researchers suggest (e.g., Suddaby, 2006), the formulation of grounded theory was never intended to encourage research that ignores existing knowledge. The challenge in analyzing a body of published 
knowledge is to freshly observe and learn from the plurality of cases contained therein. Therefore, while we analyzed with a grounded theory lens, we explicitly considered biases, not wanting to be adversely influenced by pre-existing definitions and categorizations. Indeed, during the second reading of the articles we started to notice repetition of information and connotations in the literature not apparent earlier. The two coders first agreed on the main categories - abstract themes, categories and definitions - and then formulated sub categories across all analyzed papers. This method ensured inclusion of previously unidentified or little studied e-Recruiting themes in the literature, important for new theorizing.

Among the 45 studies, two e-Recruiting process models figured prominently: Bartram's (2000) three sequences involved in internet recruitment, and Lee's (2007) model of the e-Recruiting process. In order to present the interconnections between the emerging codes, concepts, and categories in the 45 articles that went beyond these models, six figures and one table were built. In the Findings section we will illustrate the precise analytical steps taken. We chose to present the detailed data analyses in that section in order to show how the analyses step by step influenced the results. In this sense, the chosen approach is a transparent interpretive process rather than a deductive one. We will thus document how the analytical procedures aided the new-theory building, including the choice of explanations for eRecruiting behaviours.

\section{Results}

\section{Perspectives}

Based on open and theoretical coding as well as comparative analysis procedures, the perspectives taken across all articles seemed to us to fall into three major categories. A frequently discussed actor in the e-Recruiting literature is of course the applicant (and/or jobseeker). A jobseeker becomes an applicant when he/she applies for a job. This category was developed by grouping the preliminary concepts 'applicant's and jobseeker's view.' These concepts were based on codes like: “... that explicates how jobseekers interact with and respond to website characteristics..." (Cober et al., 2004; p. 623). Here we see researchers identified with the jobseeker's view when using an e-Recruiting website. Similarly, we also found a subset of publications concerned with the concept of the recruiter's view. This classification is verified with a sample transcript: "A summary of recruiters' perspectives..." (Lee, 2007; p. 82) Furthermore, the category organization emerged. This category was developed by grouping the concepts 'organization's and 
company's view; as in e.g.: “...we examine the effects of information technology on the recruitment function of organizations" (Singh \& Finn, 2003: p. 395). These researchers examined from the perspective of an organization the effects of information technology on recruitment. Because not all of the 45 selected articles fell into just one of the aforementioned three perspectives, a category labeled other was formed. Because of the fragmented nature of the rest of the perspective categories, no cohesive additional perspective could be formed. Articles in the residual "other" perspective involve reference to instances of e-Recruiting in a certain country or sector. Only four articles reflect more than one of these four perspectives (see figure 2).

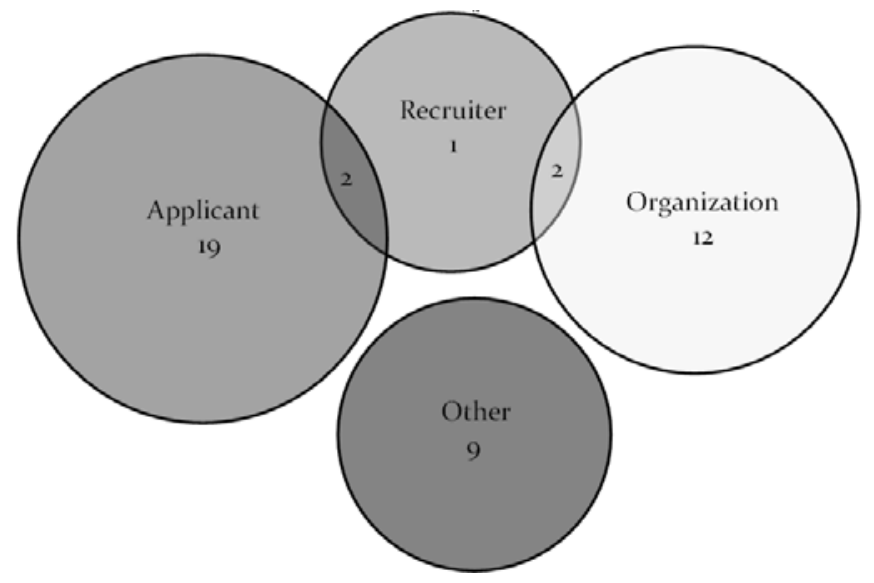

Figure 2

Perspectives taken by the 45 academic e-Recruiting articles

\section{Themes}

The content analysis of all 45 papers resulted in ten categories or themes. Many of the articles address more than one theme. These themes are listed here in a descending order representing the number of times each was addressed (see also Figure 3).

\section{Corporate/commercial recruiting website (characteristics)}

The most popular theme is corporate or commercial recruiting websites and/or their characteristics. The codes contained in the articles subsuming this theme are: "internet job boards", "general purpose job boards", "recruitment websites" and "job sites". The codes that formed the concept organizational recruitment websites are: "employer website", "career site" and "corporate (recruitment) website." 


\section{Jobseekers'/Applicants' attraction/image/perception of an organization}

This theme subsumed articles that studied either organizational attraction, the image of an organization and/or the perception of an organization of jobseekers and/or applicants. These categories were merged into one because of the overlap of the intended operationalizations across the studies. Codes that were formed for the concept attraction are: "how perceptions of organizational website content and style influence organizational attraction", "attraction in a web-based context" and "applicant attraction to organizations in an online recruitment context". An example of the use of the concept of organizational image is: “... website design features on prospective applicants' evaluations of a hiring company's online recruitment image" (Braddy et al., 2003; p. 374).

\section{Presenting or evaluating technologies/techniques/ frameworks/models regarding e-}

\section{Recruiting services}

This theme was assigned to articles that presented or evaluated e-Recruiting technologies, techniques, frameworks or models regarding e-Recruiting services. The codes that formed the concepts are contained in the label, except for occasional prefixes about the specifics that are incorporated in the overall discourse.

\section{General e-Recruiting research}

Since the e-Recruiting research field is relatively young, some of the 45 articles merely conceptualize or describe the phenomenon of e-Recruiting. The papers subsumed into this theme are mostly qualitative, offering richly detailed basic information.

\section{Organizations' decisions to recruit online and/or its implications}

Some studies focus on the decision of an organization to start recruiting online. This theme includes articles that deal with an organization's online recruitment and/or the implications of such recruitment. Theme five reflects a series of decision-related concepts that are grouped into one supra category: most of these publications contained both concepts and closely related contents. Examples of codes which motivated the formation of these concepts into one theme are: "insights into the use and success of online recruitment" and "decision of companies to recruit online". 


\section{Jobseekers' decision/willingness to apply}

These articles investigate a jobseeker's decision and/or willingness to apply for a job. This concept derived from the following codes: "intentions to pursue employment", "willingness to apply to the organization", "applicant decisions" and "likelihood to pursue an interview or accept a position".

\section{Fit}

These articles examine objective fit, applicant fit, applicant pool fit and all adjoining areas. Overall, theme seven evolved from concepts about fit. Examples of codes that formed these concepts are: "objective P-O fit", “subjective P-O fit", "objective fit", “applicant pool fit" and "fit feedback."

\section{Online job search process}

Theme eight is a category that emerged from different concepts about the online job search process of the applicant. Emerging codes are: "how people search for job-related info on the web", "experience of applicants with searching for jobs on the Internet" and "job search procedures."

\section{Résumés and/or selection process}

This theme was assigned to articles that study paper and/or electronic résumés and/or handle the selection process of an organization. Theme nine consists of research with concepts about (parts of) the selection process largely related to résumés. The related codes are "paper versus electronic résumé" and "applying technology in selection process."

\section{Web-based versus paper-based job postings}

This theme was assigned to research investigating differences between web-based and paperbased job postings. The code "web-based versus paper-based job postings" is consequently the important concept in this theme.

\section{Included themes and potential avenues for future research}

Figure 3 is a simple bar chart portrayal of the number of articles that were coded with a particular theme. Salient themes studied in e-Recruiting research are clearly the characteristics of e-Recruiting websites and jobseekers'/applicants' attraction/image/perception to an 
organization. Further, many articles present or evaluate e-Recruiting technologies, techniques, frameworks or models and present general descriptions about e-Recruiting research. Very little research has been done on web-based versus paper-based job postings, résumés and the selection process. Also, little attention has been given to studying various kinds of fit like applicant fit, applicant pool fit and objective fit (see Dineen et al., 2009).

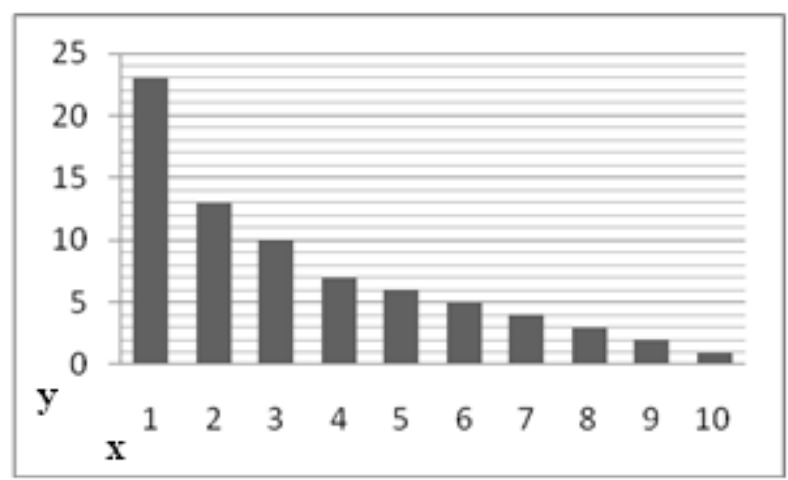

Figure 3

Relative popularity of e-Recruiting research themes

$x$ : number of theme, $y$ : number of articles with theme $x$

\section{Relating emerging themes to the identified perspectives}

Table 1 represents the associations between the themes and the perspectives. This table was constructed by tracing the themes and perspective categories back to the concepts; and then further, the concepts back to the articles that enabled us to derive these classifications. When one or more of the articles revealed salient concepts to multiple categories, a checkmark was put in the table.

\begin{tabular}{|c|c|c|c|c|}
\hline & Applicant & Recruiter & Organization & Other \\
\hline 1 & $\sqrt{ }$ & $\sqrt{ }$ & $\sqrt{ }$ & $\sqrt{ }$ \\
\hline 2 & $\sqrt{ }$ & & & \\
\hline 3 & $\sqrt{ }$ & $\sqrt{ }$ & $\sqrt{ }$ & $\sqrt{ }$ \\
\hline 4 & $\sqrt{ }$ & $\sqrt{ }$ & $\sqrt{ }$ & $\sqrt{ }$ \\
\hline 5 & & & $\sqrt{ }$ & \\
\hline 6 & $\sqrt{ }$ & & & \\
\hline 7 & $\sqrt{ }$ & & $\sqrt{ }$ & \\
\hline 8 & $\sqrt{ }$ & & & \\
\hline 9 & $\sqrt{ }$ & & $\sqrt{ }$ & \\
\hline 10 & $\sqrt{ }$ & & & \\
\hline
\end{tabular}

Table 1

Overview of the studied themes (rows) and perspectives taken (columns) in academic e-Recruiting research to date 
Virtually all themes are related to the applicants' perspective. Theme five - on organizational decision making to recruit online and its implications - is the only one in which applicants have not been heretofore studied explicitly. The themes that are studied from all four perspectives are those about websites, technologies/techniques/frameworks/ models and general e-Recruiting research. Finally, Table 1 shows a clear lack of research from the recruiter's perspective which is an important finding in this round of the analyses.

\section{Advancing e-Recruiting Theory}

We analyzed how themes and theories have changed over time. Analyzing change is important to grounded theory and offers a way of breaking a phenomenon down over time. In 2000 Bartram presented a sequential model of the three essential stages - an event structure in internet recruitment: (1) attraction, (2) recruitment and (3) selection. Initially, only attraction and recruitment were suggested to play a major role in e-Recruiting, but selection duties were and are recognized to be increasingly influenced by e-Recruiting processes (Bartram, 2000). Attraction is understood by Bartram as the process of drawing people into a large pool. Recruitment, in turn, filters the number of people down using key criteria. Selection, finally, judges from among the cohort of remaining people. Figure 4 shows which of the three e-Recruiting events are covered by the ten identified themes.

Drawing people into a large pool is an activity that can be done via information systems with recruiting technology. Theme one relates to Bartram's attraction event. This theme also plays a role in the recruitment stage of Bartram's schema because recruiting websites have search features that enable recruiters to reduce the number of suitable applicants. Theme two, i.e. organizational attraction, image and perception of an organization, also relates to Bartram's category of attraction. In this sense, job seekers are drawn into such a pool if they want, so to speak, to be in that specific race. An organization's positive image and applicants' positive perception of that organization can enhance attraction. Theme three on technologies/techniques/frameworks/models for e-Recruiting services is relevant to Bartram entire event structure in making e-Recruiting effective (attraction, recruitment and selection). Similarly, theme four, general Recruiting studies is functional and cohesive across all three of Bartram's phases. Theme five, an organization's decision to recruit online and its implications, does not refer to Bartram's sequence directly, but of course anticipates it. Theme six, applicants' decisions or willingness to apply for a job, also plays a role in the attraction phase of Bartram. This concept reflects applicant motivation to pass the threshold 
and move into an applicant pool. Theme seven, on fit, plays a role in all three events of Bartram. Concepts like applicant pool fit relate to the fit of applicants in the attraction phase/event. Concepts like Person-Organization fit, which are closely related to applicant attraction to an organization, relate to each stage of Bartram's sequences since the better the fit, the more likely that the applicant continues the recruitment process.

The online job search process theme fits into the attraction event of Bartram. This process concept at this particular stage represents a rather broad node since it pertains to the entire search process of an applicant. This starts with being drawn into a pool in the attraction event and ends either when the applicant is rejected during the recruitment event or is selected during the selection event. Theme nine on résumés and the selection process relates only to selection. When drawing applicants into a pool during attraction, résumés screening is not yet relevant. During the recruitment event, résumés can be used to cut down the number of applicants. The selection concept also covers the process of cutting down the volume of applicants in the recruitment event. Theme ten (web-based versus paper-based job postings) connects only to attraction in Bartram's model. Once an applicant has seen an online job posting, he/she is either drawn into the pool or is not.

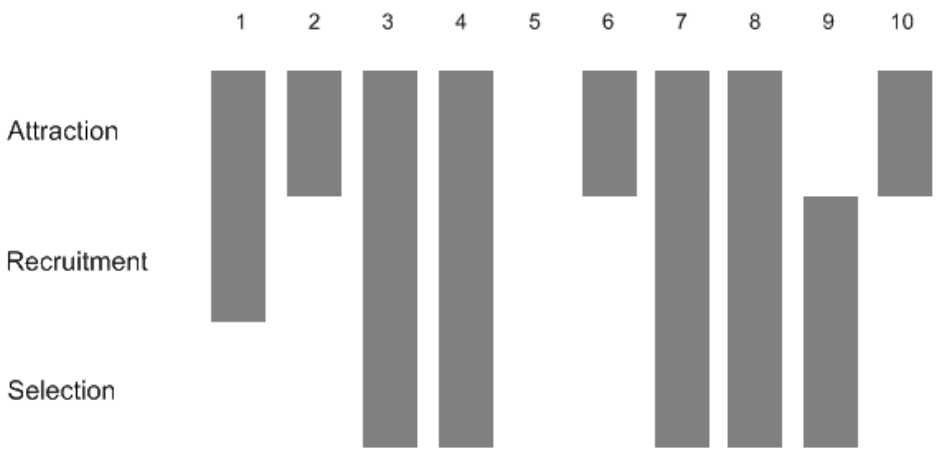

Figure 4

Comparing Bartram's sequence of three e-Recruiting phases and the ten identified e-Recruiting themes 


\section{Extending Lee's (2007) Model}

In identifying the studied e-Recruiting processes, themes and perspectives within the academic literature to date, one may then proceed to link that knowledge up to the one recent model that is fundamental: the work by Lee (2007). In comparison to Bartram's (2000), Lee's paper describe in depth the e-Recruiting process of corporate career websites. It consists of eleven consecutive steps divided into four clusters. The first cluster includes the following steps: identification of hiring needs, submission of job requisition, approval of job requisition and job posting on the Internet. The second cluster includes online job search by applicants. and the submission of applications. The third cluster involves searching the applicant database, evaluation of résumé/application and interviewing by hiring managers. The fourth and final cluster considers pre-employment screening, job offers and employment contracts. Alongside these processes Lee provided a component-based architecture for holistic eRecruiting systems (Lee, 2007).

The eleven consecutive steps of the e-Recruiting process that Lee suggested for corporate career websites seem relevant and applicable for commercial recruiting websites: particularly if the architecture of holistic e-Recruiting systems is eliminated and two steps are added: jobseeker posts résumé and searching jobseeker database (see figure 5). These two steps form a parallel path from the jobseekers' online job search to the evaluation, along with the submission of applications and searching the applicant database. We derived this addition from our applicant and recruiter perspective, as well as from themes one, eight and nine. From an applicant perspective, a résumé is posted on a commercial recruiting website as part of a job search process. From a recruiter perspective the jobseeker database is searched. Both applicant and recruiter use the features available on commercial recruiting websites. Notice the difference between a jobseeker and an applicant; a jobseeker becomes an applicant when he/she applies for a job. This subtle transformation is something that seems not yet clearly defined in e-Recruiting literature. 


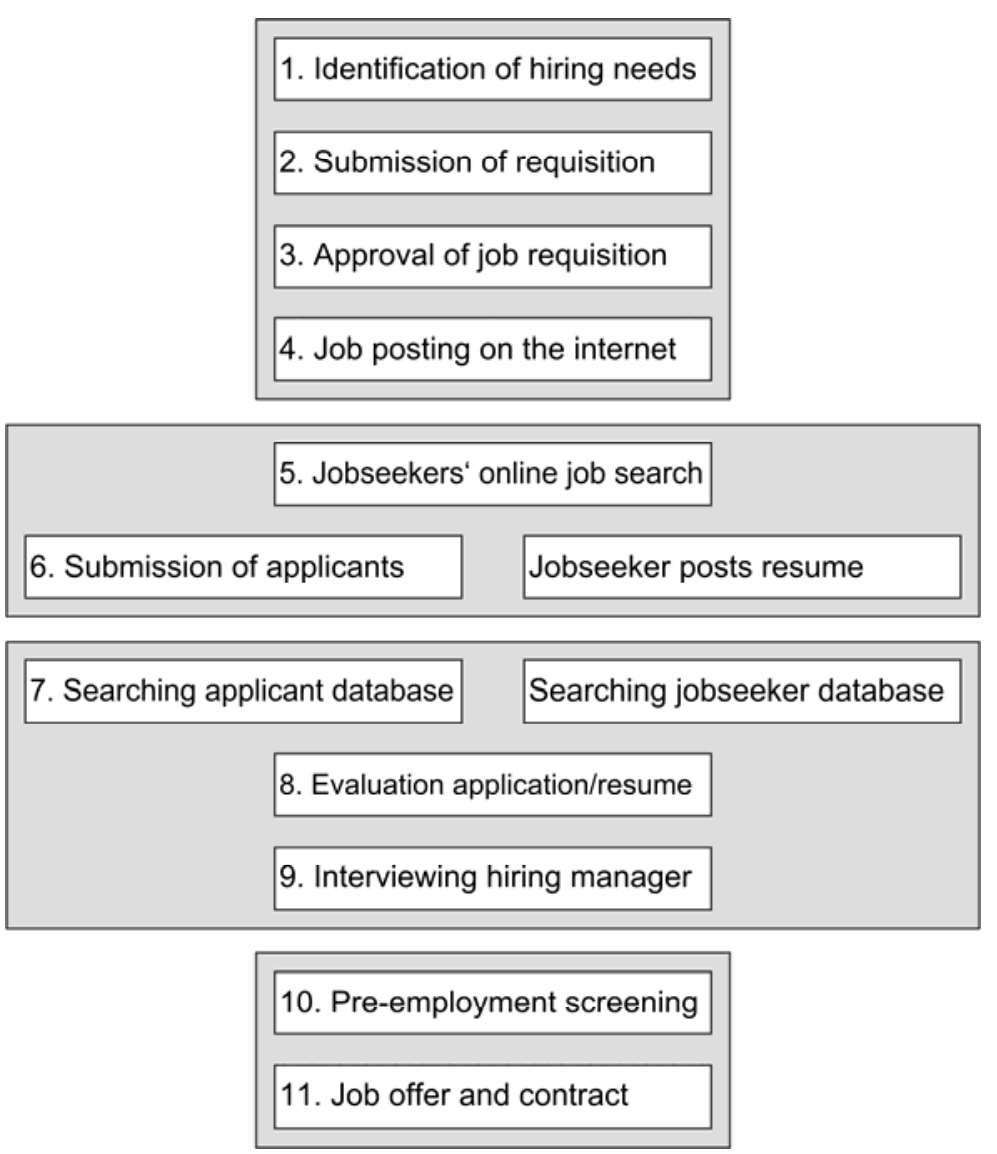

Figure 5

Extending Lee's model, incorporating the applicant perspective

Furthermore, we projected the identified ten themes onto the eleven consecutive steps of Lee: depicted in Figure 6. Like the sequence of three events of Bartram (2000), theme five is not related to any of Lee's steps. Surprisingly, there has not yet been research addressed to Lee's first three steps - identification of hiring needs, submission of job requisition and approval of job requisition. Although these steps seem more relevant to management research, it is feasible that they are influenced by Lee's other steps of the e-Recruitment process, and would be seen to change during or due to the switch from traditional to online recruiting. In this context Parry and Tyson (2008) state that the shift from traditional to online recruiting may not be as simple as swapping the means. They argue that the use of the Internet may require a basic change in the wider recruitment process.

The fourth step (posting a job on the Internet) and the fifth step (online job search by applicants) have been addressed in numerous articles examining organization familiarity, image, attraction, website navigational ease, information, style and the job search process itself (Allen et al., 2007; Braddy et al., 2003; Braddy et al., 2006; Braddy et al., 2008; Bratina \& Bratina, 1998; Cober et al., 2003; Cober et al., 2004; Dineen et al., 2002; Dineen et al., 
2007; Dineen \& Noe, 2009; Feldman \& Klaas, 2002; Hu et al., 2007; Jansen et al, 2005; Robbins \& Stylianou, 2003; Thompson et al., 2008; Thomas \& Ray, 2000; Van Hoye \& Lievens, 2007; Williamson et al., 2003; Zusman \& Landis, 2002).

Lee's suggested sixth step (submission of applications) is discussed in several of the analyzed papers, categorized in theme six which reflects applicants' decision or willingness to apply online; and theme nine addressing résumés (Allen et al., 2007; Braddy et al., 2003; Elgin \& Clapham, 2004; Jansen et al., 2005; Maurer \& Liu, 2007; Zusman \& Landis, 2002).

The seventh step (searching applicant databases) and the eighth step, (evaluation of résumés and applications) have to date barely been studied in the academic literature. An exception is Smith (2004) who encourages elimination of further human elements in data collection, and the alternative examination of applications strictly via statistical prediction, in an effort to lower the recruiting costs.

On the last three of Lee's steps, practically no academic publications have appeared. Only one of the set of 45 articles examines computer-assisted screening interviews. This is surprising inasmuch as researchers a decade ago had already pointed out that selection duties were increasingly being influenced by e-Recruiting processes (Bartram, 2000; Smith \& Rupp, 2004).

A comparison of Bartram's three events for online recruitment and the 11 consecutive steps of Lee are depicted in figure 7. Theme five (Organizations' decisions to recruit online and/or its implications) is not represented in this figure. This is because it is a prerequisite for e-Recruiting. In the predominant definitions of e-Recruiting, the process only starts when the decision to recruit online is already made. Only after that decision starts do we see the first step of Lee. Those first three business processes are not discussed in Bartram's sequence. Hence one may conclude that both Lee and Bartram, each in their own way, defined the eRecruiting sequences too narrowly. 
1. Identification of hiring needs

2. Submission of requisition

3. Approval of job requisition

4. Job posting on the internet

5. Jobseekers' online job search

6. Submission of applicants

7. Searching applicant database

8. Evaluation application/resume
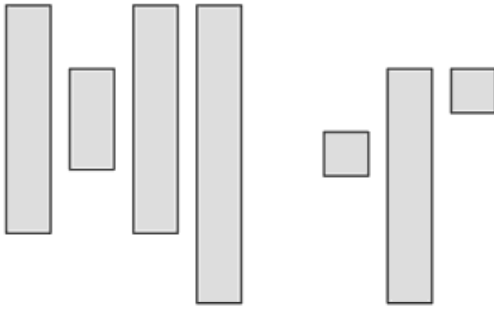

9. Interviewing hiring manager

10. Pre-employment screening

11. Job offer and contract

\section{Figure 6}

Projecting the ten e-Recruitment themes onto the eleven consecutive steps of Lee

1. Identification of hiring needs

2. Submission of requisition

3. Approval of job requisition
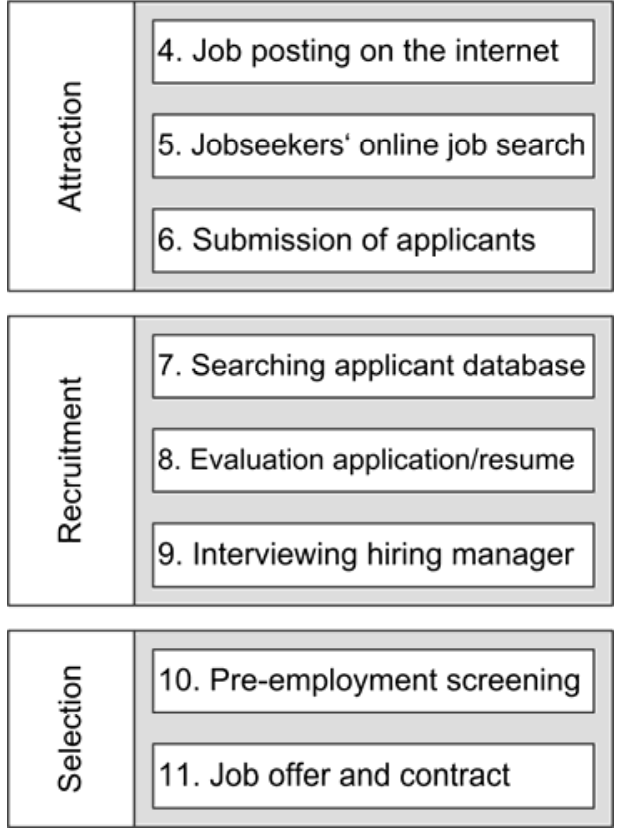

Figure 7

Comparison between Bartram's sequence of three and Lee's 11 consecutive steps 
We found, moreover, that current e-Recruiting literature is primarily concerned with investigating Lee's steps four (posting a job on the Internet), five (online job search by applicants) and six (submission of applications). The research to date on these steps has two points of major agreement.

First, navigational usability affects applicants' organizational attraction. In 2003 Braddy et al. (2003) and Cober et al. (2003) noted that navigational usability can affect organizational attraction. Williamson et al. (2003) tested a model showing that the orientation of a website and individual differences of applicants may have an indirect influence on organizational attraction, in the main due to the perception of a website's usability. Following up on the research of Williamson et al. (2003), Cober et al. (2004) showed that individual's perceptions of a website's usability impacts applicants' evaluations of employers. He showed that recruiting websites with a logical navigational flow positively affect applicants' views on employers. In this context, Braddy et al. (2008) showed that organizations with easily navigational websites received more favorable organizational evaluations. Putting these findings together, if organizations put up easy-to-navigate (recruiting) websites, they will tend to have a positive influence on applicants' organizational attraction.

The second point of agreement is that organizational familiarity is not related to organizational attraction. Allen et al. (2007) has found that mere familiarity with an organization may not be sufficient to enhance applicants' attraction to an organization. Braddy et al. (2008) follow up on this point, showing even more generally that the effect recruitment websites have on applicants' perception of an organization is not a function of the familiarity the applicant had with the organization. This research of Braddy et al. shows that Allen et al. did not take into account the possibility that applicants might be more likely to visit websites of organizations that they are familiar with. This is a major challenge within current e-Recruiting research: a better more focused understanding of the motivation behind applicants' search for and choice of recruiting website is sorely needed. We may hypothesize that the estimated strong market penetration of dominant recruiting sites such as monster.com play a dominant role; however, that being said, it is also highly probably that a host of other factors such as branch affiliation when using industry specific job sites, or regional presence of job sites may be equally attractive for many applicants. Similarly, Dineen et al. (2002) has critically mentioned the lack of e-Recruiting studies on applicants' online search and choice processes.

Koong et al. (2002) identified important attributes of commercial recruiting websites, drawing the conclusion that not all have equal "capabilities." They found difference in the 
number of attributes and the types of resources differed greatly. Most research to date suggests that commercial recruiting websites lack the same capabilities and types of attributes as corporate career websites. Corporate recruiters are often supported by established and mature organizational resources, and robust internal human resources information systems (Lee, 2007; Koong et al., 2002). This may imply that recruiters prefer using their internal corporate career website to external commercial recruiting websites, provided the internal systems are perceived to meet their recruitment needs (Pearce \& Tuten, 2001). However, because commercial recruiting websites often allow applicants to advertise themselves by posting their own application homepage, along with direct applications for a specific job, it would be interesting to have analytics and know precisely who is interested in such public presentations (i.e. job seekers, recruiters, marketers), and if recruiters continue to use such a feature to find applicants in light of the obvious flaw that online applicant pools tend to be overwhelmingly outdated overnight. .

\section{Grounded definition of e-Recruiting}

From a Grounded Theory perspective, the question may be asked concerning all the serious literature, what is the definition of e-Recruiting? In order to define the phenomenon, it is vital to first consider prior conceptualizations. Parry and Tyson (2008) argue e-Recruiting is more than simply recruiting using electronic means, including "those practices and activities carried out by the organization with the primary purpose of identifying and attracting potential employees" (Breaugh \& Starke, 2000: p. 431). Galanaki (2002) earlier incorporated within the scope of e-Recruiting all common ways to use the Internet as a means to recruit and perform related online activities. The threefold common means described are: (1) adding recruiting pages to an existing organization site, (2) using websites specialized in recruiting, and (3) using electronic advertisements on media sites. According to Galanaki the activities that fall within the scope of e-Recruiting are remote interviews and assessments, smart agents to search the Internet and interactive tools (Galanaki, 2002). Taking into account these overviews and the analyzed literature, we think the following definition is generally adequate:

e-Recruiting is the online attraction and identification of jobseekers using corporate or commercial recruiting websites, electronic advertisements on other websites; or an arbitrary combination of these channels including optional methods such as remote interviews and assessments, smart online 
search agents or interactive communication tools between recruiter and jobseeker/applicant with the goal of effectively selecting the most suitable candidate for a vacancy.

\section{Learning from E-Recruiting research over time}

When Lee's proposed steps in the e-Recruiting process and the studied papers in this review are taken together, there are apparent major empirical gaps in the research output for verifying the first three steps (identification of hiring needs, submission of job requisition and approval of job requisition) and the last five steps (searching the applicant database, the evaluation of résumés and applications, pre-employment screening, job offers and employment contracts). The problem here is that these topics that have hardly been empirically addressed are precisely those expected to become increasingly relevant in the future (Bartram, 2000; Lee, 2007; Parry \& Tyson, 2008; Singh \& Finn, 2003). Also, the fourth step (posting a job on the Internet), fifth step (online job search by applicants) and sixth step (both submission of applications and jobseeker posts résumé) would no doubt benefit from new research. ERecruiting researchers are challenged to extend prior research and address these identified gaps, to keep developing and testing hypotheses in regard to the e-Recruiting processes. . Our identified categories provide a starting point to shed light on underrepresented research and thereby to extend current knowledge.

At the turn of the century Thomas and Galanaki suggested future research focus on the effectiveness of e-Recruiting services (Galanaki, 2002; Thomas \& Ray, 2000). Galanaki proposed establishing a connection between employee satisfaction and size of an organization, number of e-Recruitment practices, the extent of use and the integration of eRecruiting in the overall recruitment processes (Galanaki, 2002). Thomas suggested examining criteria such as demographic characteristics of individuals recruited online, determining yield ratios, retention and developing turnover measures. Consequently, in the future, outcome measures such as job performance, job satisfaction and organizational commitment could then be compared between individuals who were recruited online with those recruited via traditional newspaper ads, career fairs or personal recommendations (Thomas \& Ray, 2000). Neither the research suggestions by Thomas and Galanaki or the relevance of these results regarding the effectiveness of e-Recruiting have been addressed within the published literature in the field. 
In 2002 Dineen suggested future e-Recruiting research should examine how tailored feedback influences applicant attraction to an organization, self-selection and eventually financial outcomes for an organization (Dineen et al., 2002). In $2007 \mathrm{Hu}$ addressed some of these issues suggested by Dineen, finding that providing personally tailored feedback to applicants can affect their reactions in the application process. Hu followed up on this and stressed the value of continuing to examine a range of issues related to the provision of personally tailored feedback on recruitment websites. He proposed investigating specifically whether providing more detailed and individually tailored feedback would impact applicants' organizational attraction ( $\mathrm{Hu}$ et al., 2007). Future research needs to continue to examine and build upon Dineen's and Hu's early attempts to understand the processes of personal feedback during the online application process, and the relationship with organizational attraction and self-selection.

Another major area where there is little published research available involves comparative knowledge about the advantages and differences of using web-based versus paper-based job postings, résumés and the selection process. Notable exceptions include the study of Zusman (2002) which assessed to what extent applicants prefer web-based to traditional recruiting methods; and work by Elgin and Clapham (2004) showing that a paper résumé produced a friendlier and warmer impression of the applicants' personality than an electronic résumé. Electronic résumés did produce the impression of higher intelligence, more technical expertise and better overall qualifications. We infer that - depending on applicants' choice to use online versus paper-based résumés - recruiters may draw different conclusions in regard to the qualities of the candidates. Therefore, applicants may be able to influence recruiters' perceptions by using different application procedures. In order to inform recruiting professionals as well as the literature, future studies are needed to extend this stream of comparative research.

Surprisingly, of the 45 analyzed publications in e-Recruiting research, few consider the recruiters' perspective. Most attention is directed to the perspective of the applicant, employing organizations and the commercial recruiting websites. In sum, 14 of the 17 identified quantitative papers focus on applicants, while only one used recruiters. Among the selected articles there are only two qualitative and three conceptual articles discussing the recruiters' perspective. In 2003 Anderson stated next to nothing was known about recruiter adoption decisions and reactions to expectations, or willingness to adopt new human resource information technologies for applicant selection (Anderson, 2003). Since 2003 no research regarding these topics has been published in the selected international peer-reviewed journals. 
This clearly represents a gap in this field. Finally, we would like to point out that there is overreliance on experiments that test recruitment websites by letting participants browse those websites. The key issue of people originally getting to those particular websites is mostly overlooked. It could very well be that the attraction, image and perception of those websites and organizations plays a role before people actually visit the website. Although some researchers test familiarity of participants with the websites or organizations beforehand (Cober et al., 2003; Braddy et al., 2008; Allen et al., 2007), no research participant is allowed to find and/or choose the website to use. The circumstances and motivation behind these searches and choices appears a neglected area of research within the e-Recruiting field.

\section{Conclusion}

In this paper, we extended the 11 consecutive steps of Lee (2007) to make it applicable to commercial recruiting websites (graphically depicted in figure 5). We showed that the sequence of events for internet recruiting as defined by Bartram (2000) is too narrow, and related the sequences to the emergent themes within the field to date. These analyses revealed a series of new gaps in the field. Thus, in spite of the large amount of research published on eRecruiting, there remain many possibilities to advance our understanding of e-Recruiting research and practice in areas that have received little attention. Especially important are the recruiters' perspective, and research regarding the influence of e-Recruiting on the recruitment process. We showed that academic research efforts concerning Lee's first three steps - identification of hiring needs, submission of job requisition and approval of job requisition - have not yet been undertaken.

Further, we noted very little research has been undertaken to challenge what has been published in the field so far. Also, the motivation behind applicants search for and choice of recruiting website is an area demanding serious investigation. Most research has been done on applicants' attraction, image and perception of organizations and organizations' corporate career websites, which we classified in theme two and is associated with the applicant perspective. Major points of agreement from this research stream suggest navigational usability affects applicants' organizational attraction while organizational familiarity is not related to attraction. This shows the need for expanding research in the entire e-Recruiting field to address the many identified gaps and to confirm or question current knowledge.

In regard to our own lens, we note two limitations and two strengths of this Grounded Theory study. First, the data used as earlier stressed consisted only of articles from published 
peer-reviewed international journals, and not additional primary interview or observational data. At the same time, this is a strength of this study since it provided a systematically selected set of comprehensive data and includes clues for the possible replication of the study. In a traditional Grounded Theory study that important task is very rarely possible. Second, because traditional Grounded Theory papers require more in depth discussion of the interconnection of categories, themes and concepts as well as theory building efforts, our results are presented in a highly condensed manner. We illustrated a novel use of Grounded Theory, leading to a better understanding of the knowledge gaps in the e-Recruiting literature. Future studies might usefully analyze the empirical e-Recruiting studies by quantitative metaanalyses for which the field at this point in time is not yet ready, as shown in Figure 1 (too little overlap).

In conclusion, we note that there are some practical implications of this study for managers of e-Recruiting services and human resource professionals. Managers need to consider the complete e-Recruiting process, and not concentrate on only parts such as the selection component. Understanding why applicants are attracted to certain corporate websites or e-Recruiting services has so far been overlooked. Organizations typically invest more energy in testing their systems instead of understanding why applicants visit their online career sections. Applicants require discretion of personalized data, desire quick responses from recruiters, and efficient systems enabling reliable matching of the quality of a job to the applicants' profile.

Human Resource professionals should develop various ways to communicate with applicants online, and foster lasting e-relationships with those rejected applicants who could conceivably be later recruited. Designers, e-Recruiting system developers and recruiting professionals interacting with jobseekers and applicants are challenged to help further optimize both the efficiency and human elements in research on e-Recruiting. 


\section{References}

Allen, D.G., Mahto, R.V. \& Otondo, R.F. 2007. Web-Based Recruitment: Effects of Information, Organizational Brand, and Attitudes toward a Web Site on Applicant Attraction. Journal of Applied Psychology, 92(6): 1696-1708.

Anderson, M. 2003. Applicant and recruiter reactions to new technology in selection: A critical review and agenda for future research. International Journal of Selection and Assessment, 11(2-3): 121-136.

Bartram, D. 2000. Internet Recruitment and Selection: Kissing Frogs to find Princes. International Journal of Selection and Assessment, 8(4): 261-274.

Braddy, P.W., Meade, A.W. \& Kroustalis, C.M. 2006. Organizational recruitment website effects on viewers' perceptions of organizational culture. Journal of Business and Psychology, 20(4): 525-543.

Braddy, P.W., Meade, A.W. \& Kroustalis, C.M. 2008. Online recruiting: The effects of organizational familiarity, website usability, and website attractiveness on viewers' impressions of organizations. Computers in Human Behavior, 24(6): 2992-3001.

Braddy, P.W., Thompson, L.F., Wuensch, K.L. \& Grossnickle, W.F. 2003. Internet recruiting: The effects of web page design features. Social Science Computer Review, 21(3): 374385.

Bradley, K. \& Smyth, B. 2003. Personalized information ordering: A case study in online recruitment. Knowledge-Based Systems, 16(5-6): 269-275.

Bratina, T.G. \& Bratina, T.A. 1998. Electronic career search. Journal of Employment Counselling, 35(1): 17-24.

Cober, R.T., Brown, D.J., Keeping, L.M. \& Levy, P.E. 2004. Recruitment on the net: How do organizational web site characteristics influence applicant attraction? Journal of Management, 30(5): 623-646.

Cober, R.T., Brown, D.J. \& Levy, P.E. 2004. Form, content and function: An evaluative methodology for corporate employment Websites. Human Resource Management, 43(23): 201-218.

Cober, R.T., Brown, D.J., Levy, P.E., Cober, A.B. \& Keeping, L.M. 2003. Organizational web sites: Web site content and style as determinants of organizational attraction. International Journal of Selection and Assessment, 11(2-3): 158-169.

Dineen, B.R., Ash, S.R. \& Noe, R.A. 2002. A web of applicant attraction: Personorganization fit in the context of web-based recruitment. Journal of Applied Psychology, 87(4): 723-734.

Dineen, B.R., Ling, J., Ash, S.R. \& Delvecchio, D. 2007. Aesthetic properties and message customization: Navigating the dark side of web recruitment. Journal of Applied Psychology, 92(2): 356-372.

Dineen, B.R. \& Noe, R.A. 2009. Effects of Customization on Application Decisions and Applicant Pool Characteristics in a Web-Based Recruitment Context. Journal of Applied Psychology, 94(1): 224-234.

Elgin, P.D. \& Clapham, M.M. 2004. Attributes associated with the submission of electronic versus paper résumés. Computers in Human Behavior, 20(4): 535-549.

Feldman, D.C. \& Klaas, S.B. 2002. Internet job hunting: A field study of applicant experiences with on-line recruiting. Human Resource Management, 41(2): 175-192.

Galanaki, E. 2002. The decision to recruit online: A descriptive study. Career Development International, 7(4): 243-251.

Glaser, B. \& Strauss, A. 1967. The Discovery of Grounded Theory: Strategies for Qualitative Research. Chicago: Aldine. 
Hamilton, R.J. \& Bowers, B.J. 2006. Internet recruitment and e-mail interviews in qualitative studies. Qualitative Health Research, 16(6): 821-835.

Hogler, R.L., Henle, C. \& Bemus, C. 1998. Internet recruiting and employment discrimination: A legal perspective. Human Resource Management Review, 8(2): 149164.

Hu, C., Su, H.C. \& Chen, C.I.B. 2007. The effect of person-organization fit feedback via recruitment web sites on applicant attraction. Computers in Human Behavior, 23(5): 2509-2523.

Jansen, B.J., Jansen, K.J. \& Spink, A. 2005. Using the web to look for work: Implications for online job seeking and recruiting. Internet Research, 15(1): 49-66.

Koong, K.S., Liu, L.C. \& Williams, D.L. 2002. An identification of Internet Job Board attributes. Human Systems Management, 21(2): 129-135.

Lee, I. 2005. Evaluation of Fortune 100 companies' career web sites. Human Systems Management, 24(2): 175-182.

Lee, I. 2007. An architecture for a next-generation holistic e-Recruiting system. Communications of the ACM, 50(7): 81-85.

Lehman, H. \& Fernandez, W.D. 2007. Adapting the Grounded Theory Method for Information Systems Research, QualIT Conference. Wellington, New Zealand.

Lievens, F., Van Dam, K. \& Anderson, N. 2002. Recent trends and challenges in personnel selection. Personnel Review, 31(5-6): 580-601.

Lin, B. \& Stasinskaya, V.S. 2002. Data warehousing management issues in online recruiting. Human Systems Management, 21(1): 1-8.

Lincoln, Y. \& Guba, E. 1985. Naturalistic Inquiry. Beverly Hills: Sage.

Llorens, J.J. \& Kellough, J.E. 2007. A revolution in public personnel administration: The growth of web-based recruitment and selection processes in the federal service. Public Personnel Management, 36(3): 207-221.

Maurer, S.D. \& Liu, Y. 2007. Developing effective e-Recruiting websites: Insights for managers from marketers. Business Horizons, 50(4): 305-314.

Parry, E. \& Tyson, S. 2008. An analysis of the use and success of online recruitment methods in the UK. Human Resource Management Journal, 18(3): 257-274.

Pearce, C.G. \& Tuten, T.L. 2001. Internet recruiting in the banking industry. Business Communication Quarterly, 64(1): 9-18.

Ployhart, R.E., Weekley, J.A., Holtz, B.C. \& Kemp, C. 2003. Web-based and paper-andpencil testing of applicants in a proctored setting: Are personality, biodata, and situational judgment tests comparable? Personnel Psychology, 56(3): 733-752.

Robbins, S.S. \& Stylianou, A.C. 2003. Global corporate web sites: An empirical investigation of content and design. Information and Management, 40(3): 205-212.

Singh, P. \& Finn, D. 2003. The effects of information technology on recruitment. Journal of Labor Research, 24(3): 395-408.

Smith, A.D. \& Rupp, W.T. 2004. Managerial challenges of e-Recruiting: Extending the life cycle of new economy employees. Online Information Review, 28(1): 61-74.

Smyth, B., Bradley, K. \& Rafter, R. 2002. Personalization techniques for online recruitment services. Communications of the ACM, 45(5): 39-40.

Stone, D.L., Stone-Romero, E.F. \& Lukaszewski, K. 2006. Factors affecting the acceptance and effectiveness of electronic human resource systems. Human Resource Management Review, 16(2): 229-244.

Strohmeier, S. 2007. Research in e-HRM: Review and implications. Human Resource Management Review, 17(1): 19-37.

Suddaby, R. 2006. From the Editors: What Grounded Theory is not. Academy of Management Journal, 49(4): 633-642. 
Terzis, V. \& Economides, A.A. 2005. Job Site Evaluation Framework (JSEF) and comparison of Greek and foreign job sites. Human Systems Management, 24(3): 223-237.

Thomas, S.L. \& Ray, K. 2000. Recruiting and the web: High-tech hiring. Business Horizons, 43(3): 43-52.

Thompson, L.F., Braddy, P.W: \& Wuensch, K.L. 2008. E-recruitment and the benefits of organizational web appeal. Computers in Human Behavior, 24(5): 2384-2398.

Tong, J.P.C., Duffy, V.G., Gross, G.W., Tsung, F. \& Yen, B.P.C. 2005. Evaluating the industrial ergonomics of service quality for online recruitment websites. International Journal of Industrial Ergonomics, 35(8): 697-711.

Van Hoye, G. \& Lievens, F. 2007. Investigating Web-based recruitment sources: Employee testimonials vs. word-of-mouse. International Journal of Selection and Assessment, 15(4): 372-382.

Webster, J. \& Watson, R.T. 2002. Analysing the past to prepare for the future: Writing a literature review. MIS Quarterly, 26(2): 13-23.

Williamson, I.O., Lepak, D.P. \& King, J. 2003. The effect of company recruitment web site orientation on individuals' perceptions of organizational attractiveness. Journal of Vocational Behavior, 63(2): 242-263.

Young, J. \& Foot, K. 2005. Corporate E-cruiting: The construction of work in fortune 500 recruiting Web sites. Journal of Computer-Mediated Communication, 11(1):44-71.

Zusman, P.R. \& Landis, R.S. 2002. Applicant preferences for Web-based versus traditional job postings. Computers in Human Behavior, 18(3): 285-296. 


\section{Appendix A}

Table A1: Human Resources Management, Organizational Behavior, Psychology and Management Publications

\begin{tabular}{|c|c|c|}
\hline Year & Title & Journal \\
\hline 2009 & $\begin{array}{l}\text { Effects of Customization on Application Decisions and } \\
\text { Applicant Pool Characteristics in a Web-Based } \\
\text { Recruitment Context }\end{array}$ & Journal of Applied Psychology \\
\hline 2008 & $\begin{array}{l}\text { An analysis of the use and success of online recruitment } \\
\text { methods in the UK }\end{array}$ & Human Resource Management Journal \\
\hline 2007 & $\begin{array}{l}\text { Web-Based Recruitment: Effects of Information, } \\
\text { Organizational Brand, and Attitudes Toward a Web Site } \\
\text { on Applicant Attraction }\end{array}$ & Journal of Applied Psychology \\
\hline 2007 & $\begin{array}{l}\text { Aesthetic properties and message customization: } \\
\text { Navigating the dark side of web recruitment }\end{array}$ & Journal of Applied Psychology \\
\hline 2007 & $\begin{array}{l}\text { A revolution in public personnel administration: The } \\
\text { growth of web-based recruitment and selection processes } \\
\text { in the federal service }\end{array}$ & Public Personnel Management \\
\hline 2007 & $\begin{array}{l}\text { Developing effective e-Recruiting websites: Insights for } \\
\text { managers from marketers }\end{array}$ & Business Horizons \\
\hline 2007 & Research in e-HRM: Review and implications & Human Resource Management Review \\
\hline 2007 & $\begin{array}{l}\text { Investigating Web-based recruitment sources: Employee } \\
\text { testimonials vs. word-of-mouse }\end{array}$ & $\begin{array}{l}\text { International Journal of Selection and } \\
\text { Assessment }\end{array}$ \\
\hline 2006 & $\begin{array}{l}\text { Organizational recruitment website effects on viewers' } \\
\text { perceptions of organizational culture }\end{array}$ & Journal of Business and Psychology \\
\hline 2006 & $\begin{array}{l}\text { Factors affecting the acceptance and effectiveness of } \\
\text { electronic human resource systems }\end{array}$ & Human Resource Management Review \\
\hline 2004 & $\begin{array}{l}\text { Recruitment on the net: How do organizational web site } \\
\text { characteristics influence applicant attraction? }\end{array}$ & Journal of Management \\
\hline 2004 & $\begin{array}{l}\text { Form, content and function: An evaluative methodology } \\
\text { for corporate employment web sites }\end{array}$ & Human Resource Management \\
\hline 2003 & $\begin{array}{l}\text { Applicant and recruiter reactions to new technology in } \\
\text { selection: A critical review and agenda for future } \\
\text { research }\end{array}$ & $\begin{array}{l}\text { International Journal of Selection and } \\
\text { Assessment }\end{array}$ \\
\hline 2003 & $\begin{array}{l}\text { Organizational web sites: Web site content and style as } \\
\text { determinants of organizational attraction }\end{array}$ & $\begin{array}{l}\text { International Journal of Selection and } \\
\text { Assessment }\end{array}$ \\
\hline 2003 & The effects of Information Technology on Recruitment & Journal of Labor Research \\
\hline 2003 & $\begin{array}{l}\text { The effect of company recruitment web site orientation } \\
\text { on individuals' perceptions of organizational } \\
\text { attractiveness }\end{array}$ & Journal of Vocational Behavior \\
\hline 2002 & $\begin{array}{l}\text { A web of applicant attraction: Person-organization fit in } \\
\text { the context of web-based recruitment }\end{array}$ & Journal of Applied Psychology \\
\hline 2002 & $\begin{array}{l}\text { Internet job hunting: A field study of applicant } \\
\text { experiences with on-line recruiting }\end{array}$ & Human Resource Management \\
\hline 2002 & The decision to recruit online: a descriptive study & Career Development International \\
\hline 2002 & Recent trends and challenges in personnel selection & Personnel Review \\
\hline 2000 & $\begin{array}{l}\text { Internet Recruitment and Selection: Kissing Frogs to find } \\
\text { Princes }\end{array}$ & $\begin{array}{l}\text { International Journal of Selection and } \\
\text { Assessment }\end{array}$ \\
\hline 2000 & Recruiting and the web: High-tech hiring & Business Horizons \\
\hline 1998 & Electronic career search & Journal of Employment Counseling \\
\hline 1998 & $\begin{array}{l}\text { Internet recruiting and employment discrimination: A } \\
\text { legal perspective }\end{array}$ & Human Resource Management Review \\
\hline
\end{tabular}


Table A2: Information Systems Publications

\begin{tabular}{|c|c|c|}
\hline Year & Title & Journal \\
\hline 2008 & $\begin{array}{l}\text { Online recruiting: The effects of organizational } \\
\text { familiarity, website usability, and website attractiveness } \\
\text { on viewers' impressions of organizations }\end{array}$ & Computers in Human Behavior \\
\hline 2008 & $\begin{array}{l}\text { E-recruitment and the benefits of organizational web } \\
\text { appeal }\end{array}$ & Computers in Human Behavior \\
\hline 2007 & $\begin{array}{l}\text { The effect of person-organization fit feedback via } \\
\text { recruitment web sites on applicant attraction }\end{array}$ & Computers in Human Behavior \\
\hline 2007 & $\begin{array}{l}\text { An architecture for a next-generation holistic e- } \\
\text { Recruiting system }\end{array}$ & Communications of the ACM \\
\hline 2005 & Evaluation of Fortune 100 companies' career web sites & Human Systems Management \\
\hline 2005 & $\begin{array}{l}\text { Job Site Evaluation Framework (JSEF) and comparison } \\
\text { of Greek and foreign job sites }\end{array}$ & Human Systems Management \\
\hline 2005 & $\begin{array}{l}\text { Corporate E-cruiting: The construction of work in } \\
\text { fortune } 500 \text { recruiting Web sites }\end{array}$ & $\begin{array}{l}\text { Journal of Computer-Mediated } \\
\text { Communication }\end{array}$ \\
\hline 2004 & $\begin{array}{l}\text { Attributes associated with the submission of electronic } \\
\text { versus paper résumés }\end{array}$ & Computers in Human Behavior \\
\hline 2004 & $\begin{array}{l}\text { Managerial challenges of e-Recruiting: Extending the } \\
\text { life cycle of new economy employees }\end{array}$ & Online Information Review \\
\hline 2003 & $\begin{array}{l}\text { Internet recruiting: The effects of web page design } \\
\text { features }\end{array}$ & Social Science Computer Review \\
\hline 2003 & $\begin{array}{l}\text { Global corporate web sites: An empirical investigation } \\
\text { of content and design }\end{array}$ & Information and Management \\
\hline 2002 & An identification of Internet Job Board attributes & Human Systems Management \\
\hline 2002 & $\begin{array}{l}\text { Data warehousing management issues in online } \\
\text { recruiting }\end{array}$ & Human Systems Management \\
\hline 2002 & $\begin{array}{l}\text { Personalization techniques for online recruitment } \\
\text { services }\end{array}$ & Communications of the ACM \\
\hline 2002 & $\begin{array}{l}\text { Applicant preferences for Web-based versus traditional } \\
\text { job postings }\end{array}$ & Computers in Human Behavior \\
\hline
\end{tabular}

Table A3: Other Publications

\begin{tabular}{lll}
\hline Year & Title & Journal \\
\hline 2006 & $\begin{array}{l}\text { Internet recruitment and e-mail interviews in qualitative } \\
\text { studies }\end{array}$ & Qualitative Health Research \\
2005 & $\begin{array}{l}\text { Using the web to look for work: Implications for online } \\
\text { job seeking and recruiting }\end{array}$ & Internet Research \\
2005 & $\begin{array}{l}\text { Evaluating the industrial ergonomics of service quality } \\
\text { for online recruitment websites } \\
\text { Personalized information ordering: A case study in } \\
\text { online recruitment }\end{array}$ & $\begin{array}{l}\text { International Journal of Industrial } \\
\text { Ergonomics } \\
\text { Keb-based and paper-and-pencil testing of applicants in }\end{array}$ \\
2003 & $\begin{array}{l}\text { a proctored setting: Are personality, biodata, and } \\
\text { situational judgment tests comparable? } \\
\text { Internet recruiting in the banking industry }\end{array}$ & \\
2001 & & Business Communication Quarterly \\
\hline
\end{tabular}




\title{
CHAPTER 4
}

\section{Managing Recruitment and Selection in the Digital Age: E-HRM and Resumes ${ }^{6}$}

\begin{abstract}
Recruiters, in the business of screening job applicants, are increasingly dependent on information systems especially digital resume databases. However, the current literature does not provide a consensus on the requirements for resume content for digital recruiting. This research contributes to the understanding of the different requirements of recruiters for offline and online resumes. We offer an analysis of the relevant literature; interviews with recruiters; and content analysis of the resume fields of 40 e-Recruiting sites. Based on this we identified a number of challenges in categorizing digital resume data and digital matching between resumes and job advertisements. We identify areas for further research on the maintenance and extension of online resume databases and derive recommendations for digital resume design.
\end{abstract}

Keywords: e-HRM, Digital Resumes, Recruiter Requirements, Workflows.

\footnotetext{
${ }^{6}$ This paper has been published in Human Systems Management.

A previous version of this paper has been published in the Proceedings of the European Conference on Information Systems, June 7-9, 2010, Pretoria, South Africa.
} 


\section{Introduction}

In the world before the web good employee selection was seen as the sine qua non of rational business; yet not all employees were selected in systematic or smart ways. Increasingly, careful and efficient selection of employees is seen as a critical task for organizations (Hough \& Oswald, 2000). Although some selection aspects such as the employment interview have attracted much research attention (Kinicki \& Lockwood, 1985; McDaniel et al. 1994; Huffcut et al., 2001; Schmidt \& Zimmerman, 2004), the management of requirements for digital resumes has received little academic scrutiny (Furtmueller et al., 2010). The literature available on resume preparation, construction, design and content; and e-Recruiting mainly originates from practitioner journals (Holley et al., 1988; Hutchinson \& Brefka, 1997; Crosby, 1999) and books (Ryan, 1997; Besson, 1999). As a result, many of the recommended practices are not based on empirical research. It is no wonder then that there is little agreement about which resume fields are essential for effective selection procedures.

A further issue is that most available literature on resume design is focused on the United States (Gueutal \& Stone, 2005; Ross \& Young, 2005), with scant attention to other cultural contexts (Ruël et al., 2004; Furtmueller et al., 2010). Organizations, recruiters and applicants frequently use different terminology to mean similar things, leading to difficulties in interpreting and matching digital resume fields with the content of job advertisements. In this paper, we discuss knowledge representation challenges in categorizing digital resume profiles. As Glynn and Raffaelli (2010) state:

"In order for fields to flourish, there needs to be some level of standardization (or agreed-upon principles) in practices, norms, conventions, or cognitive templates in order to enable communication, comparability—and even competition—among ideas and theories" (p. 6).

Additionally, compared to research into applicants' perceptions on e-Recruiting (Feldman \& Klaas, 2002; Zusman \& Landis, 2002; Lee et al., 2008; Furtmueller et al., 2010), there has been limited research on recruiters' views as to their requirements for resume design (Brown \& Campion, 1994; Cole et al., 2007). This imbalance is surprising since (corporate) recruiters constitute the clients who usually pay for using online recruiting services such as Monster, Careerbuilder or Stepstone.

While Information Systems publications have investigated e-Recruiting business processes (McIntyre et al., 1980; Dipboye et al., 1984); architectures (Lee, 2007); implementation (Ruël et al., 2004); usability (Feldman \& Klaas, 2002; Dineen et al., 2007), 
and general design aspects (Chapman \& Webster, 2003; Furtmueller et al., 2009); we lack knowledge of the essential elements that should be included in a digital resume form. In a recent literature review on e-Recruiting, Wolfswinkel et al. (2010) argued the main inadequacy of current research is its non-theoretical character. In practice, many different terms are used for the same resume field descriptions across online career sites.

The purpose of this current study is to add to the e-HRM literature and specifically, the study of digital resume management. We used multiple sources of information, including a literature analyses (Wolfswinkel et al., 2012), interviews with recruiters and a systematic analysis of the resume fields of the 40 largest Dutch e-Recruiting sites to derive the critical fields required by recruiters for digital resumes. We also examine issues related to matching resume data with job advertisement data, and the processes required to maintain a standardised set of digital resume fields. We discuss how digital resume fields and search functions may be complemented to improve the identification of qualified candidates. This requires consistency particularly in the representation of candidates' biographical data.

The rest of this paper is structured as follows. We first discuss gaps in the literature and present the research methods (literature analyses, interviews and resume field content analyses on recruiting sites). Then, we present the results of the interviews and propose the essential components of digital resumes. We discuss the findings in light of previous literature, derive recommendations for digital resume design, and outline implications for research.

\section{Resumes and e-Recruiting}

In the academic literature, several reviews have appeared on personnel selection (Monahan \& Muchinsky, 1983; Bartram, 2000; Hough \& Oswald, 2000; Anderson, 2003). They emphasize that biographical data in the form of resumes are the most commonly used information in personnel selection. Some researchers even suggest that every selection decision includes an evaluation of biodata (Brown \& Campion, 1994). Resumes generally represent a structured, professional profile that showcases an applicant's strengths, accomplishments, interests, skills, and work-related experiences (Ross \& Young, 2005). The pre-screening of resumes is a key phase in personnel selection processes. Recruiters use resume information to draw conclusions about an applicant's work-related skills, abilities, motivation, personality, and job fit (Brown \& Campion, 1994; Chapman \& Webster, 2003). The resume is thus a critical tool for evaluating the potential suitability of any given applicant for a particular job, and it 
determines increasingly often who is invited for additional screening (Reeve et al., 2006; Sackett \& Lievens, 2008).

Recent developments in recruitment practices show that job applicants, as well as professional recruiters and organizations in need of personnel, are increasingly turning to the internet. Recruiters use it to advertise job postings and search applicant pools, while job seekers use it to apply online (Cappelli, 2001). In the last decade, e-Recruiting has spread around the globe, and has become a leading e-commerce application. Currently, 40,000 job boards are live 24/7, and all Fortune 100 companies recruit via the internet. The major advantages of e-Recruiting services include cost savings, efficiency, and convenience for both recruiters and job seekers (Bartram, 2000). A number of e-Recruiting sources are available for job seekers and recruiters, including online job boards, niche job portals, e-Recruiting consortia and corporate career websites. Online job boards act as recruiting intermediaries between recruiters and job seekers (Furtmueller et al., 2009). Today, virtually every corporate website and commercial job board accepts online resume submissions via online forms and resume builders. Incoming resumes are routinely stored in an internal database designed to be used specifically by automated candidate management processes. These resume databases continue to gain popularity, yet little research has been conducted on design, actual use, and impacts. In fact, online resume data has been widely criticized for difficulties in clear and consistent interpretation (Ryan \& Ployhart, 2000; Smith \& Rupp, 2004; Furtmueller et al., 2010).

While most professionals agree that resumes are vital, there is no consensus over resume design requirements and the specific content to be included in resume forms. This lack of consensus on what constitutes appropriate biodata for a resume is problematic. If biodata is seen as including such things as interests, personality, skills, and values, it becomes difficult to distinguish biodata from other measures. In an attempt to clarify matters, Mael (1991) provided a taxonomy of biodata items. He stated that the core attribute of biodata is that the items pertain to historical events that may have shaped the person's behaviour and identity (p. 763). This broad definition however does little to inform researchers about specific resume components. Ross and Young (2005) conducted a comprehensive review of academic resume design literature including journals, periodicals, and book publications. Their research revealed eight salient resume categories: (1) career objectives, (2) educational record-college, (3) educational record-high school, (4) related work experience, (5) nonrelated work experience, (6) personal information, (7) professional and personal involvement, and (8) references. They derived 72 resume content items. This classification provides a 
starting point for our investigation, although some limitations of their research should be noted (Mumford, 1999). Ross and Young's (2005) resume items have been tested only with recruiters in the recreation and leisure services industry, and it is unclear if these resume items are similarly relevant for all the other industries.

While digital resumes have many advantages, the matching of job candidates to vacancies is still challenging in the absence of some standardization in resume content fields. Initial evaluation of applicants, i.e., to filter out those that are unsuitable without screening out good candidates, is still a time-consuming challenge. Inasmuch as the Web makes it easy for job seekers to apply for many jobs in a short time period (Lee et al., 2008); the consequence is that companies may be inundated with a large number of resumes, many from unqualified applicants (Lee, 2005).

Recruiters encounter different challenges when working with digital (online) compared to print (offline) resumes. Digital resumes can be used in automated processes such as for example, automated storage, searching, pre-selection, comparison and ranking of candidates. Digital resumes may be easily transferable to other systems and it is relatively easy to update their content. Moreover, digital resumes offer the chance to send automatic replies to applicants (Lin \& Stasinskaya, 2002). In offline or printed resumes, consistent resume design is less of an issue; applicants have the possibility to fully customize their resumes (Knouse, 1994). However, in the initial screening phase recruiters need to invest more time in interpreting print resumes. Also in the task of systematically comparing resumes' contents (Smith \& Rupp, 2004; Furtmueller et al., 2010) recruiters need to spend more time when resumes are not standardized. While (standardized) digital resumes aim to offer more systematic and faster resume screening, achieving this benefit depends on the way resume fields are structured and classified, including the availability of search functions that recruiters desire (Furtmueller et al., 2010).

Internet research in recent years has offered new knowledge on effective searching: allowing targeted searches on many internet services such as books, hotels or restaurants. Prerequisites for effective searching in e-Recruiting include the systematization of knowledge of resume field representations as well as the structuring of job advertisement content.

A good match between a candidate and a job needs to be bilateral as it requires considering both applicant and recruiter preferences (Anderson, 2003). In practice, there is very little standardisation (Koong et al., 2002). Digital resume applications are often designed independently, either internally by organisations or by commercial job portal providers. Typically there is limited or no information exchange across the various providers, or between 
candidates and providers. This literature analysis of resumes, e-Recruiting practices and preselection technology suggests that a more structured and sophisticated understanding of online resume design is needed. Such knowledge could be used to enrich resume form design. We address the following research question: "What are the requirements of digital resume forms from the recruiters' perspective?" This main question is broken down into the following three sub-questions:

1. Which fields in digital resume forms are significant from the recruiters' perspective?

2. How can the fields used in digital resume forms be systematically represented?

3. What workflow process can be used to utilise digital resume fields and search function to improve recruiters' identification of prospective staff?

\section{Method}

The requirements for resume forms were developed using a mixed methods approach; analyzing literature; interviewing recruiters; and content-analysis of the resume fields of 40 eRecruiting sites (Mingers, 2001). In order to gain a better understanding of these requirements, we also examined the designs of resume forms on leading-edge e-Recruiting sites based on both the literature and our interview data.

\section{Interviewing recruiters}

It has frequently been argued that involving end-users (such as users of e-Recruiting sites, that is, recruiters) in system design is a critical factor in the successful implementation and operation of information systems. IS researchers have claimed that the direct interview remains the best technique for eliciting requirements (Alvarez \& Urla, 2002). In order to interview recruiters from a variety of sectors and industries in the Netherlands we first determined which specific companies were active at two career fairs, the Nobiles career event in Utrecht and the Nationale Carrierebeurs in Amsterdam. Using the contact data on the career fair websites, we emailed 72 organizations (belonging to various branches) and requested 30 minute interviews during the career fair. To encourage participation, we offered to share the results of the study with the organisations that agreed to participate. The interviews were semi-structured and included open-ended questions. Before the career fair, the questions were pilot-tested with one recruiter and an academic who are both actively involved in e-Recruiting research, and the interview protocol was refined. Overall, seventeen recruiters agreed to be interviewed. The sample consisted of twelve females and five males, 
with ages from 22 to 37 (average 30). Combined, they had between 1 to 15 years of professional experience, with an average of 5 years. Four of these recruiters worked in consulting firms, three in finance organizations, two for IT companies, two for technical companies, and one each in trade, utilities, pharmacy, education, transportation and recruiting. Recruiters were asked which resume fields are important to them and which fields, search options and functions should be added to current online resume forms. The typical interview was on site and took about 25 minutes. In most cases it was not possible to extend the interview longer since job applicants were waiting to talk with the recruiters. While a tape recorder was taken to the interviews, the noisy career-fair environment led the interviewer to take comprehensive field notes during and after each interview.

\section{Data analyses of e-Recruiting websites}

In order to get a comprehensive overview of resume forms currently used in practice, we analyzed the 40 largest e-Recruiting sites in the Netherlands. We selected these largest sites since they attract a wide variety of different applicant groups, and therefore should collectively represent best practice in resume design. We began by familiarizing ourselves with all the sites by visiting them and carefully reading and comparing the different resume fields used across the sites. We used the classification system from Ross and Young (2005) as a starting point. Two coders then wrote down and coded independently every resume category including fields, field type and input options. Emerging differences in categorization were discussed between the two coders, and new codes were added to supplement the Ross and Young framework where required. After the initial development of the resume coding categories, the fields from all recruiting sites were categorized and a resume knowledge representation framework was formulated.

To control how many websites we needed to analyze to reach code saturation for the resume fields, we documented the progression of resume field identification after each website. Code saturation was reached after analyzing 14 e-Recruiting sites. In total, 114 resume fields were identified within the studied 40 recruiting sites, all of which have been used in at least one website. Of these attributes, 78 fields (68\%) were identified within the first two websites. An additional 36 attributes were identified in the next twelve websites. After the fourteenth website, no new fields were discovered (see figure 1). By achieving code saturation for the resume fields in our study, we believe our findings apply to the full range of resume design practices in contemporary Dutch e-Recruiting websites. 


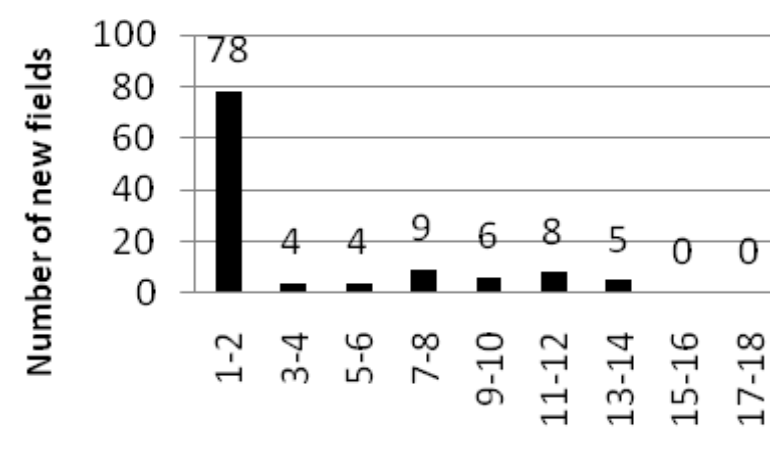

General e-Recruiting Websites

Figure 1

Data saturation of resume fields on general e-Recruiting websites

\section{Results}

In what follows we will describe first the resume requirements emerging from the interviews with recruiters. Then, we will present and discuss the results of the e-Recruiting website analyses and the relevant components of digital resumes. The integration of these findings into a knowledge representation framework (Zeleny, 1989) of data requirements for digital resumes will facilitate the next stage of development of a digital resume design ontology. However, in this paper we have stopped short of specification of a detailed ontology, as this is a technical process with (likely) a different readership, and different theoretical foundations. Next we will discuss requirements for recruiting workflows: to improve matching between resumes and job advertisements. Finally we suggest areas for future research into the maintenance and extension of resume knowledge representation frameworks.

\section{Recruiters' preference}

The interviews with recruiters were useful to gain insight into their usage of e-Recruiting sites, and their perspectives on important resume and search fields. Over a third of the interviewed recruiters identified applicants' education and years of professional work experience as highly important resume criteria. Further, they frequently requested information on extra activities, ambitions, desired job, personality, hobbies and interests, phone number, and personal information. Approximately $25 \%$ of the recruiters were dissatisfied with the current e-Recruiting websites, and felt that rather than there being missing data, there was too much unnecessary data:

"There are too many fields in a resume. I only want to know their name, phone number, education and work experience” 
and "I see no need for additions because then it would be even less manageable and would take more administrative time."

Another recruiter argued:

"I only want to get to know about their past work experiences:

related to the prospective job: not paper filling!"

It was emphasized to us that resumes should be easily readable. However, some of the recruiters we interviewed did identify additional data requirements. One recruiter wanted to know the reason why an applicant had left the previous job while another demanded knowledge tests:

"Before an applicant gets invited for a job interview, he has

to do an analytical and mathematical test online, however

first we always look through their resumes."

Three recruiters requested the inclusion of phone numbers so that they could talk to a potential applicant immediately, before another employer made contact. Two recruiters found the highest education level very important. Another wanted to know how quickly an applicant had finished their formal educational trajectory. Recruiters differed to some extent in terms of the criteria they required for searching and filtering online resumes. The most frequently requested search filter (by almost 70\% of recruiters) was years of professional work experience. More than half of the interviewees preferred to search for job titles (or synonyms of that job title) when filtering applicant databases.

"Sometimes a job title has multiple meanings, like an

architect can design buildings or computer software."

One-third of the recruiters preferred to search for applicants who lived close to the company location. Also, a third of the recruiters stated they usually searched for education level, e.g. highest degree obtained. Some recruiters noted that they liked to search for industry or branch type. Three of the 17 recruiters explained that they wanted as many suitable applicants as possible, and would then manually check all the resume forms of the pre-filtered applicants. Six recruiters felt that determining what resume design and search criteria are important largely depends on the vacancy. In this context, two IT recruiters noted additional criteria such as specific expertise or years of experience with a specific programming language would be useful. Two recruiters searched for applicants with a certain career level. One recruiter suggested they always filter out applicants who are not actively seeking a job. Another recruiter requested the ability to filter out applicants who do not want to travel. One recruiter 
wanted to search for those applicants who had indicated a desired salary level that was similar to the level offered by the hiring organization.

\section{Website analysis}

Three researchers carefully reviewed resume field options of the 40 largest Dutch eRecruiting sites (for a complete listing of these sites: see Appendix A). We compared the resume fields used in these sites with what we found in the resume design literature and with the interview results. While the recruiting sites in the study shared many features in their resume fields and subfields, they also differed in several areas, and in the labeling and extensiveness of fields they used. For instance, some sites include a field only for the most recent professional experience while others provided the option to fill in multiple previous positions. Similarly, educational levels, skills, job titles and demographic data were clustered in various ways across the studied websites. Not all systems include all relevant fields suggested in the literature. Importantly, we found that many resume forms used variations of unstructured textboxes, checkboxes or select boxes for capturing data. This meant that although required fields might be present, they would not be easily searchable using criteria relevant for recruiters, due to their unstructured format.

\section{Digital Resume Design}

Based on the literature analyses, the integration of insights from the interviews with recruiters and the e-Recruiting website analysis, we derived the relevant content for digital resumes. Compared to previous literature, two new resume categories have been added: career status and desired job; other salient resume fields are personal and contact information, education, work experience, extra activities, skills and references. In this section, we present a justification for each category based on literature, interviews, or website analysis. In some cases, we returned to previous research, in an effort to further explicate our findings. This allows us to contextualize our study and to note where our findings diverge from those of previous researchers. Our use of multiple, independent data-gathering techniques give us considerable confidence in the robustness and completeness of these findings.

\section{Personal and Contact Information}

The inclusion of personal information, such as age, gender, ethnicity, marital status and a photograph is generally included at the discretion of the applicant (Ross \& Young, 2005). In 
the research literature few employers have indicated that personal information is desirable in resumes. Hutchinson and Brefka (1997) found that inclusion of personal information was typically considered unimportant, and some respondents pointed out that such information would be "struck out" for legal reasons. Holley et al. (1988) found that more than half of the applicants for Director of Personnel positions provided marital status, and many chose to include their age and number of children. They suggest prospective employers are barred from requesting certain types of information, and thus some may prefer not receiving such information for fear of discrimination claims. Personal information is usually supplied by job applicants in order to enhance their chances of obtaining an interview (McIntyre et al., 1980) despite the fact that such information has also been found to create discriminatory evaluations in pre-selection decisions (Harris, 2004).

Some applicants falsely believe that they are required to provide personal information in their resumes, unaware perhaps that anti-discrimination legislation in many countries makes it illegal for employers to base hiring decisions on such information. Essential information in each resume, according to Ross and Young (2005), is an applicant's telephone number. This was confirmed by our interviews; three recruiters requested the inclusion of phone numbers so that they could immediately talk to a potential applicant. The region where a candidate lives (during the time of the job application) is seen as important, while specific address, fax and social security number are not important. Further, age, birth date and place, gender, marital status, number of dependents, military experience, photograph and ethnicity were rated as not important by Ross and Young. Monsterboard.nl, the largest Dutch eRecruiting site belonging to the largest US-based e-Recruiting firm, does not require applicants to fill in personal information such as gender or birth date, but all the other Dutch e-Recruiting sites we analyzed require applicants' gender and birth date. Stepstone.nl, a Norwegian site, even demands information about nationality. A Dutch public-sector site, 'werkenbijde-overheid.nl,' asks for marital status. Similarly, one of our interviewed recruiters stated: "As a recruiter, you want to know everything you can about any potential applicant." Yet, most resume forms let the applicant choose to show or hide personal and contact information from potential employers. In case of a fully anonymous resume (a resume without personal and contact information) recruiters can get into contact with applicants by anonymous mail. Also, the applicant can choose not to include their resume information in resume databases. In such cases, applicants can manually send in online resumes when responding to a job advertisement. 'Nuwerk.nl' gives the option to explicitly include or exclude selected companies from seeing the resume profile. In this way, applicants can be 
confident their current employer cannot find them in a pool of job seekers. We conclude that since employers are prohibited from selecting employees based on gender, birth date, nationality or marital status, online resume forms should ideally not even ask for this personal information.

\section{Education}

A significant number of researchers (Augustin, 1991; Knouse, 1994; Besson, 1999; Cole et al., 2007) agree with our interviewed recruiters that educational experience is an essential component of a good resume. A recruiter may use this section to match particular job requirements with the educational accomplishments of applicants. Applicants' competencies may be further judged on the basis of the reputation of schools attended (e.g., a prestigious private school versus a regional or state university) and the field of study. Moreover, it may be possible to infer the degree of motivation of the applicant from the duration of their program of study. Degrees received and the dates they were awarded should be included under the education section in reverse chronological order. The most suitable education to be included in resumes should be either university/college or high school level. Crosby (1999) suggests that high school educational information should be included for applicants who apply for internships or student projects, and by recent graduates. However, Hutchinsons and Brefka (1997) argue there is little value in listing high school information unless it is the applicants' sole educational experience or directly related to the open position. Researchers have frequently suggested the inclusion of grade point average (GPA). This might be due to recruiters' beliefs that a GPA reflects in part on the candidate's intelligence, motivation, and other abilities needed on the job (Roth \& Bobko, 2000). For experienced professionals, recruiters place more emphasis on relevant previous work experience (Hutchinson \& Brefka, 1997). Ross and Young (2005) differentiate between college experience and high school experience. Overall, college experience, field of study, internship experience, major area of study, type of degree earned and date of graduation were all rated as very important. The name of college/university attended, honors and awards, participation in campus organizations, GPA in major, GPA overall, list of college courses taken, transcripts, participation in athletics and class rank were rated as somewhat important. In contrast to college and university history, name of high school attended, and other information from the applicant's high school record, such as participation in athletics and GPA were rated as not important (Roth \& Bobko, 2000). 


\section{Work Experience}

In the work experience section, job titles, major duties and responsibilities of the jobs listed by the applicant can be compared with the requirements of the job to which a candidate applies (Schmidt \& Zimmerman, 2004). Ross and Young (2005) found the following parameters very important: job responsibilities, dates of employment, position title, achievements and accomplishments, reason for leaving, name of employer, name of supervisor, part-time or full-time status, location of employer and salary. Similarly, Cole et al. (2007) found that hiring managers find information provided by job candidates about individual job achievements, holding a supervisory position, full-time work experience, and internship experience to be significant. Although some researchers (Crosby, 1999) recommend including full- and part-time job information, and non-related work experience in resumes, Ryan (1997) suggested the inclusion only of work experience that is meaningful and directly relevant to the position sought. In organizations where work is accomplished by networks of project-based teams, and by people who can adjust to more flexible assignments, the tradition of clearly defined jobs with position titles that convey meaning outside particular work groups and companies is rapidly eroding. Hence, it is important to have descriptions and titles for job openings that will be understood by employers. In our recruiting website analyses, we found some sites only require applicants to fill-in their most recent or current work experience. This finding corresponds with our interview results. Four recruiters mentioned that resumes should be easily readable and not be overloaded with information. If a site enables the filling-in of multiple experiences, then the most recent or relevant work experience that is related to the desired job should be clearly indicated. Then the applicant's prior responsibilities and achievements should be identified.

Moreover, based on the literature, recruiting websites should include a checkbox so applicants can see if a job is full-time or part-time. Both literature and our interviews underline the high importance placed on job titles. Current recruiting websites force recruiters to fill in several different but synonymous different job titles since parts of many job titles very often apply to similar work (software engineer, software developer, programmer).

Also, many job titles (like architect) can have multiple cross-domain meanings, e.g., a building architect or a software architect. It is therefore very important that job titles are clearly defined (Furtmueller et al., 2010) and recruiting sites should take synonyms into account. We recommended that professional or occupational associations should be more engaged in standardizing and categorizing job titles. 


\section{Extra Activity}

Cole et al. (2007), Brown and Campion (1994) as well as the recruiters involved in this study consider extracurricular activities the third most important section of the resume. These activities include memberships in professional societies, holding elected offices, voluntary community activities (Ross \& Young, 2005) and engagement in university or social clubs. The number and type of activities (i.e., professional vs. social) and the number of leadership positions held influence their picture of an applicant's leadership capabilities, interpersonal skills, and motivational qualities. Given that most entry-level applicants' prior work experience is either limited or non-existent (Cole et al., 2007), recruiters are likely to focus more on an applicant's academic qualifications and extracurricular activities. Ross and Young (2005) label this category "personal and professional involvement", and find it should include, in order of importance: certifications, professional organizations, community involvement, professional presentations delivered, professional conferences attended, and professional publications. All of these resume content items were seen as very important by our interviewees. Hobbies are considered only somewhat important in Ross and Young's (2005) study while four of our 17 recruiters considered hobbies highly important. The resume design literature suggests an applicant's prior positions held in association with extracurricular activities to be very important for inclusion in resume forms. Collecting information about these extracurricular activities could be more structured in online resumes, for example by enabling applicants to fill in each experience separately, as they do in the education and work experience sections. For each experience the specific date (for a publication or presentation) or period (for community involvement and memberships) should be stated.

\section{Skills}

The online resume forms of the 40 Dutch recruiting sites require applicants to fill-in only a fairly standard set of generic skills. For instance, in regard to computer skills, only working knowledge of Microsoft Office elements such as Word, Excel or PowerPoint are specifically listed in the online resume forms. These skill lists should be extended in order to more comprehensively reflect an applicant's computer skills. For instance, programs like AutoCAD, Photoshop, or Sketchup or other industry specific software and programming languages should be included.

An indication of level of experience (beginner, intermediate, advanced, expert) would strengthen the usefulness of the skills section. Two of the IT recruiters we interviewed stated 
that information on applicants' detailed programming languages and experience level is needed. Skills databases need to be integrated with human resource information systems in order to systematically match language skills, software skills, business skills, law skills, project management skills, etc. with a given vacancy.

\section{References in Resume Forms}

Ross and Young (2005) identified references from previous employers as very important. They saw references from teachers; reference letters attached and references available on request as somewhat important, while references from relatives were not seen as important. As an alternative to including references in the resume, Besson (1999) suggested a separate list of references should be sent to the prospective employer only when the candidate becomes a finalist for the position. In our website analyses, only one of the 40 websites asked applicants for references, and none of the interviewed recruiters expressed the need for references $^{7}$ on the initial application.

\section{Career Status}

We found that recruiters want to be able to filter on a range of criteria such as whether applicants are currently available to start a job and are eligible to work in the country; years of experience, education level; career level; current or last job title(s) and employer. These issues are covered by the field career status. It can be used as a search filter.

Updated information on the current career status of registered applicants is important so that recruiters who use digital resume pools can first invest their screening time in candidates that are currently available. When recruiters use resume databases to first filter for the best-fitting applicants for their advertised jobs, several routine challenges arise. It is often the case that the applicant has by this time found a job elsewhere, or found the company or job description unattractive; and consequently does not respond to the recruiter's invitation for an interview. Naturally, applicants are more likely to apply to job advertisements when they know the job description and the hiring company (Sylva \& Mol, 2009). This implies applicants need to take a proactive role, and decide for themselves if they want to be regarded as a candidate by specific hiring organizations (Sinar et al., 2003).

\footnotetext{
${ }^{7}$ This might be a Dutch bias since the Netherlands lacks a culture of making and conveying and using reference letters in HRM-type matters, unlike most Anglo-Saxon countries where those letters do play a role.
} 


\section{Desired Job}

The resume field desired job is important for recruiters who use digital resumes, as they need to know how likely it is that a specific applicant will take a specific job in a specific organization. Some of our interviewees noted they stopped using resume pools due to lack of applicant responsiveness and because they were not convinced that applicants actually desired to work for their organization if they only appeared as latent job seekers and did not apply directly for a specific advertised job.

Ross and Young (2005) showed that specific information on an applicant's career objectives is very important. They suggest including in resumes a brief but specific objective statement, identifying the type of position the candidate is seeking. This could be either job focused or career focused. However, our interview results and the website analysis show that this is not likely to satisfy recruiters' needs. Recruiters need more detailed information about applicants when using resume databases. Yet, applicants do not always directly apply to recruiters' specific job advertisements; when recruiters use resume pools they assume the proactive role in searching for suitable candidates. In this case they desired an extra resume category, which we labeled "desired job" indicating the fit between the candidate's aspirations and the advertised job.

Selection research not only concentrates on person-job fit; but other fit constructs such as an individual's compatibility with his or her organization, work group, and supervisors (Kristof-Brown et al., 2005; Ryan et al., 2005). In our proposed "desired job" category, the applicant should at least fill-in the date when he or she is available to start a new job, preferred job title(s), job status, industries, companies, salary, and hours per week he or she wants to work.

Also, location is important: some recruiters mention wanting to be given information on the work commuting distance from the applicant's home address, or eventual need for relocation, in order to judge the feasibility of hiring the candidate. If a website also offers international jobs, the desired salary should take currency issues when relevant into account (for example, by allowing site users to select the required currency from a list). 


\section{Challenges and limitations of intelligent matching}

We now illustrate the challenges encountered in effective matching of resume and job ad content. Figure 2 below shows data from a typical applicant profile and job ad. The classification of various attributes (i.e. education, languages, skills, etc.) should enable intelligent matching. However building up ontology for applicant and job ad descriptions is complex. The example shows that the description in the job ad requires a candidate who speaks at least one Eastern European language; the applicant profile lists Romanian under languages indicating a fit with the job ad. The skills ontology therefore needs to be build up the way that languages are classified, e.g. in Eastern European languages (or Slavic), Germanic, Roman, and Indic language families. Classifications of the Japanese family, for example, range from one language (a language isolate) to nearly twenty. A major current problem is that applicants tend to fill in concrete details in resumes (specific school attended, concrete field of study) whereas e-Recruiting systems structure data according to broad categories for skills, education level and type. As most search is keyword based (also not considering homonyms, i.e. bank=financial institution, bank=an applicant's name), matching results between applicant and job profile remain unreliable. In order to allow matching systems to improve recruiters' work routines, classification difficulties need to be addressed. Continuing our illustration, the job ad excerpt requires skills in object-oriented programming language; the applicant filled in the online resume that he had skills in Java. Here also the IT skill ontology would need to know that Java belongs to the object-oriented programming languages so that this candidate is identified by the recruiters' search query.

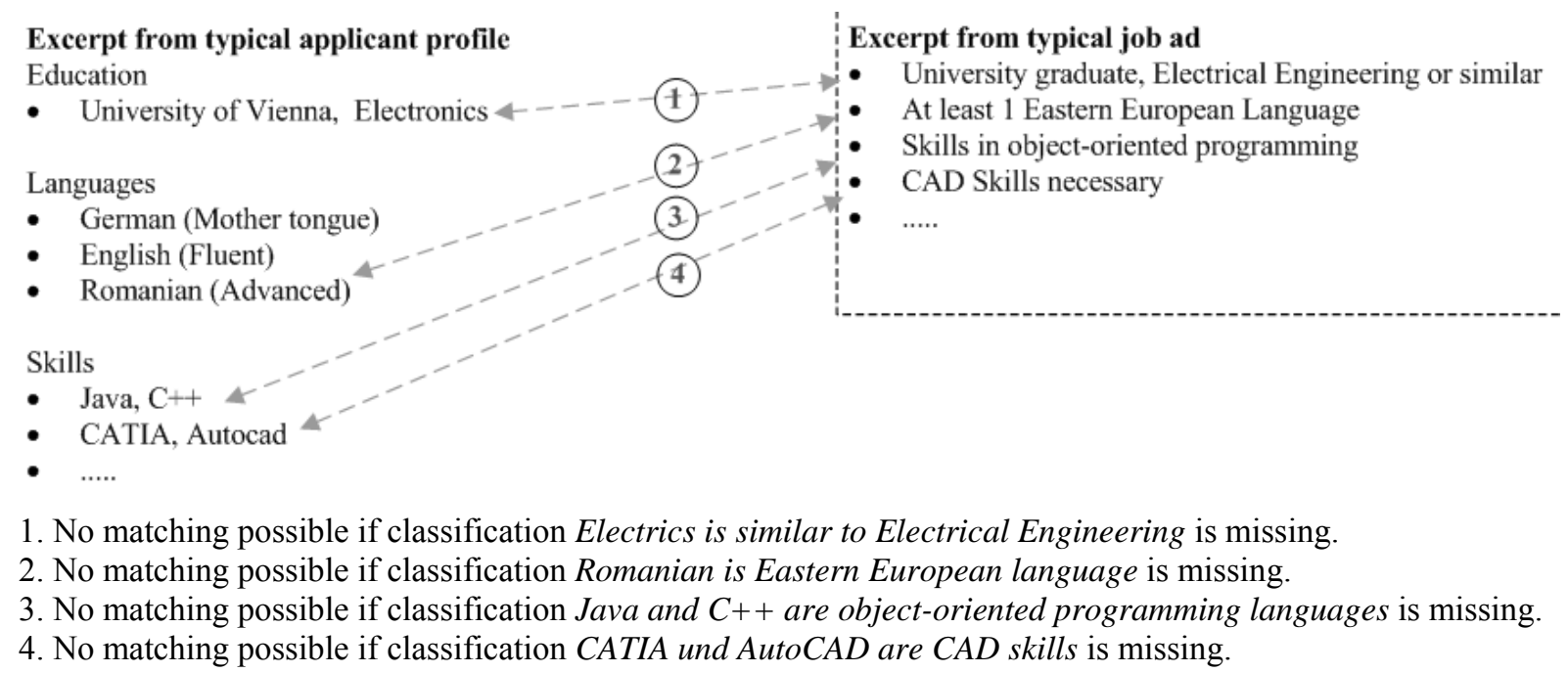

Figure 2

Excerpt for an applicant profile and a job ad 


\section{Developing workflows and maintaining resume content data}

Enacting useful applications of online resumes by recruiters requires more than just a knowledge representation framework. The framework must be sophisticated and able to support a network of inter-related classifications (Zhao \& Du, 2011). A process is required for structuring and classifying unstructured job and applicant data in conformance with the knowledge engineering framework (Zeleny, 1989). Finally, since any classification system will be incomplete, a workflow is required enhancing the framework as part of its ongoing use. Most current e-Recruiting systems, however, have no automated categorization, and no easy ability to add new knowledge, and therefore search queries can lead to dissatisfying results. Manual classification is prevalent which requires HR assistants to classify job advertisements into job category, branch, type of employment and region. More sophisticated classifications into detailed education type or job-related experience and skills have not been accomplished by most systems yet.

A further challenge is the maintenance of the knowledge representation framework in response to new jobs and other categories. Although our research into the required fields for digital resume design was comprehensive and drew on data from multiple sources, it is inevitable that new fields, or new categories for existing fields, will continue to emerge. New courses and degrees, and new technologies and programming languages need to be able to be incorporated into the framework.

The framework must be adaptive and extensible. In principle, the following workflow process is required to maintain the framework. If applicants suggest new terms that the system does not know these should be put into a separate group. The different context suggestions should be socialised by subject matter experts using collaborative processes involving users and developers. The disputed terms can then be incorporated into the existing framework, or used as a basis for extensions to the framework. A categorization processes for unknown terms that enables them to be added to the structured content system is essential for the success of any e-Recruiting field framework.

\section{Discussion}

When applicants send print resumes to an organization, usually recruiters assume that the applicants are eager and willing to take the advertised job (Monahan \& Muchinsky, 1983; Dipboye et al., 1984). With digital resumes this is often not the case. It is easy for applicants to send their resumes to many different organizations with little effort and cost. 
In particular when recruiters use digital resume pools, several challenges arise. Recruiters may get frustrated if they have identified a seemingly perfect candidate but potential candidates with active-appearing resumes appear nonresponsive due to changed circumstances in their career status. Several of our interviewed recruiters noted that resume profiles get easily out-dated. Recruiters had experienced many "hits" which suggested suitable candidates, only to find that while initially a profile seemed suitable for an advertised job, due to changes in the applicants' career experiences and interests they were no longer an effective match.

Previous research suggests that registered users of e-Recruiting services are not longterm active users. Usually, job searchers tend to look through the published job ads, fill in resume forms and apply to the e-listed jobs. As soon as they have found a new job, there is very little reason to return to a career site again. And it is difficult to design the technical features of online services and simultaneously lead new social practices for on-going communications (Szmigin et al., 2005).

Due to the exchange-based nature of recruiting services, large numbers of e-Recruiting initiatives fail (Furtmueller et al., 2010). Many providers try to solve this dilemma by accumulating masses of resumes, (i.e. registered applicant profiles) so that simply more suitable profiles for the same job advertisements appear to be available. The problem of outmoded profiles is, however, not solved this way (Smith \& Rupp, 2004). Many of the applicants have already found a job or their contact data has changed. Therefore, a major design challenge is to implement features to motivate applicants to keep their profiles up-todate. Some research suggests additional features to encourage stickiness and returning visits; such as enhancing the playfulness of the site, or implementing skill competitions and the ability for applicants to rank themselves compared to other registered applicants on the site (Furtmueller et al., 2009). Effective management of online resume data could also facilitate regular prompting of applicants to confirm if their details are correct and if they are still jobhunting.

When recruiters receive print resumes, after an initial screening they reply with a rejection or an invitation to submit more documents for additional screening or an invitation for an interview or further testing. In the offline context, the applicant is usually removed from the pool of applications after their application has been considered, although some organizations keep resumes stored for later possible job interviews.

In the digital context, resumes can be stored lifelong. In order to get a systematic overview of the available candidates, one needs to build in a 'career state' entry: to flag the 
willingness of a person to interview at some point (e.g. available on a specified date, currently not available, or latent job seeker, that is, open for job offers however currently in a job). By paying more attention to practice-oriented resume design, recruiters' time investments would decrease considerably. Similarly, automated rejection mails to unsuitable resume profiles can enable efficient communication. Finally, system designers are challenged to create privateinformation space into the applicant profile base (for applicants; friends of applicants and for HR recruiters).

We expect future e-Recruiting services to include social network functionalities among registered users: in order to build trust as well as ward off the fear that personalized resume data will be misused.

\section{Contribution to Research and Practice}

This study's analysis of the relevant literature; interviews with recruiters; and content-analysis of the resume fields of 40 e-Recruiting sites contributes to the understanding of varying requirements of offline and online resumes. Second, we shed light on some of the challenges of online matching of resume data to job requirements, and maintaining a structured framework for resume data.

We suggest processes for structuring and matching job and applicant data, and discuss approaches for maintaining and extending the framework. Third, this study has resulted in a number of design recommendations. Fields that could result in claims of discrimination, for example, age, gender and marital status should be excluded from digital resume databases (Harris et al., 2004; Ross \& Young, 2005). Furthermore, the equivalency of job titles is complex and requires ongoing input from professional and occupational associations to ensure consistent classification. Information about extracurricular activities needs to be more structured, and more similar to job information. Skills classifications need to be integrated from a number of disciplines, including language, software and, business.

We propose two new resume fields specifically relevant for effectively working with digital resume databases: career status and desired job. We recommend using fewer open textfield options in online resume forms and instead a focus on "select" fields which can be classified for matching job ads and resume profiles. Needless to say, textboxes do not support structured searching or automated pre-selection and filtering of candidates. Still, textboxes have been found useful for screening after an initial assessment (i.e. first screening of the hard facts required for a job) has taken place. In order to lower the time spent in pre-selection 
processes, various phases in the selection process need to be integrated as discussed earlier in the literature (Gueutal \& Stone, 2005). Our interviews suggested that in a first level selection, recruiters usually do not require all resume content data; there is no need for most of the unstructured information in textboxes or specific street address of an applicant. Basic initial information which is required includes eligibility to work in the country, availability, education level, skills and years of work experience. If these first-level selection criteria are assessed positively, a second level selection should take place (showing specific resume details of applicants, that is, textboxes where applicants express their talents in writing, which also allows recruiters to assess their level of writing fluency). This second-phase may need to include more unstructured written information. Alternatively, upon the initial pre-selection round a phone interview or other selection techniques may take place.

A major challenge in resume design is to establish a standardized vocabulary for resume fields. Our study clearly revealed that the currently used online resume forms use many different synonyms for the same resume field. For instance, some portals ask applicants to fill in their earliest possible starting date, others the earliest beginning date or job enter date - terms which obviously relate to the same construct. And some information services request applicants to fill in an exact day of the month whereas others require filling in 'start month' and year. This research provides a springboard for sematic web applications that will enable the implementation of intelligent, adaptable and extensible e-Recruiting portals and applications. This has great potential to bring productivity gains in this specific aspect of the e-HRM industry.

\section{Implications for Future Research}

The challenge remains to classify resume information across sectors, countries, languages and laws affecting the job search and hiring process. Clearly, both research and practice would benefit from a more unified or standardized language for digital resume forms. However, this knowledge source is complex to develop, and would require various syntheses from areas as broad as Linguistics, Human Resources, Computer Science, Information Systems, and even Psychology. To date, there appears little knowledge sharing across organizations and research

disciplines when it comes to e-Recruiting portal design (Wolfswinkel et al., 2010). Researchers from technical disciplines (Information Systems, Computer Science) and social sciences (Human Resource Management, Psychology) have worked independently from each other. Fortunately, in the past decade, scholars have started to undertake joint interdisciplinary 
efforts to understand the phenomenon and its multilevel implications within and across organizations; leading to several special issues on e-HRM between 2004 and 2012 (e.g. Human Resource Management, 2004 and 2008; International Journal of Human Resource Management, 2009; European Journal of International Management, forthcoming).

Clearly, more technical research is needed in the e-HRM domain to develop an adaptive e-Recruiting ontology that can learn new skills such as applicants' various computer or language skills. In order to enable effective matching, comprehensive skill ontologies need to be agreed upon within the recruiting sector. Research suggests that better taxonomies would produce better selection decisions (Terzis \& Economides, 2005; Furtmueller et al., 2010).

As educational programs and skills change over time, skill ontologies for resume fields would need to allow learning from new users who fill in new skills which the system did not know before. Yet, different users will likely interpret skill levels differently. Therefore skill tests may need to be included when filling in resume forms. This would provide a more objective comparison of resume content data. An intelligent resume screening system could aid in the recommendation of applicants to recruiters (Viswesvaran, 2003). Also workflows for using, maintaining, and enhancing resume databases need to be developed in order to enhance recruiters' effectiveness in using such systems.

This study is not without limitations. Quantitative research involving a larger sample of recruiters would be helpful for identifying essential and nice-to-have resume categories in a more comprehensive way. Furthermore, our suggested resume content fields may need revision depending on emerging novel job classifications and industry types in a growing universe of e-Recruiting services. We focused exclusively on analyzing Dutch e-Recruiting sites and interviews with Dutch recruiters. Resume preferences and resume fields may be categorized differently in other cultures outside the Netherlands. 


\section{Conclusion}

This paper addresses and synthesizes requirements of online resume forms into a knowledge framework. We conducted interviews with 17 full-time recruiters, and content analyzed the resume forms of the 40 largest Dutch e-Recruiting sites which provided insights into best practice in content items used in resume forms. These current practices were compared with extant resume design literature and concepts emerging from interviewing recruiters about their everyday professional experience. This research is useful for managers and designers of online resume forms, recruiters, applicants and academics engaged in e-Recruiting research. We synthesized and explained the content of the most sought after relevant digital resume fields by recruiters: career status, desired job, education, work experience, extracurricular activities, skills, personal information and contact information.

This research provides two new resume fields beyond what is found in the existing academic literature: career status and desired job. Both of these categories provide useful information for recruiters using resume databases for searching and matching. "Current career status" makes it virtually effortless to quickly sort out applicants that are not suitable for the open position, and "desired job" gives the recruiter information as to whether an applicant would be actually interested in an offered job. Further, we have represented the fields in a structured way that will enable design and development.

Despite the popularity of e-HRM (Ruël et al., 2004; Gueutal \& Stone, 2005), the full potential of online recruiting is not being realized due to ongoing difficulties in matching and searching on resume fields. Filtering resumes and identifying suitable applicants, let-alone suitable applicants that are actually interested in the position, remains the same labor intensive, hit-or-miss process that it was in pre-digital times. In this study, we identified some of the reasons why this is the case, and proposed some solutions.

The knowledge representation framework and the insights gleaned from this exploratory study may aid in improved design that will enable recruiters to harness the business potential of the online resume databases in the future. 


\section{References}

Alvarez, R. \& Urla, J. 2002. Tell me a good story: Using narrative analysis to examine information requirements interviews during an ERP implementation. Data Base for Advances in Information Systems, 33(1): 38-52.

Anderson, N. 2003. Applicant and recruiter reactions to new technology in selection: A critical review and agenda for future research. International Journal of Selection and Assessment, 11(2-3): 121-136.

Augustin, H.M. 1991. The written job search: A comparison of the traditional and a nontraditional approach. The Bulletin, 54: 13-14.

Bartram, D. 2000. Internet recruitment and selection: Kissing frogs to find princes. International Journal of Selection and Assessment, 8(4): 261-274.

Besson, T.J. 1999. Resumes. (3rd Ed.) New York: John Wiley.

Brown, B.K. \& Campion, M.A. 1994. Biodata phenomenology: Recruiters' perceptions and use of biographical information in resume screening. Journal of Applied Psychology, 79(6): 897-908.

Cappelli, P. 2001. Making the most of online recruiting. Harvard Business Review, 79(3): 139-146.

Chapman, D.S. \& Webster, J. 2003. The use of technologies in the recruiting, screening, and selection processes for job candidates. International Journal of Selection and Assessment, 11(2-3): 113-120.

Cole, M.S., Rubin, R.S., Field, H.S. \& Giles, W.F. 2007. Recruiters' perceptions and use of applicant resume information: Screening the recent graduate. Applied Psychology. An International Review, 56(2): 319-343.

Crosby, O. 1999. Resumes, applications, and cover letters. Occupational Outlook Quarterly, 4(2): 2-15.

Dineen, B.R., Ling, J., Steven, S.R. \& DelVecchio, D. 2007. Aesthetic properties and message customization: Navigating the dark side of web recruitment. Journal of Applied Psychology, 92(2): 356-372.

Dipboye, R.L., Fontenelle, G.A. \& Garner, K. 1984. Effects of previewing the application on interview process and outcomes. Journal of Applied Psychology, 69(1): 118-128.

Feldman, D.C. \& Klaas, B.S. 2002. Internet job hunting: A field study of applicant experiences with on-line recruiting. Human Resource Management, 41(2): 175-192.

Furtmueller, E., Wilderom, C. \& Mueller R. 2010. Online Resumes: Optimizing Design to Service Recruiters. Proceedings of the European Conference on Information Systems, paper 53.

Furtmueller, E., Wilderom, C. \& van Dick, R. 2009. Utilizing the Lead User Method for promoting Innovation in e-Recruiting, in Handbook of Research on E-Transformation and Human Resources Management Technologies, 251-2273, (Eds). Bondarouk, T.V., Ruël, H.J.M., Oiry, E. \& Guiderdoni-Jourdan, K. 2009. Information Science Reference, Hershey: New York.

Furtmueller, E., Wilderom, C. \& van Dick, R. 2010. Sustainable e-Recruiting portals: How to motivate applicants to stay connected throughout their careers? International Journal of Technology and Human Interaction, 6(3): 1-20.

Glynn, M.A. \& Raffaelli, R. 2010. Uncovering Mechanisms of Theory Development in an Academic Field: Lessons from Leadership Research. Academy of Management Annals, 4(1): 359-401.

Gueutal, H.G. \& Stone, D.L. 2005. The brave new world of e-HR: human resources management in the digital age. San Francisco, CA: Jossey-Bass. 
Harris, M.M., Lievens, F. \& van Hoye, G. 2004. I think they discriminated against me: Using prototype theory and organizational justice theory for understanding perceived discrimination in selection and promotion situations. International Journal of Selection and Assessment, 12(1-2): 54-65.

Holley, W.H., Higgins, E. \& Speights, S. 1988. Resumes and cover letters - What do HR managers really want? Personnel, 65(12): 49-51.

Hough, L.M. \& Oswald F.L. 2000. Personnel selection: looking toward the future-remembering the past. Annual Review of Psychology, 51: 631-664.

Huffcutt, A.I., Conway, J.M., Roth, P.L. \& Stone, N.J. 2001. Identification and meta-analytic assessment of psychological constructs measured in employment interviews. Journal of Applied Psychology, 86(5): 897-913.

Hutchinson, K.L. \& Brefka, D.S. 1997. Personnel Administrators' Preferences for Resume Content: Ten Years After. Business Communication Quarterly, 60(2): 67-75.

Kinicki, A.J. \& Lockwood, C.A. 1985. The interview process - An examination of factors recruiters use in evaluating job applicants. Journal of Vocational Behavior, 26(2): 117125.

Knouse, S.B. 1994. Impressions of the resume - The effect of applicant education, experience and impression management. Journal of Business and Psychology, 9(1): 33-45.

Koong, K.S., Liu, L.C. \& Williams, D.L. 2002. An identification of Internet Job Board attributes. Human Systems Management, 21(2): 129-135.

Kristof-Brown, A.L., Zimmerman, R.D. \& Johnson, E.C. 2005. Consequences of individuals' fit at work: A meta-analysis of person-job, person-organization, person-group, and person-supervisor FIT. Personnel Psychology, 58(2): 281-342.

Lee, I. 2005. Evaluation of Fortune 100 companies' career web sites. Human Systems Management, 24(2): 175-182.

Lee, I. 2007. An architecture for a next-generation holistic e-Recruiting system. Communications of the ACM, 50(7): 81-85.

Lee, I., Dehkordi-Vakil, F. \& Kaul, T. 2008. Evaluating job applicants' perceptions of corporate career web sites. Human Systems Management, 27: 321-330.

Lin, B. \& Stasinskaya, V.S. 2002. Data warehousing management issues in online recruiting. Human Systems Management, 21(1): 1-8.

Mael, F.A. 1991. A conceptual rationale for the domain and attributes of biodata items. Personnel Psychology, 44(4): 763-792.

McDaniel, M.A., Whetzel, D.L., Schmidt, F.L. \& Maurer, S.D. 1994. The validity of employment interviews - A comprehensive review and meta-analysis. Journal of Applied Psychology, 79(4): 599-616.

McIntyre, S., Moberg, D.J. \& Posner, B.Z. 1980. Preferential treatment in preselection decisions according to sex and race, Academy of Management Journal, 23(4): 738-749.

Mingers, J. 2001. Combining IS research methods: Towards a pluralist methodology. Information Systems Research, 12(3): 240-259.

Monahan, C.J. \& Muchinsky, P.M. 1983. Three decades of personnel selection research: A state-of-the-art analysis and evaluation. Journal of Occupational Psychology, 56: 215225.

Mumford, M.D. 1999. Construct Validity and Background Data: Issues, Abuses, and Future Directions. Human Resource Management Review, 9(2): 117-145.

Reeve, C.L., Highhouse, S. \& Brooks, M.E. 2006. A closer look at reactions to realistic recruitment messages. International Journal of Selection and Assessment, 14(1): 1-15.

Ross, C.M. \& Young, S.J. 2005. Resume preferences - Is it really "business as usual"? Journal of Career Development, 32(2): 153-164. 
Roth, P.L. \& Bobko, P. 2000. College grade point average as a personnel selection device: Ethnic group differences and potential adverse impact. Journal of Applied Psychology, 85(3): 399-406.

Ruël, H.J.M., Bondarouk, T.V. \& Looise, J.C. 2004. E-HRM: innovation or irritation? An exploration of web-based human resource management in five large companies. Management Revue, 15(3): 364-380.

Ryan, A.M. \& Ployhart, R.E. 2000. Applicants' perceptions of selection procedures and decisions: A critical review and agenda for the future. Journal of Management, 26(3): 565-606.

Ryan, A.M., Horvath, M. \& Kriska, S.D. 2005. The role of recruiting source informativeness and organizational perceptions in decisions to apply. International Journal of Selection and Assessment, 13(4): 235-249.

Ryan, R. Winning resumes. 1997. New York: John Wiley.

Sackett, P.R. \& Lievens, F. 2008. Personnel selection. Annual Review of Psychology, 59: 419-450.

Salgado, J.F. 2001. Some landmarks of 100 years of scientific personnel selection at the beginning of the new century. International Journal of Selection and Assessment, 9(12): $3-8$.

Schmidt, F.L. \& Zimmerman, R.D. 2004. A counterintuitive hypothesis about employment interview validity and some supporting evidence. Journal of Applied Psychology, 89(3): 553-561.

Sinar, E.F., Reynolds, D.H. \& Paquet, S.L. 2003. Nothing but 'net? Corporate image and webbased testing. International Journal of Selection and Assessment, 11(2-3): 150-157.

Smith, S.L. \& Rupp, W.T. 2004. Managerial challenges of e-Recruiting: extending the life cycle of new economy employees. Online Information Review, 28(1): 61-74.

Sylva, H. \& Mol, S.T. 2009. E-Recruitment: A study into applicant perceptions of an online application system. International Journal of Selection and Assessment, 17(3): 311-323.

Szmigin, I., Canning, L. \& Reppel, A.E. 2005. Online community: enhancing the relationship marketing concept through customer bonding. International Journal of Service Industry Management, 16(5): 480-496.

Terzis, V. \& Economides, A.A. 2005. Job Site Evaluation Framework (JSEF) and comparison of Greek and foreign job sites. Human Systems Management, 24(3): 223-237.

Viswesvaran, C. 2003. Introduction to special issue: Role of technology in shaping the future of staffing and assessment. International Journal of Selection and Assessment, 11(2-3): 107-112.

Wolfswinkel, J., Furtmueller, E. \& Wilderom, C. 2010. Reflecting on e-Recruiting Research Using Grounded Theory. Proceedings of the European Conference on Information Systems, paper 52.

Wolfswinkel, J., Furtmueller, E. \& Wilderom, C. 2012. Using grounded theory as a method for rigorously reviewing literature. European Journal of Information Systems (in press).

Zeleny, M. 1987. Management support systems: Towards integrated knowledge management. Human Systems Management, 7(1): 59-70.

Zeleny, M. 1989. Knowledge as a new form of capital, part 1: division and reintegration of knowledge. Human Systems Management, 8(1): 45-58.

Zeleny, M. 1989. Knowledge as a new form of capital, part 2: knowledge-based management systems. Human Systems Management, 8(2): 129-143.

Zhao, S. \& Du, J. 2011. The application of competency-based talent assessment systems in China. Human Systems Management, 30(1): 23-37.

Zusman, R.R. \& Landis, R.S. 2002. Applicant preferences for Web-based versus traditional job postings. Computers in Human Behavior. 18(3): 285-296. 


\section{Appendix A:}

Largest e-Recruiting websites in the Netherlands

http://www.hrlog.nl/2008/10/06/hrlog-top-40-3e-kwartaal-2008, retrieved Sep 4, 2011

$\begin{array}{ll}\# & \text { url } \\ 1 & \text { http://www.monsterboard.nl/ } \\ 2 & \text { http://www.nationalevacaturebank. } \\ & \text { nl/ } \\ 3 & \text { http://www.intermediair.nl/ } \\ 4 & \text { http://www.totaljobs.nl } \\ 5 & \text { http://www.jobbingmall.nl/ } \\ 6 & \text { http://www.randstad.nl } \\ 7 & \text { http://www.volkskrantbanen.nl/ } \\ 8 & \text { http://www.uitzendbureau.nl/ } \\ 9 & \text { http://www.jobtrack.nl } \\ 10 & \text { http://www.jobrapido.nl } \\ 11 & \text { http://www.nuwerk.nl } \\ 12 & \text { http://www.tempo-team.nl } \\ 13 & \text { http://www.vacaturekrant.nl/ } \\ 14 & \text { http://www.stepstone.nl } \\ 15 & \text { http://www.werk.nl } \\ 16 & \text { http://www.studentenwerk.nl/ } \\ 17 & \text { http://vacature.overzicht.nl/ } \\ 18 & \text { http://www.werkenbijdeoverheid.nl } \\ 19 & \text { http://www.zoekbijbaan.nl/ } \\ 20 & \text { http://www.bijbanen.nl } \\ & \end{array}$

\# url

terboard.n! 


\title{
CHAPTER 5
}

\section{Designing Service Systems for e-HRM: \\ The Service-dominant Logic $^{8}$}

\begin{abstract}
Many organizations use e-HRM (Electronic Human Resource Management) for purposes of automating administrative practices, but relatively few personnel departments use IT as a service to support strategically important business processes and decisions. Previous studies have identified a number of obstacles on the development of e-Recruiting technology components. In this study, we aim to understand how a service-oriented approach can inform the improvement of (global) e-Recruiting services, and the parallel development of appropriate technology components to enable and sustain process improvement. We report on a major, highly successful design science project carried out over seven years, which used a service engineering life-cycle to design, develop, implement and evaluate a leading eRecruiting system. We discuss the business context and motivation, and the development process; we then present the conceptual design of a series of technology artifacts. These include a conceptual ontology for digital resume content, classifying staffing processes for the automatic extraction of relevant meta-data for applicant selection, and a workflow for resume searching, maintenance and extension of e-Recruiting services. Concluding, we provide an agenda for future research on globalizing and strategizing e-HRM services, and some insights for future service engineering projects.
\end{abstract}

Keywords: Global Human Resources and Recruiting, Service Dominant Logic, Design, Service Engineering, Ontology.

\footnotetext{
${ }^{8}$ A revised version of this paper is under consideration for publication in the Journal of Strategic Information Systems (second revision).

This paper was accepted for presentation at the Academy of Management Meetings in Boston, USA, Aug 3-7, 2012.
} 


\section{Introduction}

Increasing competition for talented employees or human capital is a global phenomenon. As a consequence, the human resource (HR) function, and in particular effective and efficient staff sourcing or e-Recruiting is seen as strategically important to most organisations (Huselid \& Becker, 2011, Schuler et al., 2010). The ability to accommodate national, regional, and global staffing needs has become critical with the development of economic unions such as the EU, where people can already travel freely to live and work across borders; and a move towards free labour markets in regions such as the Association of South East Asian Nations (ASEAN) (Collings et al., 2009). In many large organizations around the world, activities within the human resource function, especially recruitment are targeted for a service-oriented approach to development and deployment. In this paper we offer theoretical and practical insights on a service engineering life-cycle approach for recruiting services, based on a seven-year service engineering project in the e-HRM area. We do so in the context of the service-dominant-logic of business, which defines a service as "the application of specialised competencies (knowledge and skills), through deeds, processes and performances for the benefit of another entity or the entity itself" (Vargo \& Lusch, 2006, p. 283).

Recruitment has been defined as an organization's actions to bring a job opening to the attention of potential job candidates, selecting and influencing candidates so that the best possible candidate accepts a job offer (Schuler et al., 2010). Recruiting involves a set of specialised processes that are increasingly supported by information technology. Examples are advertising jobs online; soliciting responses; screening applicants; and determining appropriate candidate-job-salary fits. These recruiting services are provided by internal HR departments or sometimes in part by external agencies (Bartram, 2000; Luftman \& Zadeh, 2011). Globally oriented firms strive to improve recruiters' ability to handle job postings and job applications; in other words they aim to minimize paperwork and automate key recruiting activities (Collings et al., 2009). Large organizations are already using e-Recruiting as the primary method for job-publishing and personnel selection (Lee, 2011), and they tend to set the standard for smaller organizations. E-Recruitment has transformed organizational recruitment processes including the ways in which recruiters publish vacancies and communicate with (potential) applicants. However, after an initial uptake of digital advertising of positions and submission of digital resumes, the e-HRM market has been fairly static, and has been slow to move to a service-oriented paradigm. 
Recruiting is a natural candidate for service development as recruiting services exemplify the service dominated logic of business. However much of this potential is yet to be realized. To our knowledge, the project reported in this paper is one of the first large-scale commercial recruiting portals designed using a service-centered paradigm. Based on Vargo and Lusch (2006), service-centered recruiting can be seen to serve four functions: 1) Identify or develop core competences that constitute the set of knowledge and skills of an economic entity that together must offer competitive advantages (specialised competencies in recruiting offer competitive advantage to the organisation); 2) Attract other agents/entities (or potential customers) that could benefit from these competences (high quality recruiting practices assist in attracting and retaining staff at all levels); 3) Cultivate relationships that involve the customers in developing customized, competitively compelling value propositions to meet specific needs (this has been under-investigated in the past; we report on how our solution enables this) ; and 4) Gauge feedback from the market by analysing the performance so that one may continuously learn how to improve the firm's service proposition (this is also an area where we believe our solution is superior to many previous offerings).

The conceptualisation of Electronic Human Resource Management (e-HRM) as a service presents organisations with both challenges and strategic opportunities for personnel departments' processes through information systems. The notion of technology "as a service” is evolving, with an increasing interest in decoupled and unbundled access to IT functionality (Bardhan et al., 2010). In line with the increasingly important service-orientation in delivering IT services, Tim O'Reilly (2005) defined Web 2.0 as consisting of services rather than heavyweight applications and products that can be syndicated, extended and mixed. In an HR sourcing context, this would suggest the ability to decouple online job advertising and applicant processing from (for example) heavy weight enterprise systems or integrated human resource management information systems. It would entail the offering of job advertisements and initial applicant screening or self-evaluation via a range of channels such as professional social media sites and niche job portals, as well as organization web pages. An obvious example of this would be the job board on the professional social media site LinkedIn. Accessing HR sourcing as a service in IT terms would mean that regardless of which channel potential job candidates had chosen to apply through, an employing organizations is able to seamlessly push out their job vacancies to such a board, as well as advertising their vacancies on their own organizational portal, and then combine the applicants attracted via multiple channels for purposes of efficient screening. 
The technologies typically supporting the HR staffing requirements are relatively limited and unsophisticated compared to many other areas of business. While online advertising of vacancies is almost universally used by organizations (Lee, 2011), and online resumes and applications are the default method of expressing interest in a job by applicants (Gueutal \& Stone, 2005), most other HR sourcing processes, such as applicant screening, are still done largely manually and considered rather hit or miss (Reddick, 2009). Similarly, online recruiting sites tend to contain a large pool of applicants that are currently not seeking employment, or whose details are out-of-date (Furtmueller et al., 2011). The current research reported in this paper is motivated by the apparently slow and limited development of IT as a service to support the business services offered by recruiters. We aim to demonstrate how a service-oriented approach can improve global e-Recruiting services, and the development of appropriate technology components to enable and sustain process improvement.

Previous studies have identified a number of obstacles to development of e-Recruiting technology components. These include: a lack of consistent requirements for digital resume fields (Koong et al., 2002; Furtmueller et al., 2011; In Lee, 1997); difficulty in setting and maintaining standards for resume data within and between countries (Schuler et al., 2010); and difficulties in matching inconsistent or unstructured data supplied by candidates to organization requirements (Malinkowski et al., 2006). Achieving any sort of standardisation in digital resume design is recognised as non-trivial, since while professional knowledge and skill-sets may be understood globally, local and national recruiting markets all have distinctive features governed by culture and legislation. For example, in the USA, recruiters are prevented from seeking information about a candidate's gender or age but may be required to meet hiring targets based on ethnicity. In some Northern European countries candidates are required to supply their marital status and age when filling in online resume forms whereas requesting such personal information is protected by anti-discrimination laws in other countries.

Some academic studies have attempted to address these issues, in particular, by trying to identify a standardized set of requirements for digital resume fields (Furtmueller et al., 2011). The HR-XML (Human Resources XML) Consortium has developed a library of schemas for HR transactions, as well as options and constraints governing the use of those elements (HR-XML Consortium, 2011). However, if it were as simple as identifying a set of global requirements and implementing them in XML, there would be no further obstacles to rapid progress in effectively managing organizations' recruiting activities. Widely-used XML standards for HR data have been slow to evolve, due complexities in extending the 
requirements to accommodate new and emerging skill-sets, job titles and educational qualifications, and differing interpretations of $\mathrm{CV}$ terms between organizations and between organizations and candidates (Mochol et al., 2007).

There has been a lack of mutual understanding between system designers and HR practitioners, which has led to many failed e-HRM projects in organizations (e.g., Tansley et al. 2001; Smale \& Heikkilä, 2009; Martin \& Reddington, 2010). Gardner et al. (2003), for instance, discovered that rather than freeing up time for HR practitioners, the implementation of technology in personnel departments led to the replacement of administrative duties with technology-related ones, and thus did not improve HRM services performance. Other studies show that HR professionals were unsuccessful in using technology to initiate and support strategic decisions (Dery \& Wailes, 2005); and that technology was primarily used to support routine administrative HR tasks (Haines \& Lafleur, 2008; Hussain et al. 2007). In addition, utilizing the potential of technology in managing human resources was constrained by the complexities of people dynamics such as managing employee acceptance of new e-HRM systems (Grant et al., 2009).

In this paper, we report on a large-scale, long-term and highly successful design science project which takes a service engineering life-cycle approach to e-Recruiting service improvement. Below, we briefly introduce the design science paradigm, the service engineering life-cycle, including the theoretical foundations of the study. We then present the conceptual design of a series of technology artifacts which were developed to meet the business service requirements we identified. We offer a discussion that considers the business domain of e-Recruiting, and share the experiences gained from carrying out a service engineering project. We end by specifying implications for future research and outline the potential of our findings for improved globalizing and strategizing of e-Recruitment. This approach offers the opportunity for greatly increased sophistication and effectiveness in eHRM especially for trans-national and global organizations.

\section{Use of the Design Science paradigm}

Design Science is an emerging research paradigm in Information Systems which aims to provide guidelines for creating and evaluating IT artifacts that are defined as "models (abstractions and representations), methods (algorithms and practices), and instantiations (implemented and prototype systems). These [artifacts] are concrete prescriptions that enable IT researchers and practitioners to understand and address the problems inherent in developing and successfully implementing information systems within organizations (Hevner 
et al., 2004, p.77). We have positioned this study within the design science research paradigm because it is an excellent fit with the requirements of design science research: that it should have clear relevance to practice; produce one or more artifacts; communicate to both management and design-oriented audiences, demonstrate rigour in the development of those artifacts; produce artifacts that are complete and effective for the problem they set out to solve; make a contribution to research; and be informed by theory (Hevner et al., 2004).

This project is at the nexus of theory and practice, and is based on extensive engagement with the practitioner community. Our findings are based on insights gathered from multiple sources, including comprehensive literature analyses (Wolfswinkel et al. 2012); interviews with recruiters; interviews with applicants, an analysis of 40 e-Recruiting websites in the Netherlands; and the first author's seven year-long involvement in the design, market implementation, and operation of one of Austria's central e-Recruiting services with over 20,000 active resume profiles and over 10,000 job ads. The requirements analysis and justification of the relevance of this investigation are reported in various of our earlier studies (e.g. Ettinger et al., 2009; Furtmueller et al., 2010; Furtmueller et al., 2011); we build on these studies by summarizing salient insights. This previous work acts as a pre-evaluation of the importance and relevance of the problem, and presents our initial clarification of some of the service requirements. This follows the advice of Pfeffers et al. (2007) who are in favour of integrating scholars' earlier research on the topic.

Design science research produces one or more artefacts. The current project produced a wide range of strategic artefacts, a selection of which is reported in detail in this paper. We present those components which are central to the effective operation of e-Recruiting services and at the same time are not commercially sensitive to publish.

For a true design science approach, and not merely system or service development, the research must demonstrate rigour in the development and evaluation of the artifacts (Korthaus et al., 2009). Consequently, we followed a service design life cycle using multiple methods of data collection, analyses, implementation and evaluation for continuous service improvements informed at each point by appropriate theory (Iivari \& Venable, 2009; Fielt et al., 2010). Research rigour in the project was ensured by rich data collection and continuous evaluation. For instance, we used an open source environment for the evaluation of our artifacts and were able to include feedback from a global community of recruiters, applicants and developers to enhance our understanding of the issues and solutions. We note that von Krogh and Häflinger (2010) in a recent Journal of Strategic Information Systems drew attention to the increasing importance of including open source evaluations. We systematically analysed feedback of e- 
Recruiting users (applicants, recruiters, managers of organizations) during the development, prototyping and market implementation stages. This enabled us to improve both the quality of the recruiting services and the design process.

Design science should offer clear communication to both technology and management audiences (Hevner et al., 2004). This requirement has guided our choice of reporting. We have chosen to present technology artifacts at the conceptual design level, as this is intelligible to a general audience and aims to span the gap between human resources management and IT specialists, this follows Pfeffers et al.'s (2007) call for reporting of design science results. In their view, they should be accessible for various audiences. Bridging the communication gap between human resource management scholars and practitioners, on the one hand, and information systems and computer science ones, on the other hand, is a topic that is widely discussed in e-HRM literature. Our motivation for this study includes the high failure-rate in e-HRM implementations that we mentioned earlier. This research has been carried out iteratively in the research-practice nexus: informed by research and continuously evaluated in the market-place. We believe this amply demonstrates effective communication and engagement with both communities

Literature suggests that a design artifact is complete and effective when it satisfies the requirements and constraints of the problem it was meant to solve. In this domain, no one can reasonably make claim to completeness as HR processes, practices and regulations are continually changing; instead the approach was to develop technologies to support the human resources function that included learning mechanisms and dynamic capabilities in the systems design (see also Gregor et al. (2006) for a discussion on the transformational dimension in the realization of business value from information technology). We present effective, expandable and flexible artefacts: according to the prime aim of design science: "to determine how well an artifact works, not to theorize about to prove anything about why the artefact works" (Hevner et al., 2004, p. 88). We will show artifacts that have shown to work well and have gained a leading market share, suggesting strong efficacy for the previously identified business problems in managing organizations' recruiting requirements. Considering their wide implementation and usage, as well as our previous publications on the subject, we claim our solutions, if not complete, are satisfactory, i.e., satisficing (Simon, 1996).

This paper's research contribution is twofold. We reflect on our experience of conducting a service engineering project and present various technology artifacts. The derived knowledge including processes for structuring job and applicant data; design artifacts and workflows could serve as model for the development of similar systems. Second, we offer 
service improvement insights on the effective management of (global) e-Recruiting services. This knowledge is important for scholars in human resource and services management, information systems; strategic, international and organization studies. Ostrom et al. (2011) recently postulated that ideally service design is a collaborative and cross-disciplinary activity crossing management and technology fields.

\section{Service Design Cycle and Kernel Theories}

Design science proposes the use of "kernel theories" (theoretical foundations) to inform the design and evaluation of the technology artefact, and to contextualise the contribution to knowledge arising from such evaluation. The design of e-Recruiting service solutions for use by a global community poses multiple challenges that do not exist in a single organisational context. This is common to service science, management and engineering (SSME) research (Spohrer et al., 2011), and all research which aims to bridge the business and technology requirements for optimizing services. This task is complicated due to 1) the multi-disciplinary nature of service design; and 2) the lack of any clearly established and generally accepted methodology for designing, documenting and implementing service components. For instance, some scholars consider software development life cycles and prototyping as methodologies (Avison \& Fitzgerald. 2006) while others view these approaches only as "skeletal guidelines within which methodologies operate" (Conger, 2011; p. 2). Overall, the waterfall model (Royce, 1972) which consists of phases of activities where one phase is regarded as input for the next phase, is still a widely used model.

Selecting a rigorous service engineering approach was challenging as dynamic methodologies and processes have only just begun to emerge in the literature (Conger, 2011; Kohlborn et al., 2009). Further, it has been suggested that existing software engineering practices and methods may not be appropriate for service engineering per se (Papazoglou et al., 2008). Recent examples of service engineering methodologies that we were able to identify emerged from earlier research on Service Level Management (Sturm et al., 2003), IT Service Management Forum (ITSMF, 2004) or International Standards Organization (ISO) on IT Service Management (ISO 20000, 2005). In many cases, these studies are either highly conceptual (Chesbrough \& Spohrer, 2006; Gupta and Prakash, 2001; Korthaus et al., 2007) or designed for a particular context (Teubner, 2007) and not specifically for global human resources sourcing. Some may cover only a subset of the life-cycle (Kohlborn et al., 2009). Further, much of the work we are reporting on was highly innovative at the time, and predated the publication of these more recently published guidelines (Conger et al., 2011). There 
is one reasonably well-cited web services development life cycle (Papazoglou et al. 2008) that represents a good fit to our lived experience of e-HRM service design and implementation that we have used to frame our methodology discussion (Figure 1).

Business Domain
Business Processes
(HR sourcing)

\section{Figure 1 \\ Services design for global human resources sourcing (adjusted from Papazoglou et al. 2008)}

This model splits service engineering into a logical layer consisting of the business domain (for example, sales, or here: human resources), and the business processes (for example, purchasing, or here: recruiting). Typically, each business process is supported by business services. In global human-capital or staffing sourcing for example, there is the creation, modification and deletion of job and applicant profiles, and related actions and transformations. In terms of the lower three layers of Figure 1, this marks the transition to the physical layer, with conceptual design of infrastructure services that are realised in semantic web components to be used by multiple channels, organisations, individuals and communities.

For our service development, design and delivery, we developed a service design cycle which was broadly nested in the system development life cycle, adapted extensively for our particular human-resource services context. As shown below, our approach converges with the web services development life cycle hierarchy of Papazoglou et al. (2008), which was developed independently. The method could be viewed as an iterative process view of the layered model proposed by Papazoglou (2008). This gives us additional confidence in the 
rigour and efficacy of our method. An overview of our method is included as Figure 2. We then describe the various phases of the project in order to contextualise the artifacts that we present following this overview.

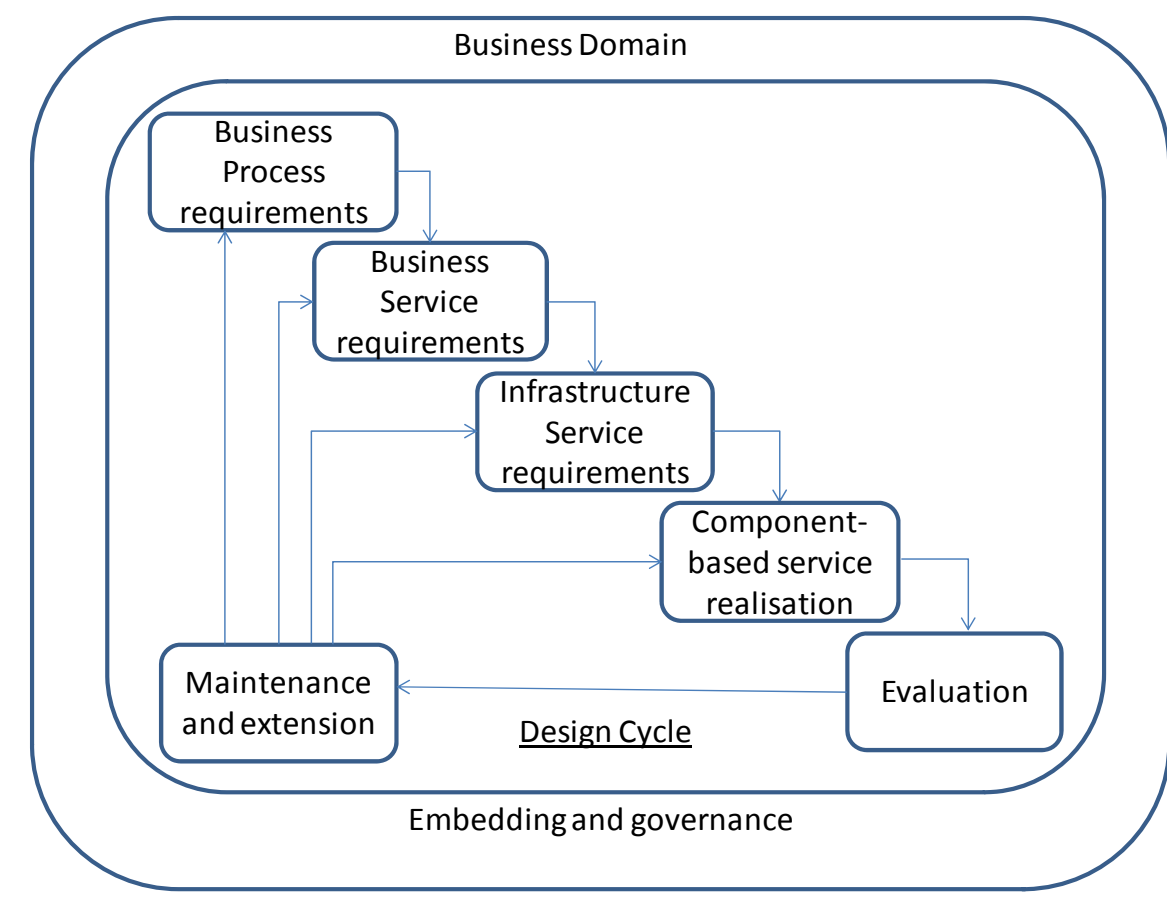

Figure 2

Services development method for global human resources sourcing

The business domain for the research is strategic global HR management, including recruiting. Research in strategic HRM is increasingly focussed on the efficacy of the bundle of operational services with which HR management and/or strategic IT implementation is played out in practice (Lee, 2011; Schuler et al., 2010, Teece, 2009). This recognised the increasing interest and attention by global organizations to their human resource practices so that staff can be deployed flexibly and cost effectively to respond to organizational needs. Organizations require that resource requirements can be better planned and additionally, that individuals can meet their own goals, by being supported and enabled to develop their careers within the company (Hoffman \& Hoffman, 2007). This is reflected in a requirement for global 'talent management' - the ability to search the whole own organization for the availability of the needed skills in order to avoid "the costs associated with laying off people in one group while hiring the same talent into another" (p. 20). Furthermore, just as there are increasingly global recruiting requirements within global companies, there is a trend towards the free movement of labour within regional economic communities, and organizations wish to be able to access this international talent pool. Moreover, competitive business environments are driving the desire for better intra-organizational service levels and cost savings: this can be 
supported by automating parts of the personnel function, including a better integration of recruiting systems with corporate-wide business systems (Beulen, 2009).

Consequently, key staff within organizations is aware that IT-enabled staffing activities need to be integrated seamlessly along the entire recruiting process in order to take full advantage of emerging technologies and the available prospective personnel (Bondarouk \& Ruël, 2007). Research has shown that investments in IT require complementary investments in non-IT processes, structures and organizational resources to generate value (Melville, 2004) as the effects of IT resources on performance parameters result from a continuous interplay with other complementary resources (Teece et al., 1997).

For an organization's recruiting function go smoothly, it needs to support certain business processes requirements. On the organization's side this includes: advertising vacancies, matching applicants to vacancies, filtering applicants, contacting applicants, and checking on the status of latent and potential applicants. On the applicant's side this includes: filling out a digital resume and communicating relevant skills and experience, scanning for vacancies, advising on changes of status, and on the self-evaluating suitability and fit for any posted or offered positions. Although digital recruiting portals are widely used, a lot of manual intervention is still needed, which incurs unnecessary costs. For example, current processes are impeded by a lack of a unified or standardized classification system for candidates' skills and experiences, and the fact that many online resume forms make extensive use of unformatted text. This requires recruiters' time in analysing resumes in the initial screening phase. If recruiters were enabled by the system to more efficiently compare resumes' contents with job requirements (Viswesvaran, 2003), it would save time as well. Our research is therefore aimed at improved service quality through process improvement with IT, rather than organizational- process innovation. In particular, this research focuses on improving the representation of candidates' biodata; identifying and filtering job-suitable candidates, and matching potential candidates to particular jobs. These processes are aimed to support e-Recruiting services for applicants, portal providers, and employing organizations, and for national, international, and niche recruiting markets.

The business service requirements are service quality and process improvement for managing organizational staffing. While digital resumes aim to offer systematic and quicker resume screening, their actual benefits depend on the way resume fields are structured and classified, including the availability of search functions that recruiters desire (Zusman \& 
Landis, 2002). The theoretical foundations for this phase come from the (International) Human Resource Management, Services and Information Systems literature. This has identified challenges to automating personnel selection tasks such as screening resume fields across national boundaries; keeping applicant profiles current; timely response to job ads; the ability to source talent globally; and the ability to maintain contact with latent or potential job-seekers (Furtmueller et al., 2010). The e-HRM industry has been slow to meet these needs (In Lee, 2011). Currently e-HRM offerings are characterised by general job boards which typically try to serve a wide range of needs within one platform. Emerging alternatives are so called niche job-seeking portals (for example for medical or IT skills) because general purpose portals did not provide sufficiently specific or granular skill and job categories (Lee, 2007). There is also a tendency for job boards to operate as country-specific islands, rather than serving a global community.

A failure to conceptualize e-HRM as a business service has also led to ongoing issues with customer (job seeker) engagement in the recruiting process by (for example) keeping their resumes current, pre-qualifying themselves for jobs, and indicating their desired job and longer-term career aspirations. This in turn has led to a relatively stagnant e-HRM market, which has lacked the tools to develop adaptive systems that can support continuous improvement.

The infrastructure service requirements involve the specification and development of automated processes for digital resumes. This entails, for example: automated storage; searching, pre-selection; comparison and ranking of candidates; transfer of selected data to other systems; updating of resume content; and automatic reply to applicants (Bartram, 2000; Lee, 2005). Loose coupling is becoming a fundamental element of service-oriented infrastructures (Bardhan et al., 2010). The infrastructure service components identified for global human resources sourcing are: 1) a conceptual resume ontology for HR sourcing based resume content analyses and an adaptive skill ontology 2) a web crawler to search and store job ads in database; 3) a classifier to extract meta data such as job title, skills, experience, branch, location, company name, etc.; 4) a key word search function for applicant pools based on profession, region, etc. (active recruitment); 5) a (simple) matching function based on applicant profile or search assistant (passive recruitment), 6) e-Recruiting workflow, and 7) ontology enrichment and maintenance. Accordingly, we present in the remainder of the conceptual designs for a these components to support effective matching of resume content and job ad data, and strategies for system maintenance and service extension. 
Component-based service realisations represent tasks for IT service engineering the design, build and technical evaluation of the infrastructure service components. Essentially, the service-oriented paradigm is a decomposition process that results in modularity; this implies that the means to solve business problems can be broken down into smaller and more manageable components (Bardhan, 2010). We have chosen not to include formal specifications for the service components in this research report. There are two reasons for this. The first is that some components are commercially sensitive and cannot be reproduced in the public domain. The second is that the kernel theories for this stage drew on software engineering research in sematic web, ontology and workflow specification (Fensel et al, 2011). These have very large literatures that are potentially relevant but outside the scope of this paper. Further, not all aspects of this theory are equally relevant to our context. Formal modelling and workflow specification languages such as UML (Larman et al., 2004) and YAWL (Adams et al., 2011) can be used in both conceptual modelling and software development application domains, but the limitation is that they contain many constructs that are only used by software developers, so their suitability for modelling and communicating real world phenomena has been questioned (Fensel et al., 2011). Therefore, we have chosen to present conceptual designs for the components in a form that is accessible to a general audience.

Evaluating the effectiveness of a new set of service operations and their deployment, sustainability or service improvement presents a number of challenges. Design science guideline suggest that the "artifact is complete and effective when it satisfies the requirements and constraints of the problem it was meant to solve." Moreover, it needs to include "the integration of the artefact within the technical infrastructure of the business environment" (Hevner et al., 2004, p.85). Considering the wide-reaching implementation of our eRecruiting service components, and our seven years of development and re-design cycles, considerable service improvements were achieved. We are therefore confident that our developed technical service components are effective tools to meet global staffing requirements. In a traditional software engineering life-cycle, the software would be evaluated against the user requirements. Since services are aimed at a community, involving collaboration in highly distributed environments (Papazoglou et al., 2008), and need to be evolutionary and adaptive, traditional models of testing are unlikely to be appropriate for the design and deployment of such services. A number of evaluation techniques are suggested for the design science life-cycle in the human sourcing domain. These include testing using 
scenarios of use to demonstrate the utility of the artefact, and observation of the artefact in use in a business context. In this study, both techniques were applied. Conceptual evaluations were carried out on the component designs, using scenarios derived from job portals and applicant profiles. These are reported later in this paper. The technical implementations were then evaluated for their effectiveness in achieving business process improvements and are effectively implemented on e-Recruiting services around the globe (an example is http://www.uni-absolventen.at or http://fh-absolventen.at). In particular, the open source platform http://drupal.org where we share individual software components recognizes that 70,689 websites use parts of our developed Rules module and 21 organizations have installed our full e-Recruiter service package (Dec 1, 2011). It is not our intention to report on all these modules and process improvements in detail. For more detail, the reader is referred to our central developer site: http://epiqo.com/en/recruiter. In this study, we use the lessons learnt from that project for those who are planning to design context-specific similar service engineering projects in the human resources domain. For purposes of potential evaluation, figure 3 describes the relevant infrastructure service components and the criteria that were applied. A selection of these artifacts is reported below. Of these, the web crawler enables several of the other components, and is not described separately. 


\section{Infrastructure service components}

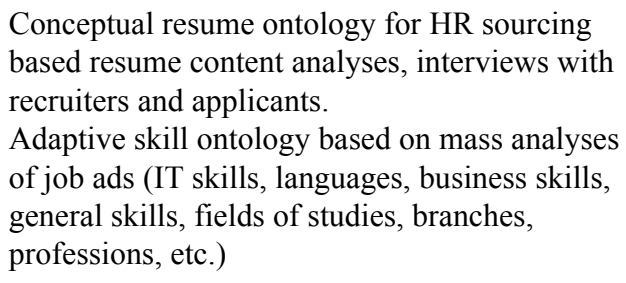

Conceptual resume ontology for HR sourcing based resume content analyses, interviews with recruiters and applicants.

Adaptive skill ontology based on mass analyses of job ads (IT skills, languages, business skills, general skills, fields of studies, branches, professions, etc.)

Web crawler to search and store job ads in database

Classifier to extract meta data such as job title, skills, experience, branch, location, company name, etc.

Intelligent and adaptive searching (in applicant
pools) based on profession, region, etc. (active
recruitment)

Simple matching function based on applicant profile or search assistant (passive recruitment)

E-Recruiting workflow

Ontology enrichment and maintenance

\section{Evaluation criteria}

Ability to classify previously unknown values for skills, languages, professions, etc.

Ability to identify jobs posted on websites and store in a database

Ability to recognise, extract and classify unstructured data and text using meta-data

Ability to return appropriate matches from applicant pools

Ability to match applicant profiles to job criteria

Ability to coordinate the sourcing processes

Ability to enrich and maintain the sourcing services

Figure 3

Infrastructure service components for e-Recruiting services

The service maintenance and extension phase is a key point of departure between service engineering and traditional software engineering. The key difference between the "goods dominated" approach to business and the "service dominant logic" is that services emerge in "open" processes where customers participate as co-producers and while goods are produced in closed production processes where the customer only perceives the goods as outcomes of the process (Grönroos \& Ravald, 2011). This is a critical difference for service component engineering vs. traditional software engineering (Vessey \& Conger, 1994).

In a traditional software life-cycle, maintenance and enhancement is something that takes place in a series of bounded and finite cycles (closed processes) after the initial implementation of the software. In a service life-cycle the components need to be able to engage with their environment in open and adaptive processes (Fielt et al., 2010). The ability to adapt, learn, self-manage and self-configure for multiple environments needs to be engineered into the components (Papazoglou et al., 2008). This means that maintenance and 
extension can no longer be considered as a separate phase of service engineering, but as a critical function that is engineered into the component design. As a result, an extension of the design science evaluation guidelines is needed if wanting to use it in service engineering contexts: given that service components are not engineered to be "complete" but must be capable of speedy extension, and are not intended to satisfy a static set of requirements, but need to be responsive to emergent requirements.

The embedding and governance phase is another point of departure from traditional models of developing and deploying IT solutions. The value of a service emerges through exchange and use. Consequently, e-Recruiting services are not valuable unless there is a high degree of adoption by recruiters and job seekers. This depends on the flexibility to span national and regional boundaries and meet the needs of a global community. The human resources ontology was designed to be adaptive and extensible at a technical level, but at a business level, the domain expertise from job seekers and recruiters needs to be continually captured and incorporated in order for the ontology to meet the needs of both recruiters and applicants. New data (skills, jobs, qualifications) need to be able to be classified into the ontology. One solution would be that a standards body, such as ISO should manage the standards. However, the limitation of this approach is that while many categories are of global interest, there is a continuously changing range of national and regional variations that may not always of relevance to a wider community. Standards classification bodies have shown to be not sufficiently agile and adaptable; they tend to restrict the rapid responsiveness required by users of e-Recruiting services.

The preferred IT-based option for this recruiting situation is to use a form of crowdsourcing service model. We utilise both recruiters and users of the service to participate in the classification of the continuously emerging new data. Using this option enables recruiters, globally, to tap into specific local knowledge. Applying crowdsourcing greatly reduces the requirement for individual organisations with a need to recruit to stay informed about skills of global applicants and industry recruiting practices. Collective maintenance of the ontology will also encourage the on-going dialogue that is desired between applicants and recruiters within and between markets. 


\section{Selected e-HRM Service Artifacts}

In this section, we report on selected artifacts from our seven year project of developing, deploying and managing e-HRM services. Given the multiple deliverables of this e-Recruiting design project, it is not possible to reproduce all the documents as artifacts in this report. Some of the artifacts are commercially sensitive. Hevner et al. (2004) encourage collaborative industry/academic research and publication of relevant knowledge emerging from such projects. Through our presentation of the technology specification for global staffing services we aim to accelerate the development of independent and scalable solutions of large-scale global staffing systems. Since formal software specification systems and notations tend to suffer from a lack of intelligibility to the general reader, we decided not to include technical specification of the HR ontology and workflow that would add formal languages to this paper. The problem of effective communication and understanding among stakeholders involved in design, development, implementation, usage and refinement of recruiting artifacts is acknowledged within the software engineering community. We chose to communicate the results of design science research to both a technical and HR management audience, at the same time. We have adopted "UML-like" diagramming conventions for the representation of a simplified resume knowledge representation and some principles from YAWL in our workflow diagrams. This approach has of necessity required some trade-offs in the rigorous formal specification of the solutions. In the remainder, we first present a conceptual knowledge framework for relevant digital resume content, followed by a discussion on the extraction of relevant meta data during selection processes and classifying requirements. After providing conceptual solution approaches to these issues, we present a workflow for resume searching, maintenance and extension of information services to address global staffing needs.

\section{Conceptual ontology for HR sourcing and digital resume design}

We synthesized knowledge for the development of the conceptual representation of resume forms based on: analyses of personnel selection and resume literature; interviews with recruiters (Furtmueller et al., 2011, Ettinger et al. 2009); interviews with (lead user) applicants (Furtmueller et al., 2010), content analyzing resume forms on 40 e-Recruiting systems; and usability testing of resume forms (Jansen et al., 2008). In some cases, we returned to the literature after our data gathering and analysis cycles to further explicate findings. This allowed us to contextualize our study and to note where our findings diverge from those of previous researchers. Two coders who are experienced in handling digital 
resume forms developed the initial resume fields based on the available literature on personnel selection. We then asked two practicing recruiters to review these categories for understandability and suitability of label description and relevance. Also the three authors of this paper reviewed the proposed resume field categorization. We then studied 40 eRecruiting sites and discovered many overlaps in resume field and subfield classification. However they also differed significantly in the content, labeling and extensiveness of resume fields. For instance, some included a field only for the most recent professional work experience while others provided the option to fill in multiple work experiences. Similarly, educational levels, skills, job titles and demographic data were clustered in various ways across the studied e-Recruiting services. We noted that existing resume forms used many variations of unstructured textboxes, checkboxes or select boxes. Not all systems included all relevant fields suggested in the literature, and some fields were not easily searchable using criteria relevant for recruiters, due to their unstructured format. Therefore, we needed a systematic and implementable ontology.

We present a synthesis of the most commonly required resume fields (see Fig. 4). Every resume field is presented in a box, with the title and multiplicity shown in the table header. The multiplicity shows how many times the box can be filled-in. For example, an applicant can fill-in no work experience, or multiple work experiences $\left(0 \ldots{ }^{*}\right)$. Personal information can only be filled-in once (1). Further, the fields (attributes) and their field types and input options are given. The type of the field is included if this is not a text field (for example Select). "Select" means that the applicant has to select an option from a drop-down menu; the options are given in brackets. Select fields are important for the subsequent use of online resume data by recruiters, as they can be searched on, due to their structured format.

The most relevant resume fields for recruiters using digital resume databases for applicant searching and matching are: career status, desired job, education, work experience, extracurricular activities, skills, personal information and contact information. We enriched previous academic literature with two specific relevant resume fields: career status and desired job.

Current career status (actively looking for a new job; has job but open to new job offers, currently not available) makes it virtually effortless to quickly sort out applicants that are not suitable for the open position. Effective management of online resume data should include regular prompting of applicants to confirm if their details are correct and if they are still job-hunting. 
The "desired job" category gives the recruiter information as to whether an applicant would have an active interest in an offered job; this is important given that applicants apply to many organizations since the emergence of online recruiting services, without clearly laying out their specific interest to work for a specific organization (see also Furtmueller et al., 2011). Our proposed conceptual ontology meets the requirement for smarter key word searching, as it systematizes a number of fields that were previously presented as unstructured text.

A critical insight from this analysis is that service-oriented staffing needs to include a highly transient, ongoing conversation and exchange: the e-HRM service can test and prequalify the relative value an applicant has on the job market, which enables much better targeting of applications. This is highly beneficial for both the applicant and the organisation. Similarly, Malinowski et al. (2006) argue that a good match between a candidate and a job needs to be bilateral as it requires considering both applicant and recruiter preferences.

Many providers try to solve the challenge of the exchange-based nature - which is inherited in recruiting services - by accumulating masses of resumes. Accordingly, more suitable applicant profiles are available for the same job offers. The problem of outdated profiles is however not solved this way since registered applicants have often already found a job or their contact data has changed. Therefore, a major design challenge in enabling serviceoriented staffing is to implement features to motivate applicants to keep their resume profiles up-to-date. Some research suggests enhancing playfulness, implement skill competitions and ranking of applicants compared to other registered applicants on career sites (Furtmueller et al., 2010). 


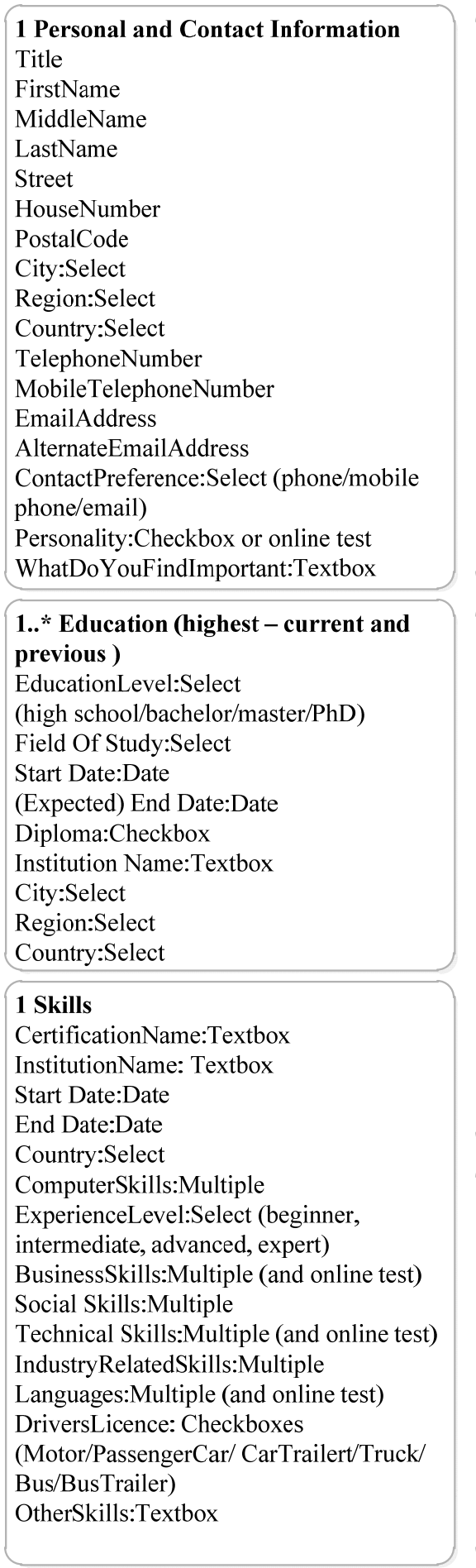

\section{Career Status}

CareerStatus:Select

(actively looking for a job, has job but

open to new opportunities, not available)

Resume (date created)

Resume (date updated)

EligibilityToWorkInCountry:Select

CurrentOrLastJobTitle

CurrentOrLastEmployer

CurrentOrLastSalary:Amount:Integer,

Period:Select (hour,day,month,year),

Industry:Checkbox

CareerLevel:Select

(high school, bachelor, master, entry level, experienced (non-manager), experienced

(manager), manager, executive, senior

executive)

EducationLevel:Select

YearsOfProfessionalWorkExperience

..*Work experience
JobTitle:Select
CompanyName
Industry:Select
BusinessArea:Select
City:Select
Country:Select
StartDate:Date
EndDate:Date
CurrentPosition:Checkbox
JobDescription:Textbox
JobResponsibilities:Textbox
AchievementsAndAccomplishments:Text
box
LearnedSkills:Textbox
SupervisoryPosition:Checkbox
InternshipExperience: :Textbox
References:Upload

\section{Extra Activity}

Memberships:Multiple

OrganisationName:Textbox

StartDate:Date

EndDate:Date

ExtraActivities:Textbox:Date

Volunteering:Textbox:Date

HonorsAndAwards:Multiple

Description:Textbox:Date

ProfessionalPresentations:Multiple:Date

ProfessionalPublications:Multiple: Date

HobbiesAndInterests:TextBox

OtherActivities:Textbox

\section{Desired Job}

Description:Textbox

Industry:Checkbox

BusinessArea:Checkbox

CompanyType:Checkbox

(public/private/nonprofit)

Job Status:Checkbox

(fulltime, part-time, project)

JobType:Checkbox

(employee, temporary, internship, seasonal, volunteer)

MinimumHoursPerWeek:Integer

MaximumHoursPerWeek:Integer

StartAvailability:Date

EndAvailability: Date

MinimumSalary:Amount:Integer

Currency:Select

JobTitlesYouWant:Textbox

JobTitlesYouDontWant:Checkbox

CompaniesWhereYouWantTo

Work:Checkbox

CompaniesWhereYouDon'tWantTo

Work:Checkbox

MinimumCompanySize:Integer

MaximumCompanySize:Integer

FringeBenefits:Textbox

MinimumEducationLevel:Select

DiversityPolicy:Checkbox

(job for person older than 45, disabled person, foreigners)

PreparedToMove:Checkbox

TravelDistance:Integer

MaxDaysPerMonthAwayFromHome: Integer

DesiredLocations:Multiple

Country:Select

City:Select

WorkJurisdiction:Checkbox

\section{Figure 4 \\ Conceptual ontology for digital resumes}

\section{Classification to extract relevant meta-data during the selection processes}

Enacting useful applications of digital resumes requires more than just a conceptual knowledge engineering framework. The framework must be sophisticated and able to support a network of inter-related classifications. A process is required for structuring and classifying 
unstructured job and applicant data in conformance with the knowledge engineering framework. Classification issues are complex and require the ability to link specific information provided by applicants (for example, competency in a specific programming language) with the general skills required by recruiters (for example, knowledge of an objectoriented programming language (Malinkowski et al., 2006). One of the advantages of UML for knowledge engineering is that it supports multiple inheritances from different classes. This supports the complex matching required between recruiters' requirements and resume information. This is illustrated in Figure 5. This shows $C++$ as a subset of both programming languages and object-oriented languages, so that applicants with $C++$ skills would be returned by searches on either category.

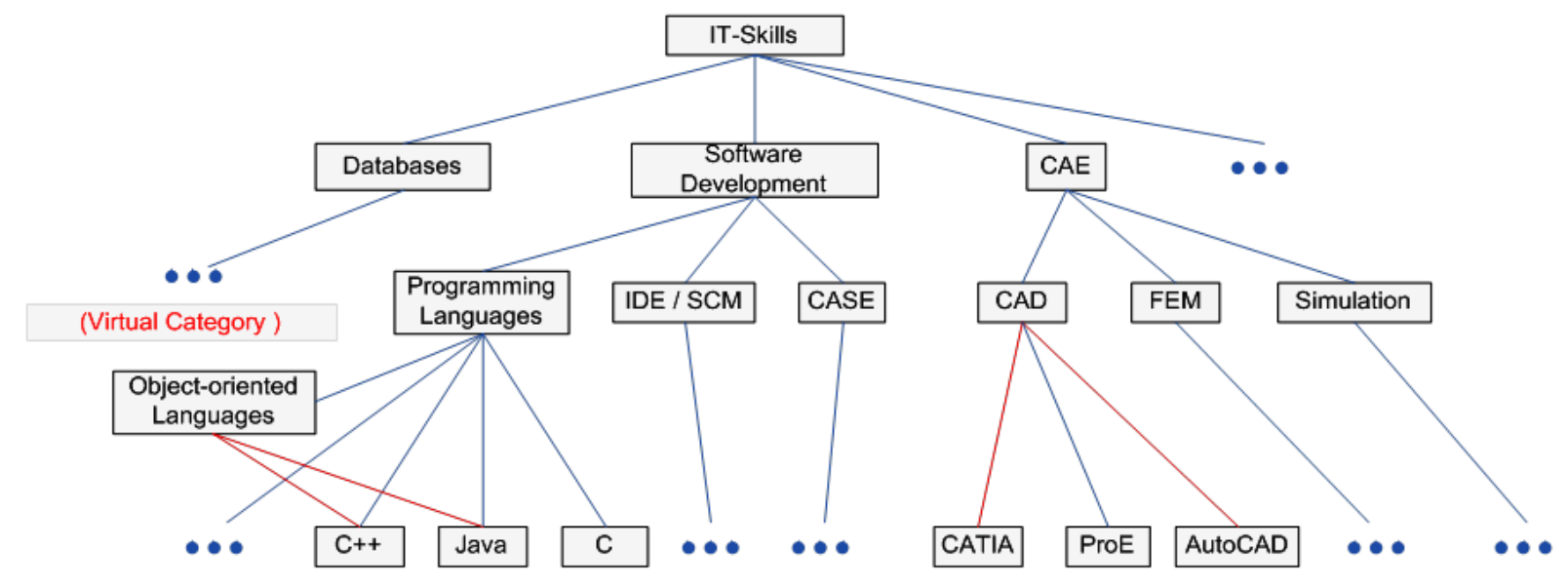

Figure 5

Classification outline IT skills

Ontology research provides fertile ground for structuring such data used in personnel information systems. The provision of domain-based human resources representation schemes to facilitate automated reasoning and selection is essential (Bardhan et al., 2010). Because semantics require commonality and rigor with domain specific phrases, words, and concepts, it appears logical that organizations, branches and industries need to (continuously) devise their semantics for employee sourcing. While literature discusses using semantic web in eRecruiting (Falk et al., 2006; Malinkowski et al., 2006), most of this research assumes that job ads are already available in semantically usable forms (including RDF information). Yet, over $90 \%$ of digital job ads consist of unstructured HTML or PDF text. The deficiencies of a website's machine processing ability result from the inability of current web technologies, such as HTML, to semantically annotate the content of a given website. While computers can 
easily display the content of an HTML site, they lack the ability to interpret the content properly and to provide effective matching between applicants and jobs.

\section{Intelligent and adaptive searching}

Recruiters benefit from improved search options when screening online resumes. For example, a recruiter may be looking for a candidate that Java, However, knowledge of a programming language occurs in a range from novice to expert, and different users will interpret their skill level differently. The intelligent and adaptive search function can prioritize applicants' level of Java knowledge into various excellence levels. Skill tests may be included when filling in resume forms to get more objective comparison of resume content data. The intelligent resume screening system will also recommend applicants to recruiters who filled in related skills, i.e. Java is an object-oriented programming language, and so if the user fills in another object-oriented programming language, this applicant may be also recommended by the system, however ranked on a lower matching level (Resnick \& Varian, 1997). Results for search queries should be ranked based on similarity of the initial search query with the applicant profile.

Intelligent searching and matching also supports adaptive profile design, i.e. if an applicant fills out computer science as education, then more IT skills should be suggested by the system; if one fills out a law degree, more specific law skills should be suggested by the resume form. As many online resume forms are not filled out completely, fast loading resume forms using for instance JavaScript and Ajax are needed to motivate applicants to fill out their full profiles. Page loading time needs to be minimized to enable quick inserting of resume content data (Braddy et al., 2009).

This dynamic approach, supported by an adaptive searching and matching function, enables a digital "dialogue" between the recruiting software and the applicant, which is similar to that normally conducted by human agents. Information relevant to the position can be solicited iteratively, and refined and clarified, rather than simply representing an applicant's "best guess" of what is required. This is beneficial to the applicant (in that they are able to give the most complete information relevant to the position) and the recruiter (in that they are able to achieve more accurate and nuanced filtering of candidates. 


\section{Job and applicant matching}

In order to address these problems, first unstructured job ads need to be converted into machine-readable format (i.e. information extraction) so as to enable efficient processing (saving structured data in job ad databases or transfer to other systems via HR-XML). Currently manual classification is prevalent which mostly requires administrative assistants to classify job ads into job category, branch, type of employment and region. More sophisticated classifications into detailed education type or job-related experience and skills had, to our knowledge, not been accomplished by recruiting software previous to our project. Figure 6 presents the currently widely used manual structuring process of applicant and job ad data.

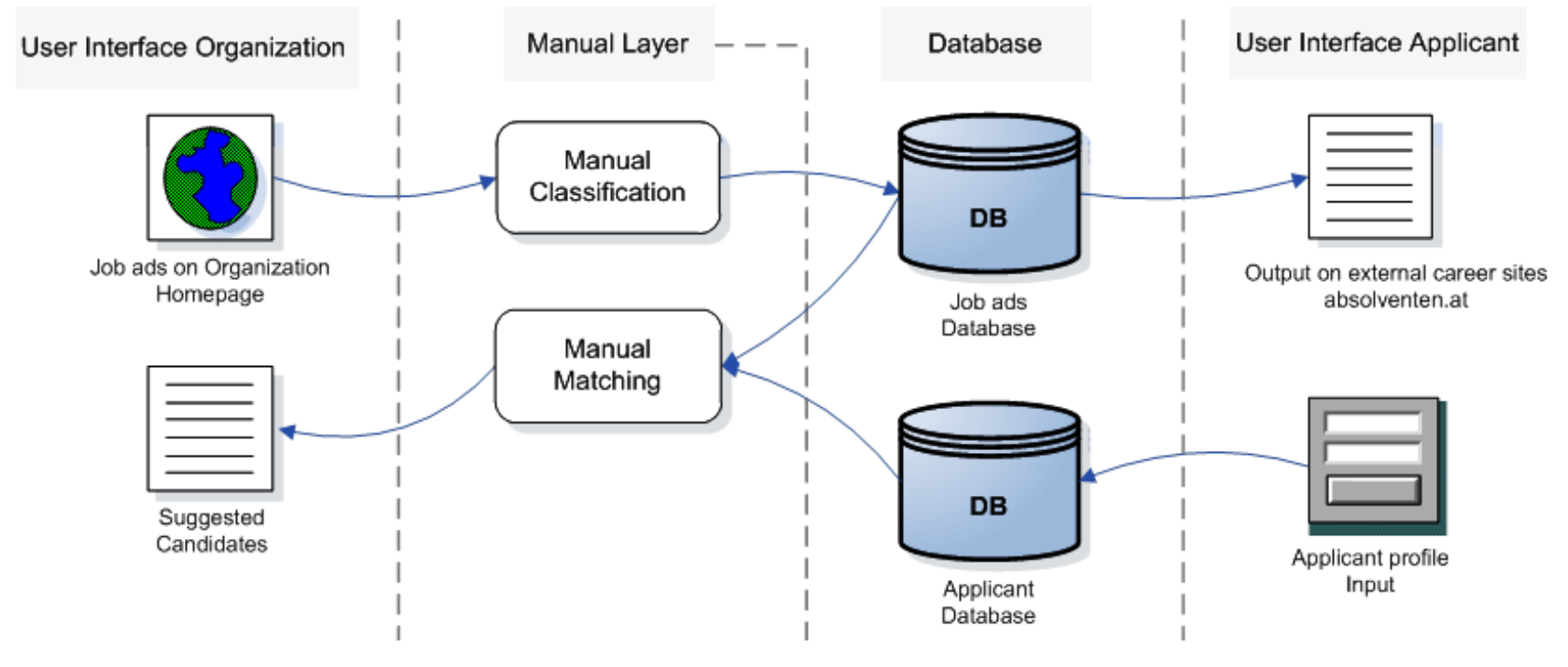

Figure 6

Manual classification of applicant and job ad data (before automation)

In order to enable automatic matching, a machine-readable format needs to be reached. Using information extraction procedures the result is a semantically structured job ad (see Figure 7). In the case of applicant data, this data should be collected through structured resume data. Following this, structured data from jobs ads and resumes are stored in the relevant databases. Filters allow various outputs on websites, (e.g. filter candidates with geology education or with more than 10 years in senior executive roles) or deliver relevant matching data via RSS to job applicants and recruiters. In carefully observing and analysing the technical and market operations of various career portals, we found evidence that extending job ad and resume content with semantics clearly contributes to applicants and recruiters improved search experience, precision, usability and consequently, services delivery. 


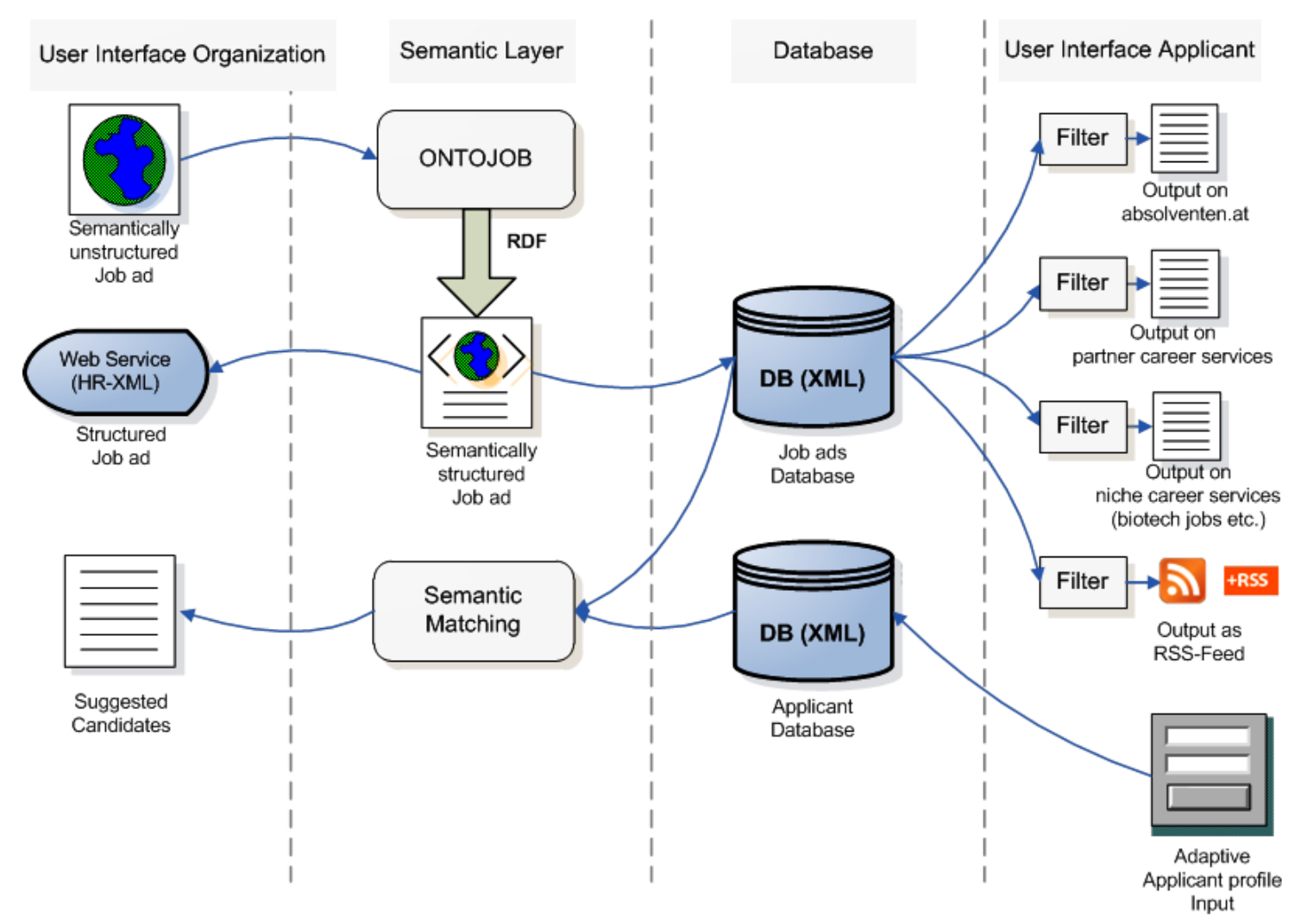

Figure 7

Semantic classification of applicant and job ad data (after automation)

Semantic matching is a technique which combines annotations using controlled vocabularies with background knowledge about a certain application domain. Using Semantic Web technologies (Fensel et al., 2011) in the domain of e-Recruitment can overcome the problems of job ad distribution and difficulties with machine processability of existing job and applicant data information. This can substantially increase market transparency, lower transaction costs and speed up the recruitment process of organizations. Researchers and HR practitioners are becoming increasingly aware of the need for serious engagement with human resources ontology, understood as a general theory of the types of entities and relations making up their respective domains of enquiry (i.e. ontology for computer skills, language and other aspects of resumes), to provide a solid agreed upon foundation for their work (Weitzel et al., 2009).

\section{e-Recruiting workflow and services maintenance}

Since any classification system will be incomplete, a workflow is required for applying and enhancing the framework as part of its ongoing use. Also the HR ontology needs to be maintained and extended in response to new jobs, resumes and other categories. A proposed e-Recruiting workflow is described in figure 8. In the first phase of the realization, a 
sophisticated web crawler that continuously searches online for new listed jobs, stores them in a job ad database and uses ontology for classification is required. Following, a wrapper coverts unstructured HTML or PDF into XML using rules framework with a-priori knowledge. The maximum information extraction currently possible from job ads takes place. A term filter should analyse all terms of job ads and should check if the current HR ontology already knows terms. If the system does not know some of the terms, these should be put into a separate group which we call greylist. Various methods are useful to give meaning to terms placed in the greylist: use of Wikipedia or wordnet; context tuning (determining probability percentage for adding an unknown term); and checking co-occurrence (giving weights to related terms). In a system which we label merger, the different context suggestions get harmonized so as to enable a collaborative process in the next step. Thereafter, users (i.e. applicants, recruiters, developers) are invited to help in the categorization processes of unknown terms. The final step is a collaboration filter that sorts the most appropriate classification by users and places the new term in the HR ontology is a certain significance threshold is reached. The suggested workflow implies that recruiting services provide (at least) two-way information about the core competencies and skills of applicants and organizations. The proposed services aim to match applicants with job ads in a mutually beneficial way. Negotiating and performing a job involves two parties in reaching agreement on terms and conditions that provide a compelling value proposition; and both organizations and applicants require marketplace feedback to determine whether their expectations are realistic. Accordingly, e-Recruiting services should facilitate a more timely and on-going exchange of information among and between stakeholder groups. A major difficulty arises since not all registered applicants in applicant pools are currently available, but they may still wish to keep in touch with organisations that are of interest to them as future employers. To date, organisations waste a great deal of time reviewing pools of out-of-date resumes. The ability for applicants to communicate their real-time job-seeking status, desired job attributes and tracking applicants changing career status is therefore paramount for effective digital recruiting (Mochol et al., 2007). Further, applicants may not be aware how their skills and experience compare with others, so a self-evaluation service for applicants may both increase the likelihood that suitably qualified people apply for jobs, and that applicants could achieve their career aspirations. Also applicants are confronted with a range of challenges: often job ads are outdated; the job was already given to someone; organizations may leave job ads online to collect resumes for later usage while applicants desire a job at the moment of online searching; or organizations post jobs ads to pretend organizational growth and success. 
Organizations must learn to harness real-time resume and job ad data and develop efficient feedback mechanisms for product development, customer service, and resource allocation.

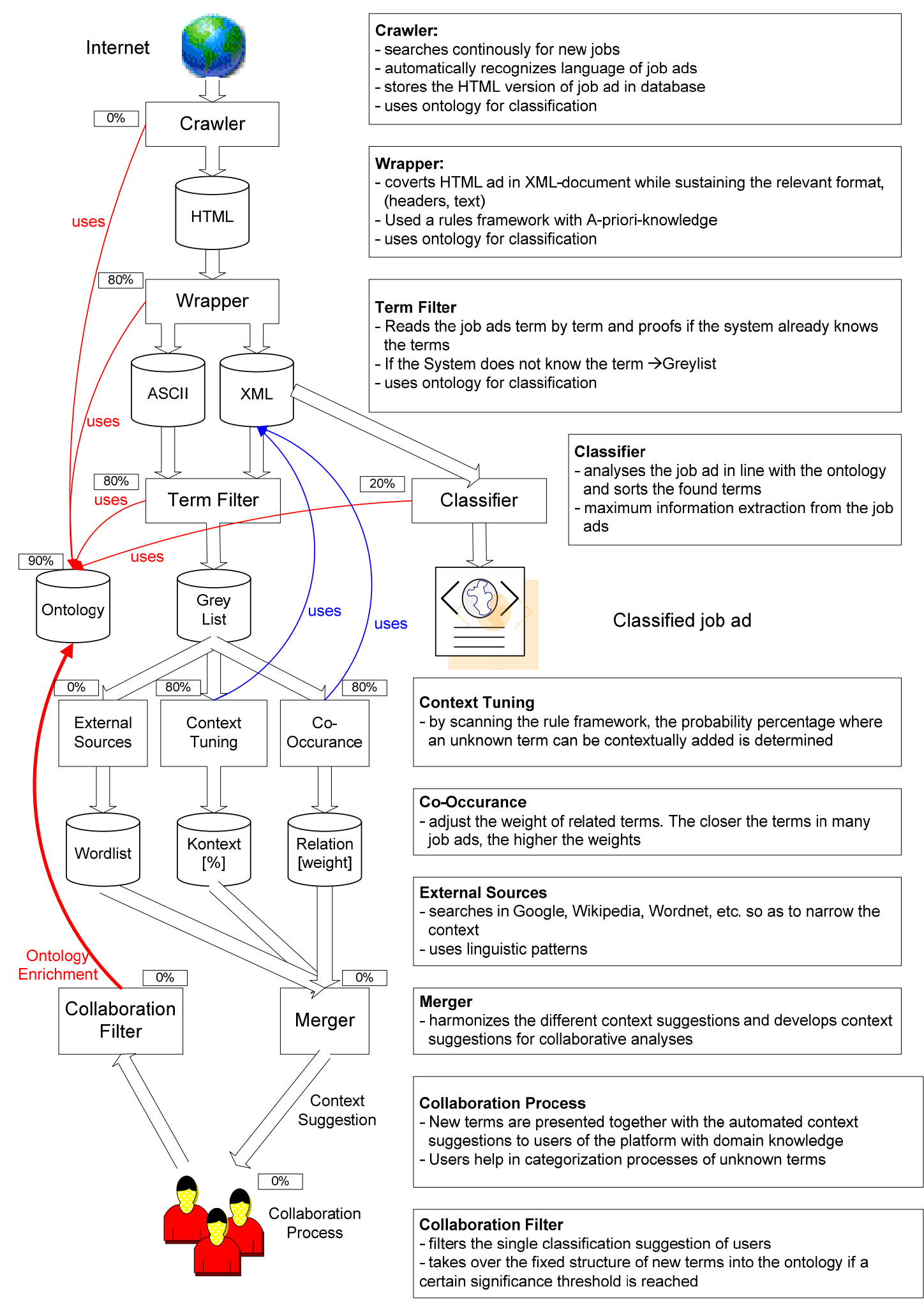

Figure 8

E-Recruiting workflow 


\section{Discussion}

In this section we contextualise our research within strategic HR-sourcing and service-science and design science literature. In order to create business value, the IT-services we have described - and a service orientation in the HR function - need to be embraced by HR practitioners. The success of the portal project has offered a number of insights into the ways in which IT-based services translate into improved business processes and a mutually beneficial exchange between job-seekers and organizations. This is enabled by the technology, but does not happen automatically; it requires a perspective shift by recruiters. For example, rather than seeing the long life of digital resumes as a disadvantage of digital recruiting, if more attention is paid to service-oriented resume design as we describe, it can add value for both parties. Properly managed, e-HRM services can transition recruiting from a "deal" between applicant and organization based around a specific position, to a "relationship" between individuals and organizations, based on ongoing communication and negotiation about person-position fit.

Digital recruiting services make it easy for applicants to send their resumes but become rapidly outdated. It is frustrating for recruiters to identify perfect candidates with active-appearing resumes who are nonresponsive due to changed circumstances in their career status (Feldman \& Klaas, 2002; Lin \& Stasinskaya, 2002). When recruiters receive print resumes, after an initial screening they reply with a rejection or an invitation to submit more documents for additional screening or an invitation for an interview or further testing. In the offline context, the applicant is usually removed from the pool of applications except the organization keeps resumes stored for later possible jobs interviews. In contrast, in the digital context, resumes can be stored lifelong. This offers the potential for a dialogue with candidates of potential interest to the organisation.

In order to achieve this, various career states should be recorded to the applicant to indicate if they are willing to interview at a certain time (e.g. available on, currently not available, latent jobs seeker i.e. open for job offers however currently in a job). This example demonstrates the importance of the interaction of technology, organisations, and applicants in co-creating value (Grönroos \& Ravald, 2011). The technology offers persistent data, the ability to record career state, and searchability, but both organisations and applicants must move from a "deal-oriented" view of job seeking to a "relationship-oriented" view for this innovation to add value for them. 
A service-oriented approach can allow recruiters to deliver value for candidates by offering services that build trust. A recent innovation is the creation of private (for applicants and friends of applicants and public (for HR recruiters) spaces of the applicant profile. This allows to e-Recruiting services to enable social network functionality among registered users (Brown \& Vaughn, 2011). This functionality fosters engagement, builds trust, and wards off the fear that personalized resume data will be misused.

As we mentioned earlier, the engagement of the practitioner community in "crowdsourcing" the maintenance and extension of the ontology (standardized vocabulary) for e-HRM has been critical to its success. As reported by other researchers (Malinkowski et al., 2006), a major challenge for effective recruiting is to establish a standardized vocabulary for resume and job ad content. Our research clearly revealed that online resume forms use many different synonyms for the same resume field. For instance, some career services ask applicants to fill in their earliest possible working start date, others the earliest beginning date or job enter date - terms which all relate to the same construct. Some information services request applicants to fill in exact day of the month whereas others require filling in 'start month' and year. The development of an adaptive skills ontology reflecting applicants' various hard skills such as computer or language skills was challenging (Weitzel et al., 2009), yet systematically structuring soft, social and leadership skills to enable effective prescreening of resumes was even more challenging. Skill ontologies for the HR domain require ongoing adjustments by their user community to organizational and regional needs.

This study offers an early example of a successful large scale service engineering project. Since the project pre-dated emerging research literature on service engineering methodologies, we relied on previous knowledge of software engineering, reflective practice, and continuous evaluation to inform our approach. The life-cycle we followed also constitutes a research contribution.

Although conceptual methods are beginning to emerge in the literature, relatively few have been trialed in large-scale projects. We refer to the conceptual model of service engineering previously presented. Our experience suggests that effective service design and deployment requires a multi-disciplinary approach that "slices" each layer. This presents a number of challenges as each layer has its own research literature, specialized skill-set and vocabularies. Leadership which can traverse and integrate the contributions required from each layer is essential, and will likely require a new generation of service managers with an understanding of how to integrate business and IT contributions. 
We have presented a version of this conceptual model as a high-level methodology (Figure 2). The convergence between our effective practice and the emerging research literature gives confidence in both the rigour of our methods, and provides some empirical evidence in support of the emerging theoretical models. We also note that especially in the early stages, there is some similarity with existing software development methodologies. In our view, service-oriented engineering and software engineering diverge most in what we have described as the maintenance and extension phase and the embedding and governance phase. Traditional information systems can be seen as a punctuated equilibrium - a version of the system is designed and implemented, and then remains static until the next round of "enhancements".

Service oriented technologies, by contrast, should be designed to be inherently learning and adaptive to their environment. The ontology, supported by the classifier and workflow that we have presented are dynamically extensible; can add new skills; and can facilitate negotiation and dialogue between applicants and recruiters without requiring a system enhancement - these capabilities are in-built. Similarly, the embedding and governance phase is a major point of departure from traditional systems development. Service oriented IT systems are not "implemented" in the traditional sense. They are either appropriated and/or embedded in their community (in which case they are successful), or they are not.

Without continuous extension arising from use by applicants and recruiters, and the ability to crowdsource knowledge about new jobs, skills, qualifications, and other categories in the ontology, our solutions could not create value. The on-going management and governance is distributed into the user community. 


\section{Future Research}

We have presented a solution that is adaptive to different categories of skills and experience. A future area of research is to enhance the solution to enable multi-cultural and multi-lingual capabilities. There is a strong motivation for this. In order to globalize staffing services and attract high quality applications from a global labor pool, open job ads currently need to be published online in one commonly accepted language (e.g. English) or to be translated in the applicants' local or preferred language. Doing such translation is manually not cost-effective.

Global e-Recruiting services need to be enhanced to include automatic translation and matching services of relevant job ad and resume content. Such systems may increasingly motivate applicants to apply to jobs across boundaries and enable organizations to find the best available candidate for an opening. Organizations that aim to expand to another country may get a quick overview on, for instance, where most chemical engineers or IT experts live.

There are significant points of departure from traditional systems development and implementation particularly in the maintenance and extension, embedding and governance phases. We offer some preliminary insights from a successful project. This suggests that existing knowledge about system implementation, maintenance and governance is not appropriate in a services context. Further research is recommended into effective practices to promote and manage the diffusion and embedding of new IT services.

\section{Conclusion}

We recall that this project aimed to demonstrate how a service-oriented approach to eHRM systems enabled business process improvement and more effective global HR management and sourcing. Using a multidisciplinary design-science lens embedded in HRM and service engineering literature, we presented in this paper technology artifacts for automating organizations staffing services. While sound service-oriented architecture is critical to the successful development of complex systems and seamless integration with other systems, it has not been well established for organizations' IT-enabled human resources and recruiting practices. Filtering resumes and identifying suitable applicants that are actually interested in open positions, remains a depressingly hit-or-miss process. In this study, we identified some of the reasons why this is the case, and proposed some solutions.

The theoretical implications our results are to bring together the concepts of eRecruiting services architecture and the options that are inherent in the dynamic design and 
operation of market structures, processes and workflows for strategic human resources souring. These solutions are innovative and offer a way forward for known issues identified by e-HRM researchers, such as: developing and maintaining a consistent, extensible, and learning vocabulary and matching process; bridging the boundaries between researchers, developers, recruiters and applicants; managing the long-life of digital resumes and leveraging this into a dialogue between recruiters and applicants; crowdsourcing local knowledge of skills and qualifications; and offering the potential for greater automation of many currently manual functions.

This research is useful for organizations to more effectively coordinate recruiting processes; internationally-oriented strategists who need to optimize global recruiting services; designers and developers of service-oriented staffing systems; and academics engaged in Strategic e-HRM type research. We also offer some general insights based on our experience of a large, successful service development project, for methodologies for IT service development, and areas of future research in managing service development projects.

Many challenges remain. There is a future requirement to classify resume information across various languages, industries, countries and laws affecting the job search and hiring process (Ruel et al., 2004). Service development of this nature requires diverse resources from many fields, and orchestrating them can be very challenging. We hope our experience will stimulate knowledge sharing across organizations, industries, cultural boundaries and disciplines for more effective e-Recruiting services design, and more effective approaches to service design in other business domains. 


\section{References}

Adams, M., Hofstede, A.H.M. \& La Rosa, M. 2011. Open Source Software for Workflow Management: The Case of YAWL. IEEE Software, 28(3): 16-19.

Bardhan, I., Demirkan, H., Kannan, P.K., Kauffman, R.J. \& Sougstad, R. 2010. An Interdisciplinary Perspective on IT Services Management and Services Science. Journal of Management Information Systems, 26(4): 13-65.

Bartram, D. 2000. Internet recruitment and selection: Kissing frogs to find princes. International Journal of Selection and Assessment, 8(4): 261-274.

Beulen, E. 2009. The contribution of a global service provider's Human Resources Information System (HRIS) to staff retention in emerging markets: Comparing issues and implications in six developing countries. Information Technology \& People, 22(3): 270288.

Bondarouk, T. \& Ruël, H. 2008. HRM systems for successful information technology implementation: evidence from three case studies. European Management Journal, 26(3): 153-165.

Bondarouk, T. \& Ruel, H. 2009. Electronic human resource management: Challenges in the digital era. International Journal of Human Resource Management, (20): 505-514.

Braddy, P.W., Meade, A.W., Michael, J.J. \& Fleenor, J.W. 2009. Internet recruiting: Effects of website content features on viewers' perceptions of organizational culture. International Journal of Selection and Assessment, 17(1): 19-34.

Brown, V. \& Vaughn, E. 2011. The writing on the (facebook) wall: The use of social networking sites in hiring decisions. Journal of Business and Psychology, 26(2): 219225.

Brynjoslfsson, T., Feller, F., Pope, A., Emerson, B. \& Murphy, C. 2008. Designing a core of IT artifact for knowledge management systems using participatory action research in a government and a non-government organization. Journal of Strategic Information Systems, 17(4): 249-267.

Chesbrough, H. \& Spohrer, J. 2006. A Research Manifesto for Services Science. Communications of the ACM, 49(7): 35-40.

Collings, D., Scullion, H. \& Dowling, P. 2009. Global staffing: A review and thematic agenda. International Journal of Human Resource Management, 20(6): 1253-1272.

Conger, S. 2011. Software development life cycles and Methodologies: Fixing the Old and Adopting the New. International Journal of Information Technologies and Systems Approach, 4(1): 1-22.

Davis, M.D., Spohrer, J.C. \& Maglio, P.P. 2011. Guest editorial: How technology is changing the design and delivery of Services, Operations Management Research, 4: 1-5.

Demirkan, H., Spohrer, J. \& Krishna, V. (Eds.). 2011. The Science of Service Systems. In Series: Service Science: Research and Innovations in the Service Economy, Springer.

Ettinger, E., Wilderom, C. \& Ruel, H. 2009. Web recruiters service quality criteria: a content analysis. Proceedings of the International Conference on System Science. Hawaii.

Falk, T., Heese, R., Kaspar, C., Mochol, M., Pfeiffer, D., Thygs, M. \& Tolksdorf, R. 2006. Semantic web technologies in job recruitment processes. Informatik Spektrum, 29(3): 201-209.

Feldman, D.C. \& Klaas, B.S. 2002. Internet job hunting: A field study of applicant experiences with on-line recruiting. Human Resource Management, 41(2): 175-192.

Fensel, D., Facca, F.M. Simperl, E. \& Toma, I. 2011. Semantic Web Services. Heidelberg: Springer. 
Fielt, E., Korthaus, A.I, Kohlborn, T.S. \& Rosemann, M. 2010. Sourcing business and software services. Proceedings of the 14th Pacific Asia Conference on Information Systems, 1890-1897, Taipei, Taiwan: National Taiwan University.

Fredriksson, R., Barner-Rasmussen,W. \& Piekkari, R. 2006. The multinational corporation as a multilingual organization: The notion of a common corporate language. Corporate Communications An International Journal, 11: 406-423.

Furtmueller, E., Wilderom, C. \& van Dick, R. 2009. Utilizing the Lead User Method for promoting Innovation in e-Recruiting. In: Handbook of Research on E-Transformation and Human Resources Management Technologies. (Ed.) T.V. Bondarouk, H.J.M. Ruël, E. Oiry and K. Guiderdoni-Jourdan, 251-273. New York: Information Science Reference.

Furtmueller, E., Wilderom, C. \& van Dick, R. 2010. Sustainable e-Recruiting portals: How to motivate applicants to stay connected throughout their careers? International Journal of Technology and Human Interaction, 6(3): 1-20.

Furtmueller, E. Wilderom, C. \& Tate, M., 2011. Managing recruitment and selection in the digital age: e-HRM and resumes. Human Systems Management, 30:1-17.

Gardner, S.D., Lepak, D.P. \& Bartol, K.M. 2003. Virtual HR: The impact of information technology on the human resource professional. Journal of Vocational Behavior, 63(2): 159-179.

Gregor, S., Martin, M., Fernandez, W., Stern, S. \& Vitale, M., 2006. The transformational dimension in the realization of business value from information technology. Journal of Strategic Information Systems, 15: 249-270.

Grönroos, C. \& Ravald, A. 2011. Service Business Logic: Implications for Value Creation and Marketing. Journal of Service Management, 22(1): 5-22.

Gueutal, H.G. \& Stone, D.L. 2005. The brave new world of eHR: human resources management in the digital age. San Francisco, CA: Jossey-Bass.

Gupta D. \& Prakash N. 2001. Engineering methods from method requirements specifications. Requirement Engineering, 6(3): 135-160.

Hannon, J., Jelf, G. \& Brandes, D. 1996. Human resource information systems: Operational issues and strategic considerations in a global environment. International Journal of Human Resource Management, 7: 245-269

Haines, V.Y. \& Lafleur, G. 2008. Information technology usage and human resource roles and effectiveness. Human Resource Management, 47(3): 525-540.

Heikkilä1a, J-P. \& Smale, A. 2011. The effects of language standardization on the acceptance and use of e-HRM systems in foreign subsidiaries. Journal of World Business, 46(3): 305313.

Hevner, A., March, S.T., Park, J. \& Ram, S. 2004. Design Science Research in Information Systems. MIS Quarterly, 28(1): 75-105.

Hoffmann, C., \& Hoffmann, K. 2007. HR Can do Business! Delivering the Right Workforce. International Human Resource Information Management Journal, 11(5): 19-33.

Hough, L.M. \& Oswald, F. 2000. Personnel Selection: looking towards the future remembering the past. The Annual Review of Psychology, 51: 631-664.

HR-XML Consortium www.hr-xml.org, Dezember 8, 2011.

Hussain, Z., Wallace, J. \& Cornelius, N.E. 2007. The use and impact of human resource information systems on human resource management professionals. Information and Management, 44(1): 74-89.

Huselid, M.A. \& Becker, B.E. 2011. Bridging macro and micro domains: Workforce differentiation and strategic human resource management. Journal of Management, 37: 421-428.

ISO 20000. 2005. Information Technology - Service Management - Part 1: Specification, and Part 2: Code of Practice. Geneva, Switzerland: International Standards Organization. 
ITSMF. 2004. The IT Service Management Forum. An Introductory Overview of ITIL. Pasadena: CA.

Iivari, J. \& Venable, J. 2009. Action Research and Design Science Research - Seemingly Similar but Decisively Dissimilar. European Conference of Information Systems. Verona, Italy.

Jansen, C., Furtmueller, E. \& Wilderom, C. 2009. Usability Study on Dutch e-Recruiting Services: Limitations and possibilities from the applicants' perspective. Proceedings of the International Conference on Enterprise Information Systems. Milan Italy: Insticc.

Klein, H.H. \& Myers, M.D. 1999. A set of principles for conducting and evaluating interpretive field studies in information systems, MIS Quarterly, 23(1): 67-93.

Koong, K.S., Liu, L.C. \& Williams, D. 2002. An identification of Internet job board attributes. Human Systems Management, 21(2): 129-135.

Kohlborn, T., Korthaus, A., Chan, T. \& Rosemann, M. 2009. Identification and analyses of bsuiness and software services - A consolidated approach. IEEE Transactions on Services Computing, 2(1): 50-66.

Korthaus, A. Schwind, M. \& Seedorf, S. 2007. Leveraging Semantic Webtechnologies for business component specification, Web Semantics: Science, Services and Agents on the World Wide Web, 5: 130-141.

Korthaus, A., Kohlborn, T., Rosemann, M. \& Couzens, J. 2009. Empirical evaluation of a service analysis and design methodology. Proceedings of the Australian Conference on Information Systems. Melbourne, Australia.

Krajewski-Siuda, K., Romaniuk, P., Madaj, B., Forbes, J. \& Hubicki, L. 2008. Brain drain threat-Polish students are not satisfied with labor market options for health professionals in Poland. Journal of Public Health, 16(5): 347-351.

Larman, C. 2004. Applying UML and Patterns: An Introduction to Object-Oriented Analysis and Design and the Unified Process. 3rd Ed. Upper Saddle River, NJ, USA: Prentice Hall.

Lee, I., 2005. Evaluation of Fortune 100 companies' career web sites. Human Systems Management, 24(2): 175-182.

Lee, I. 2007. An architecture for a next-generation holistic e-Recruiting system. Communications of the ACM, 50(7): 81-85.

Lee. I. 2011. Modeling the benefit of e-Recruiting process integration. Decision Support Systems, 51(1): 230-239.

Lin, B. \& Stasinskaya, V.S. 2002. Data warehousing management issues in online recruiting. Human Systems Management, 21(1): 1-8.

Luftman, J. \& Zadeh, H.S. 2011. Key information technology and management issues. Journal of Information Technology, 26: 193-204.

Malinowski, J., Keim, T., Wendt, O. \& Weitzel, T. 2006. Matching People and Jobs: A Bilateral Recommendation Approach. Proceedings of the International Conference on System Sciences. Hawaii.

Martin, G. \& Reddington, M. 2010. Theorizing the links between e-HR and strategic HRM: a model, case illustration and reflections. International Journal of Human Resource Management, 21(10): 1553-1574.

Melville, N., Kraemer, K. \& Gurbaxani, V. 2004. Review: information technology and organizational performance: an integrative model of IT business value. MIS Quarterly, 28(2): 283-322.

Mochol, M., Wache, H. \& Nixon, L. 2007. Improving the Accuracy of Job Search with Semantic Techniques. Lecture Notes in Computer Science, 4439: 301-313.

O’Reilly, T. 2005. What Is Web 2.0. www.oreilly.com, September 30, 2005. 
Ostrom, A.L., Bitner, M.J., Brown, S.W., Burkhard, K.A., Goul, M., Smith-Daniels, V., Demirkan, H. \& Rabinovich, E. 2010. Moving forward and making a difference: Research priorities for the science of service. Journal of Service Research, 13(4): 4-36.

Papazoglou, M.P., Traverso, P., Dustdar, S. \& Leymann, F. 2008. Service-oriented computing: a research roadmap. International Journal of Cooperative Information Systems, 17(2): 223-255.

Peffers, K., Tuuanen, T., Rothenberger, M.A. \& Chatterjee, S. 2007. A Design Science Research Methodology for Information Systems Research. Journal of Management Information Systems, 24(3): 45-77.

Reddick, C.G. 2009. Human Resources Information Systems in Texas City Governments: Scope and Perception of its Effectiveness. Public Personnel Management, 38(4): 19-34.

Resnik, P. \& Varian, H.R. 1997. Introduction to the special issue on recommender systems. Communications of the Association for Computing Machinery, 40(3): 56-59.

Ross, C.M. \& Young, S.J. 2005. Resume preferences - Is it really "business as usual"? Journal of Career Development, 32(2): 153-164.

Royce, W. 1970. Managing the Development of Large Software Systems. Proceedings of IEEE Wescon, 26: 1-9.

Ruël, H.J.M., Bondarouk, T.V. \& Looise, J.C. 2004. E-HRM: innovation or irritation? An exploration of web-based human resource management in five large companies, Management Revue, 15(3): 364-380.

Ruta, C.D. 2005. The application of change management theory to HR portal implementation in subsidiaries of multinational corporations. Human Resource Management, 44: 35-53.

Schuler, R.S., Jackson, S. \& Tarique, I. 2010. Framework for Global Talent Management: HR Actions for dealing with Global Talent Challenges. In: Global Talent Management. (Ed.) H., Scullionv \& D.G., Collings. London: Routledge.

Spohrer, J.C., Demirkan, H. \& Krishna, V. 2011. The Science of Service Systems. In: Service Science: Research and Innovations in the Service Economy, 325-358, Springer.

Sturm, R., Morris, W. \& Jander, M. 2003. Foundations of Service Level Management. Indianapolis, IN: Sams Publishing.

Tansley, C., Newell, S. \& Williams, H. 2001. Effecting HRM-style practices through an integrated human resource information system - An e-greenfield site? Personnel Review, 30(3): 351-370.

Teece, D.J. 2009. Dynamic capabilities and strategic management: organizing for innovation and growth. USA: Oxford University Press.

Teubner, R.A. 2007. Strategic information systems planning: A case study from the financial services industry. Journal of Strategic Information Systems, 16: 105-125.

Vargo, S. L. \& Lusch, R.F. 2004. Evolving to a new dominant logic for marketing. Journal of Marketing, 68: 1-17.

Vessey, I. \& Conger, S. 1994. Requirement Specification: Learning Object, Process, and Data Methodologies. Communications of the ACM, 37(5): 102-113.

Viswesvaran, C. 2003. Introduction to special issue: Role of technology in shaping the future of staffing and assessment. International Journal of Selection and Assessment, 11(2-3): 107-112.

Von Krogh, G. \& Haeflinger, S. 2010. Opening up design science: The challenge of designing for reuse and joint development. Journal of Strategic Information Systems, 19: 232-241.

Weitzel, T., Eckhardt, A. \& Laumer, S. 2009. A framework for recruiting IT talent: Lessons from Siemens. MIS Executive, 8(4): 175-189.

Wolfswinkel, J., Furtmueller, E. \& Wilderom, C.P.M. 2012. Reviewing e-Recruiting Literature Using Grounded Theory. European Journal of Information Systems, in press. 
Welch, D.E., Welch, L.S. \& Marschan-Piekkari, R. 2001. The persistent impact of language on global operations. Prometheus, 19: 193-209.

Zusman, R.R. \& Landis, R.S. 2002. Applicant preferences for Web-based versus traditional job postings. Computers in Human Behavior, 18(3): 285-296. 


\title{
CHAPTER 6
}

\section{IT Professionals’ Preferred Modes of Being Recruited in the Contemporary Economy ${ }^{9}$}

\begin{abstract}
After theorizing on effective recruiting from a resource-based view and on staffing trends in the current IT sector, we point in this paper to applicants' preferred recruiting modes. Based on thorough analysis of the relevant literatures, we conducted in-depth interviews with IT professionals and analyzed minutely their transcripts: in order to report and rank their preferred recruiting modes. The findings of the study provide an enriched conceptual staffing model, specifically geared to young IT professionals; it strengthens the value of internet recruiting as the preferred medium. Moreover, we show why certain traditional and web 2.0 recruitment practices are seen as either attractive or unattractive. Recruiters are warned, on that basis, to steer their recruiting practices in line with applicants' preferred communication modes. Implications for attracting and recruiting IT professionals in the contemporary economy are discussed.
\end{abstract}

Keywords: IT Professionals, Recruiting Practices, Economical Changes.

\footnotetext{
${ }^{9}$ This paper has been published in the European Journal of Management.

A previous version of this paper has been presented at the International Academy of Business and Economics, Barcelona, Spain, June 3-5, 2011.
} 


\section{Introduction}

The business world witnessed an immense technological revolution in the 1990s, placing increasing emphasis on the work of information technology (IT) professionals. The introduction of the worldwide web in the early 1990s followed by the internet revolution brought increased visibility to the work of IT firms, departments and professionals. The culmination of the Y2 crisis in 2000 motivated global technical communities to solve the millennium problem collaboratively (Friedman, 2006; Ployhart, 2006). Other business trends such as service-based economies, increased globalization, professionalization and the need for enhanced customer service has augmented the role of IT employees in the work place (Jepsen, 2009; Laumer et al., 2008; Luftman \& Kempaiah, 2008).

IT professionals have helped to enhance organizational productivity, redefine work boundaries, and support critical intra- and inter-firm functions (Gallivan et al., 2004). Employers of IT professionals tend to place a high premium on problem-solving, teammanagement, decision-management, and relationship-management skills (Agarwal \& Ferratt, 2002; Gallivan et al., 2004). Further, IT staff is known to exhibit quintessential work characteristics such as being high achievers; seeking challenging environments; working nontraditional hours; and identifying strongly with professional development (Laumer, 2009; Luftman \& Kempaiah, 2008). The question arises how to hire and retain such superior talent? IT employers indicate that recruitment and hiring of talent is the primary concern in this industry. In a 2007 survey of 112 companies, staffing of IT professionals comprised about $31 \%$ of employers' budgets (Luftman \& Kempaiah, 2008). As the demand and budgets for hiring these professionals increase, there are barriers in getting the required talent for all levels (Luftman \& Kempaiah, 2008; Overby, 2006). First, some countries have experienced a reduction in the number of students enrolling for IT-related studies over the last decade (Baker, 2006; Overby, 2006). For instance, between 2001-2005, US universities have observed as much as a 50\% decrease in enrolment for IT-related subjects (Baker, 2006). On the other hand, emerging economies such as India and China have an abundant supply of computer engineers making outsourcing options to these countries financially attractive for multinationals (Meredith, 2007; Takeuchi \& Nomura, 2008, see Table 1).

A second barrier to satisfactorily recruiting IT personnel pertains to the IT-industry's reputation for chronic job hopping; IT professionals tend to seek constantly better career opportunities. Poaching or creaming off the best talent is occurring much in this sector (Gallivan et al., 2004; Laumer, 2009). Given that recruiting practices have undergone a 
profound shift in the past decade, largely due to the emergence and diversity of internet recruiting, little empirical research has looked at how young IT professionals prefer to be recruited. The input of young IT professionals might be of significant value to those designing IT-recruiting experiences, thereby (sometimes unintentionally) flagging to young recruits what kind of firm they represent.

While most of the recruiting literature informs on how organizations can internally implement and manage Human Resource Management (HRM) and recently also e-HRM systems to optimize recruiting processes, this study enhances our understanding of young IT professionals' desirable and undesirable recruiting and communication modes during staffing processes. The findings of this research provide insights into how organizations can best design effective recruitment experiences for young IT professionals as part of their broader human resource strategy. Accordingly, we address the following research question: What recruiting practices do young IT professionals perceive as attractive and unattractive?

The paper is structured as follows. First, a theoretical overview is given of the staffing function in light of the resource-based view; we then chronologically review recruitment trends in attracting talented IT professionals to organizations. Next, we describe the qualitative methods employed in this study and present the findings and discuss the relative attractiveness of the various literature-based recruiting modes. Finally, we derive implications for organizations interested in attracting and recruiting academic and ambitious IT graduates and reflect upon the study for the purpose of drawing new-research options to bring forward this strategic HRM/IT domain.

\section{Theoretical Framework}

In the resource-based view (RBV) of the firm Barney $(1986,2001)$ gave new insights to enhancing a firm's sustainable competitive advantage. He suggested that organizations look inward, towards their employees, and adopt HRM practices that provide them with value and distinctiveness. Therefore an increased awareness that employees and HRM practices can provide organizations with sustainable competitive advantage is by now completely entrenched; yet the development of competitive HRM practices including effective recruiting channels to attract new talent is still underexploited by most economic agents (Barney, 2001).

Lepak and Snell (1999) integrated concepts of the RBV and identified a staffing typology that can enhance value and uniqueness of any organization, namely: 1) Internal Recruitment 2) External Recruitment 3) Outsourcing 4) Partnerships. Employees are considered valuable when they provide significant contributions to both internal and external 
customers and affiliated organizations. Employees are especially unique when their KSAs (knowledge, skills, and abilities) are inimitable and therefore not easily available to competitors. Thus, each staffing option can be used to further develop an organization's sustainable competitive or professional advantage. Internal recruitment can be used to develop core strategic skills, such as industry-specific talent, so that such talent becomes idiosyncratic and non-transferable. External recruitment can be used to obtain specific KSA's (such as advanced education and/or superior management skills) to enhance immediate organizational or professional value. Outsourcing could be used for peripheral skills so that quality time can be devoted to strategic functions, increasing an organization's advantage. Hybrid staffing practices between external and internal actors could also be adopted when such blending is conducive to the organization's strategy (Lepak \& Snell, 1999).

Advancing these thoughts, Girard and Fallery (2009) suggest that the dynamic nature of today's technology allows organizations to manage and coordinate the various options of the staffing typology of internal, external, outsourcing and partnership. Moreover, the social and interactive natures of the current technology help identify and build organizational capital of unique and valuable members. Further, Strohmeier (2007) suggests e-HRM practices (such as e-Recruitment) can have positive organizational effects on the level of operations (increasing firm efficiency), intra-firm relations (integrating different departments) as well as strategic transformations (major decisions aimed at firm performance). While adopting an eHRM approach to enhance competitive advantage it is crucial to adopt practices that are not merely off-the-shelf products as they can easily be duplicated. A unique outreach approach to prospective (and current) employees is needed in order to exploit human resources in humane, sustainable and valuable ways.

Orlikowski $(1992,2010)$, in her Social Construction theory, argues that technology can be interpreted only in terms of the members that employ and utilize the technology. The members who use technology create unique social frameworks in terms of their roles, values, and interpretations. The theory emphasizes the importance of interpreting technology via its social members. Orlikowski introduced the concept of "technologies of practice" suggesting that organizations and its members can gain any positive effect of technology only if members become experts in using the technology involved, something that can happen only with consistent practice. For instance, bank employees who are reluctant or limit their use of the business software SAP are less likely to derive organizational benefits from the software program (Dery et al., 2006). Orlikowski's theory is relevant to our study as it identifies members who use technology as the key social interpreters. Besides this, she suggests that 
consistent interaction between humans and technology creates higher efficiency both at the (prospective) employee and organizational levels (Orlikowski, 2010; Orlikowski \& Barley, 2001). In this respect, the use of technology in the recruitment and selection process is a key new possibility and challenge in effective personnel selection. Despite evidence that recent technology has enriched the available modes of recruitment, little research has investigated which of the new technologies are preferred from the applicants -in this case IT professionals' perspectives. More understanding of the changing demands of job-entering professionals would aid in optimizing recruiting practices. Hence we suggest that IT-recruiting specialists in particular need to know more about young IT professionals' preferred recruiting modes.

\section{Recruiting IT Professionals: A Literature Review}

In order to obtain the pertinent literature on recruiting practices for IT staff, a comprehensive search was undertaken. In addition to searching relevant articles specifically in Human Resource Management, Organizational Behavior and Information Systems journals, the research data bases Web-of-Science, Scopus, ACM Digital Library and AIS Electronic Library have been covered. Several keywords were used to find related recruiting literature: IT recruit*, IS recruit* recruiting, recruiting practices, recruiting modes, recruit* engineers, IT staff*, IT career, IT workforce, IT profession, internet recruit* online recruit*, web-based recruit*, new media recruit*. The literature selection procedure was as follows. First, articles were excluded based on title and abstract. Second, an article had to be published in an international peer-reviewed journal and recruitment of IT staff or related engineering fields had to be the major focus of research. Two researchers engaged in removing the articles that did not fit these criteria, including the removal of duplicates. The final literature sample for reviewing recruitment-mode relevant literatures was determined by doing forward and backward reference checks and of course by reading the full texts of the selected articles.

Reviewing the literature revealed that scholars have noted salient changes in recruitment practices before (Gallivan et al., 2004; Laumer et al., 2008). Over the decades (beginning in the 1980s), recruiting has shifted from traditional print advertisements to online job ads and recently interactive three-dimensional avatars and social networks. In a content analysis of 2.297 job advertisements, (Gallivan et al., 2004) documented a consistent increase of IT careers between 1988-1995. The global trend of e-Recruitment began when Monster.com launched its operations in 1994 and introduced the pioneering concept of posting and storing resumes online. Most IT organizations followed the protocol of using e- 
Recruitment to hire their applicants. The IT industry was lucrative and employees from this field were in high demand. The US technology industry even signed an agreement with the federal government allowing qualified international IT employees to enter the country with minimum visa restrictions. Following the dot.com boom in the year 2000, research focused on how to attract IT professionals (Thomas \& Wise, 1999). After this boom was over, most research was oriented towards economical concepts such as employee turnover, cost effectiveness and demand and supply of labour. In 2001, there was a distinct reduction in career opportunities for IT employees: to be attributed to the dot.com bust. By 2001, employers strongly preferred to use e-Recruitment methods (such as company websites) to attract potential applicants. Newspaper advertisements witnessed a $62 \%$ reduction of print advertisements for IT jobs (Gallivan et al., 2004). Later, a more humanitarian approach, focussing on work-life balance, retention and flexible careers, evolved. The recent behavioural trend in IT shows that IT professionals put increasingly weight on personorganization fit, personality traits and organizational attractiveness (Cable \& $\mathrm{Yu}, 2006$; Williamson et al., 2008).

According to Agarwal and Ferratt (2002) recruitment practices of IT professionals can be enriched by "strategic levers." Strategic levers reflect a strong coordination of HRM and IT strategies in functional areas such as staffing, compensation, training and development, rewards and work-life balance practices. Therefore organizations in need of IT personnel prefer to adopt recruitment practices that IT applicants find attractive to use. IT employees have been found to have a proclivity for e-Recruitment methods; the very nature of their jobs dictates they spend most of their day life online (Laumer et al., 2008; Lee, 2007).

In adopting e-Recruitment, Lee (2007) developed an eight-step data-management system to refine e-Recruitment practices: allowing firms to manage applicants systematically, from initial applications to final job offers. Given IT employee preference for e-Recruitment methods, organizations would need to make it a strategic priority to make e-Recruitment channels attractive to prospective applicants. One aspect in that aim is 'employer branding:' an organization's efforts to promote, both within and outside the firm, a clear view of what makes it different and desirable as an employer. In particular, the Marketing literature studied IT professionals in the context of organizational branding and marketing to these groups (Moroko \& Uncles, 2008). Employees may need to feel a strong sense of pride to work for their organizations which is encouraged by organizational branding practices (Sartain, 2005; 2006). For instance, Google Inc's., extensive array of benefits of diverse ethnic on-site restaurants, corporate presentations of global leaders, inimitable work-environment of 70-20- 
10 (main work/professional development/creativity) are distinguishing practices helped to have branded the Internet leader as inimitable (Iyer \& Davenport, 2008). Eckhardt et al. (2008) suggest that employer branding should be included as a definite part of any eRecruitment data system. Such a system can help track whether employer branding does provide quality hires or whether organizations should invest more time in adjusting their recruitment strategies.

Moreover, research indicates that IT professionals are slowly moving into threedimensional virtual worlds for recruitment needs. Virtual worlds allow users to be engaged as if they were actually present at the site making the situation seemingly real (Barnes, 2007). In an empirical study of 9679 applicants from various employment categories (midmanagement, professionals, graduates among others), Laumer et al. (2008), observed that $53.4 \%$ of the Information Systems and $43.8 \%$ of the Computer Scientists used predominantly virtual communities to glean their preliminary recruitment information about prospective companies. In 2007, IBM Germany launched a virtual recruitment center through Second Life which allows prospective applicants and employers to have interactive recruiting dialogue. Applicants can seek private or public dialogues to clarify any job questions or concerns they may have. Further the virtual recruitment center can also conduct corporate recruitment fairs and events to discuss job expectations, company culture, and even specific applicant concerns (Laumer et al., 2008).

Agarwal et al. (2006) suggest that IT organizations that adopt a human capital-focused strategy (which emphasizes long term investment in their employees) will demonstrate positive organizational outcomes. In their study of 100 IT organizations, they identified organizations that had a human capital-focused profile, stressing internal recruitment, development and training; they had reduced turnover rates. Therefore in developing middle and upper level talent, IT organizations need to consider a long term strategy and invest in internal recruitment strategies. The implementation of e-HRM has changed the entire way recruitment is handled (Strohmeier, 2007). In the past few years, social networking and other web 2.0 services have provided new means for internet recruitment (Shen \& Eder, 2009). In this context, Girard and Fallery (2009) demonstrated in an international recruitment study of 11 French software companies that organizations are slowly moving from traditional internet recruiting practices, i.e. Web 1.0 such as job boards, career websites, and other e-Recruitment practices to Web 2.0 recruiting with SecondLife, blogs, and Facebook. That study showed that early web practices were not adequate enough for recruiting quality applicants. Web 2.0 enables distinct advantages as it allowed companies to brand themselves uniquely and 
innovatively enhance their social image. It allows organizations to expand their recruiting channels and address both active and passive job searchers. Finally, the very nature of recently emerging Web 2.0 recruiting allows extensive social dialogues with applicants, probing specifically about their KSAs and work experiences. Recruitment experts consider using various e-Recruitment channels, including branding efforts, and a thorough assessment of KSAs as important steps in any recruitment process (see, e.g., Fernández-Aráoz et al., 2009). Leading telecommunication companies such as T-Mobile actively use Web 2.0 recruitment methods. T-Mobile introduced Facebook in 2007 in order to attract applicants and it provided a social platform for dialogue among applicants. This recruitment practice is extremely successful as the applicant pool predominantly reflects young technology graduates who prefer such technology-based interactions.

This literature review has shown that recruitment practices for IT professionals have considerably changed during the past decades. Due to the gap in knowledge on eventual changes of IT applicants' perceptions of attractive and unattractive recruiting practices (particularly since the recent economic macro changes impacted organizations' financial situation and image as attractive employer), we conducted an in-depth, qualitative study querying young IT professionals about their preferred recruiting modes. 


\section{Method}

In pursuing more understanding of what young IT professionals find attractive recruiting practices, we conducted an in-depth interview study with 22 individuals. We focused on recent IT graduates because members of this group of job-entering university graduates are placed to signal future demand. The population consists of all those who were finishing up their Master-of-Science degree in Dutch University's programs in Information Systems, Computer Science or Business Information Technology. The in our study approached graduating students were all in the process of planning to enter the IT job market for a full time position. In total, we invited 58 IT graduates of one of the three Dutch technical universities to participate in the study.

Twenty-five graduates agreed to be interviewed resulting in a response rate of $43.1 \%$. Three graduates cancelled the interviews on a short notice. Fifty percent $(n=11)$ of respondents were younger than 25 years and the other $50 \%(\mathrm{n}=11)$ were between the age groups of 25-31. Among the respondents, $73 \%$ were male $(n=16)$ and $27 \%$ were female $(n=6)$ graduates. The sample was predominantly European but also included a few students from Asian and African origins; they all aimed to enter the European and particularly the Dutch IT workforce. All had gained previous IT sector experience, at the very least, on the basis of university internships.

\section{Means of data collection}

Before conducting the interviews, the interviewees received an e-mail that explained the study's purpose and the set of initial interview questions. Following this mail, each interviewee was contacted in order to arrange interview appointments. For each of the 22 indepth interviews we carried out, we used a semi-structured interview scheme. This scheme had been initially pilot tested with four other IT graduates. The interview questions aimed at identifying, categorizing and ranking what recruiting practices they find appealing and nonappealing. Each interview lasted between 60 and 90 minutes, and started with the academic goal of the study and an assurance of confidentiality of their data. Then, they were asked to spontaneously identify and thoroughly describe attractive and unattractive recruitment practices and communication channels they had encountered when looking for a job. They were further asked to share experiences they (and other IT professionals they knew) had made so far in respect to attractive and unattractive organizational recruiting practices. We also inquired about their perceptions of absolutely positive, delightful and extremely negative and 
unpleasant recruitment experiences. We then fed back to each interviewee their identified recruitment practices; each one was asked to rethink those practices during the interview and supplement information if anything mentioned in their answers did not fully capture their understanding of IT staff recruitment in the contemporary economy. Comprehensive field notes were taken during all interviews. After they had given their own definitions of desirable and undesirable recruiting practices, they were given a list of traditional and web 2.0 recruiting practices derived from the extant literature analyses. Following, they were asked to mark these practices as either attractive or unattractive and describe in depth why they saw differences in attractiveness. The final stage of the interviews focused on the current economic recession (since 2009) and whether this event had influenced the attractiveness of organizations and recruitment practices for IT professionals.

\section{Data analyses}

All interviews were tape-recorded with the consent of interviewees. The total interview time on which basis we report the results below was 1.245 minutes ( 21 hours and 13 minutes). The interviews were transcribed verbatim by the same interviewer. Individual transcripts were then sent for member checking. Each interviewee received their individual interview transcription within a week after the interviews: to determine the accuracy and credibility of the collected data (Creswell, 2009). The interviewees were given the opportunity to adjust, comment, correct their statements and also add additional information if needed. Moreover, comprehensive notes were taken during these processes for purposes of complementing the audio data. The data analysis followed principles of qualitative data analysis (Miles \& Huberman, 1994), and more specifically of the CIT (critical incident technique). The CIT method (see Flanagan, 1954 for details on the methodology) was selected to inductively identify categories described as attractive and unattractive recruitment practices. This method was initially developed to categorize pleasant (attractive) and unpleasant (unattractive) experiences of individuals and emphasizes the discovery of categories over confirmation. In specific, it considers "the stories that people have told and asks questions of the stories in order to classify each one within the scheme” (Bitner et al., 1990, p. 73). In the initial phase of analyzing, in order to make two independent coders familiar with the data, they read the transcripts while listening to the audio tapes. This process was tedious yet generative because while doing so both researchers extracted insights pertaining to both the content of our research and the means to analyze the data. Openly coding the data involved examining, 
comparing and categorizing data. Qualitative research scholars (Denzin \& Lincoln, 2000; Patton, 2002; Strauss \& Corbin, 1990) compare coding to breaking down information into specific categories. Coding provides two important purposes: "convergence and divergence" of interview data such that researchers can identify recurring themes and also categorize dissimilar data. Following Patton's (2002) advice, we will provide interview information in quotes wherever applicable so that readers can have a glimpse of the interview verbatim. After the two coders had developed preliminary codes, they compared and then refined them; differences in interpretation were resolved through extensive discussions. For example, the category 'career fair' included internal in-house fairs or social gatherings organized by prospective employers and external career events that are usually sector-specific, professional and university fairs. Frequently, interviewees insisted on collapsing recruiting practices together in fewer synthetic categories (e.g., private or extended business networks, via university, former employers, word-of-mouth endorsements, in one category which we labeled "referrals"). Throughout the coding process, the questioning of each coding interpretation aimed to verify that it was well grounded in the verbatim statements. We moved iteratively between the collected data; conceptualizations emerging in our field notes; memos and discussions; and relevant literature to refine and develop relevant conceptual dimensions and categories reflecting the views of young IT professionals' recruiting practices. This constant comparative and iterative method of data analysis (Strauss \& Corbin, 1998) added rigor to the coding process. It forced the researchers to return to the data again and again: to ensure each interpretation found support in the transcripts. For each statement, we compared data across informants to understand how these concepts related to similar recruiting practices. The discussions resulted in nine salient non-overlapping sets of recruiting practices. This initial categorization was further discussed with two of the interviewed IT professionals to further strengthen interpretative validity. Minor refinements in the sub-categories of recruiting practices were revealed, but no adjustments of the categorization of the nine salient practices emerged.

In what we report, below, we will include a rank order of what the interviewees saw as attractive or unattractive recruiting practices. In a different part of the interview we had asked respondents to rank order a set of recruitment practices which were drawn from the literature. Content analysis of these responses was conducted to ascertain the highest-ranked or most attractive recruiting practice across both data sets, i.e., the inductively derived recruiting practices by open interviewing, and the deductively categorized recruiting practices derived through literature analysis. 


\section{Results}

This study shows that the most preferred recruitment means for Dutch IT professionals are 1) internet recruiting practices; 2) career fairs; 3) and employee referrals. Print media, telecommunication (phone, SMS and telemarketing) and commercials (radio, TV) were considered the least attractive recruiting modes. Based on open interviewing, nine major recruiting practices emerged (see Table 1) which we will discuss in the remainder of the paper.

Table 1

Attractive and Unattractive Recruiting Practices: Derived from Open Interviews

\begin{tabular}{|c|l|l|c|c|c|}
\hline Rank & $\begin{array}{l}\text { Recruiting } \\
\text { practice }\end{array}$ & Examples & Attractive & Unattractive & $\begin{array}{c}\text { Not } \\
\text { identified }\end{array}$ \\
\hline 1 & $\begin{array}{l}\text { Internet } \\
\text { recruiting }\end{array}$ & $\begin{array}{l}\text { Company websites, online job sites, } \\
\text { branch associations, email, } \\
\text { networking sites, podcasts, RSS; } \\
\text { online company videos, blogs }\end{array}$ & $95 \%$ & $5 \%$ & $0 \%$ \\
\hline 2 & Career fairs & $\begin{array}{l}\text { Internal (in-house fair or social } \\
\text { gathering) and external (sector- } \\
\text { specific, professional and university } \\
\text { fairs). }\end{array}$ & $84 \%$ & $2 \%$ & $14 \%$ \\
\hline 3 & Referrals & $\begin{array}{l}\text { Private or extended business } \\
\text { networks, via university, former } \\
\text { employers, word-of-mouth } \\
\text { endorsements }\end{array}$ & $54 \%$ & $0 \%$ & $46 \%$ \\
\hline 4 & $\begin{array}{l}\text { Company } \\
\text { projects }\end{array}$ & $\begin{array}{l}\text { Bachelor, Master thesis, Internships, } \\
\text { summer jobs }\end{array}$ & $41 \%$ & $0 \%$ & $59 \%$ \\
\hline 5 & $\begin{array}{l}\text { Pro-active } \\
\text { recruiters }\end{array}$ & Direct approach of recruiters & $18 \%$ & $0 \%$ & $82 \%$ \\
\hline 6 & $\begin{array}{l}\text { Recruiting } \\
\text { agency }\end{array}$ & $\begin{array}{l}\text { Employment Office } \\
\text { University career center }\end{array}$ & $14 \%$ & $2 \%$ & $84 \%$ \\
\hline 7 & Commercials & Radio, TV & $1 \%$ & $18 \%$ & $81 \%$ \\
\hline 8 & $\begin{array}{l}\text { Telecommu- } \\
\text { nication }\end{array}$ & $\begin{array}{l}\text { Phone, SMS, telemarketing } \\
\text { call center recruitment }\end{array}$ & $1 \%$ & $36 \%$ & $63 \%$ \\
\hline 9 & Print media & $\begin{array}{l}\text { Newspaper ads, branch magazines, } \\
\text { postal mail, brochures, flyers }\end{array}$ & $2 \%$ & $73 \%$ & $25 \%$ \\
\hline & & & & \\
\hline
\end{tabular}

In addition to interviewing and inductively analyzing recruiting-practice preferences, the interviewees were presented with a set of traditional and web 2.0 recruiting practices (derived from our extensive analyses of the relevant literatures); they had to mark them as either attractive or unattractive (Table 2). These deductive ratings led to more understanding of IT professionals' recruiting needs. By content-analyzing this specific interview data, we got insights into the relative weights of attractive and unattractive recruitment practices. 
Table 2

Attractive and Unattractive Recruiting Practices: Based on Rankings in the Literature

\begin{tabular}{|c|c|c|c|}
\hline Traditional Recruiting Practices & Attractive & Unattractive & Authors \\
\hline Personal Network/Referrals & $96 \%$ & $4 \%$ & $\begin{array}{l}\text { (Goldenberg et al., 2001; Zottoli \& } \\
\text { Wanous, 2000) }\end{array}$ \\
\hline $\begin{array}{l}\text { Internships, student BA/Master's } \\
\text { projects }\end{array}$ & $95 \%$ & $5 \%$ & $\begin{array}{l}\text { (Beenen \& Mrousseau, 2010; Enneis } \\
\text { et al., 1973) }\end{array}$ \\
\hline $\begin{array}{l}\text { Career fair outside organization e.g. } \\
\text { university, professional fairs }\end{array}$ & $91 \%$ & $9 \%$ & (Collins \& Stevens, 2002) \\
\hline $\begin{array}{l}\text { Online company presentation (career } \\
\text { section on website) }\end{array}$ & $84 \%$ & $16 \%$ & $\begin{array}{l}\text { (Mumford, 1999; Sylva \& Mol, } \\
\text { 2009) }\end{array}$ \\
\hline Career fair in organization & $82 \%$ & $18 \%$ & (Collins \& Stevens, 2002) \\
\hline $\begin{array}{l}\text { Adventure events e.g. practiced in } \\
\text { consultancies }\end{array}$ & $77 \%$ & $23 \%$ & (Roy \& Cornwell, 2003) \\
\hline Sponsorship & $64 \%$ & $36 \%$ & $\begin{array}{l}\text { (Jalleh et al., 2002; Quester \& } \\
\text { Thompson, 2001) }\end{array}$ \\
\hline $\begin{array}{l}\text { Organizations' external quality } \\
\text { certification (e.g. best place to work) }\end{array}$ & $64 \%$ & $36 \%$ & $\begin{array}{l}\text { (Guler et al., 2002; Withers \& } \\
\text { Ebrahimpour, 2000) }\end{array}$ \\
\hline Competitive skill tests & $59 \%$ & $41 \%$ & (Ployhart, 2006) \\
\hline Assessment centers & $43 \%$ & $57 \%$ & $\begin{array}{l}\text { (Lievens, 2002; Thornton Iii \& } \\
\text { Gibbons, 2009) }\end{array}$ \\
\hline Recruitment via intermediary agency & $36 \%$ & $64 \%$ & $\begin{array}{l}\text { (Dibbern et al., 2004; Fish \& } \\
\text { Macklin, 2004; Kalleberg \& } \\
\text { Marsden, 2005) }\end{array}$ \\
\hline Job ads in newspapers or magazines & $32 \%$ & $68 \%$ & (Dibbern et al., 2004) \\
\hline Commercial on radio & $31 \%$ & $69 \%$ & (Ekelund Jr et al., 1999) \\
\hline Commercials on television & $27 \%$ & $73 \%$ & (Bowman, 1976; Krugman, 1965) \\
\hline Print mailings/newsletter & $27 \%$ & $73 \%$ & (Rogers, 1996) \\
\hline
\end{tabular}


Table 2 Continued

Attractive and Unattractive Recruiting Practices:

Based on Rankings in the Literature

\begin{tabular}{|c|c|c|c|}
\hline Web 2.0 Recruiting Practices & Attractive & Unattractive & Authors \\
\hline Videos about organization & $89 \%$ & $11 \%$ & $\begin{array}{l}\text { (Allen \& Van Scotter, 2004; Walker } \\
\text { et al., 2009) }\end{array}$ \\
\hline Business networking sites & $87 \%$ & $13 \%$ & (Vermeiren, 2009) \\
\hline Online referral systems & $87 \%$ & $13 \%$ & (Brandel, 2006; Moser, 2005) \\
\hline $\begin{array}{l}\text { Syndication (RSS) to get newsfeeds } \\
\text { about the organization }\end{array}$ & $77 \%$ & $23 \%$ & (Girard \& Fallery, 2009) \\
\hline Employee blogs & $74 \%$ & $26 \%$ & (Walker et al., 2009) \\
\hline $\begin{array}{l}\text { Search engine optimization } \\
\text { (SEO) }\end{array}$ & $68 \%$ & $32 \%$ & (Cober et al., 2003) \\
\hline Wikis about organization & $64 \%$ & $36 \%$ & (Cox, 2005) \\
\hline Podcasts about organization & $64 \%$ & $36 \%$ & (Girard \& Fallery, 2009) \\
\hline Organization blogs & $61 \%$ & $39 \%$ & (Sackett \& Lievens, 2008) \\
\hline Social networking sites & $53 \%$ & $47 \%$ & $\begin{array}{l}\text { (Boyd \& Ellison, 2007; Ortiz et al., } \\
\text { 2006; Smith \& Kidder, 2010) }\end{array}$ \\
\hline Virtual worlds recruiting & $9 \%$ & $91 \%$ & $\begin{array}{l}\text { (Barnes, 2007; Laumer et al., 2008; } \\
\text { Shen \& Eder, 2009) }\end{array}$ \\
\hline
\end{tabular}

All but one of the interviewees described internet recruiting practices as most attractive, followed by career fairs and employee referrals.

"Everything without internet is unattractive, maybe there is one other channel, like hearing things from a friend."

"It is my life. I do everything on the web."

Not surprisingly perhaps, young IT professionals being so accustomed to information technology in their daily life prefer to search for jobs online, instead of relying on traditional means.

"If I want to work in a company, then I prefer to first look at their website. It says something about the company if they have a professional site with relevant information about their products, how it is to work there, what kinds of people they look for etc.". 
Recently, the literature begun to shed light on career web site attributes related to applicant attraction and firm reputation (Williamson et al., 2010). One of the puzzling consequences of internet recruiting seems to reside in its effect on organizational image. The recruiting literature suggests that being successful when attracting applicants entails maintaining a favorable recruitment image (Gatewood et al., 1993). Therefore, organizations should endeavor to relay information in ways that enhance their recruiting image (Braddy et al., 2003). Feldman and Klaas (2002) reported that most applicants and organizations are (considering) shifting to the internet recruiting channel. Therefore, research is urgently needed that identifies characteristics of internet recruiting practices and how it may strengthen an organization's recruitment image.

Among the interviewees, an organization's use of web 2.0 applications was found to indicate an innovative organizational image; it was seen to represent openness, social responsiveness, progress in technology, personalization, interactivity, modernity, positivity, increased presence, a fast company, dynamite, etc.: in sum, an attractive organization. In addition, interviewees reported an interest in reading employer blogs and listening to podcasts, provided the company information is up-to date.

"Blogs would be attractive because, then you can actually get to see little bit or actually get to hear a little of the experiences of current employees."

Some of our respondents noted the biases of blogs from organizations or employees: "Online blogs and videos are interesting but they are public. So, they are tainted ... They are biased. Organizations make it always positive." Similarly, already ten years ago, Cappelli (2001) noted negative as well as positive effects of the increase in internet recruiting practices; and there are still many hurdles to effective online recruiting. In the process of using the internet for searching jobs, applicants either visit the organizations' websites to search for openings or look through job listings on job sites, branch specific recruiting sites and university sites. After submitting an application (e.g. filling out an online resume or sending an email application), applicants preferably want to be contacted by recruiters via email which has been described as a fast and easy way to communicate. Yet, email applications also have been found to have the disadvantage of "not being spontaneous, spam or not being replied back." Although IT professionals like to search through job ads online, they dislike it if jobs ads are double posted at various job sites.

"The same jobs are frequently double posted across various places in 
the internet; this is really annoying as I can't skip them when searching online, and often need to go over old or previously read ads again.

Sometimes ads are posted again after a few months. I am not sure why companies do this. I sometimes ask myself maybe no one wants to work there or the person who started left the job right away, maybe it is not a good company to work for, or maybe they just forgot to put the ads offline. I find this strange."

Further, recruiting sites need to be high in information quality

"I like to see a professional and clean site; there needs to be some structure which helps me to quickly find the job I am looking for, select a region, jobs ads need to be updated and contain contact information to recruiters."

Even security of personalized data is of increasing concern most young IT professionals are willing to subscribe to organizations' or internet recruiting services newsfeeds during periods of searching and switching jobs.

"Of course RSS feeds is a very good channel because you can just get digest of information that is coming from different sources, straight to your email or something. So it's really helpful when you look for a job."

Not surprisingly at the moment, most professionals have a social and/or business networking profile such as Facebook and LinkedIn and some use Twitter to get updated. However, the attractiveness of these mediums for recruiting purpose greatly varies per type of networking site. While business networking sites such as LinkedIn are valued for recruiting purposes, social networking sites are treated somewhat skeptical as reported by several interviewees:

"There is a difference between using social and business networks, social networks are for friends, business networks are for jobs and referrals. I do not want to see recruiters checking my personal data on Facebook."

In this context, network recruiting services may gain importance:

"With network recruiting such as H3.com, you can suggest people you know for a job. If you can get a consultant for company $X$, then you will get $\$ 1000$. But if you don't know someone directly but you know someone that knows one who fits the job, then you still get \$ 100 and the other person gets $\$ 1000$. However, if I recommend someone that is not good for the job, then my reputation goes down. So I'll make sure I'll give them a really good candidate. I really would like it if someone would recommend me via H3 or LinkedIn.” 
"Recruitment is going to shift in the future towards online referrals and networks instead of bluntly sending stuff via e-mail. I would really prefer this soft side of recruiting over the old ways."

Considering identified traditional recruiting practices, most young professionals reported they like company career fairs:

"I like trade fairs or career fairs where you can directly walk to and talk to people working in different companies, it saves time as you have them all together at one place and you can ask them what they have to offer."

Interestingly, one interviewee expressed that sometimes companies send the wrong representatives to career fairs. Recruiters with detailed knowledge about job specifications would be more desirable at such events.

"Those guys that are often there aren't really smart. They're just marketers. They don't know anything about jobs, just give you brochures, the only thing they do is get you to go there."

More communication channels for direct interaction with recruiters are demanded e.g. via online means such as blogs, networks or online career fairs with interaction possibilities. In addition, some graduates voiced appreciation of pro-active recruiting or scouting of them at the premises of their university:

"I really like it when companies take the initiative to look for new staff, when they come to me to recruit me."

"When organizations send recruiters or other employees to the university, sometimes they do lectures or offer Master projects, this shows the organization is active."

This latter insight, i.e., the need to be personally approached by prospective employers, supports the point that Goles (2001) had made: that universities are the main source of recruiting new IT talent. Clearly, as the war for talent continues, organizations are challenged to invest and dedicate more effort to excel in on-campus recruitment.

Note, furthermore, that print media belonging to traditional recruitment means (e.g. newspapers job ads, flyers, company brochures) got ranked as the least attractive mode for recruiting young IT professionals (16 out of 22 interviewees).

"I don't read newspapers. I read internet pages, blogs and so on. I won't buy some newspaper, so I will not read such job ads. This is not an attractive channel to get in touch with people working in the IT field.” 
"You see companies that put posters on trees or something like that, that has no prestige, this is not reliable enough, the weather changes quickly and then it looks dirty, also "if I don't recognize such ads, I will not read them... newspapers even... when I am in the university sometimes people give me brochures... a piece of paper."

"By post mail...for me post mail is a one way channel of communication... yeah even e-mail is... but I can reply to it easily... but that's not the case with post mail. You cannot ask or explain.”

The second most unattractive source was via telecommunication (i.e., communicating with potential applicants via the phone); SMS; telemarketing; or call center recruitment approaches. Nearly $40 \%$ of the interviewees described direct phone calls by recruiters as pushy, aggressive and inconvenient: especially if calls are received without sending an email beforehand.

"The call center approach... they just start calling people based on their resume. For lot of people it would be unattractive if this happens via phone, you have no time to prepare or so."

"If they send an email this is fine however not just calling me without informing me before."

Interestingly, 91\% of the interviewed IT professionals find recruiting in virtual worlds unattractive. Contrary to previous research (Bray \& Konsynski, 2007; Laumer et al., 2008) second life was identified as not suitable for communicating with recruiters:

"The hype of virtual world stuff is over; organizations must know that no one is using this for searching a serious job."

\section{Recruiting IT Professionals in the Contemporary Economy}

Most interviewed graduates reported that they perceive the economic situation has impacted the ways organizations manage recruitment. Associated changes in this regards relate to higher entry barriers, in particular with large organizations as explained by several young professionals:

"I would say it's difficult to enter a large company... because you have to be really, really good... go through assessments and stuff...."

"Ya...they are more critical about whom they hire. So I see organizations as more difficult to enter."

"About my perception, yes, it is influenced by this event. Because large 
organizations will demand more qualified and useful people; to survive and keep their best work in their field area, they only hire the best people."

Frequently, graduates noted the increased competition and demands set by organizations in the recruitment process. Yet no single interviewed graduate is afraid of not finding a job. Moreover, young IT professionals appeared very self-confident:

"I believe with my degree in information technology, I don't have to worry that much about jobs."

"It's not really a problem for us... we are always criticized for... as we can always get a job and they always want us."

Several interviewees argued that generally more staff with IT skills is needed in contemporary times due to automating and cost savings, e.g. "when companies are cutting costs they are often investing in information management because they can save a lot of costs with these investments." Also we noted a large consensus about an increase in flexible work arrangements in the IT sector:

"What they do is they try to attract temporary people... who work on a temporary basis."

"They hire expensive consultants which is quite contradictory in the financial crisis. But they hire consultants to work for them and get rid of them when needed. They just say we don't require you anymore."

Another trend concerns the growth of freelance jobs and setting up own businesses:

"More and more people can work on their own; many already do freelancing jobs during their studies, and will also have side jobs in future."

"So now in this economy I know for sure that I'm going to end-up with my own business when I finish my studies."

Although large organizations are increasingly associated in media with layoffs, young professionals still find them the most attractive site for launching their careers.

"So for me I think it would be wise to look for large companies with good reputations...which have gone through crisis before ... to be able to survive another crisis. I'm very ambitious I'd like to go for Google, IBM, Oracle."

Financial organizations such as banks and insurances were described as responsible for much of the current economic situation and have lost therefore attractiveness for several of the interviewed IT graduates. While many reported various cases of layoffs in their personal 
network due to the financial crisis, an economically instable situation is not seen as a permanent state.

"The economy always goes in a circular motion so basically what goes up must come down and what goes down is going to go up again."

\section{Discussion}

The diffusion of internet-based recruiting practices, together with the current worldwide economic slump, has impacted the various modes of recruiting new personnel. While the recent HRM literature stresses how organizations may internally best deal with electronic Human Resource Management (e-HRM) systems, in order to optimize entire recruiting processes, we also need to know more about the behaviour of those searching for jobs. This study identified the most preferred recruitment methods for Dutch IT professionals: Internet recruiting practices, employee referrals and career fairs. Print media and telecommunication (phone, SMS and telemarketing) recruitment methods were seen as the least attractive recruiting modes. A challenge for designing recruiting strategies lies in the fact that IT professionals represent a bunch of candidates with strongly held views about the ideal (e-) application process. It is indispensable for organizations to understand what those individuals need or want in this regard. In this study we found that IT professionals acted in recruiting processes in certain patterns; they use certain channels to seek information about potential employers and vacancies. Additionally, they use certain modes of applying. Organizations need to adjust to these behavioral patterns and publish their vacancies in their preferred channels and adopt their most wanted application procedures in order to attract prospective employees. While IT recruiters do tend to focus on internet recruiting, at the same time various traditional recruiting modes were identified by our respondents as highly attractive: personal networks; referrals; internships; trainee programs; Bachelor and Master projects in organizations; career fairs; sponsorships; and adventure events such as practiced in ITconsulting. The initial information about most of these traditional means (e.g., when and where is the next career fair) also requires recruiters' effort, especially in terms of advancing their organizations' online image In this context, online referral systems; business networking sites; videos about organizations; search engine optimization; RSS syndication; employee blogs; wikis have been described as innovative preferred recruiting practices. Among the more traditional recruiting practices, especially personal networks and referrals were found the most attractive. Past research has shown that applicants who are recruited by current employees have a better person-organization and person-job fit, largely because current 
employees provide realistic job previews. Such internal information about their new job helps applicants to make easy transitions into their work environments. In a study of 767 engineers regarding recruitment sources and HR outcomes, Moser (2005) showed that applicants who had been referred by current employees achieved three HR outcomes; more job satisfaction; stronger organizational commitment and fewer unfulfilled job expectations.

The resource-based view supports the view that current-employee referrals help organizations to attract and recruit new, fitting personnel in efficient ways. Conceiving of one's current pool of employees as an idiosyncratic recruiting network, may thus aid in recruiting effectiveness. Applicants emerging through this networked channel tend to have not only realistic job expectations, they are better grounded in the given organizational culture and are fairly fast cognizant of their customers and competitors alike (Brandel, 2006; Moser, 2005). Lepak and Snell (1999) added to this that "developing employees" to this effect within an organizational context is a source of competitive or professional advantage because all valuable resources that are "weaned" in a specific organizational context are difficult to duplicate.

Based on Lepak and Snell's (1999) RBV staffing typology, we propose a staffing model of Dutch IT professionals' preferred recruitment practices (see Table 3). In this framework, preferred external recruitment practices include various internet practices such as company websites; online job sites; branch associations; email applications; networking sites; podcasts; RSS; online company videos; blogs; wikis; SEO. Further, preferred internal recruiting practices focus on employee referral including private or extended social or business networks, referrals via family and friends, former employers, word-of-mouth endorsements. Partnerships include company projects and career fairs. Finally, outsourcing the recruitment function does resemble the identified recruiting agencies in the form of employment offices and university career centers.

Both academics and recruiting practitioners need to note the continuous changes in recruiting practices which seem to stem to a large extent from new means of technology for interacting with applicants. All small and big changes in the various recruiting requires from IT professionals quite a bit of adaptation type skills as well. 
Table 3

Staffing Model of Dutch IT Professionals’ Preferred Recruitment Practices (Adopting from Lepak's and Snell's RBV Staffing Typology)

\begin{tabular}{|l|l|l|l|}
\hline$\#$ & $\begin{array}{l}\text { RBV Staffing } \\
\text { Typology }\end{array}$ & $\begin{array}{l}\text { Dutch IT Professionals' Preferred } \\
\text { Recruitment Practices (\%) }\end{array}$ & Staffing Characteristics \\
\hline 1. & $\begin{array}{l}\text { External } \\
\text { Recruitment }\end{array}$ & Internet Recruitment & $\begin{array}{l}\text { Company websites, online job sites, branch } \\
\text { associations, email, networking sites, } \\
\text { podcasts, RSS, online company videos, } \\
\text { blogs, wikis, SEO. }\end{array}$ \\
\hline 2. & $\begin{array}{l}\text { Internal } \\
\text { Recruitment }\end{array}$ & Employee Referrals & $\begin{array}{l}\text { Private or extended social or business } \\
\text { networks, referrals via university, family and } \\
\text { friends, former employers, word-of-mouth } \\
\text { endorsements. }\end{array}$ \\
\hline 3. & Partnerships & $\begin{array}{l}\text { Company projects } \\
\text { Career Fairs }\end{array}$ & $\begin{array}{l}\text { Bachelor, Master thesis, internships, summer } \\
\text { jobs, sponsorship. }\end{array}$ \\
\hline 4. & Outsourcing & Recruiting agency & $\begin{array}{l}\text { University career center, Employment } \\
\text { offices. }\end{array}$ \\
\hline
\end{tabular}

This qualitative study, based on in-depth interviews with 22 IT Dutch graduates, is not without limitations. First, the results cannot be generalized; it may not be representative of the whole population of Dutch IT graduates. Further, we do not know at present to what extent the identified categorization of attractive and unattractive recruitment practices easily transfer to other cultures. Quantitative studies are needed for more robustly uncovering linkages across larger samples of applicants behaviorally engaged in searching for IT jobs. However, this exploratory study provides at least three contributions. First, it offers a staffing model specific for young IT professionals. These findings give guidance to both practitioners and scholars on preferred methods of recruitment of Dutch IT professionals. This is particularly significant as the world (business) community is increasingly acting as a global market place and understanding of the favored modes of recruitment in other countries is a given for instance for foreign multinationals (Friedman, 2006; Meredith, 2007).

Second, the study strengthens the results identified in other European recruitment research (e.g., Girard \& Fallery, 2009; Strohmeier, 2007) that internet recruiting has become the preferred method of recruitment for IT professionals, and not only from the employer's perspective (as discussed in the recruiting literature). We show with this study how this applies specifically to the less studied applicants' points of view. The very nature of IT jobs involves a work environment to interact consistently with technology: reinforcing the concept of "technologies of practice" (Dery et al., 2006; Orlikowski, 1992). This idea suggests that expertise in any technology allows for personal and organizational efficiency. This reasoning implies that IT professionals prefer using internet recruitment as they have become very efficient in using technology and therefore realize personal efficiency. Third, whereas 
previous research has identified characteristics of traditional recruiting strategies that play an instrumental role in shaping applicants' perceptions of recruitment image, this study begins to address the relevance of recently emerging recruitment trends and associated web 2.0 recruitment modes. To the best of our knowledge, hardly any study to date has provided a grounded categorization of the preferred recruitment modes from young IT professionals' views, including the embedding in the relevant literatures. Importantly, not all internet recruitment mediums are preferred by IT professionals, e.g. a previously active practice such as Second Life recruitment (Laumer et al., 2008) are not catching Dutch IT professionals' interest anymore; and also social networks need to be applied here with caution. Our studied sample of IT professionals (who clearly differentiate between social and business networks) show a dislike for recruiters who endeavor to market, spy and communicate with them through private social networks.

\section{Conclusion}

In this study, we focused on young IT professionals' preferred modes of being recruited in the contemporary economy. We chose this group of highly trained academic labor because they are increasingly scarce at the moment in Europe while much needed in order to upgrade the quality and efficiency of organizational (back-office) processes. Moreover, they set the tone for recruitment-practice developments in other professional fields. We found evidence for the idea that ambitious recruiters need to continuously adopt recruiting practices, in line with applicants' preferred communication channels. Seen from a labor-market supply view, there is scant literature on how macro changes such as the diffusion of the internet; increased use of electronic human resource management tools (i.e., e-Recruiting); and the current economic changes have impacted IT professionals' job search behaviour.

Also due to increasing networked communications and competition among companies for hiring the best talent, recruiters need to know more about how the applicants deal with the recruiting channels. As job-entering university graduates are crucial in fulfilling high future demands in the IT sector, they also trail-blaze new recruiting practices. That is why we found it imperative to do in- depth analyses of young professionals' experiences and needs in terms of desirable and undesirable recruiting practices.

In sum, in this study we have first carried out a systematic content-analysis of the HRM \& IT literatures on traditional versus web 2.0 recruiting practices. We then conducted in-depth interviews with young IT professionals on what they find attractive and unattractive 
in current recruiting practices; we included in every interview our presentation of the practices salient in various relevant literatures and elicited their reactions to them; this way we captured a broad-based set of views of applicants being recruited for IT jobs; given that we carried out the interviews at the end of 2009, a particular downtown phase of the Western economy.

We found that young IT graduates in the Netherlands when searching for a first full time job use predominantly online recruiting channels. Concomitantly they see organizations that use web 2.0 recruiting practices as highly innovative, open, social and most positive. They find postal applications and telemarketing for recruiting purposes unattractive. Even during the current economic downtown that did actually hit the (Dutch and European) labor market, the interviewed young IT professionals appeared very self-confident of finding a job and being needed in organizations: to support cost savings and innovation enabled through process automatization and new technology. Searching behaviour for (IT-) jobs does still differ across professions and countries.

Therefore, e-HRM scholars might be interested to explore commonalities and differences for recruiting IT professionals among other countries to provide prescriptive guidance to human resource practitioners. The rising usage of information systems in staff recruitment, both on the employer and applicant sides, asks for innovative or integrated or consistent IT-HR strategies and methods of e-Recruiting. 


\section{References}

Agarwal, R., Brown, C., Ferratt, T. \& Moore, J. 2006. Five mindsets for retaining IT staff. MIS Quarterly Executive, 5(3): 137-149.

Agarwal, R. \& Ferratt, T.W. 2002. Enduring practices for managing IT professionals. Communications of the ACM, 45(9): 73-79.

Allen, D.G. \& Van Scotter, J. R. 2004. Recruitment communication media: Impact on prehire outcomes. Personnel Psychology, 57(1): 143-171.

Baker, E. 2006. IT talent shortage. CIO Insight, 73: 1-2.

Barnes, S. 2007. Virtual worlds as a medium for advertising. SIGMIS Database, 38(4): 4555.

Barney, J.B. 1986. Organizational culture - can it be a source of sustained competitive advantage. Academy of Management Review, 11(3): 656-665.

Barney, J.B. 2001. Is the resource-based "view" a useful perspective for strategic management research? Yes. Academy of Management Review, 26(1): 41-56.

Beenen, G. \& Mrousseau, D.M. 2010. Getting the most from MBA internships: Promoting intern learning and job acceptance. Human Resource Management, 49(1): 3-22.

Bitner, M.J., Booms, B.H. \& Tetreault, M.S. 1990. The service encounter - diagnosing favorable and unfavorable incidents. Journal of Marketing, 54(1): 71-84.

Bowman, G. W. 1976. Demand and supply of network television advertising. Bell Journal of Economics, 7(1): 258-267.

Boyd, D.M. \& Ellison, N.B. 2007. Social network sites: Definition, history, and scholarship. Journal of Computer-Mediated Communication, 13(1): 210-230.

Braddy, P.W., Thompson, L.F., Wuensch, K.L. \& Grossnickle, W.F. 2003. Internet recruiting: The effects of web page design features. Social Science Computer Review, 21(3): 374-385.

Brandel, M. 2006. Fishing in the global talent pool. Computerworld, 40(47): 33-35.

Bray, D.A. \& Konsynski, B.R. 2007. Virtual worlds: Multi-disciplinary research opportunities. SIGMIS Database, 38(4): 17-25.

Cable, D.M. \& Yu, K.Y.T. 2006. Managing job seekers organizational image beliefs: The role of media richness and media credibility. Journal of Applied Psychology, 91(4): 828840.

Cappelli, P. 2001. Making the most of on-line recruiting. Harvard Business Review, 79(3): 139-146.

Cober, R. T., Brown, D. J., Levy, P. E. \& Cober, A. B. 2003. Organizational web sites: Web site content and style as determinants of organizational attraction. International Journal of Selection and Assessment, 11(2-3): 158-169.

Collins, C.J. \& Stevens, C.K. 2002. The relationship between early recruitment-related activities and the application decisions of new labor-market entrants: A brand equity approach to recruitment. Journal of Applied Psychology, 87(6): 1121-1133.

Cox, A. 2005. What are communities of practice? A comparative review of four seminal works. Journal of Information Science, 31(6): 527-540.

Creswell, J.W. 2009. Research design: Qualitative, quantitative, and mixed methods approaches (3rd exp. and upd. ed ed.). Los Angeles, CA: Sage.

Denzin, N.K. \& Lincoln, Y.S. 2000. Handbook of qualitative research (2nd ed.). Thousand Oaks: Sage.

Dery, K., Hall, R. \& Wailes, N. 2006. Erps as 'technologies-in-practice': Social construction, materiality and the role of organisational factors. New Technology, Work and Employment, 21(3): 229-241. 
Dibbern, J., Goles, T., Hirschheim, R. \& Jayatilaka, B. 2004. Information systems outsourcing: A survey and analysis of the literature. Data Base for Advances in Information Systems, 35(4): 6-98.

Eckhardt, A., Weitzel, T. \& Laumer, S. 2008. Extending the architecture for a next generation holistic e-Recruiting system. International Conference on Information Resources Management, paper 27.

Ekelund Jr, R.B., Ford, G.S. \& Jackson, J D. 1999. Is radio advertising a distinct local market? An empirical analysis. Review of Industrial Organization, 14: 239-256.

Enneis, W., Ward, L.B. \& Athos, A.G. 1973. Student expectations of corporate life implications for management recruiting. Personnel Psychology, 26(2): 288-291.

Feldman, D.C. \& Klaas, B.S. 2002. Internet job hunting: A field study of applicant experiences with on-line recruiting. Human Resource Management, 41(2): 175-192.

Fernández-Aráoz, C., Groysberg, B. \& Nohria, N. 2009. The definitive guide to recruiting in good times and bad. Harvard Business Review, 87(5): 74-84.

Fish, A. \& Macklin, R. 2004. Perceptions of executive search and advertised recruitment attributes and service quality. Personnel Review, 33(1): 30-54.

Flanagan, J.C. 1954. The critical incident technique. Psychological Bulletin, 51(4): 327-358.

Friedman, T.L. 2006. The world is flat: A brief history of the twenty-first century (1st updated and expanded ed.). New York: Farrar Straus and Giroux.

Gallivan, M.J., Truex Iii, D.P. \& Kvasny, L. 2004. Changing patterns in it skill sets 19882003: A content analysis of classified advertising. Data Base for Advances in Information Systems, 35(3): 65-85.

Gatewood, R. D., Gowan, M. A. \& Lautenschlager, G.J. 1993. Corporate image, recruitment image, and initial job choice decisions. Academy of Management Journal, 36(2): 414-427.

Girard, A. \& Fallery, B. 2009. E-recruitment: New practices, new issues an exploratory study. International Workshop on Human Resource Information Systems, Milan, Italy.

Goldenberg, J., Libai, B. \& Muller, E. 2001. Talk of the network: A complex systems look at the underlying process of word-of-mouth. Marketing Letters, 12(3): 211-223.

Goles, T. 2001. A view from the entry level: Student perceptions of critical information systems job attributes, ACM SIGCPR Conference: 57-64. San Diego CA.

Guler, I., Guillen, M.F. \& MacPherson, J.M. 2002. Global competition, institutions, and the diffusion of organizational practices: The international spread of iso 9000 quality certificates. Administrative Science Quarterly, 47(2): 207-232.

Iyer, B. \& Davenport, T.H. 2008. Reverse engineering google's innovation machine. Harvard Business Review, 86(4): 58-69.

Jalleh, G., Donovan, R.J., Giles-Corti, B., D'Arcy, C. \& Holman, J. 2002. Sponsorship: Impact on brand awareness and brand attitudes. Social Marketing Quarterly, 8(1): 35 -45 .

Jepsen, T. 2009. IT challenges for 2009: Fixing the it infrastructure. IT Professional, 11(1): 4-5.

Kalleberg, A.L. \& Marsden, P.V. 2005. Externalizing organizational activities: Where and how us establishments use employment intermediaries. Socio-Economic Review, 3(3): 389-416.

Krugman, H.E. 1965. The impact of television advertising - learning without involvement. Public Opinion Quarterly, 29(3): 349-356.

Laumer, S. 2009. Non-monetary solutions for retaining the it workforce. Proceedings of the Americas Conference on Information Systems, San Francisco, CA.

Laumer, S., Eckhardt, A. \& Weitzel, T. 2008. Recruiting IT professionals in a virtual world. Proceedings of the Pacific Asia Conference on Information Systems, Suzhou, China. 
Lee, I. 2007. An architecture for a next-generation holistic e-Recruiting system. Communications of the ACM, 50(7): 81-85.

Lepak, D.P. \& Snell, S.A. 1999. The human resource architecture: Toward a theory of human capital allocation and development. Academy of Management Review, 24(1): 31-48.

Lievens, F. 2002. Trying to understand the different pieces of the construct validity puzzle of assessment centers: An examination of assessor and assessee effects. Journal of Applied Psychology, 87(4): 675-686.

Luftman, J. \& Kempaiah, R. 2008. Key issues for IT executives 2007. MIS Quarterly Executive, 7(2): 99-112.

Meredith, R. 2007. The elephant and the dragon : The rise of India and China and what it means for all of us. New York: W. W. Norton.

Miles, M.B. \& Huberman, A.M. 1994. Qualitative data analysis: An expanded sourcebook (2nd ed.). Thousand Oaks, CA: Sage.

Moroko, L. \& Uncles, M.D. 2008. Characteristics of successful employer brands. The Journal of Brand Management, 16: 160-175.

Moser, K. 2005. Recruitment sources and post-hire outcomes: The mediating role of unmet expectations. International Journal of Selection and Assessment, 13(3): 188-197.

Mumford, M.D. 1999. Construct validity and background data: Issues, abuses, and future directions. Human Resource Management Review, 9(2): 117-145.

Orlikowski, W.J. 1992. The duality of technology - rethinking the concept of technology in organizations. Organization Science, 3(3): 398-427.

Orlikowski, W.J. 2010. The sociomateriality of organisational life: Considering technology in management research. Cambridge Journal of Economics, 34(1): 125-141.

Orlikowski, W.J. \& Barley, S.R. 2001. Technology and institutions: What can research on information technology and research on organizations learn from each other? MIS Quarterly: Management Information Systems, 25(2): 145-165.

Ortiz, J.A., Tapia, A. \& Maldonado, E. 2006. Recruiting diverse, high-skilled it employees through existing virtual social networks. Proceedings of the SIGMIS, Claremont, California, USA.

Overby, S. 2006. The new it department: The top three positions you need. CIO, 19(6): 1-8.

Patton, M. Q. 2002. Qualitative research \& evaluation methods (3rd ed.). Thousand Oaks, CA: Sage.

Ployhart, R.E. 2006. Staffing in the 21st century: New challenges and strategic opportunities. Journal of Management, 32(6): 868-897.

Quester, P.G. \& Thompson, B. 2001. Advertising and promotion leverage on arts sponsorship effectiveness. Journal of Advertising Research, 41(1): 33-47.

Rogers, J.L. 1996. Mail advertising and consumer behaviour. Psychology \& Marketing, 13(2): 211-233.

Roy, D.P. \& Cornwell, T.B. 2003. Brand equitys influence on responses to event sponsorships. Journal of Product and Brand Management, 12: 377-393.

Sackett, P.R. \& Lievens, F. 2008. Personnel selection. Annual Review of Psychology, 59: 419-450.

Sartain, L. 2005. Branding from the inside out at yahoo! HR's role as brand builder. Human Resource Management, 44(1): 89-93.

Sartain, L. 2006. Brand from the inside, Leadership Excellence, 23: 18-18: Executive Excellence Publishing.

Shen, J. \& Eder, L. 2009. Exploring intentions to use virtual worlds for business. Journal of Electronic Commerce Research, 10(2): 94-103.

Smith, W.P. \& Kidder, D.L. 2010. You've been tagged! (then again, maybe not): Employers and facebook. Business Horizons, 53(5): 491-499. 
Strauss, A. \& Corbin, J. 1998. Basics of qualitative research: Techniques and procedures for developing grounded theory (2nd ed.). London: Sage.

Strauss, A. \& Corbin, J.M. 1990. Basics of qualitative research: Grounded theory procedures and techniques. Newbury Park, Cal.: Sage Publications.

Strohmeier, S. 2007. Research in e-HRM: Review and implications. Human Resource Management Review, 17(1): 19-37.

Sylva, H. \& Mol, S.T. 2009. E-recruitment: A study into applicant perceptions of an online application system. International Journal of Selection and Assessment, 17(3): 311323.

Takeuchi, K. \& Nomura, M. 2008. It-based industrial development in india and trends in human resources development with the aim of realizing a knowledge-based society. Quarterly Review, 26: 36-51.

Thomas, K.M. \& Wise, P.G. 1999. Organizational attractiveness and individual differences: Are diverse applicants attracted by different factors? Journal of Business and Psychology, 13(3): 375-390.

Thornton Iii, G.C. \& Gibbons, A.M. 2009. Validity of assessment centers for personnel selection. Human Resource Management Review, 19(3): 169-187.

Vermeiren, J. 2009. How to really use linkedin; discover the true power of LinkedIn and how to leverage it for your business and career. Charleston, SC: Booksurge.

Walker, H.J., Feild, H.S., Giles, W.F., Armenakis, A.A. \& Bernerth, J.B. 2009. Displaying employee testimonials on recruitment web sites: Effects of communication media, employee race, and job seeker race on organizational attraction and information credibility. Journal of Applied Psychology, 94(5): 1354-1364.

Williamson, I.O., King, J. E., Lepak, D. \& Sarma, A. 2010. Firm reputation, recruitment web sites, and attracting applicants. Human Resource Management, 49(4): 669-687.

Williamson, I.O., Slay, H. S., Shapiro, D.L. \& Shivers-Blackwell, S.L. 2008. The effect of explanations on prospective applicants reactions to firm diversity practices. Human Resource Management, 47(2): 311-330.

Withers, B. \& Ebrahimpour, M. 2000. Does iso 9000 certification affect the dimensions of quality used for competitive advantage? European Management Journal, 18(4): 431443.

Zottoli, M.A. \& Wanous, J.P. 2000. Recruitment source research: Current status and future directions. Human Resource Management Review, 10(4): 353-382. 


\title{
CHAPTER 7
}

\section{Sustainable e-Recruiting Services: How to Motivate Applicants to Stay Connected Throughout their Careers? ${ }^{10}$}

\begin{abstract}
Almost all e-Recruiting services are forgotten about by applicants who have found a new job, and they thereby inherently and notoriously suffer from outdated applicant profiles. This study seeks to get a programmatic handle on this endemic portal issue by exploring how to motivate applicants to keep their profiles up-to-date and stay connected with one specific recruiting portal throughout their careers. We interviewed three stakeholders - applicants, system analysts and programmers at a nationwide (Austrian) e-Recruiting service, and found striking differences in their interpretation of system requirements for long-term usage and loyalty. First, system analysts easily speak of future requirements and hypothetical possibilities to achieve competitive advantage and differentiate their company's e-services. During the interviews they quite spontaneously in narratives cast themselves into different roles and better empathize with user needs than did the programmers. Second, applicants describe system requirements in the form of past stories where the language is rich and inviting. Finally, programmers describe requirements in a rather abstract and analytical way, often not using full sentences and rather just isolated phrases referring to standards, code requirements, integration and code adaptability optimization. Many interviewees describe system requirements closely related to system, service and information quality criteria, a pattern in line with De Lone \& McLean's (2003) Information Systems Success Model. The implications of this in-depth survey of different vantage points more sustainable e-Recruiting research, design and development is sketched out in some detail.
\end{abstract}

Keywords: e-Recruiting, Sustainable Services, User Bonding.

\footnotetext{
${ }^{10}$ This paper has been published in the International Journal of Technology and Human Computer Interaction.

This paper has been selected for reprinting in Human Interaction with Technology for Working, Communicating and Learning: Advancements (66-86). (Ed). Mesquita, A., Information Science Reference: Hershey, PA, 2012.

A previous version of this paper has been presented at the American Sociological Association in the Communication \& Information Technologies Division, Worlds of Work: Communication \& ICT, MIT, Boston, USA, July 31, 2008.
} 


\section{Introduction}

Communication between customers using a web service and the staff responsible for the service's development (such as system analysts, programmers, web designers, system testers, etc.), although it is important in all phases of systems development, is normally almost entirely absent. From a sustainability point of view this communication is crucial, and is even more essential during requirements analysis. In its simplest form, requirements determination entails eliciting and encoding into the new system the requirements that potential and/or current users verbalize to system analysts. Usually, the analyst works with end-users to establish an understanding of their needs, then designs system alternatives and documentation of those requirements for the programmers. One consistent finding in the Information Systems (IS) archives is that development hinges on the communication difficulty between analysts and users (Bostrom, 1989); it is routinely problematic due to cognitive and vocabulary-type limitations (Byrd et al., 1992). There is a rich body of interview-type research documenting this commonplace mismatch in the expectations of analysts, programmers and clients.

Many IS researchers describe interviewing as the best elicitation technique for requirement analyses (Alvarez \& Urla, 2002). There of course is a diverse range of interview formats and techniques (e.g., structured or unstructured), but generally it is fair to say that in the final analysis they all depend on interactional talk between those who (re-)design or further develop the service and those who use it. Since the obtained data is, in this sense, partly a function of the talk between a (potential) client and a system designer, the study of this talk itself is central to comprehending how information is captured in this client-analyst link. Considerable attention has been directed to the problematic nature of system analyst-toclient communication, yet research focusing on the critical intermediate communication among system designers, programmers and users is rare. Hardly anyone has analysed their different interpretations of requirement specifications and communications outcomes (Pfleeger \& Atlee, 2010).

This chapter aims to help renew scholarship on requirements analysis in the context of sustainable e-Recruiting services. Based on in-depth interviews with users, system analysts and programmers of a niche e-Recruiting platform for engineers, I emphasize how differently these three stakeholders interpret system requirements for long-term usage. I elaborate upon their insight that so-called domain expert researchers (i.e., professionals with expertise in a specific related field such as e-Recruiting platform design) may add significant value to the 
enterprise from narratives of involved participants in a system-development project. Using an expert researcher for purposes of interpreting and comparing focused communication outcomes can dramatically improve the interpretation and perceived usefulness of the articulated experiences, e.g., reports of navigation troubles, of involved parties. This type of captured tacit knowledge may enable e-Recruiting provide a smoother portal and service and differentiate themselves from their competition. We first review the relevant literatures; we then present the research site and the collected data. Following, we illustrate the narrative analyses, results and derive concluding as well as future-study insights.

\section{Theoretical Background}

\section{IS Requirement Analyses and User Involvement}

The idea of involving users in IS development stems from the recognition that involving users provides multiple benefits. Potential users as a result of their pre-involvement may have increased desire to actually use the specific new/revised service, and may even enhance their experience of the service. It will likely further increase user accountability for the system's design, resulting in higher user satisfaction, commitment and reduced resistance to renewing or innovating services (Amoako-Gyampah, 2007). Generally, innovative and market-oriented development of new products and services has been associated with high-user involvement (von Hippel, 2007). A decade ago high IT-service success was shown to be a function of the active involvement of members of the user community (Doherty et al., 2003). Even earlier, it was found that development times was reduced when continuous acceptance tests occurred during service development (Iansiti \& MacCormack, 1997). What remains unknown and problematic is precisely the nature and degree user involvement needs to be organized into the (re)design process of services and their organization (Rondeau et al., 2006). It is acknowledged by almost everyone that involving users can lead to innovative service ideas, yet typically users' ideas are seen as too difficult to implement or too costly to realize. Overall, there is no widely accepted general definition of user involvement in the archives. . It has for a quarter century been identified as synonymous with contacting with users (Grudin, 1991), participation of users (Ives \& Olson, 1984), user-centred design (Noyes \& Baber, 1999), and user engagement (Wagner \& Piccoli, 2007).

It has been reported in the research literature that many system failures are due to the lack of clear and specific information requirements (Buchanan, 2007; Davis, 1989). Most development engineers have little or no experience as an end-user in the application domain 
for which they develop the software. Development is routinely technology (or solution) driven without a contextualized sense of those who will use it and the difficult specific issues that should be addressed. We very often offer products and services to customers not based on their actual needs but rather on what updated hardware and software packages allow engineers to do. In a study of information systems projects, Jenkins et al. (1984) found that over half of the examined systems had problems and required the analysts to return to the requirements analysis phase. Moreover, when as so often happens errors in requirements analysis are not found until later stages of the implementation process, costs or failure rates can rise significantly (Marakas \& Elam, 1998). Hence, determining accurate information requirements are very significant for both researchers and practitioners alike.

Given the costs consequent persistent problems of poor builds caused by an incorrect analysis of customer's requirements, it was inevitably that requirements analyses would come to play an increasingly important role in software development, Information systems implementations are notoriously difficult. A variety of difficult problems that present themselves when trying to obtain a robust set of system requirements, Requirements analysis is intensely interactive. In its simplest form during a systems development project it entails encoding into the new information system any requirements that users verbalize. The primary means for obtaining data is the direct interview (Holtzblatt \& Beyer, 1995). Interviews are recognized as a potentially rich but a notoriously difficult method of data elicitation (Moody et al., 1998). While some system analysts perceive user narratives collected in interviews as messy or uncodeable data, we find the insights they provide to be valuable. This may be especially true for e-Recruiting services which unlike other information systems, such as social or business networks, face far more struggles of maintaining active user (applicant) profiles. Hence, a better understanding of the stories, explanation and interpretations of users, system analysts and programmers for continued use of such portals should be very fruitful.

\section{Narratives and IS Research}

Narratives have been defined as tales, stories or the recital of facts, and usually are told in the first person. In this research tradition, stories and individuals' experiences rather than logical arguments are the normal vehicle through which meaning is communicated (Sarbin, 1995). Narrative theory can be seen as part of social construct theory, as meaning is assigned through definite processes of interaction. This account is also closely linked to Weick's (1995) emphasis on organizational sense-making. The narrative approach contrasts to rationalist 
perspectives because rather than explaining events by establishing their causes they are made understandable by being integrated within a sequence. In a similar vein Czarniawska (1997) describes narratives as interpretations of events which reflect significant issues the author wishes to dramatize and emphasize. Likewise, interviewees not only organize their world through these narratives, but as well perform stories consistent with their expectations, values and identity.

Research on narratives in the area of information systems, is a relatively new and expanding field. Davidson (1997) used narrative analysis to examine sense-making and interpretation during an IS development project. Scarbrough (1997) explored the idea of strategic IT as a particular form of social labelling. Brown (1998) examined the use of narratives that organizational members used to create meaning and gain political advantage during an IT implementation. In another case Brown and Jones (1998) examined a failed IS project and afterwards the kinds of individual narratives that emerged. Fincham (2002) explored a narrative perspective on success and failure in computer-systems development. Alvarez and Urla (2002) argued that in the field of information systems implementation narrative analysis provides richer information than data acquired in conventional systems requirements analysis. For all these investigators narratives provide a window into the pragmatic and emic perspectives of information system users. They argue these perspectives are valuable to the successful assessment and design of new information systems, and analysts should become more skilled at conducting and interpreting interviews. Hence, interviewers should actively engage in seeking stories from users, system analysts, developers, designers and testers, and interpret them to reveal their encoded information. Requirement analyses would not only benefit from the improvement of interview techniques, but also from more acute methods for analysing the rather messy qualitative data that interviewees provide. Bartis and Mitev (2008) recently combined constructionist and critical approaches, evolving a narrative methodology to discuss the launch of an information system.

I see the concept of identity construction as particularly useful for the art of conducting requirement-analytical interviews. During those interviews individuals express their thoughts, intentions, desires, feelings, values and attitudes. Put differently, in narrating our experiences and attitudes we define ourselves as the implied subject of the narrative, and possibly at the same time as members of groups sharing a similar identity (such as Programmer, System Analyst or User Identity or Professional of a certain organization). Through the elicitation of requirements, the interviewees are regarded as the source of knowledge. In this sense it is through linguistic expressions the interviewees' identities are 
produced. This chapter hopes to contribute to this growing corpus of research by analysing user, system designer and programmer narratives. The goal is to better understand and make use of different requirements produced by different interviewee groups. Interview-generated narratives from different involved stakeholders, mediated by a communicative or action researcher, will provide valuable insights into system-development projects.

\section{Research on E-Recruiting}

E-recruiting services have spread across the globe in the last decade. Although research into e-Recruiting is still sparse, surveys from professional organizations such as the Society for Human Resource Management (SHRM) frequently report on the staffing/recruiting area, and specifically online recruiting as one of the most critical HR duties. Until about five years ago most studies focused on applicant reactions (e.g., Dineen et al., 2007; Feldman \& Klaas, 2002; Zusman \& Landis, 2002). Research has sought to find out why companies and recruiters decide to use e-Recruiting (Parry, 2008). Further, Wolters' study of job boards found a negative relationship between the amount of information given for a job and the percentage of suitable reactions (Wolters, 2006). The emerging importance of e-Recruiting services to identifying talent and meet staffing is becoming recognized. Perhaps too many online career services are emerging -- in the current German market a new e-Recruiting portal is announced approximately every two weeks.

Unlike social networks, one key problem for e-Recruiting portals is that in general their registered users are not long-time active users. Usually, employees looking for a job tend to search through the published job ads and apply to the e-listed jobs. As soon as they have found employment there is hardly any reason to return to a site again. Consequently, large numbers of e-Recruiting initiatives fail (Feldman \& Klaas, 2002; Lin \& Stasinskaya, 2002). Another struggle involves the challenge of delivering semantically accurate search results when offering applicant-pool search functions. Besides this, posting resumes on job boards requires careful consideration of privacy and security issues. Often, both an applicant's and recruiter's name, address and phone number are displayed for anyone to see. Another problem e-Recruiting services face is the frequently reported dissatisfaction with slow responses from applicant pools. For example, consider business networks such as LinkedIn or Xing whose registered users tend to be employed and generally not easily motivated to switch jobs. While business networks are too slow in meeting urgent staffing needs, many general job boards are densely packed if not overloaded with job postings, invariably minimizing the visitors per job 
ad. Further, many online career services allow recruiting sites' visitors to upload resumes or fill out pre-defined online resume forms and find information about suitable job openings. However, some recruiting providers warn applicants that their profiles have a limited shelf life, e.g., 6 weeks and will then be deleted, so as to offer only up-to-date profiles. This widespread practice causes some frustration among many registered applicants who have spent a significant amount of time filling out resume forms. Other providers accumulate vast collections of resumes and advertise that they have the most registered applicant profiles. However, in such resume databases a vast number of the profiles are at any moment not upto-date -- the applicants having already found a job or their contact data having changed. This is especially important for recruiters who can search in large applicant pools because they may well not have effective access to their desired candidates. Hence, a major challenge e-Recruiting services face is to keep the applicants' profiles up-to-date. E-recruiting services also need to demonstrate their performance through high amounts of applicants visiting their sites, evidenced by clicking on ads; high ratings on page impressions; a high accuracy of the matching between job ads and resumes; and by their ability to quickly suggest appropriate candidates to recruiters (Smith \& Rupp, 2004; Zhao, 2006).

There has been a rapid growth of niche recruiting services entering the market. We assume that niche recruiting services are similar to niche communities. These are prototypically based on shared interests, and where the commonality of users will contribute to a higher sense of belonging to the platforms and a higher likelihood to remain and contribute to the shared goals of those portals. In general, communities depend on people visiting the sites, participating in social interactions, and on of users' loyalty (Kim, 2000). Although communities are conceptualized and studied in many diverse ways (Boyd \& Ellison, 2007; Knoke \& Kuklinski, 1982; Van Dijk, 2006), many researchers agree networked communities are best defined on the basis of shared identity, interests, and commonality among their members (Castells, 2004; Plickert et al., 2007; Preece, 2000; Turkle, 1995). Further, offline activities have been found to increase the solidarity of virtual communities and strengthen the ties between members (Ellison et al., 2007; Wellman et al.,2002; Wellman \& Haythornthwaite, 2002). It may well be that these concepts transfer to niche recruiting services (i.e., career community platforms). In sum, there appear to be sufficient justification for exploring actual user requirements that applicants, system analysts and programmers associate with sustainable e-Recruiting services.

Given the scanty academic research on these issues, our guiding research question is manifestly elementary: What system requirements do e-Recruiting services need to implement 
in order to motivate users to keep their applicant profiles up-to-date (even though they may have a job), and therein stay connected with one specific recruiting portal over their entire career?

\section{Method}

\section{Research Site and Data Collection}

The chosen e-Recruiting company aims to become Austria's leader in intelligent online recruiting and career networking for engineers. The company since its founding in 2005, has developed many partnerships with engineering schools and companies across Austria and obtained research grants for developing Web 2.0 technologies for e-Recruiting services. The company's employees' participate regularly in international conferences and are recognized within the www.drupal.org developer community. They also participate in international programming competitions and have regularly taken mentor roles at Google summer of code events. The company actively collaborates with its registered applicants, recruiters and developers in an effort to capitalize on and distribute knowledge for system design improvements (e.g., von Hippel, 2007).

Given our study's essentially exploratory nature, we adopted qualitative requirement interviews with registered applicants, system analysts and programmers. Our narrative research methodology focuses on understanding how interviewees deal with experience by constructing stories and listening to the stories (Riessman, 1993). All interviewed participants were asked about their ideas on system requirements that might get users to return to the site throughout their careers, and how to motivate them to keep their applicant profiles up-to-date.

We randomly selected one registered user from each Higher Technical School (HTL) in Austria from the recruiting database. The interviewees had a minimum of three years of work experience, and were interviewed by phone. Fifty-eight male engineers and two female engineers were interviewed, a sample which reflects the gender ratio for Austrian HTL engineers. The interviews typically lasted about 20 minutes. All telephone interviews were taped to capture the narratives. Also, during all interviews field notes about relevant and salient themes were taken. Further, on several occasions when interviewees had too little time for the interview or needed more time to think about their answers several follow-up interviews were done. In addition, we interviewed six system analysts and eight programmers experienced in e-Recruiting service development. These 14 interviews each lasted about an hour. Narratives were recorded with the consent of interviewees and preserved anonymously. 
We sought to gain their confidence in telling us their side of the story in a climate of trust. This was supported by the neutral investigation of a researcher rather than by the standard direct requirement interviews done between system analysts and end-users. We noted right after conducting the first interviews that across subjects' narratives there were several contradictions and overlaps of requirement specifications. Also, meeting minutes were compiled from several status-update staff meetings with system analysts and programmers. It is a generally taken for granted policy that system analysts record memos of their new ideas or requirements for system improvements. These memos are usually once a week computerized by an administrative assistant, allowing the system analysts to review, structure and publish their ideas on the company's project intranet site. We got access to the memos and studied the user-based system requirement comments. Programmers typically do not record memos, but rather enter their status updates on the same project intranet. On this project management site, programmers communicate textual messages via theme-oriented blogs, upload manuals, define milestones and schedule project tasks. We obtained a password and achieved full access to the digital communications. We also had the opportunity to access the e-Recruiting system, which provided us with a deeper understanding current features and functions of the software. While interviewing, tracking digital data, observing meetings and asking questions, we carefully wrote detailed field notes that were enormously valuable later when doing our in-depth analysis. Researchers such as Van Maanen (1995) regard field notes as the secret papers of social research that comprise the most important observations.

\section{Data Analyses}

We wisely heeded Buchanan and Dawson's (2007) suggestion narratives should be analysed in relation to the sense-giving and sense-making of other stories and interpretations. In this vein, our analyses of certain groups of interviewees seek to accommodate the overlaps, ambiguities and contradictions that are part of the storytelling process and audience interpretations. The great challenge lies in analysing components of data while also engaging in a meta-analysis that provides a synthesis that is both poly-vocal and represents coherently the meaning of the collected data. Hence, we followed the call for more informed studies that combine elements of narrative research and contextual analysis. We did not rely solely on stand-alone stories to understand the sense-making and sense-giving associated with interviewee experiences. We tried to understand the broader context in which repeated 
descriptions both account for and shape the processes of which they seek to make sense (Buchanan \& Dawson, 2007).

We first listened to all audio tapes of the interviews with the applicants, system designers and programmers, and then compiled narratives of salient parts of the interviews. Our strategy was to next compare these with the content of the field notes, meeting minutes and digital communications. During this lengthy process we identified broad themes in the data and reduced them to more precise categories (Miles \& Huberman, 1994; Yin, 2003). We went back and forth between the different perspectives of the three groups of interviewees and altered existing requirement categories as other categories emerged or were eliminated (see Table 1). We found this first structural analysis helpful for the purpose of getting a broad overview of emerging themes, categories and sub-categories.

In order to enhance theoretical grounding and to more comprehensively understand the interview text, we analysed the collected narratives. The emphasis during at this stage was on stories and based on the language and interactions specifically documenting users' intentions about returning to an e-Recruiting site and staying actively involved over time. Therefore, we included also intonation, volume, pacing and other qualities of speech to capture the feel of the interviews. Symbols used in the transcribed extracts were: Exclamation [!]; word emphasized by speaker [Italics]; pause [...]; hesitating $[<<$; \{nonlexical utterances ; [explanatory note]. Speakers were identified by I [Interviewer]; P [Programmer]; SA [System Analyst], U [User]. Our methodology of analysis was related Erving Goffman's (1981) remarks about requirement-analysis interviews, particularly his definition of "footing" as the relationship between speakers wherein speakers can take on several different social roles, from which they can move in and out. For example, at one moment a speaker may be a User of an information system and in the next moment a Programmer of a different system himself. Quite apart from Goffman's dramaturgical model, it is manifest that in everyday life as we speak we shift footing which helps us to establish relationship with others so that the meaning of what we say can be better interpreted and understood. We found these social interactions -- representing particular presentations of self and dynamic shifts between frames -- useful for analyzing the communication of users, system analysts and programmers. 


\section{Results}

Our guiding research question was: What system requirements do e-Recruiting services need to realize in order to motivate users to keep their applicant profiles up-to-date (even though they are employed) and stay connected with one specific recruiting portal over their career? We illustrate the results with precise detailed exemplary quotes from system analysts, applicants and programmers. A general trend among the three interviewee groups emerged. First, system analysts tend to talk about future requirements and hypothetical possibilities to achieve competitive advantage and differentiate their portal on the market. They tend to switch into different roles during the interview, and better empathizing with user needs than programmers do. Second, applicants describe system requirements in the form of past stories where the language is inviting and rich. Applicants also talked about their experiences with and perceptions of other effective and similar information systems they had used. Finally, programmers describe requirements in a rather abstract and analytical way, often not using full sentences to describe requirements. They repeatedly refer to standards, code requirements, integration and code adaptability optimization. Further, many interviewees describe system requirements closely related to system, service and information quality criteria of general website usage (DeLone \& McLean, 2003). Table 1 presents a summary of the interview results. The following passages portray several conversations between the interviewer and the study participants.

\section{Requirement Interview with System Analysts}

1. I: I want to find out what system requirements that e-Recruiting services need to realize so as to motivate users to keep their applicant profiles up-todate $\{\mathrm{um}\}$ and stay connected with one specific recruiting portal over their career stages.

2. SA: Well $\{\mathrm{um}\}$; first of all, we have to make sure that we list as many jobs as possible; we need to list all jobs available in a specified region [!] This means, we need to develop a sophisticated job crawler that automatically collects new listed jobs from all existing websites in Austria that have job openings for our target group.

3. I: Why is this so important?

4. SA: If we have all the available open engineering jobs online for our niche group, then users might use our system rather than the general job boards 
which are overloaded with many irrelevant job postings. [SA shakes head, laughing].

5. I: $\{\mathrm{um}\}$ but if you have so many jobs, the clicks per ad may be fewer, no?

6. SA: You need to make the service more exclusive so that people feel good. $<<$ only registered users should be able to see all job postings. This way, we will get more people to sign up and make them curious and come back.

7. I: But why should the users keep their profiles up-to date just because you have many jobs for the specific niche?

8. SA: After you get the job crawler right, you need to give them accurate and customized search results. [...] Sure, users will most likely not return to our website and maintain their profiles if they get disappointed with our search.

9. I: So what does this mean?

10. SA: This means, we have to improve the semantic matching [!] and integrate users' voice by crowd-sourcing and build up adaptive skill ontologies. [...] If users get bad job search results and are overloaded with job offers that don't fit their applicant profile, they are more likely to lose trust in the quality and credibility of our platform. It's a waste of their time to look through irrelevant job postings. If our goal is to get them come back to the site, we should work to provide better search results than other providers."

11. I: Well, [...] I guess there are many platforms out there with good search results, so why exactly should the users re-visit your e-Recruiting service for the long run. Many have already found a job, so why re-visit the site?

12. SA: It comes down to niche portals. They are arranged around users who have something in common, who share something $<<$ whatever this is, doesn't matter. $<<$ Our internal analysis shows $<<$ listen, what really matters is that recruiting services should develop strong ties with specific niche communities, educational portals or branch networks $\{\mathrm{um}\}$ and get users to sign up when they still have offline ties to other potential users. If you get a whole network of people sign up together, $\{\mathrm{um}\}$ whole graduating classes this is the best[!] This will certainly have an impact on user return rate.

13. I: But $\{\mathrm{um}\}$ usually they already have alumni clubs, what's the advantage? 
14. SA: The advantage is that they can simply keep in touch $\{\mathrm{um}\}$ and follow each other's career paths. [...] If they just sign up for the sake of getting a job and cannot connect with people online, the career site has little to offer other than at the time the applicant searches a job.

15. I: So why should they maintain the profile then?

16. SA: Just look at facebook, myspace or studivz [!] they maintain their profile because their friends do also, so if you get people who have connections with each other, they are more likely to continue these connections online, for whatever reason, if this is about jobs or something else. In our case it's jobs."

The interview opens with the general question about how e-Recruiting portals can achieve an actively participating user base. The system designer responds with "first of all”, indicating to the listener that he will describe a list of events or actions that over time will enable them to get users to come back to the site, rather than what will take place at a specific point in time. He speaks in the plural, indicating that he thinks and works in terms of "we" instead of "I." Specific suggestions included listing all jobs available in a specified region, and continuously updating the job offers for specific target groups or niches so that users see highly relevant content. The interviewer inquires about the importance of these suggestions.

The system analyst then makes hypothetical statements ("then users may rather use our system") and blames the inefficiencies of general job boards on the fact that many list irrelevant and do not list niche-specific job postings. The interviewer keeps challenging the system analyst by more directly questioning his narratives. An argument to make the service exclusive followed, wherein "only registered users should be able to see all job postings."

Finally, the system analyst got back to the sequence begun at line 2 - "After you get the job crawler right, you need to give them accurate and customized search results". He concluded by explaining how to improve the semantic matching and integrate users' voice by crowd-sourcing and building up adaptive skill ontologies. In this sense, he suggested the registered user community play be an active part in the evolution of the portal. The analyst further identified future requirements, deriving hypothetical possibilities to achieve competitive advantage and differentiate the portal on the market. The interviewer maintained a critical voice. The system analyst then came to the conclusion that what really matters is receiving many users from niche communities who have strong offline ties with other potential users. However, the interviewer countered that some users may already be part of other alumni networks. The system analyst also strongly emphasizes the claims that for the 
"whole graduating classes this is the best [!] This will certainly have an impact on user return rate" which should be presented as a hypothesis about what could prove to work, i.e., sustain recruiting portals. For example, in the context of designing active communities, research has been conducted on how to improve community-support systems design (Geib et al., 2005; Rheingold, 2000). The analyst concludes by searching for the universality of his responses "If you get people who have connections with each other, they are more likely to continue these connections online, for whatever reason, if this is about jobs or anything else. In our case it's jobs".

\section{Requirement Interview with Users (Applicants)}

1. I: Can you think about system requirements the e-Recruiting portal where you recently registered would need to realize so as to motivate you to keep your applicant profile up-to-date [...] and also to stay connected with this specific portal over your career stages?

2. A: I was wondering $\{\mathrm{um}\}$ you must have many people registered in the engineering portal, and probably I know some people who are registered there. I have been out of school already a couple of years and lost touch with most of my former schoolmates. However, in your resume forms I had to fill out my graduating year and my school. So I would be interested what careers those people have now.

3. I: How could this be done?

4. A: You have all the data and the database behind. Just open the platform for search so that people see who is there.

5. I: What do you want to do, just find their profile and that's it?

6. A: Maybe they work in some interesting company where I am also interested, we could exchange experiences. [...] Or they went to some graduate school that I am interested in.

7. I: How could this system requirement be realized?

8. A: I don't know [...] maybe a forum, blog or something like that where people can discuss job-related stuff. I am on studiVz.de, there you can put up more stuff about yourself, not just stuff about your job, but fun stuff. All kinds of community or social network features would enhance the current e-Recruiting platform. 
9. I: Would you use the recruiting platform more intensely and for the long run if it included such community features?

10. A: I don't have much time. $\{\mathrm{um}\}$ I am already on several networks. On the other hand, $<<$ I spent 5 years in this school. I am an HTL engineer like many others. I would use it if there are people I know. I would not just link up with strangers. I have a job now, $\{\mathrm{um}\}$ so I would not use it for getting a job right now, maybe in the future. Currently, I would only like to see who else is there, how many folks from my former class, school are registered and then get in touch with them, it's also easier than calling.

11. I: Do you primarily communicate about job-related things in such a platform? $\{\mathrm{um}\}$ What are the information requirements, the necessary contents on the platform?

12. A: It is a starting point to talk about jobs. $<<$ This is a recruiting portal right, so you could blog how work is in different companies, how much they pay or how the work climate is. Maybe for the recent graduates some help in preparing application documents or interview tips. It is more authentic if it comes from fellow graduates than from some external agency.

13. I: What else could such a portal offer so that you and other registered applicants come back and re-use it?

14. A: Nowadays privacy is an issue. $\{\mathrm{um}\}$ How can you make sure $\{\mathrm{um}\}$ that my current boss will not find my profile in the database? I would prefer to have a private and a public profile, one for friends and one for the rest of people. Also, there needs to be the possibility to deactivate my profile, hence including many options of profile setting is an issue so that I would maintain my profile there.

15. I: What else matters to you?

16. A: Most important is the job aspect. I would find it interesting to follow others career paths. However, only talking about jobs is boring. I spend some time on games. Probably some possibility to play games with other users, maybe even solving some tricky technical question together, some intelligence games, I always liked to play games. 
17. I: Now, when you think about rather technical system requirements, what comes into your mind?

18. A: First, the site needs to load fast and be accessible all the time, I need to find stuff that I am looking for, it needs to be easy to get my things done, if this concerns applying for a job or blogging or linking with other users. I already lost some resume data at other portals, I certainly will never return to a site where I invested time and lost my data.

The usefulness of networked online communities evident in the above interview above has already been discussed with reference to e-Recruiting. For example, Butler (2001) claims online career services - beyond being instrumental career-move services - may be seen and understood as virtual social communities rather than only. Khapova (2006) argues that to grasp the various ways people make use of online career services studies should include the design principles of a traditional community as well as incorporate social network research. Some researchers support the idea that innovative online career services require more "crossfertilization" among users and those who design und sustain services (Khapova, 2006; von Hippel, 2007). There is significant warrant to assume that e-Recruiting platforms can only be sustainable if they transform into highly participative and continuously innovating ecommunity platforms organized around niches of users sharing a similar social identity. This requires rejecting the traditional presuppositions about e-Recruiting, namely the "one-sizefits-all” Monsterboard-type services, in lieu of more customer-centric and niche approaches. Hence, exchange-based e-Recruiting platforms are challenged to transform into lasting career networks.

Many of the interviewed engineers noted the need in Austria for a common online career service for all HTL engineers. In particular, they have been frequently found it easier to keep in touch with and follow their fellow students' career paths with an integrated social network and community features running within career services. One engineer noted: "When getting a job in a different location in Austria, it's great to search if any of my schools' graduates works in the same area or company.” In this sense, some researchers suggest that people use communities ${ }^{11}$ by merely adding internet contact to existing telephone and face-toface contacts, or by adding a clone of their normal means of communication to the internet ( Wellman et al., 2001; Wellman et al., 2002). This also seems to apply to most of the interviewed applicants who want to easily renew contact with former classmates via the

\footnotetext{
${ }^{11}$ Examples are facebook, myspace or friendster.
} 
platform. Our informants identified a wide range of ideas they wanted to exchange online with fellow engineers (see Table 1, Information and Social Requirements). They predominantly intend to communicate online with fellow acquaintances known offline from their schools or via extended networks (friends of friends). Interestingly, they did not seem to be keen on imitating a network with fellow engineers who were fully strangers. Fifty-six of the sixty engineers reported they would use an online career service for the long run if it were specifically targeted at engineers' needs. In contrast, the majority of these users indicated they were not inclined to sign up at a general online job board that attracts the full range of job seekers. General jobs boards are seen as exchange-based career tools for finding a job when needed, but among the interviewed users it was not desirable to connect online in such job boards with unknown users.

Social presence theorists (Biocca et al., 2003) argue that the presence of other members (which can be complemented by offline interactions) may foster the ties of community members to their online community. It would thus seem paramount to recognize and understand the full range of determinants of long-term sustainability of online career communities, from how users judge online features, such as the quality of a career community's service, its system, and the provided information (DeLone \& McLean, 2003), to offline features such as the routine activities of users (Wellman \& Haythornthwaite, 2002). Offline activities have been found to increase the solidarity and cohesiveness of virtual communities, and they strengthen the ties between members. A better understanding of the match between what is being offered (the supply) and (potential) users' interests has been found to be helpful in promoting a stronger desire to participate and interact with other members, leading to shared feelings of belonging, responsibility, and commitment to the community (Kim, 2000). In brief, when developing recruitment sites the social identity of various user segments needs to be seriously taken into account throughout, from day one. . We noted engineers were very open to interacting with their fellow engineers, online as well as offline. It is ironic that hyperspace has been so tardy in finally catching up with the title of Emile Durkheim's famous $19^{\text {th }}$ century dissertation The Division of Labour in Society. These insights offer a fairly new network opportunity for transforming classical "job boards" to sustainable "career communities."

Engineers' impressions of the webpage and resume forms were largely positively evaluated and regarded as meeting users' needs, as reflected in the words of one young engineer: "I was impressed how well this career service knows the details of my specific subjects of study, and guides me though the online application by making suggestions. I have 
already filled out other online resumes at some corporate homepages, but none of the other forms has been so carefully adjusted to the profile of an HTL graduate." Some engineers were slightly put off by the rather lengthy resume forms or the support of uploading larger files. It appeared important that the career site is clearly structured into sections for applicants and companies. A recurrent set of important factors requisite to re-using the service emerged: a feeling or sense of privacy and of being in control; enabling social connections with peers; integrating playful features; easy navigation and quick loading of the pages (see also Davis, 1989; DeLone \& McLean, 2003). Many users supported the portal making it possible to designate themselves in their own career profile as either an active or a passive job-searcher. System designers are must somehow meet the important challenge to create private (for friends) and public (for HR recruiters) spaces for the users' applicant profile, an essential tool for building trust and warding off the fear that confidential personalized resume data will be misused. As one engineer described: "How can you make sure that my boss will not find my profile in the database?" and "Sure, I want my profile for friends to look different than my applicant profile."

Let us sum up the main points the reader should take away from my account so far in terms of another interview. It is evident that many of the identified requirements just outlined overlap with the archival identified criterion of e-service quality, particularly that e-Recruiting services should pay close attention to users' social and psychological requirements by enhancing self-esteem, fostering a sense of privacy and a feeling of being in control, and enabling social connections with peers and integrating playful features.

\section{Requirement Interview with Programmers}

1. I: When you think about your programming work $\{\mathrm{um}\}$ what can you do, $\{\mathrm{um}\}$ I mean what kind of system requirements can you think about so as to motivate applicants to keep their profiles up-to-date and re-visit this specific recruiting portal over their career stages?

2. P: Include cookies so that users remain logged in and system recognizes returning users $\{\mathrm{um}\}$; and when they open our website, automatically move cursor to $\log$ in.

3. I: Why is this so important?

4. P: Always logged-in [...] rather re-visit the site when specifications are set that way. 
5. I: Interesting. Anything else from the developing side that you can do to get applicants to be more active and re-visit?

6. P: APIs, clearly define applications for integration, $\{\mathrm{um}\}$ open ID integration, [...] Ajax, $\{\mathrm{um}\}$ [Interviewer expresses uncertainty what the terms mean] accessible on every internet browser, $\{\mathrm{um}\}$ sure strong hardware [...] good code is modular, allow modules to be built, tested, and debugged independently [...] SPI plug-in interface, enabling multiple implementations.

7. I: Well, $\{\mathrm{um}\}$ there are a lot of different things. $<<$ First, what is and how do APIs and open ID integration motivate applicants to keep their profiles up to date and re-visit the site?

8. P: API stands for application programming interface. It saves time. Optimizing APIs helps to access parts of other sites and integrate it with our own site. This is good for users, because APIs guarantee that other programs using a common API, e.g., other social networking sites will have similar interfaces. $\{\mathrm{um}\}$ So API-like interfaces allow applications on different platforms or written in different languages to interoperate. This makes it much easier to integrate stuff, e.g., your personal profile from other social networking sites, easier for users to learn new programs, saves time, convenient.

9. I: So why is this in particular important for e-Recruiting sites?

10. P: It is not just for e-Recruiting sites, developers in general need to think about including APIs in whatever applications they develop, especially if they expect the applications to last and interact with other applications. It saves time for users and developers if you include APIs, it's also easier to review the source code.

11. I: And because it saves time, they are more likely to update their profile and stay connected?

12. P: $\{\mathrm{um}\}$ No, but everybody has many other profiles, has signed up elsewhere, so if they can use their personal data that they typed in elsewhere, it is convenient, take all your data with you, all your friends etc.

13. I: What else is important?

14. P: HR-XML interface to link the recruiting platform to different 
companies, this make the communication and data transfer more efficient.

15. I: What does this exactly mean?

16. P: Then the applicant can directly apply to more companies at once by only filling out the profile only one time, this would be one application, for instance. So, they would re-use the site because it is convenient.

17. I: What else can motivate applicants to keep their profiles up to date and re-visit the recruiting site?

18. P: It depends if they want news and what kind of news. News reader that displays RSS feeds about or any other content they want to keep up-to date. The applicant needs to have enough customization options without having to regularly check the site for updates, they don't need to re-visit the page if they get the info via newsfeed this is also fine.

19. I: Ok, I understand.

20. P: And also the standard things SEO $\{\mathrm{um}\}$ SOA $\{\mathrm{um}\}$ don't use strings if a better type exists $\{\mathrm{um}\}$ coupling between software components so that code can be reused $\{\mathrm{um}\}<<$ WSDL $\{\mathrm{um}\}$ UDDI [...] SOAP which allows different distributed web services to run on a variety of software platforms and hardware architectures $<<$ Choosing the proper language, java is really good when it comes to platform independence. Sorry, I don't know if this all makes sense to you, I mean for programmers this is all standard requirements to think about when coding.

21. I: You are right, $\{\mathrm{um}\}$ there are a lot of terms that I am not familiar with. Nevertheless, I will note all of them. Just continue what you think matters most in respect of developing sustainable e-Recruiting portals.

22. P: You always have to balance between pre-defined standards, e.g., within the specific software you are using but also develop customized solutions, e.g., for specific user niches. Also, you should follow the WCAG, web content accessibility guidelines. [...] Privacy settings, SSL encryption is an important issue [!] due to all the sensitive data we collect from the applicants.

23. I: In how far do privacy settings help you to get them back and re-visit the site?

24. P: There is much going on with data abuse, hence you have to offer very 
transparent ways so that users fully understand what happens with their data $\{\mathrm{um}\}$ who has access to their profile, so that they trust your portal.

While system analysts tend to describe requirements more from a long-term strategic and market-oriented point of view, the interviewed programmers based their arguments on purely technical requirement specification. Programmers use technical terms and abbreviations (e.g., APIs, Follow WCAG Guidelines for, e.g., disabled users, open ID integration, Ajax, SSL encrypted etc.) when referring to system requirements. It is interesting to note that programmers can in fact explain many coding procedures they apply in order to get applicants to be more active and to re-visit e-Recruiting sites. In the programmers' talk, we find frequent use of generalizations. For example, they mention that some features are not solely focused on enhancing user loyalty to a specific e-Recruiting service, but rather for general website retention. Also, many features are described as standard in coding. Moreover, programmers claim they do not necessarily require users to re-visit a website so as to accomplish user retention. They describe customized communication means such as a news reader that displays RSS feeds which allow applicants to remain updated and active users without needing to regularly to re-visit the website. .

\section{Conclusion and Outlook}

This paper addressed what it takes in e-Recruiting to achieve active long-term participation by users (registered applicants). We conducted requirement interviews with registered users, system analysts and programmers. By drawing on raw data collected in system requirement interviews and engaging in narrative analysis of rich and meaningful patterns of emergent insight, we arrived at coherent interpretations about how to wisely evolve an e-Recruiting system for the long-term. The involvement of an e-Recruiting researcher who acted as intermediate analyst and interpreter of the collected interview data helped to reveal new perspectives. Although my analysis is qualitative and interpretative in nature, the theoretical stance put forth helped to blend together an insightful coherent interpretation of multi-voiced divergent narratives in IS requirement analyses interviews. The users' perspective indicates that it is plain insufficient to just develop niche portals for specific applicants (such as engineers, lawyers) or field segments (such as chemistry, pharmacy). What seems to have an influence on users' active long-term participation in niche portals is the opportunity to maintain communication with other professionals (in our case engineers) who already know 
each other from their school days, offline network or via friends of friends (FoF). We find that applicants are more likely to re-use e-Recruiting services (and keep their applicant profiles up-to-date) if the services are transformed into highly participative career communities organized around niches of users sharing a similar social identity, common interests and preexisting offline ties. The interviewed engineers appeared eager to reinvent their offline interactions with fellow engineers into online interactions in niche-based career communities if they saw doing so an opportunity for career advancement. They are also willing to maintain these online ties if within these groups they are sharing a similar social identity offline (before entering the online career community). Thus, we our investigation corroborates Boyd's finding (2008) that users of online communities are looking to do more than just meet new people. Instead, our informants - the engineers - primarily expressed interest in communicating with people who are already a part of their extended offline social network. Further, the interviewed system designers described system requirements more from a longterm strategic and market-oriented point of view, whereas the programmers based their arguments on purely technical requirement specification. Given that the language and the expression of requirement specifications of the three stakeholders are very different, we conclude the inclusion of a neutral researcher as observer, interviewer and data analyst provides meaningful new insights in system requirement analysis.

This study's limitations (especially the sole focus on one niche e-Recruiting service) may suggest to some readers that the findings point to only one of many possible interpretations. Nevertheless, the collected wide range of data (memos, taped interviews, digital and textual data, meeting minutes) embody a multi-threaded chain of evidence that is necessary in achieving reliability in qualitative research (Yin, 2003).

On a practical level our advice to niche career platforms is that they are wise to complement their traditional job posting services with social network and community applications so their hard won users can find, connect with and/or follow their peers' career paths. Our results suggest that e-Recruiting portals require not only useful information sections on careers and continuing education, but can also encourage social exchanges of their users if they perceive that doing so might contribute to advancing their careers. The future is likely to belong to those providers who rethink the elusive nature of loyalty in hyperspace, and to best understand their users' shared social identity. Once they grasp this they should strive to provide semantic technologies that genuinely enhance users' online experiences in terms of social exchange, self-esteem, privacy, sense of control and playfulness. 
Table 1

\section{Requirement \\ Specifications}

System

Requirements

Users (Applicants)

- Fast loading of website

- Stable system availability

\section{System Analysts}

- Fast and strong server, stable system availability

- Strong hardware: smooth when more users are online

simultaneously, Optimization of software

- Strong software

- High reliability

- Possibility of different profile views for friends and - Optimize back-up capability

public view

- Different options to determine privacy settings

- High security and privacy settings, invitation by friends necessary to register, making platform exclusive.

\section{Programmers}

- Accessible on every internet browser

- Strong hardware equipped for heavy demand, high server power

- Keep updating software to enhance possibilities for user

- When opening website, automatically shift cursor to log-in box

- Include cookies so user remains logged-in and system recognizes returning users

- Ajax

- Privacy, SSL encrypted

Define processes, interfaces e.g., HR-XML to link the recruiting platform to different companies and make the communication and data transfer more efficient so applicant can directly apply to more companies simultaneously by filling in profile only once

- SPI, SEO, SOA, WSDL, UDDI, SOAP

- Modular code structure, re-useable code and possibility to extend the code, documentation, tests, layering

- Balance between pre-defined standards of specific software and developing customized solution

- Code reliability, nodes relevance, debugging

- Multilingual capability

Information - Timeliness: latest news, latest and many relevant Requirements

customized job postings, structured conten
- Send job updates

- How to prepare application documents

- Interview tips

- Blurbs on trainee programs

- Links to companies, internal contact persons

- Company Career Day blurbs

- Online story pages

- First years as an engineer

- My worst and best career start

- Not overloaded

- Download section

- Salary calculator, Alumni calendar

- Career ABC, search for A (Audi), B (BMW) and

link with users' experience reports

- Branch categorization

- Links to continuing education

- Technical blog
- Timeliness: whenever revisiting the page, provide new content and target specific information: new jobs exactly meeting my skill set and search specifications, new statistics about me: how do I score compared to others, automatic updating of contents, surprising news and experiences

- Concrete use meeting/exceeding expectation: leave data active for your next career move, communicate that the portal is an asset to retain contact with throughout life, renew your online applicant profile so that you get better job offers, possibility to use free applicant page with individual address e.g. www.fhabsolventen.at/lastname_firstname

- Don't overload page: list only relevant jobs for user's niche

- Classify contents carefully e.g., jobs meeting a certain threshold and related jobs

- Job notification where only few people have applied and matches own skills

- Education \& employer matching: which employer pays best for certain graduates/skills

- Show educational offers if skills are missing for a specific job ad
State-of the-art in all features compared to competitors

- Classification of content

- Relevance matching, multivariate ranking (e.g., show me only jobs from companies $>5000$ employees)

- Video tutorial to show what page offers, how to register, navigate, connect with user, ask questions etc.

Faceted search and browsing

- Filter content using multiple taxonomy terms simultaneously

- Search Engine Optimization (SEO)

- Push services add-ons (sms or email) rather than pull services 
Table 1

\section{Requirement Users (Applicants)}

\section{Specifications}

- Community and Social Network features:

possibility to connect with friends and $\mathrm{FoF}$ and

follow each other's career paths, share pics, reports

Social exams etc.

Requirements - Entertainment/ Playfulness: Typical community features: inviting, blogging, tagging etc.

- Interest groups for shared hobbies, sports, music, companies, travel etc.

- Discussion board, social support from community about how to deal with negative job experiences

Psychological - Reputation: word of mouth, who of my friends

Requirements know and use the portal, experience reports about good internships, highly recognized jobs at certain companies

- Self-esteem/competency features: games with other users involving technical problems, ranking of best players

- Success rate of placements: return if I or my friends received good jobs via the portal

- Feel of control: many adjustment possibilities in privacy settings, different newsfeed selection options, moderated content

\begin{tabular}{ll}
\hline Service & - Responsiveness of recruiters to applications \\
Requirements & - Responsiveness to blog posts with questions \\
& - Active profiles of other users in the database \\
& - Friendly emails and other communications even \\
& though I might not be their ideal candidate \\
& - Range of possibilities (services) \\
\hline Ease of use & - High usability \\
& - Quick and easy registration \\
& - Easy navigation \\
& - Possibility to upload different files, i.e. resume and \\
& testimonials (doc, pdf, jpg etc.)
\end{tabular}

\section{System Analysts}

\section{Programmers}

- Community and Social Network features: provide applicants with - APIs, define applications for integration of other social network the possibility to link to friends, common interest groups e.g., VIP features

club of Company XY, ccommonality of interests, goals - Open ID integration

- API Interface to other social networks, open integration of contacts

- Follow WCAG - Web Content Accessibility Guidelines for e.g., disabled users

- Entertainment/ playfulness: e.g., fun factor, applications to enable comparisons with others, registered users, friend compare etc.; functions that applicants enjoy, curiosity, possibility for interactions (tagging etc.) with other registered users

te on users profiles of site visitors

- Reputation, credibility, high quality standards, blogs about experiences, word of mouth advertising, make site more known by e.g., search engine optimization, user reports of successful placements, transparency of information

Self-esteem/competency features: ontology extension e.g., molecular biology - offer applicants different terms and ask them to order these into specific ontologies (crowd-sourcing). If one user becomes domain expert (e.g., 10 persons order it the same way in one field, give user credits and enable to use score for resume, invite former employers to provide online recommendation

- Feeling of control: adjustment possibilities, moderated conten

- Check your market value: challenge users with intelligence games, rank users, cause users to search for a job ad where they are the top candidate, show me how I rank compared to other users, friends in my network, all graduates from a specific school.

- VIP/insider community of certain companies

- Responsiveness of recruiters, customer representatives and other - Feedback forms users to requests

Communications: different channels: email, chat, phone, video - Service representative contact forms interviewing, blogging etc.

- Customer representatives training, routines, fixed times to get back to applicants

- High usability

- Easy navigation: sub-menus, put similar contents together, different views for different user needs, e.g. , structural or iconbased

- Appearance: harmonic colors, proportion of text and button

- Ongoing usability testing with users, FAQs, video tutorial,

analyze website navigation and understanding of textual meaning for different user groups

- Design appropriately for target group (age group, branches etc.)
No

\section{- High usability}




\section{References}

Alvarez, R. \& Urla, J. 2002. Tell me a good story: Using narrative analysis to examine information requirements interviews during an ERP implementation. Data Base for Advances in Information Systems, 33(1): 38-52.

Amoako-Gyampah, K. 2007. Perceived usefulness, user involvement and behavioral intention: An empirical study of ERP implementation. Computers in Human Behavior, 23(3): 1232-1248.

Bartis, E. \& Mitev, N. 2008. A multiple narrative approach to information systems failure: A successful system that failed. European Journal of Information Systems, 17(2): 112124.

Biocca, F., Harms, C. \& Burgoon, J.K. 2003. Toward a more robust theory and measure of social presence: Review and suggested criteria. Presence-Teleoperators and Virtual Environments, 12(5): 456-480.

Bostrom, R.P. 1989. Successful application of communication techniques to improve the system-development process. Information \& Management, 16(5): 279-295.

Boyd, D.M. 2008. Why youth (heart) social network sites: The role of networked publics in teenage social life. In D. Buckingham (Ed.), Youth, identity, and digital media, 119142. Cambridge, MA: MIT Press.

Boyd, D.M. \& Ellison, N.B. 2007. Social network sites: Definition, history, and scholarship. Journal of Computer-Mediated Communication, 13(1): 210-230.

Brown, A.D. \& Jones, M.R. 1998. Doomed to failure: Narratives of inevitability and conspiracy in a failed is project. Organization Studies, 19(1): 73-88.

Buchanan, D. \& Dawson, P. 2007. Discourse and audience: Organizational change as multistory process. Journal of Management Studies, 44(5): 669-686.

Buchanan, R. 2007. Understanding your users: A practical guide to user requirements: Methods, tools, and techniques. Design Issues, 23(1): 92-92.

Butler, B.S. 2001. Membership size, communication activity, and sustainability: A resourcebased model of online social structures. Information Systems Research, 12(4): 346362.

Byrd, T.A., Cossick, K.L. \& Zmud, R.W. 1992. A synthesis of research on requirements analysis and knowledge acquisition techniques. MIS Quarterly, 16(1): 117-138.

Castells, M. 2004. The power of identity. Oxford: Blackwell.

Czarniawska, B. 1997. Narrating the organization: Dramas of institutional identity. Chicago: The University of Chicago Press.

Davidson, E.J. 1997. Examining project history narratives: An analytic approach. In A.S. Lee, J. Liebenau \& J.I. DeGross (Eds.), Proceedings on Information Systems and Qualitative Research: 123-128. Philadelphia, PA.

Davis, F.D. 1989. Perceived usefulness, perceived ease of use, and user acceptance of information technology. MIS Quarterly, 13(3): 319-340.

DeLone, W.H. \& McLean, E.R. 2003. The DeLone and McLean model of information systems success: A ten-year update. Journal of Management Information Systems, 19(4): 9-30.

Dineen, B.R., Ling, J., Ash, S.R. \& DelVecchio, D. 2007. Aesthetic properties and message customization: Navigating the dark side of web recruitment. Journal of Applied Psychology, 92(2): 356-372.

Doherty, N.F., King, M. \& Al-Mushayt, O. 2003. The impact of inadequacies in the treatment of organizational issues on information systems development projects. Information \& Management, 41(1): 49-62. 
Ellison, N.B., Steinfield, C. \& Lampe, C. 2007. The benefits of facebook "friends": Social capital and college students' use of online social network sites. Journal of ComputerMediated Communication, article 12.

Feldman, D.C. \& Klaas, B.S. 2002. Internet job hunting: A field study of applicant experiences with on-line recruiting. Human Resource Management, 41(2): 175-192.

Fincham, R. 2002. Narratives of success and failure in systems development. British Journal of Management, 13: 1-14.

Geib, M., Braum, C., Kolbe, L. \& Brenner, W. 2005. Toward improved communitysupporting systems design: A study of professional community activity. International Journal of Technology and Human Interaction, 1(4): 19-36.

Goffman, E. 1981. Forms of talk. Philadelphia, PA: University of Penssylvania Press.

Grudin, J. 1991. Interactive systems: Bridging the gaps between developers and users. Computer, 24(4): 59-69.

Holtzblatt, K. \& Beyer, H.R. 1995. Requirements gathering - the human factor - introduction. Communications of the ACM, 38(5): 30-32.

Iansiti, M. \& MacCormack, A. 1997. Developing products. Harvard Business Review, 75(5): 108-117.

Ives, B. \& Olson, M.H. 1984. User involvement and mis success - a review of research. Management Science, 30(5): 586-603.

Jenkins, A.M., Naumann, J.D. \& Wetherbe, J. 1984. Empirical investigations of systems development practices and results. Information \& Management, 1: 73-82.

Khapova, S. 2006. Careers in the knowledge economy and web-based career support: New challenges and opportunities. University of Twente, Enschede.

Kim, A.J. 2000. Community building on the web: Secret strategies for successful online communities. Berkeley: Peachpit Press.

Knoke, D. \& Kuklinski, J.H. 1982. Network analysis. Newbury Park: Sage.

Lin, B. \& Stasinskaya, V.S. 2002. Data warehousing management issues in online recruiting. Human Systems Management, 21(1): 1-8.

Marakas, G.M. \& Elam, J.J. 1998. Semantic structuring in analyst acquisition and representation of facts in requirements analysis. Information Systems Research, 9(1): 37-63.

Miles, M.B. \& Huberman, A.M. 1994. Qualitative data analysis: An expanded sourcebook (2nd ed.). Thousand Oaks, CA: Sage.

Moody, J.W., Blanton, J.E. \& Cheney, P.H. 1998. A theoretically grounded approach to assist memory recall during information requirements determination. Journal of Management Information Systems, 15(1): 79-98.

Noyes, J. \& Baber, C. 1999. User-centered design of systems. Heidelberg, Germany: Springer.

Parry, E. 2008. Drivers of the adoption of online recruitment: An analysis using diffusion of innovation theory. In T. Bondarouk \& H. J. M. Ruel (Eds.), E-HRM in theory and practice. Amsterdam: Elsevier.

Pfleeger, S.L. \& Atlee, J.M. 2010. Software engineering: Theory and practice (4th ed.). Upper Saddle River, NJ: Prentice Hall.

Plickert, G., Cote, R.R. \& Wellman, B. 2007. It's not who you know, it's how you know them: Who exchanges what with whom? Social Networks, 29(3): 405-429.

Preece, J. 2000. Online communities: Designing usability, supporting sociability. Chichester: Wiley.

Rheingold, H. 2000. The virtual community: Homesteading on the electronic frontier. London: MIT Press.

Riessman, C.K. 1993. Narrative analysis. London: Sage. 
Rondeau, P.J., Ragu-Nathan, T.S. \& Vonderembse, M.A. 2006. How involvement, is management effectiveness, and end-user computing impact is performance in manufacturing firms. Information \& Management, 43(1): 93-107.

Sarbin, T.R. 1995. A narrative approach to "repressed memories". Journal of Narrative and Life History, 5(1): 51-66.

Scarbrough, H. 1997. Making the matrix matter: Strategic information systems in financial services. Journal of Management Studies, 34(2): 171-190.

Smith, A.D. \& Rupp, W.T. 2004. Managerial challenges of e-Recruiting: Extending the life cycle of new economy employees. Online Information Review, 28(1): 61-74.

Szmigin, I., Canning, L. \& Reppel, A.E. 2005. Online community: Enhancing the relationship marketing concept through customer bonding. International Journal of Service Industry Management, 16(5): 480-496.

Turkle, S. 1995. Life on the screen: Identity in the age of the internet. New York: Simon and Schuster.

Van Dijk, J.A.G.M. 2006. The network society: Social aspects of new media (2nd ed.). London: Sage.

Van Maanen, J. 1995. An end of innocence: The ethnography of ethnography. In J. Van Maanen (Ed.), Representation in ethnography: 1-35. Thousand Oaks, CA: Sage.

von Hippel, E. 2007. Horizontal innovation networks - by and for users. Industrial and Corporate Change, 16(2): 293-315.

Wagner, E.L. \& Piccoli, G. 2007. Moving beyond user participation to achieve successful is design. Communications of the ACM, 50(12): 51-55.

Weick, K.E. 1995. What theory is not, theorizing is. Administrative Science Quarterly, 40(3): 385-390.

Wellman, B., Boase, J. \& Chen, W. 2002. The networked nature of community on and off the internet. IT and Society, 1(1): 151-165.

Wellman, B., Quan-Haase, A., Witte, J. \& Hampton, K. 2001. Does the internet increase, decrease, or supplement social capital? Social networks, participation, and community commitment. American Behavioral Scientist, 45(3): 436-455.

Wellman, B. \& Haythornthwaite, C.A. (Eds.). 2002. The internet in everyday life. Malden, MA.: Blackwell.

Wolters, M. 2006. The effectiveness of job board internet recruitment. Paper presented at the First European Academic Workshop on e-HRM, The Netherlands.

Yin, R. 2003. Case study research: Design and methods (3rd ed.). Thousand Oaks, CA: Sage.

Zhao, H. 2006. Expectations of recruiters and applicants in large cities of china. Journal of Managerial Psychology, 21(5): 459-475.

Zusman, R.R. \& Landis, R.S. 2002. Applicant preferences for web-based versus traditional job postings. Computers in Human Behavior, 18(3): 285-296. 


\title{
CHAPTER 8
}

\section{Utilizing the Lead User Method for Promoting Innovation in e-Recruiting Services Design ${ }^{12}$}

\begin{abstract}
In order to maintain their customer base, many e-Recruiting services need to remain competitive by developing innovations. The Lead User (LU) Method (von Hippel, 1986) has been heralded in the new product innovation literature, but not yet been often applied in eservice settings. Based on an e-Recruiting portal, we compare service innovations emerging from information obtained in interviews with registered applicants to the service ideas from information obtained derived from lead users. While most users offered us e-services features they already knew from other platforms, lead users tended to present more novel service solutions for different user segments. Thus, carefully specifying potential customer groups at the outset of an innovation project can lead to more targeted service offerings. Applicants were found to be more inclined to re-use the same e-Recruiting portal if it incorporated features that enhance applicants' self-esteem and playfulness while searching for a new job. We find evidence suggesting e-Recruiting platforms are more likely to be sustainable if they evolve quickly into highly participative and continuously innovating e-community (network) platforms, organized around niches of users who share a similar social or professional identity. This, along with a host of other practical findings, encourages us to sketch some general implications for innovating e-Recruiting services.
\end{abstract}

Keywords: Lead User Method, Innovation, Recruiting Services, Sustainability.

\footnotetext{
${ }^{12}$ This paper has been published in the Handbook of Research on E-Transformation and Human Resources Management Technologies, 251-273, (Eds). T.V. Bondarouk, H.J.M. Ruël, E. Oiry \& K. Guiderdoni-Jourdan, Information Science Reference, Hershey: New York, 2009.

A previous version of this paper has been presented at the Annual Workshop on Open and User Innovation, Harvard Business School, Boston, USA, August 4-6, 2008.

Parts of this paper were presented at the Association of Internet Researchers Conference, October 16-18, 2008, IT University Copenhagen, Denmark.
} 


\section{Introduction}

While most of today's innovations are incremental advances of existing products and services, the LU method has been found to help generate breakthrough innovations (Franke et al., 2006; von Hippel, 2005). Innovative companies such as 3M, Johnson \& Johnson, Philips or Hilti (Luthje \& Herstatt, 2004) and even some governmental agencies have become progressively aware of and shown an interest in applying lead user studies for commercial advantage or innovation. For example, the Danish government just made user-driven innovation a national priority. The LU method is built around the assumption the most innovative new product and service ideas are typically held by just a few highly innovative "lead users." If these lead users are drawn into a process of joint development with the management team of an organization, they have been shown to contribute more to idea generation and innovation than routinely derives from internal organizational idea generation methods or external market research methods.

The innovations by lead users have been found to be crucial, particularly for the longterm performance of firms. They tend to face needs that are latent among a larger group of potential users, to be able to identify and explain these needs months or years before the rest of the potential users (von Hippel, 1988, 2005). Lead users normally benefit from their own innovations and are thus motivated to think in innovative, new ways along with their suppliers. These who have real-world experience with an unsatisfied need have been found to provide the most accurate data in the form of need-specification and ideas to meet their needs. Despite the fact that in the innovation literature breakthrough innovations based upon user studies have been regularly cited for the past 10 years (Morrison et al., 2000; Olson \& Bakke, 2001; Schreier et al., 2007; von Hippel, 2005), only a few firms have integrated lead users into their product or service development processes. This is especially telling with regards to service firms such as those offering e-Recruiting. Most LU studies have been conducted in manufacturing with the purpose of enhancing new product development.

This chapter seeks to contribute to lead user theory by inductively studying how to innovate and develop radical innovations apart from manufacturing firms. Our focus is on innovating e-Recruiting services, exploring which services an online career platform would need to offer to trigger its re-use or loyalty. The basic question being asked is: which innovations do e-Recruitment services require in order to achieve long-term participation of its users? We compare the service ideas emerging from 60 interviews with registered users (applicants) with the ideas derived from the LU method. First, we review the literature on user 
involvement in service innovations and summarize the relevant aspects of the e-Recruiting literature. We specifically point to the LU method as a primary driver of breakthrough innovations. Second, we present a close-up case study of a nationwide e-Recruiting service. Finally, we offer an analytical explanation of patterns of behaviour we report with the aim of sparking future research on innovating e-Recruiting.

\section{Theory Review}

\section{User Involvement in Service Development}

The idea of involving end-users in product and service development stems from the belief that involved users provide multiple benefits. These include users' stronger intention to actually (re)use services, and increased user accountability for the system's design, resulting in users' higher satisfaction, commitment and identification with the service (Buchanan, 2007; Wagner \& Piccoli, 2007). In the area of IT service innovation higher levels of success have been associated with the active involvement of the user community (e.g., Doherty et al., 2003). Moreover, development times can be reduced if continuous acceptance tests are carried out during service development (e.g., Iansiti \& MacCormack, 1997).

The service management literature emphasizes that a deeper understanding of customers' needs is vital for achieving high service quality (e.g., Berry, 1995; Grönroos, 2000; Matthing et al., 2006; Zeithaml, 2000). However, the exact timing of when and how extensive user involvement should be organized in planning the (re-)design process of services is unknown (e.g., Rondeau et al., 2006). While it has been found that involving users can lead to innovative service ideas, users' ideas are sometimes too difficult to obtain or too costly to realize (Magnusson et al., 2003). It is not by happenstance that there is no commonly accepted definition of user involvement. It has been seen as synonymous with contacting with users (Grudin, 1991), participation of users (Ives \& Olson, 1984), user-centered design (Noyes \& Baber, 1999), and user engagement (Wagner \& Piccoli, 2007). There are many different approaches to the involvement of users in the generation of potentially innovative activities. For example, in participatory design studies users actively take part in design activities, whereas in other approaches users are involved as providers of information (quasi consultants) or are involved as objects of observations in experiments. Generally, the level of user involvement is distributed on a continuum, starting from informative, through consultative to participative (Kujala, 2003). One of the major problems in involving users and understanding their needs is that part of users' knowledge is tacit, and to some extent not 
consciously available. In brief, they know more than they can say. Consequently, the kind of user involvement needs to be carefully thought through when aiming to collect user data on how to innovate a particular type of service.

Research into different sources of user involvement and innovation has expanded to include one particularly promising concept, "lead users," - who share the following characteristics: They (1) anticipate the future needs of a specific market and do so significantly earlier than the majority of other users, and they (2) profit strongly from the suggested innovations, in the sense that these innovations help solve their problems or enable new opportunities (von Hippel, 1986). A classic example of a lead user is Berners-Lee, who rather than setting out to invent the internet as a contemporary cultural phenomenon had just aimed to develop a tool for his work, to simply solve a problem that was hindering his efforts as a consulting engineer. Lead users, by sensing service innovations and future opportunities well before ordinary customers, have a strong desire for innovations that will solve their problems in ways that existing products and/or services cannot. They have been found to be an extremely valuable cluster of customers and/or potential customers (Franke et al., 2006; Olson \& Bakke, 2001; von Hippel, 1988).

Perhaps the one large firm that has most publicly adopted the LU method is 3M. Like many other companies, $3 \mathrm{M}$ desired a method that would help their managers and engineers create more and better breakthrough innovations. 3M conducted an internal study in which they compared the outcome of traditional ways of doing new product development (with focus groups, customer interviewing, brainstorming, conjoint analysis etc.) with the lead user method. They found that the ideas generated by the lead user method were more novel and original (i.e., more breakthrough-like), had higher success rates and ultimately market share, and as well were a better fit with 3M's strategic plans and functional capabilities. Further, research showed that successfully introducing breakthrough innovations creates large profits and sales growth (Luthje \& Herstatt, 2004; Thomke \& von Hippel, 2002; von Hippel, 2007). Similarly, Lilien et al. (2002) proved empirically that lead-user innovations have a significantly higher generation of new product lines and sales potential compared to innovations generated by traditional market research techniques.

Lagrosen (2005) emphasizes that the mere act of involving customers in the development of new services is not enough. In the same vein, von Hippel (2005) coined the term "sticky information" as a label to describe the transfer of the "right" information between lead user and producer. Von Hippel equated the stickiness of information to the cost associated with transferring such information. When information stickiness is categorized as 
low, the retrieving of important information for new service development is a minor issue. However, von Hippel's research shows information stickiness is often high, especially in the field of information technology. The LU method addresses the issue of sticky information and seems to render the traditional means of customer involvement (such as the focus group or interview) comparatively less functional for breakthrough innovation. Thus the tacit nature of information, as a common reason for information stickiness, can be reduced by the LU method and easier to access than in traditional user involvement procedures.

These traditional methods are less suitable for overcoming the information asymmetry between producer and user. A new product or service developer might consider the sticky information requisite to an innovation too expensive. They instead typically choose to develop a new service based on more easily available information that might already exist in the organization. Similarly, Shane (2000) identifies the role of prior knowledge in opportunity recognition. Prior knowledge of course has immensely wide range - from information about markets, technologies, as well as about customer problems, needs and how to serve customers. Lead users acquire knowledge about problems, needs and skills when using a certain product or service, and then leverage this hands-on knowledge to develop solutions to the problems on their own. Von Hippel notes that a special setting such as a face-to-face leaduser workshop helps the individual lead-user participants to interact, enabling the transfer of tacit knowledge (Nonaka et al., 2006).

Furthermore, it is important to include lead users with different kinds of experiences, information, needs and knowledge. Ideally, lead user workshops include different external lead users with various needs and use(r)-related knowledge, as well as various internal engineers and employees with solution-related, technical knowledge (von Hippel, 2005). Consequently, radical innovations developed during a lead user project tend to face less internal resistance, and be easier to integrate and more widely accepted by an organization's employees (Lilien et al., 2002). Conducting a lead user project can be seen as evidence of a positive attitude toward radical innovation within an organization. This literature review on lead user involvement in innovation projects strongly suggests it is a very promising method for the identification and exploitation of fundamental breakthrough ideas for innovating eRecruiting services. 


\section{E-Recruiting Services Research}

The current e-Recruiting literature points towards next generation e-Recruiting portals with web 2.0 applications. In reality, most existing e-Recruiting portals are simple job listing boards serving to replace traditional newspaper ads. In almost all industrialized countries company recruiters more and more routinely use the internet to advertise job postings and search applicant pools. It has become the new normal means for solving the very old problem of attracting a wide set of prospective candidates, performing better than and significantly displacing traditional recruiting processes (Gueutal \& Stone, 2005).

Although research on e-Recruiting is still scant (Parry, 2008; Smith \& Rupp, 2004), a surge of recent academic publications document the growing interest in these services (e.g., Anderson, 2003; Bauer et al., 2004; Lievens \& Harris, 2003; Stone et al., 2006). To date most studies have focused on applicant reactions (e.g., Dineen et al., 2007; Feldman \& Klaas, 2002; Zusman \& Landis, 2002), but far less attention has been paid to company employers' or recruiters' views on the effectiveness of different e-Recruiting services (Zhao, 2006). Although e-Recruiting services and professional networks have improved access to talent, many of these services suffer from little user participation, outdated profiles and lurking. Consequently, many fail (Feldman \& Klaas, 2002; Lin \& Stasinskaya, 2002). Clearly it is thus extraordinarily difficult to design technical features of e-Recruiting services and seed their social practices in a way that at start up generates ongoing contributions from a larger fraction of its initially no doubt primarily instrumentally oriented users (Preece et al., 2004; Szmigin et al., 2005). E-recruiting service organizations face many challenges such as keeping registered applicants profiles up-to-date, or when offering applicant-pool search functions delivering semantically accurate search results. Today the sheer large number of e-Recruiting services makes it particularly hard for anyone to differentiate itself from the others. In this context of deeply competitive market we ambitiously set out to gather empirical evidence of current innovating e-Recruiting service offerings striving to achieve more long-term commitment of various customer groups.

\section{The Case Company}

Our study concentrates on an Austrian e-Recruiting service actively involved in developing web 2.0 applications for niche recruiting platforms. The company since its establishment in 2005 has developed many partnerships with public institutions and companies across Austria, and obtained research grants for developing next-generation technologies for e-Recruiting 
services. Employees regularly participate in international conferences, programming competitions, and spend a considerable amount of time on collaboration with users (applicants) and other customers such as company recruiters in an effort to capitalize and distribute knowledge for system design improvements (e.g., von Hippel, 2007). Another unique attribute of this young high-tech firm is its target-specific focus on different applicant segments, for example an engineering recruiting portal separate from the business recruiting portal. We launched our investigation by studying its engineers' career portal.

\section{Research Strategy}

Our substantive interest is in user-driven, new e-Recruiting paths. We thus collected two sets of qualitative data in order to determine whether the ideas collected in traditional user interviews were (pace von Hippel's theory) less innovative than those derived through the LU method. I first describe how the traditional interviews were conducted, and then how we proceeded during the LU project.

\section{Traditional Interviews}

We randomly selected one registered user from each engineering college in Austria. There are 60 Higher Technical Colleges (HTLs) in Austria; we sampled and interviewed only those engineers/users from each college with a minimum of three years work experience. The interviews sought to identify service ideas potentially relevant to increasing the platform's long-term usage. We probed for users' concrete ideas about what functions an e-Recruiting service should offer which would cause users to make use of it for the long run, rather than solely for finding just a single job. All interviews were tape-recorded.

While tracking, observing, and asking questions, we kept a record of field notes that enhanced the quality of later in-depth analyses. We heeded Chatman's (1984) advice about establishing rapport with our informants so that they were more open and felt comfortable during our interactions. A second aim of these interviews was to identify a subset of users in the sample with both of the two lead user characteristics mentioned (i.e., being ahead on the identified trends and expecting high benefit from innovations). 


\section{Lead User Workshops}

We followed prior literature's outline of the LU method involving four steps, described in detail in von Hippel (1986) and Urban and von Hippel (1988). Figure 1 shows how each of the four steps were carried out.

In the $1^{\text {st }}$ step planning was done for the LU projects' broad research goal, scope (focus on the engineering recruiting portal), financials and other resource requirements. Lead User projects require the dedication of an interdisciplinary internal organization team, usually made up of people from marketing, sales, $R \& D$, and production. In this study, the Marketing \& Operations Manager, the Chief Technical Engineer and one researcher with a background in HR worked together on the plan. Research has shown that engineers from R\&D often have difficulties imagining that users of a company's products and services can develop technically sophisticated and innovative solutions. Bearing this in mind, right from the beginning we included employees from different functional lead roles in order to ensure the commitment to customer involvement in new services design.

The $2^{\text {nd }}$ step was wide ranging and synthetic. We discovered and analysed key trends and services by surveying more than 200 e-Recruiting websites, screening the relevant academic literature on e-Recruiting and following market trends about e-Recruiting services in mainly German and American e-business, management and human resource magazines (such as Business 2.0; MIT Sloan Management Review; Personal Manager etc.). Identification of needs and trends was also supported by weekly viewings a large number of podcast series (mostly from Silicon-Valley) on different e-services start-ups. We also identified and interviewed external experts with expertise in e-Recruiting. Field reports from visits to 12 career fairs were written, along with summaries of short interviews with 73 recruiters; these were done with the aim of exploring the topic of service quality criteria. However, when the opportunity arose they covered analysis of the limitations in e-Recruiting services and possible ways to enhance current services (see, e.g., Ettinger et al., 2009). Participation in academic conferences helped us to think through and take into account perspectives of researchers from a variety of fields such as internet research, information systems, semantic technology, psychology and marketing. Once we had identified the major trends and needs, we prioritized them based on their potential service innovation. Most of the evident dominant trends involved innovating by means of semantic technologies. The one most striking need all e-Recruiting services faced was finding a solution for keeping their registered applicant profiles up-to-date, and for enhancing user return rates (applicants as well 
as paying recruiters or media personnel). Typically, as soon as registered applicants found a new job they had little reason to re-visit a career site in the near term. Similarly, once recruiters had filled their open position there was no guarantee they would ever return to the same recruiting service. As the competition among the vast number of recruiting services is increasing, other players may win the battle for the chance for cooperation, and consequently, an organizations' recruiting budget the next year/period. Also, media personnel such as personnel marketers continuously look for new portals that have the best links to their target group(s). Given this dynamic and complex environment, we were guided by one central research question: Which service innovations do e-Recruitment platforms require in order to achieve the long-term participation of its users?

In the $3^{\text {rd }}$ step we identified the lead users. There is abundant empirical evidence showing average users are generally limited by constraints of attitudes about familiarity to actual products and contexts. However, the situation is different if users are progressive and leading, or trend setting. These users experience dissatisfaction with current services and are familiar with needs that will become popular in the future marketplace. We aimed in this lead user study to include different user groups. The typical users of e-Recruiting services are registered applicants, recruiters, and media (mostly personnel marketing) personnel. We originally expected to get users from all three categories to participate, but we split the workshop in two parts due to time constraints of several participants and the time needed to identify and recruit lead users. The proxy used for identifying lead users included evaluating the extent that users appeared ahead of others on our identified trends. Following prior research (Herstatt \& Vonhippel, 1992; von Hippel, 2005), we bifurcated "ahead on identified trends" into the following criteria: (1) the degree to which the interviewees agreed the trends previously identified were from their points of view in fact needed and important and (2) the ways in which the interviewees articulated technically interesting innovations regarding these trends. The proxy used for "user innovation benefit expectations" was that users expressed a benefit for the suggested services. We were essentially looking for critical users that were unsatisfied with their current or former use of e-Recruiting services, and were able to articulate these negative experiences. We knew from earlier research that it was necessary to include people with different skills, and those who had informally identified unusual needs and who expected benefits from service solutions to their needs.

Workshop 1: In the first workshop we brought together the Chief Technical Engineer, the Marketing and Operations Manager, the lead researcher of this study, three recruiters and two personnel marketers. We strived to include different types of recruiters, including one 
company recruiter, one from a personnel agency and one known to be a head-hunter. One personnel marketer works at a large corporation that markets their services to engineers, while the other works at a large educational institution that constantly needs to recruit new engineering students. The process for finding these lead users was based on a networking approach that the portal-offering firm pursued from its outset. Let us now turn to a brief comparison of the two types of search processes commonly used in lead user studies.

The first is a rather quantitative, standardized screening approach. A filter is applied when the number of customers in the market is manageable and an acceptable screening of all users is possible. This approach was impossible to realize in this case due to the large base of customer groups of e-Recruiting services. It is a hard fact that customer size and hence demand per se is impossible to precisely quantify as all larger organizations employ multiple recruiters who are themselves networked. In addition, it is well known organizations do on occasion (and even routinely) employ personnel marketing to advertise the organization to certain applicant groups and build relationships with them, on top of their actual practical recruiting for specific positions. The fact that recruiters and personnel marketers do not tend to be a loyal group of customers - being open to any new cooperation agreement to meet their staffing and advertising needs - made the selection process difficult. We also recognized the gravitas of the recruiting ramifications of secrecy for our study, rooted in the fact innovations created in the workshop often involve issues of intellectual property rights. This normal circumstance of organizational life in such cases can place significant limitations upon dealing with external parties in announcing, filling and indeed applying for jobs, e.g., the tacit invoking by all parties of the classic "need to know" principle. Given all of the above troubles, it was necessary to rely on the second strategy for identifying valuable lead users. There were clear strong advantages to adapting a non-standardized networking approach where in the main it is informal references that help to identify lead users.

The company was interacting with many recruiters and personnel marketers throughout the year by email and phone, and face-to-face at career fairs or in business meetings, or indirectly through media personnel visiting the e-Recruiting services office. Only those users that appeared to have built some lasting impression on one of the management team were approached. The three initiators of the lead user study (Chief Technical Engineer, Marketing and Operations Manager and the researcher) engaged in this networking search procedure. They set a firm deadline of one month was set for receipt of confirmations from potential lead users who might participate in the workshop. We created a list of potential participants and the researcher contacted each to check how they fared in terms of our 
identified trends. Three key selection criteria were agreed upon: they (1) needed to have noted some dissatisfaction with the current e-Recruiting services on the market, (2) articulated some suggestions for improving e-Recruiting services, and (3) expected some personal gain from innovative solutions. We received five confirmations accompanied by a strong interest to participate. We welcomed their participation by giving each of these five lead users gratis 15 job ad postings on the website, free online company presentations for one year, their company logo printed on 10,000 flyers distributed at 60 engineering schools in 2007 and four lines of text in the e-career letter to graduates.

Workshop 2: About a third of the sample of 60 registered applicants interviewed by telephone met our pre-defined selection criteria for becoming lead users. From this pool of 20 only the three most highly innovative applicants were recruited to participate in the lead user workshop. These three users agreed that long-term usage of recruiting portals was a problem. They all had undergone negative experiences with e-Recruiting services, and were highly interested in the research project; they felt finding a solution might well benefit themselves as well. One user voluntarily offered a follow-up interview to discuss things more deeply, and another expressed their intention to think more about these issues, promising to get back to the interviewers with more ideas via email. The third user told us many stories - without our probing - about how he experiences e-Recruiting services, his likes and dislikes. This made us invite these three users to participate in the full day lead user workshop, which the company labelled Vision Workshop. The cost of meals and travel expenses were reimbursed to these lead users for their participation. They were happy to be invited and enjoyed participating, expressing their ideas in lively discussions. Other workshop participants included two system designers and two platform programmers, and of course the identical company team that initiated the event.

In the 4th final step we held the two lead user workshops. The first with the recruiters, personnel marketers and company team was held in late summer, 2007; the second with the applicants and the company team was held in the early fall of the same year. Both workshops started with the announced goal of the group interaction, i.e., the overriding puzzle: Which service innovations do e-Recruitment platforms require in order to achieve long-term participation of its users? Each participant introduced himself and the company presented its organizational structure, current products and services; the latest reports about its financial growth since its business start; and projected market trends and expected future challenges. Following discussions about service innovation and a first idea collection phase on flipcharts, the participants quickly identified the need for different service innovations, depending on the 
three key customer groups of e-Recruiting services: (1) applicants, (2) recruiters and (3) personnel marketers. There are to be sure other customer groups as well, but these three groups represent the core customers of e-Recruiting services. We found that meeting and exceeding their needs will contribute most to the firm's financial figures and consequently long-term platform sustainability. Our primary interest was in improving the services for these customer groups with the goal of enhancing their long-term usage of the platform. Other customers include different public agencies (unions, associations, clubs, etc.) and private selfemployed persons or companies (e.g., self-employed consultants such as interview coaches interested in cooperation with the e-Recruiting service, publishing companies, etc.). However, these groups and people were classified as partners engaging in mainly mutual exchange of services (without financial compensation). Identified as outliers, they were not targeted in this study. Throughout the workshop, field notes were taken and immediately digitized. Memos were taken during group discussions of new service ideas and/or when summarizing discussion-themed results. Further, flipcharts were used for visualizing the research goal, the process of idea generation and for drafting the results.

Table 1

The Lead User Method as Applied in the Four Steps

\begin{tabular}{|c|c|c|c|}
\hline STEP 1 & STEP 2 & STEP 3 & STEP 4 \\
\hline $\begin{array}{l}\text { Plan } \\
\text { Project Scope }\end{array}$ & $\begin{array}{l}\text { Identify } \\
\text { e-RecruitingTrends }\end{array}$ & $\begin{array}{l}\text { Identify } \\
\text { Lead Users }\end{array}$ & $\begin{array}{l}\text { Lead User } \\
\text { Workshop }\end{array}$ \\
\hline $\begin{array}{l}\text { - Define broad } \\
\text { research scope: } \\
\text { Innovating e- } \\
\text { Recruiting services } \\
\text { - Build an } \\
\text { interdisciplinary } \\
\text { internal project team } \\
\text { - Plan finance and } \\
\text { other resource } \\
\text { requirements }\end{array}$ & 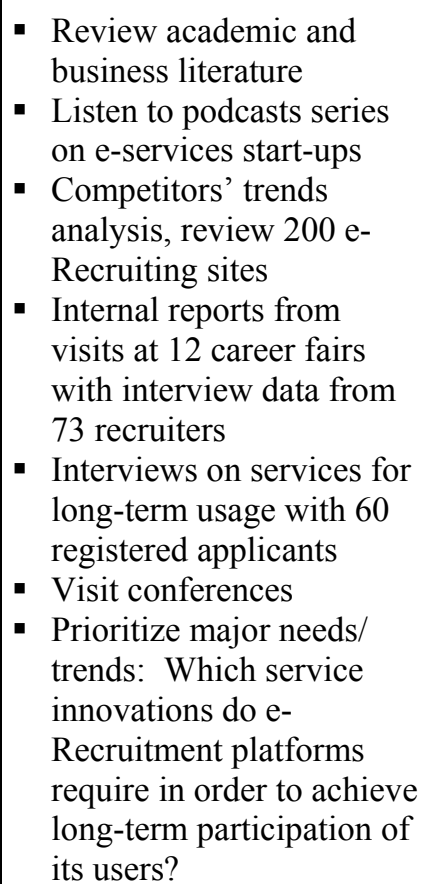 & $\begin{array}{l}\text { - Aim for a total of } 15 \\
\text { participants } \\
\text { - } 5 \text { lead users ( } 3 \text { recruiters } \\
\text { and } 2 \text { personnel } \\
\text { marketers) through } \\
\text { network search } \\
\text { - } 3 \text { lead users (applicants) } \\
\text { from telephone } \\
\text { interviews } \\
\text { - } 7 \text { members from the } \\
\text { company team: } \\
-1 \text { Chief Technical } \\
\quad \text { Engineer } \\
-1 \text { Marketing \& } \\
\text { Operations Manager } \\
-1 \text { Researcher } \\
-2 \text { System Designers } \\
-2 \text { Programmers }\end{array}$ & $\begin{array}{ll}\text { - } & \text { Workshop 1: } \\
- & 3 \text { recruiters } \\
- & 2 \text { personnel marketers } \\
- & 1 \text { Chief Technical } \\
& \text { Engineer } \\
- & 1 \text { Marketing \& } \\
& \text { Operations Manager } \\
- & 1 \text { Researcher } \\
\text { - } & \text { Workshop 2: } \\
- & 3 \text { Applicants } \\
- & 2 \text { System designers } \\
- & 2 \text { Programmers } \\
- & 1 \text { Chief Technical } \\
& \text { Engineer } \\
- & 1 \text { Marketing \& } \\
& \text { Operations Manager } \\
- & 1 \text { Researcher } \\
\text { - } & \text { Triangulation, } \\
& \text { Comparison, Evaluation } \\
& \text { of Service Ideas }\end{array}$ \\
\hline
\end{tabular}




\section{Data Analyses}

The traditional telephone interviews were analysed in a methodical fashion. The researcher first listened to all of the audio tape interviews, and then compiled narratives of each and compared them with the content of the field notes made during the interviews. Themes in the data were identified and reduced into broad categories (Miles \& Huberman, 1994; Yin, 2003). The preliminary categories were posted on the company intranet. Employees were invited to make suggestions about improving the wording of the labels and cluster related service ideas. Importantly, the service innovation ideas for enhancing long-term usage were presented and discussed with a group of six registered applicants who were then working on or had already finished their Bachelor or Master theses (which were sponsored by the e-Recruiting firm). We found this group validation of the individual interview results valuable, enabling us to see if any other service ideas would emerge and if the clustering was regarded as appropriate. Similarly, in the lead user workshop we compared the tape-recorded memos, field notes, presentation slides and notes, and we transformed this data into a few themes. This additional set of service ideas was posted on the intranet in an effort to further enrich the collected ideas.

Afterwards, the participants of the lead user workshop systematically compared the service ideas collected from both sets of data (Strauss \& Corbin, 1998). We noted patterns and overlaps of the identified service ideas; but also significant differences of service ideas collected through the traditional interviews compared to ideas from the lead users. The innovation literature shows that innovativeness is multidimensional, and thus of course it is difficult to operationalize. The recent literature treats the degree of innovativeness as comprising market, technological and organizational dimensions (Dahlin \& Behrens, 2005; Garcia \& Calantone, 2002; Lettl et al., 2008) and we used these to operationalize innovativeness.

After both workshops the core ideas were compiled and emailed to the workshop participants, who were asked to individually evaluate them in regard to the degree of innovativeness. For practical reasons, lead users only rated the market dimension, whereas the involved participants of the company team (i.e., the Chief Technical Engineer, Marketing \& Operations Manager, Researcher, 2 System Designers, and 2 Programmers) rated all three dimensions. It was not felt to be meaningful to let company-external lead users rate the internal organizational fit of the derived service ideas. Also, we found the company engineers in the best position to rate the technological feasibility, but it inopportune to ask lead users 
working in recruiting or marketing or the applicants themselves to rate the innovativeness along the technological dimension.

Specifically, the dimensions were operationalized as follows: (1) Market Dimension: how original and novel the service idea is compared to existing services in terms of (a) new benefits for a user, (b) higher benefits for a user, (c) potential for the firm's competitive advantage; (2) Technological Dimension: how quickly the service idea can be realized or technical feasibility: (a) newness of the technology needed to realize the service idea, (b) complexity to realize the service idea, (c) uncertainty about development time; and (3) Organizational Dimension: how well the service innovation fits into existing firm structure: (a) required change in competencies, (b) required change in strategy. The users rated the service ideas either as 1 (high) or 0 (low). A similar procedure has been applied in a recent LU study by Franke et al. (2006) that matches the LU method's aim of finding attractive innovations only.

\section{Findings}

Table 2 is a summary of the main ideas on innovative e-Recruiting services. The lead user method offered a clear differentiation between service innovations for the three customer groups of e-Recruiting services: applicants; recruiters and personnel marketers. Moreover, lead users came up with new product lines with services valuable for all three customer groups, i.e., including a Blog Service so applicants, recruiters and personnel marketers can have their own blog and communicate with their intended target group. In innovative companies such as Apple, it is often standard that people in important functions (e.g., Steve Jobs) have their personal blog or company blogs to update the general public on news, things of general interest and things that matter to them. If recruiters and marketers could link from their company logo to their blog, they could inform potential applicants about more firmspecific data informally without needing to meet each applicant face-to-face. Note that most recruiters or marketers publish their organization's logo or banners on e-Recruiting sites and/or present their organization profile online.

This new type of blogging practice also has implications for employer branding initiatives as it can build up large-scale, weak-tie relationships with potential applicants. Many individual or company blogs nowadays have developed wide readerships of people who regularly re-visiting them. To subscribe to a company blog via RSS newsfeed has become a widespread timesaver and may well work for recruiting services as well. Also, personnel 
marketers from educational institutes could use such blogs to keep a real-time overview of their services, announce guest speakers, events, upload pictures from graduation ceremonies etc. Further, by using blogs to communicate with the general public, the problem of space (line) limitations - which are usually much more restricted in newspaper ads - would be solved. Besides this, newspapers appear in cycles and depend on people reading them at a certain point of time, unlike the $24 / 7$ web. With a company or educational institution's blogs recruiters and marketers can chronologically order their blog feeds and invite applicants to comment or join different discussions. What has become known as the blogosphere may very well make more selective applications a reality, which could in turn significantly reduce HRM-administrative costs.

Through the LU method the idea came up to offer every applicant blog where they could initiate the communication with registered recruiters of the companies they target and exchange information with other registered applicants on experiences gained in different work settings. Such applicant blogs may serve as a kind of discussion boards, enabling authentic and social support from peers. Also, it could enable the entire application process to turn 360 degrees: i.e., if all applicants were to put their own blogs out and recruiters could "apply" to their "ads." In the traditional interviews, applicants exclusively suggested service innovations for their personal use. Even when probing long-term sustainability of e-Recruiting services in general, in the traditional interview applicants made only references to themselves; they did not identify service innovations for other potential customer groups. For example, in regard to communication tools, we note that applicants were only suggesting services for communication with other registered applicants via social networks as commonly known in other platforms. While applicants suggested including text-based information on employers with some sort of branch categorization, phone, address and email, they did not identify new communication services - such as Blogs or Live Chat - to communicate online with recruiters or educational institutes. Lead users further suggested enhancing the communication by including an Avatar in the form of a Digital Application Coach, instead of more traditional FAQ or customer service links. This animation was found to create more personal customer service than traditional text information. Both the lead users and the users from traditional interviews came up with many ideas on how to integrate social network and community features into e-Recruiting services. The regular users suggested career related and private use services so as to connect with each other, share music or videos, play games, and communicate online with other registered engineers. The users predominantly emphasized interest in communicating online with offline-known acquaintances from their prior schools 
or via extended networks (friends of friends). Interestingly, the interviewed engineers didn't seem to be keen on developing or maintaining a strong network with fully unknown engineers. Fifty-six of the sixty interviewed engineers confirmed that they would use an online career service for the long run if it was specifically targeted to engineers' needs. However, most of the interviewed users are not inclined to sign up at a general online job board that attracts many different job searchers. General jobs boards are seen as exchangebased career tools for finding a job when needed, but for the interviewed users it is not desirable to connect online in such job boards with unknown users.

Proponents of social presence theory (Biocca et al., 2003) have noted that the presence of other members (which can be complemented by offline interactions) may foster stronger ties of participants to their online service. Consequently, it is more likely that applicants who know that people like them are involved as users will maintain an up-to-date profile in niche career platforms. Moreover, we assume determinants of long-term sustainability of eRecruiting services range from understanding how users judge online features, such as the quality of a career community's service, its system, and the provided information (DeLone \& McLean, 2003) to understanding offline features such as the users' offline activities (Wellman et al., 2002). Studies of online communities have found that people's offline activities do indeed increase the solidarity and cohesiveness of online interactions (Boyd \& Ellison, 2007). Thus, offline activities strengthen the ties between members of an online portal which may cause applicants to stay connected to a specific online service.

While lead users recommended inclusion of Newsfeeds and Statistics for transparent updates depending on the different customer groups, users in the traditional interviews came up with the idea of a Newsletter which reported the latest jobs matching their own skills, new information on hiring companies, info on continuing education and other career related topics. Most e-Recruiting services offer such newsletters or job-alerts functions to keep applicants informed of new jobs and other career-related news. However, the new services that were identified by the lead users offered additional value, including a transparent newsfeed that might enhance the trust of the customer groups to the platform, and consequently improve long-term use. For example, instance, recruiters and personnel markets should have the possibility for automatic updates with information on the number of unique visitors and page impressions in different time frames (such as per week/month etc.). Also, newsfeeds with information about the number of new applicants that registered and would fit an open position in a ranking order would be valuable. Further, services such as regular updates on which applicant clicked on a specific job ad or company logo might spark a 
recruiters' interest. Such transparency features would enable recruiters and marketers to peer into what is really going on and estimate latent demand, thus feeling the "bang" for their sustained advertising investment. Another trust-related service would be to let recruiters, marketers and applicants who used different career services rate those services. There is certainly the danger here that competitors would be inclined to write negative comments on purpose. People who rate such services, therefore, may need to include some personal data, or careful monitoring of the posted comments would be deemed wise.

For educational institutes, Newsfeed could include the number of requests for certain study programmes or the amount, demographic and geographic information of people registering for educational programs. Also, the strength of cooperation with other media channels and possibilities for recruiters and marketers to include their advertising on partner channels (such as newspapers) is valuable in estimating a portal's effectiveness in reaching specific target groups.

Further, for applicants newsfeed services may cause them to keep their profile up-todate and return to the site as they get a better overview of who is interested in their profile. This may enhance users' curiosity and possibly also their self-esteem if many people viewed their profile or left messages. Also, some notification of jobs where only a few applicants have applied may save applicants time so concentrate on these rather than apply to jobs where hundreds of others have already applied. Also, applicants should get an automatic individual newsfeed on jobs matching their skills, instead of receiving traditional mass newsletter. Further, if applicants don't have the skills available yet to apply for a specific job, they should be offered educational links to institutes where they can best acquire the missing knowledge/degrees. Some other innovative services for applicants include ranking employers who pay best for graduates from different schools, and a search possibility to find friends or FoF (friends of friends) work at same organization or area.

One new service relates to visualizing applicant data by tag clouds. Such “identity clouds" can be used to indicate things in different sizes, depending on how closely related certain characteristic terms are associated with a specific person. Creating such a tag cloud for an applicant could include visualizing attended schools, skills, and work experiences. If an applicant is an expert user of a certain computer program, for instance, this would appear in larger fonts while computer programs he has only basic knowledge about would appear in smaller fonts. Also, organizations where an applicant has collected longer work-experience would appear larger than work settings where the applicant has done only an internship. The service for recruiters and marketers Visualizing Applicants may also include a map showing 
black spots (no suitable applicants) and green spots (suitable applicants), and regional distribution in line with skills. For example, where do more chemical engineers live? Similarly, the services for applicants Visualizing Jobs may include a map showing black spots (no fit with my profile) and green spots (fit with my profile) or visual info showing in what region and company I already have friends working.

Another interesting LU suggestion (fostering potentially long-term participation and up-to-date profiles) relates to the Integration of external e-HRM systems in which job ads and profiles are automatically updated. While the very large recruiting services such as Monster already have created data transfer interfaces (e.g. HR-XML) with large corporations, this feature is not yet applied much. In order to give each other the possibility to transfer sensitive employee data via shared interfaces, it requires technological savvy and trust from both cooperation partners. However if recruiting services can get more of such cooperation agreements for convenient data transfer, it is likely to enhance long-term cooperation. A major advantage of effectively working data transfers and reliable updates relates to time and cost savings. Further, applicants may re-use the services of a specific e-Recruiting site if they have the opportunity to create a neutral and free application webpage for their own general future use outside the e-Recruiting service.

Recruiters and marketers are also likely to benefit from the LU generated Fan Club service idea, wherein applicants simply add companies of interest to their search status. However, for applicants this service should better be labelled Insider or VIP Club. The careful consideration of wording (Insider vs. Fan) would enhance applicants' feelings of being special, as "insiders" who acquire better and more information about an organization because they communicate directly with desired companies' recruiters. Likewise, it is beneficial for companies to take notice of upcoming applicants with sincere current interest in their organization's profile. Direct interaction with a selected Fan Club audience should be enabled by different means of communications, starting with text messaging and/or discussion boards. Everyone on this planet believes and research has repeatedly shown that recruiting from standard applicant pools if often highly frustrating for recruiters, namely because of the small and slow response rate of applicants. Applicants may have already found a job elsewhere and are no longer available, but are still registered as job searching. While recruiters are looking forward to invite candidates from applicant pools for interviews, they routinely find themselves with no response from the registered candidates (Ettinger et al., 2009). Therefore such Fan Club features may flag who among their applicants has a current interest in a 
specific organization, enabling relationship building with candidates and furthering employer branding.

A strongly parallel case can be made for a Career Letter service as proposed by the lead users, one that would address a segmented target audience instead of the standard general newsletter services which tend go unread. Companies should be able to decide who exactly should get certain information, e.g. only mechanical engineers in a specified region or even graduates from a specific school. In the traditional interviews users suggested information on how to find jobs, how to prepare application documents, trainee programs information, links to companies and continuing education.

Other user-generated new ideas include a differentiation between applicants' personal and private page. This bifurcation came from lead users as well as regular users. It is widely accepted that recruiting services are challenged to create private (for friends) and public (for HR recruiters) spaces of the users' applicant profile. This is done so that trust is built by diminishing the serious risk/fear that personalized resume data will be abused. As one applicant stated: "How can you make sure that my boss will not find my profile in the database?" and "Sure, I want my profile for friends to look different than my applicant profile."

We found that implementing more selection criteria to enhance users' Privacy, Security and Control was strongly associated with long-term use of e-Recruiting portals. Moreover, a service labelled Career Cockpit would help recruiters to put previously selected or interviewed candidates in a history folder, save comments on interactions with candidates, etc. Having such an overview of all interactions with users of a specific recruiting portal enhances not only the transparency, but also the administration of data. For marketers this could relate to saving the advertising history in such a Career Cockpit, i.e. subscriptions, successful placements, etc.

We noted that services aiming to enhance applicants' Self-esteem / Competency are perceived by users as very positive. Such self-esteem features may build on Crowd-sourcing: for instance users should be able to compare their qualifications to other users and get ranked depending on their suitability for a specific job ad. Applicants could also be invited to expand ontologies of recruiting services (e.g. applicant skills) and may use skill test scores for their online applicant profile. If applicants can match their resume profile with different job ads, this may cause users to search for jobs where they are the top candidate, consequently strengthening platform bonding. 
With the prospective service, Check your Market Value, users should be able to compare how well they would fit a specific job description compared to other users, friends, people in a certain region, the whole network etc. This feature also relates to playfulness which has been found very important in re-using online services. Users from the telephone interviews suggested adding games and the ranking of winners. However, typical online games may not fit the strategy of e-Recruiting portals. The ideas suggested by the lead user in regard to "gaming" which allow applicants to assess their professional skills, compete against other users for expanding skill ontologies and to motivate users to check their market value are strategically related to career services.

Finally, one needs to be cautious when interpreting Table 3. First of all, although all workshop participants $(n=15)$ evaluated the degree of innovation along the market dimension, only the involved company team $(n=7)$ evaluated the technological and organizational dimension. Evaluators either judged statements as 1 (high) or 0 (low). We did not include other variation in the evaluation as we sought to concentrate on only service ideas perceived as highly innovative or not innovative. We did a tally of the numbers per statement to get an overview of which service ideas score high given our definition of innovation. It was immediately evident service ideas from the lead users score higher than service ideas from the traditional interviews, with one exception -- Social Network/Community features which represents a summary term for all ideas suggested by traditional users in regard to such applications. As discussed above, social network and community features in general have been interpreted as innovative. However, the ideas suggested in the traditional interviews largely revealed service ideas such as inviting, blogging, and tagging which are commonplace on other platforms. Nevertheless, most of the participants during the workshop had already stated that any progress toward inclusion of such features in e-Recruiting portals was innovative. However, it should be noted that when reviewing the first part of the table on the lead user ideas it is apparent that social network and community features have been split into different innovative services ideas, scoring high on the market dimension.

It should be emphasized here that high scores on the technological innovation dimension is not necessarily beneficial for those organizations hoping to advance their eRecruiting services. For instance, high scores on Uncertainty about development time make it difficult for them to plan effective advertising efforts until the products and services are readily available. A high score on Complexity to realize the service idea can be positive, as it is harder to imitate the new service; but somewhat paradoxically it also by definition often requires competencies that may well not be currently represented in the local staff. When 
looking at the organizational dimension, both a low score on Required change in competencies and Required change in strategy means the organization need not adjust their internal structure. In this case a lower score is likely beneficial because service innovations can be realized without the organization having to seriously adjust its current strategy or incur the long term costs of recruiting new employees. Those advantages are weighty, but it must be acknowledged a more quantitative evaluation with recruiters, marketers and applicants may reveal divergent evaluations along the three innovation dimensions. In any case, the dominant fact is that organizations which undertake innovation projects frequently do so in order to get an overview for their own purposes. It is quite obvious when the management team of an organization identifies practical radical innovations it is not always open to share these with the general public, which could easily risk competitors imitating their innovative service ideas before the initiating company can bring it to the market. After identification of the innovative service ideas, the company in our study not surprisingly avoided asking outsiders to evaluate and further validate the service ideas identified in this study. In conclusion, many new ideas for innovating e-Recruiting were collected, most of which relate in some form to social network and community features with different ways for communicating and bonding online. This overview of service ideas provides fresh substantive insights for further developing online career services.

\section{Future Trends}

A major and understudied challenge in today's (service) innovation management regards the practical combination of a deliberate customer orientation with the aim of creating breakthrough service innovations. Companies that cope well with this challenge make it more likely their new services will perform successfully in the market. Although most writings on the Lead User Method herald its promise, empirical documentation in case studies and analysis is scarce. We thus decided it would be worthwhile to carry out an exploratory study on the practical application of this method in the field of innovating e-Recruiting. As expected, we found that the service ideas articulated in the lead user workshop appear more innovative than those collected in the normal interviews. This general finding warrants the assumption that for e-Recruiting to be sustainable it must evolve or transform into highly participative and continuously innovating e-community platforms, organized around niches of users sharing a similar social identity. Further, our findings point to the insight that sustainable virtual career communities require not only useful information on careers and 
continuing education, but also can encourage friendship, social activities as well as (virtual) experiences that may enhance users' self-esteem. These results require far more customercentric and niche approaches to e-Recruiting than most current e-Recruiting providers of tend to offer. General and exchange-based e-Recruiting platforms might thus need to develop into comprehensive career networks, or at least offer the promise of the possibility of such networking activity in the near term. However, inasmuch as the needs of the interviewed lead users are not identical to the needs of the users who will make up the major share of tomorrow's e-Recruiting market, more research is needed to examine the very difficult question of the extent to which the lead users' service ideas in our study will be valued by the more typical future users in their target markets.

\section{Conclusion}

This chapter presented the rationale for (and findings about) employing the lead-user method in an effort to further innovate in a currently operating Austrian e-Recruiting platform. A large body of data was collected from 60 registered applicants, including 15 lead users. Table 1 arranges the service ideas which e-Recruiting platforms may deploy to better serve their key stakeholders. Our basic substantive question, asking about more sustainable use of an established niche portal, led us to find that users of this portal are more inclined to re-use the same portal if it includes community and social network features for specified user segments, sharing a similar social identity by enabling offline ties.

Concerning the application of the LU method, it was determined that the service ideas emerging from the lead user method appear more innovative than those collected in the traditional interviews. While most registered applicants identified social network and community features they already knew from other platforms, lead users came up with innovative service solutions for different user groups: applicants, recruiters and personnel recruiters. Thus at the outset drawing this distinction and carefully specifying potential customer groups of an innovation project can lead to more targeted service offerings. Both sets of interview data show it is likely that social networks and a sense of community (i.e., shared identity) is consequential for long-term sustainability of e-Recruiting services. There appears to be significant warrant for the inference that the general users will welcome the fact that "a sense of community" is built into online career portals. In developing such portals along these lines, the traditional community psychology and customer loyalty literatures 
might well be fruitful in showing further mechanisms that can be effectively transposed into this virtual, e-Recruiting type of commercial setting.

Some limitations to our study need to be noted. First, the theoretical foundation of the lead user identification process needs to be refined inasmuch as it appears to be different from case to case (Luthje \& Herstatt, 2004). Moreover, it must be acknowledged that the assessment process used in this application study is not optimal. I found it worked well as a first step in tapping a high degree of practical innovativeness. The service ideas generated by the lead users in this study already built upon the ideas gathered through the 60 traditional user-interviews, a feature that in itself in all probability increased the innovativeness of the workshops. Without a doubt more fundamental future research work in this realm will have to more independently, objectively and precisely assess the degree of innovativeness of userdriven ideas, based on engaging various e-Recruiting platforms and deploying various datacollection methods. Furthermore, social scientists may well criticize the use of the LU method as involving a self-fulfilling prophecy, namely that those (lead) users who are expected to be more innovative than the typical user may indeed turn out to be more innovative because they are treated differently by the portal organization. Hence in a pure, scientifically sound test of both user groups we might need to ensure that this and other biases are removed. However, overall for application purposes the LU method worked extremely well, particularly as we did in this case when using the traditional interview method first for purposes of identifying the best external candidates for the lead-user workshops.

Moreover, despite our promising application of the LU Method, we are intrigued by the question of gauging the extent the group setting, in our case the lead-user workshops, when compared to individual interviews with lead users, would have led to even more innovative ideas; it may well be that several users derive better ideas in isolation than in a group settings (see e.g., Heslin, 2009; Thompson, 2003). In retrospect we noted difficulties in getting all identified lead users together at one place and date, and thus individual interviews with (some) lead users would have proven even more beneficial. Hence, (resource) planning needs to be carefully integrated into undertaking a similarly successful LU-innovation project. 


\section{References}

Anderson, N. 2003. Applicant and recruiter reactions to new technology in selection: A critical review and agenda for future research. International Journal of Selection and Assessment, 11(2-3): 121-136.

Bauer, T.N., Truxillo, D.M., Paronto, M.E., Weekley, J. A. \& Campion, M.A. 2004. Applicant reactions to different selection technology: Face-to-face, interactive voice response, and computer-assisted telephone screening interviews. International Journal of Selection and Assessment, 12(1-2): 135-148.

Berry, L.L. 1995. Relationship marketing of services - growing interest, emerging perspectives. Journal of the Academy of Marketing Science, 23(4): 236-245.

Biocca, F., Harms, C. \& Burgoon, J.K. 2003. Toward a more robust theory and measure of social presence: Review and suggested criteria. Presence-Teleoperators and Virtual Environments, 12(5): 456-480.

Boyd, D.M. \& Ellison, N.B. 2007. Social network sites: Definition, history, and scholarship. Journal of Computer-Mediated Communication, 13(1): 210-230.

Buchanan, R. 2007. Understanding your users: A practical guide to user requirements: Methods, tools, and techniques. Design Issues, 23(1): 92-92.

Chatman, E.A. 1984. Field research - Methodological themes. Library \& Information Science Research, 6(4): 425-438.

Dahlin, K.B. \& Behrens, D.M. 2005. When is an invention really radical?: Defining and measuring technological radicalness. Research Policy, 34(5): 717-737.

DeLone, W.H. \& McLean, E.R. 2003. The DeLone and McLean model of information systems success: A ten-year update. Journal of Management Information Systems, 19(4): 9-30.

Dineen, B.R., Ling, J., Ash, S.R. \& DelVecchio, D. 2007. Aesthetic properties and message customization: Navigating the dark side of web recruitment. Journal of Applied Psychology, 92(2): 356-372.

Doherty, N.F., King, M. \& Al-Mushayt, O. 2003. The impact of inadequacies in the treatment of organizational issues on information systems development projects. Information \& Management, 41(1): 49-62.

Ettinger, E., Wilderom, C.P.M. \& Ruel, E. 2009. Web recruiters service quality criteria: A content analysis. International Conference on System Science, Hawaii.

Feldman, D.C. \& Klaas, B.S. 2002. Internet job hunting: A field study of applicant experiences with on-line recruiting. Human Resource Management, 41(2): 175-192.

Franke, N., von Hippel, E. \& Schreier, M. 2006. Finding commercially attractive user innovations: A test of lead-user theory. Journal of Product Innovation Management, 23(4): 301-315.

Garcia, R. \& Calantone, R. 2002. A critical look at technological innovation typology and innovativeness terminology: A literature review. Journal of Product Innovation Management, 19(2): 110-132.

Grönroos, C. 2000. Service management and marketing: A customer relationship management approach, 2nd ed ed.: X, 394. Chichester: Wiley.

Grudin, J. 1991. Interactive systems: Bridging the gaps between developers and users. Computer, 24(4): 59-69.

Gueutal, H.G. \& Stone, D.L. 2005. The brave new world of e-HR: Human resources management in the digital age (1st ed.). San Francisco, CA: Jossey-Bass.

Herstatt, C. \& Vonhippel, E. 1992. From experience: Developing new product concepts via the lead user method: A case study in a "low tech" field. Journal of Product Innovation Management, 9(3): 213-221. 
Heslin, P.A. 2009. Better than brainstorming? Potential contextual boundary conditions to brainwriting for idea generation in organizations. Journal of Occupational and Organizational Psychology, 82(1): 129-145.

Iansiti, M. \& MacCormack, A. 1997. Developing products. Harvard Business Review, 75(5): $108-\&$.

Ives, B. \& Olson, M.H. 1984. User involvement and mis success - a review of research. Management Science, 30(5): 586-603.

Kujala, S. 2003. User involvement: A review of the benefits and challenges. Behaviour \& Information Technology, 22(1): 1-16.

Lagrosen, S. 2005. Customer involvement in new product development: A relationship marketing perspective. European Journal of Innovation Management, 8(4): 424436.

Lettl, C., Hienerth, C. \& Gemuenden, H.G. 2008. Exploring how lead users develop radical innovation: Opportunity recognition and exploitation in the field of medical equipment technology. IEEE Transactions on Engineering Management, 55(2): 219-233.

Lievens, F. \& Harris, M.M. 2003. Research on internet recruiting and testing: Current status and future directions. In C.L. Cooper \& I.T. Robertson (Eds.), International review of industrial and organizational psychology, Vol. 18: 131-165. Chichester: Wiley \& Sons.

Lilien, G.L., Morrison, P.D., Searls, K., Sonnack, M. \& von Hippel, E. 2002. Performance assessment of the lead user idea-generation process for new product development. Management Science, 48(8): 1042-1059.

Lin, B. \& Stasinskaya, V.S. 2002. Data warehousing management issues in online recruiting. Human Systems Management, 21(1): 1-8.

Luthje, C. \& Herstatt, C. 2004. The lead user method: An outline of empirical findings and issues for future research. $\boldsymbol{R}$ \& D Management, 34(5): 553-568.

Magnusson, P.R., Matthing, J. \& Kristensson, P. 2003. Managing user involvement in service innovation: Experiments with innovating end users. Journal of Service Research, 6(2): 111-124.

Matthing, J., Kristensson, P., Gustafsson, A. \& Parasuraman, A. 2006. Developing successful technology-based services: The issue of identifying and involving innovative users. Journal of Services Marketing, 20(5): 288-297.

Miles, M.B. \& Huberman, A. M. 1994. Qualitative data analysis: An expanded sourcebook (2nd ed.). Thousand Oaks, CA: Sage.

Morrison, P.D., Roberts, J.H. \& von Hippel, E. 2000. Determinants of user innovation and innovation sharing in a local market. Management Science, 46(12): 1513-1527.

Nonaka, I., von Krogh, G. \& Voelpel, S. 2006. Organizational knowledge creation theory: Evolutionary paths and future advances. Organization Studies, 27(8): 1179-1208.

Noyes, J. \& Baber, C. 1999. User-centered design of systems. Heidelberg, Germany: Springer Verlag.

Olson, E. L. \& Bakke, G. 2001. Implementing the lead user method in a high technology firm: A longitudinal study of intentions versus actions. Journal of Product Innovation Management, 18(6): 388-395.

Parry, E. 2008. Drivers of the adoption of online recruitment: An analysis using diffusion of innovation theory. In T. Bondarouk \& H. J. M. Ruel (Eds.), E-HRM in theory and practice. Amsterdam: Elsevier.

Preece, J., Nonnecke, B. \& Andrews, D. 2004. The top five reasons for lurking: Improving community experiences for everyone. Computers in Human Behavior, 20(2): 201223. 
Rondeau, P.J., Ragu-Nathan, T.S. \& Vonderembse, M.A. 2006. How involvement, is management effectiveness, and end-user computing impact is performance in manufacturing firms. Information \& Management, 43(1): 93-107.

Schreier, M., Oberhauser, S. \& Prügl, R. 2007. Lead users and the adoption and diffusion of new products: Insights from two extreme sports communities. Marketing Letters, 18(1): 15-30.

Shane, S. 2000. Prior knowledge and the discovery of entrepreneurial opportunities. Organization Science, 11(4): 448-469.

Smith, A.D. \& Rupp, W.T. 2004. Managerial challenges of e-Recruiting: Extending the life cycle of new economy employees. Online Information Review, 28(1): 61-74.

Stone, D.L., Stone-Romero, E.F. \& Lukaszewski, K. 2006. Factors affecting the acceptance and effectiveness of electronic human resource systems. Human Resource Management Review, 16(2): 229-244.

Strauss, A. \& Corbin, J. 1998. Basics of qualitative research: Techniques and procedures for developing grounded theory (2nd ed.). London: Sage.

Szmigin, I., Canning, L. \& Reppel, A.E. 2005. Online community: Enhancing the relationship marketing concept through customer bonding. International Journal of Service Industry Management, 16(5): 480-496.

Thomke, S. \& von Hippel, E. 2002. Customers as innovators - a new way to create value. Harvard Business Review, 80(4): 74-79.

Thompson, L. 2003. Improving the creativity of organizational work groups. Academy of Management Executive, 17(1): 96-109.

Urban, G.L. \& von Hippel, E. 1988. Lead user analyses for the development of new industrial products. Management Science, 34(5): 569-582.

von Hippel, E. 1986. Lead users - a source of novel product concepts. Management Science, 32(7): 791-805.

von Hippel, E. 1988. The sources of innovation. New York: Oxford University Press.

von Hippel, E. 2005. Democratizing innovation. Cambridge, MA: The MIT Press.

von Hippel, E. 2007. Horizontal innovation networks - by and for users. Industrial and Corporate Change, 16(2): 293-315.

Wagner, E. L. \& Piccoli, G. 2007. Moving beyond user participation to achieve successful is design. Communications of the ACM, 50(12): 51-55.

Wellman, B., Boase, J. \& Chen, W. 2002. The networked nature of community on and off the internet. IT and Society, 1(1): 151-165.

Yin, R.2003. Case study research: Design and methods (3rd ed.). Thousand Oaks, CA: Sage.

Zeithaml, V.A. 2000. Service quality, profitability, and the economic worth of customers: What we know and what we need to learn. Journal of the Academy of Marketing Science, 28(1): 67-85.

Zhao, H. 2006. Expectations of recruiters and applicants in large cities of china. Journal of Managerial Psychology, 21(5): 459-475.

Zusman, R.R. \& Landis, R.S. 2002. Applicant preferences for web-based versus traditional job postings. Computers in Human Behavior, 18(3): 285-296. 
Table 2

Innovations from the LU Method Compared to New-Service Ideas Obtained with Traditional Interviews

\begin{tabular}{|c|c|c|c|}
\hline \multicolumn{3}{|c|}{ LEAD USER METHOD } & \multirow{2}{*}{\begin{tabular}{l|} 
TRADITIONAL \\
INTERVIEWS \\
INNOVATIONS FOR \\
APPLICANTS \\
\end{tabular}} \\
\hline $\begin{array}{l}\text { INNOVATIONS FOR } \\
\text { RECRUITERS }\end{array}$ & $\begin{array}{l}\text { INNOVATIONS FOR } \\
\text { PERSONNEL MARKETERS }\end{array}$ & $\begin{array}{l}\text { INNOVATIONS FOR } \\
\text { APPLICANTS }\end{array}$ & \\
\hline $\begin{array}{l}\text { Recruiters Blog } \\
- \text { Directly communicate with target group }\end{array}$ & $\begin{array}{l}\text { Marketers Blog } \\
\text { - } \begin{array}{l}\text { Directly communicate with target } \\
\text { group }\end{array}\end{array}$ & $\begin{array}{l}\text { Applicant Blog } \\
\text { - Directly communicate with recruiters } \\
\text { - Discussion Board: social exchange of } \\
\text { positive/negative job experiences }\end{array}$ & $\begin{array}{l}\text { Applicant Communication } \\
\text { - Internal communication with friends or } \\
\text { FoF, exchange experiences } \\
\text { Social Network features } \\
\text { - Inviting, blogging, tagging services } \\
\text { - Keep in touch with friends for career } \\
\text { purposes, connecting based on fields, } \\
\text { city groups, school groups, sports } \\
\text { groups, recommending friends } \\
\end{array}$ \\
\hline $\begin{array}{l}\text { Newsfeed Transparency/ Statistics } \\
\text { - \#Visitors, \# page impressions } \\
\text { - Detailed information which applicant } \\
\text { has clicked on job ad or company logo } \\
\text { - Ranking services: who is the best } \\
\text { suitable applicant for an open job } \\
\text { position, } 1^{\text {st }}, 2^{\text {nd }}, 3^{\text {rd }} \text { etc. } \\
\text { - Evaluation service of different } \\
\text { recruiting sites: other recruiters rank } \\
\text { services they have used }\end{array}$ & $\begin{array}{l}\text { Newsfeed Transparency/ Statistics } \\
\text { - \#Visitors, \# page impressions } \\
\text { - Detailed information which applicant } \\
\text { has clicked on ad or company logo } \\
\text { - \# Incoming information requests on } \\
\text { marketers' products and services } \\
\text { - \# People registering, applying or } \\
\text { buying the marketers services } \\
\text { - \# and strength of cooperation with } \\
\text { other media agencies to advertise more } \\
\text { efficiently }\end{array}$ & $\begin{array}{l}\text { Newsfeed Transparency/ Statistics } \\
\text {-\# Recruiters and detailed information } \\
\text { about who has visited applicant's profile } \\
\text { - \# and detailed information on new jobs } \\
\text { matching applicant's profile } \\
\text { - Show educational links if skills are } \\
\text { missing } \\
\text { - Notification on jobs where only few } \\
\text { applicants applied or only view } \\
\text { applicants clicked the job ad } \\
\text { - Matching which employer pays best for } \\
\text { graduates from different schools } \\
\text { - Friends/FoF work at same company, } \\
\text { area? }\end{array}$ & $\begin{aligned} & \text { Newsletter } \\
& \text { - Email new job offers } \\
& \text { - Events for graduates, alumni } \\
& \text { - Info on continuing education }\end{aligned}$ \\
\hline $\begin{array}{l}\text { Visualizing Applicants } \\
\text { - Map showing black spots (no suitable } \\
\text { applicants) and green spots (suitable } \\
\text { applicants), regional distribution in line } \\
\text { with skills: where are e.g., more } \\
\text { chemical engineers living? } \\
\text { - Tag cloud }\end{array}$ & $\begin{array}{l}\text { Visualizing Applicants } \\
\text { - Map showing black spots (no suitable } \\
\text { applicants) and green spots (suitable } \\
\text { applicants) } \\
\text { - Tag cloud }\end{array}$ & $\begin{array}{l}\text { Visualizing Jobs } \\
\text { - Map showing black spots (no fit with } \\
\text { my profile) and green spots (fit with my } \\
\text { profile) where are the jobs I fit best } \\
\text { - Tag cloud }\end{array}$ & $\begin{array}{l}\text { Career Info Pages } \\
\text { - How to find jobs } \\
\text { - How to prepare application documents } \\
\text { - Info on trainee programs } \\
\text { - Company online presentation }\end{array}$ \\
\hline $\begin{array}{c}\text { Live Chat } \\
- \text { Text or video }\end{array}$ & $\begin{array}{c}\text { Live Chat } \\
- \text { Text or video }\end{array}$ & $\begin{array}{l}\text { Avatar } \\
\text { - Digital application coach }\end{array}$ & $\begin{array}{l}\text { Employer communication } \\
- \text { Employer phone, address, email }\end{array}$ \\
\hline
\end{tabular}




\begin{tabular}{|c|c|c|c|}
\hline \multicolumn{3}{|c|}{ LEAD USSER METHOD } & \multirow{2}{*}{$\begin{array}{l}\text { TRADITIONAL } \\
\text { INTERVIEWS } \\
\text { INNOVATIONS FOR } \\
\text { APPLICANTS } \\
\end{array}$} \\
\hline $\begin{array}{l}\text { INNOVATIONS FOR } \\
\text { RECRUITERS }\end{array}$ & $\begin{array}{l}\text { INNOVATIONS FOR } \\
\text { PERSONNEL MARKETERS }\end{array}$ & $\begin{array}{l}\text { INNOVATIONS FOR } \\
\text { APPLICANTS }\end{array}$ & \\
\hline $\begin{array}{l}\text { Integration with e-HRM systems } \\
\text { - HR-XML so as to automatically update } \\
\text { profiles and job ads }\end{array}$ & $\begin{array}{l}\text { Integration with e-HRM systems } \\
\text { - HR-XML so as to automatically } \\
\text { update customer database }\end{array}$ & $\begin{array}{l}\text { Flexible Application Homepage } \\
\text { - Free page with individual address for } \\
\text { outside platform and future use } \\
\end{array}$ & $\begin{array}{l}\text { Data Transfer } \\
\text { - Download section, share pics, videos, } \\
\text { music, e-books etc. }\end{array}$ \\
\hline $\begin{array}{l}\text { Fan Club } \\
\text { - Applicants join company groups, better } \\
\begin{array}{l}\text { overview of } \\
\text { relationship } \\
\text { branding }\end{array} \\
\end{array}$ & $\begin{array}{l}\text { Fan Club } \\
\text { - Applicants join company groups, } \\
\text { better overview of interested } \\
\text { applicants, relationship building, } \\
\text { employer branding }\end{array}$ & $\begin{array}{l}\text { Insider/VIP Club } \\
\text { - Applicants join company groups, feel } \\
\text { special to be "insides" and directly } \\
\text { communicate with recruiters }\end{array}$ & \\
\hline \multirow[t]{2}{*}{$\begin{aligned} & \text { Career Letter } \\
&- \text { Target specific groups of users } \\
&\end{aligned}$} & $\begin{array}{l}\text { Career Letter } \\
-\quad \text { Target specific groups of users } \\
\end{array}$ & $\begin{aligned} & \text { Career Letter } \\
&- \text { Target specific groups of users } \\
&\end{aligned}$ & $\begin{aligned} & \text { Newsletter } \\
&- \text { Email new job offers } \\
&\end{aligned}$ \\
\hline & & $\begin{array}{l}\text { Differentiation between personal and } \\
\text { private page } \\
\text { - Invitation by friends necessary to } \\
\text { register, exclusivity, extended privacy } \\
\text { settings }\end{array}$ & $\begin{array}{l}\text { Differentiation between personal and } \\
\text { private page } \\
\text { - Contact info, hobbies, events, friends } \\
\text { etc. } \\
\text { - Private page with career information }\end{array}$ \\
\hline $\begin{array}{l}\text { Career Cockpit } \\
\text { - Search status: who is actively/passively } \\
\text { searching for a new job } \\
\text { - Save selected candidates, successful } \\
\text { placements etc. }\end{array}$ & $\begin{array}{l}\text { Career Cockpit } \\
\text { - Search status: who is } \\
\text { actively/passively searching for a new } \\
\text { job } \\
\text { - Save advertising history, subscriptions, } \\
\text { successful placements etc. }\end{array}$ & $\begin{array}{l}\text { Career Cockpit } \\
\text { - Search status: who is actively/passively } \\
\text { searching for a new job } \\
\text { - Save selected jobs }\end{array}$ & \\
\hline Open ID, APIs, Control/Security & Open ID, APIs, Control/Security & $\begin{array}{l}\text { Self-esteem / competency features } \\
\text { - Crowd-sourcing: integrate users to } \\
\text { expand skill ontologies, user experts can } \\
\text { compare themselves to others } \\
\text { - Enable applicants to use score for } \\
\text { resume } \\
\text { - Check your market value: show users } \\
\text { how they score compared to other users, } \\
\text { friends } \\
\text { Open ID, APIs, Control/Security }\end{array}$ & $\begin{array}{l}\text { Playfulness } \\
\text { - Online games with other users, rank } \\
\text { winners }\end{array}$ \\
\hline
\end{tabular}


Table 3

Categorizations of the New E-Recruiting Service Ideas (LU Method vs. Traditional Interviews)

\begin{tabular}{|c|c|c|c|c|c|c|c|c|}
\hline \multirow[t]{2}{*}{ E-Recruiting Innovation } & \multicolumn{3}{|c|}{ Market Dimension (n=15) } & \multicolumn{3}{|c|}{ Technological Dimension $(n=7)$} & \multicolumn{2}{|c|}{ Organizational Dimension $(n=7)$} \\
\hline & $\begin{array}{c}\text { New } \\
\text { benefits } \\
\text { for user }\end{array}$ & $\begin{array}{l}\text { Higher } \\
\text { benefits } \\
\text { for user }\end{array}$ & $\begin{array}{l}\text { Potential for } \\
\text { the firm's } \\
\text { competitive } \\
\text { advantage }\end{array}$ & $\begin{array}{c}\text { Newness of the } \\
\text { technology } \\
\text { needed to realize } \\
\text { the service idea }\end{array}$ & $\begin{array}{l}\text { Complexity to } \\
\text { realize the } \\
\text { service idea }\end{array}$ & $\begin{array}{c}\text { Uncertainty } \\
\text { about } \\
\text { development } \\
\text { time }\end{array}$ & $\begin{array}{c}\text { Required } \\
\text { change in } \\
\text { competencies }\end{array}$ & $\begin{array}{c}\text { Required change in } \\
\text { strategy }\end{array}$ \\
\hline \multicolumn{9}{|l|}{ Lead User Method } \\
\hline Blog & 6 & 7 & 7 & 0 & 0 & 0 & 0 & 2 \\
\hline Newsfeed for Transparency/ Statistics & $\underline{15}$ & $\underline{15}$ & $\underline{15}$ & $\underline{4}$ & $\underline{6}$ & $\underline{5}$ & $\underline{3}$ & $\underline{3}$ \\
\hline Visualizing Applicants/Jobs & $\overline{12}$ & $\overline{11}$ & 9 & 3 & 3 & 1 & 3 & 3 \\
\hline Live Chat & 8 & 8 & 7 & 2 & 2 & 0 & 0 & 2 \\
\hline Avatar & 9 & 12 & 8 & 4 & 4 & 5 & 2 & 2 \\
\hline Data integration with e-HRM systems & 12 & $\underline{13}$ & $\underline{13}$ & $\underline{6}$ & $\underline{6}$ & $\underline{5}$ & $\underline{3}$ & $\underline{4}$ \\
\hline Flexible Application Homepage & 9 & 8 & 5 & 0 & 0 & 0 & 0 & 0 \\
\hline Fan Club/Insider/VIP Club & 11 & 12 & 10 & 0 & 0 & 0 & 0 & 0 \\
\hline Career Letter & 9 & 8 & 8 & 0 & 0 & 0 & 0 & 0 \\
\hline Differentiation: Personal/Private page & 7 & 8 & 7 & 0 & 2 & 0 & 0 & 0 \\
\hline Career Cockpit & 12 & 13 & 9 & 3 & 2 & 2 & 0 & 0 \\
\hline Self-esteem /Competency features & $\underline{15}$ & 14 & 13 & $\underline{4}$ & $\underline{5}$ & $\underline{4}$ & $\underline{2}$ & $\underline{5}$ \\
\hline Open ID, APIs & 9 & 10 & 8 & 0 & 0 & 0 & 0 & 2 \\
\hline Control/Security & 6 & 11 & 7 & 3 & 4 & 2 & 0 & 2 \\
\hline \multicolumn{9}{|l|}{ Traditional Interviews } \\
\hline Applicant Communication & 7 & 6 & 7 & 2 & 1 & 0 & 0 & 0 \\
\hline Social Network features & 8 & 9 & 6 & 4 & 3 & 3 & 2 & 4 \\
\hline Employer communication & 0 & 0 & 0 & 0 & 0 & 0 & 0 & 0 \\
\hline Data transfer/Download & 6 & 7 & 3 & 1 & 1 & 1 & 0 & 0 \\
\hline Career Info Pages & 2 & 2 & 0 & 0 & 0 & 0 & 0 & 0 \\
\hline Newsletter & 0 & 3 & 0 & 0 & 0 & 0 & 0 & 0 \\
\hline Differentiation: Personal/Private page & 7 & 8 & 7 & 0 & 2 & 0 & 0 & 0 \\
\hline Playfulness/Online games & 6 & 4 & 2 & 2 & 1 & 0 & 0 & 2 \\
\hline
\end{tabular}




\title{
CHAPTER 9
}

\section{Globalizing e-HRM Services: Localization versus Standardization of HRM Practices ${ }^{13}$}

\begin{abstract}
Organizations today are increasingly implementing global information systems to support strategic business functions. We examine the new phenomenon of implementing e-HRM (Electronic Human Resource Management) systems on a global scale. This is the first study to reflect on the people dynamics experienced by a local e-HRM group tasked with implementing a global e-HRM strategy. Besides the implementation challenges previously reported, we identified systemic problems resulting from a tension between an arbitrage strategy for HRM management, and an aggregation strategy for e-HRM management. We found that the heterachy model of strategy (Chakravarthy \& Henderson, 2007) is difficult to enact at a global IT level. For effective global e-HRM implementation, headquarters need to define standardized requirements for e-HRM systems, while allowing subsidiaries flexibility in maintaining locally superior HR practices. Desired corporate outcomes such as consolidation, cost reduction and improved data sharing and business intelligence should not be pursued at the expense of flexibility in local HR strategy initiatives. It is paramount that headquarters maintains the trust of local staff. To that end, workarounds and requests for additional expenditure should be investigated as opportunities rather than being suppressed and ignored.
\end{abstract}

Keywords: Global Strategy, E-HRM Implementation, Localization, Standardization.

\footnotetext{
${ }^{13}$ This paper is under review with the European Journal of International Management (first revision).
} 


\section{Introduction}

Organizations today are increasingly challenged to develop new strategies for generating value from Human Resource Management (HRM). The recent financial crisis and consequential long term associated economic instabilities strongly motivate organizations to seek economies of scale, doing everything from outsourcing human resources and aligning business units across countries to becoming dependent upon unprecedented extensive supply chains. In this struggle for survival, the automation of processes has significantly contributed to organizations' time and cost savings. The use of e-HRM (Electronic Human Resource Management) in organizations is a natural candidate for automation in personnel departments. The early digitalization of personnel departments was marked by a generation of scholarly efforts to understand and explain the reasons underlying the adoption of Human Resource Information Systems (HRIS) (Mayer, 1971; Tomeski \& Lazarus, 1974; DeSanctis, 1986). Over the last decade a new generation of inquirers has emerged who recognize the potential of IT to transform human resourcing tasks on a global level (Ruel et al., 2004; Bondarouk \& Ruel, 2009; Marler, 2009). The term HRIS has been displaced by that of e-HRM (Electronic Human Resource Management). Whereas HRIS generally have a narrow scope intended to reduce HR departments' administrative burden, e-HRM promises far broader and deeper strategic service improvements and role changes for HR professionals (Bondarouk \& Ruel, 2009).

This paper contributes to the international management literature which lacks studies on this subject (Ruel, 2010). We use data from a case study on the local experience of an eHRM project team in charge of implementing a global e-HRM strategy. Traditionally, e-HRM research has focused on studying the requirements and consequences of automating human resource practices, without paying attention to the cultural context; and has sought to determine the status quo of localized e-HRM practices independently of the issues of other subsidiaries in global organizations.

Modern organizations frequently aim to survive increasing competition and globalization by adopting cost and time savings on IT. They strive to improve human resource professionals' ability to manage in a cost-effective way staffing, training and compensation by minimizing paperwork and automating key HR practices (Furtmueller et al., 2010). For example, the vast majority of large organizations routinely use e-Recruiting as the primary method for sourcing personnel (Lee, 2011). 
E-HRM has radically changed the heart, pace and radius of HR processes, and the way HR professionals are oriented towards and serve internal and external clients. In this new digitalized world, it is not at all surprising many personnel departments fear downsizing of (administrative) HR staff and tend to resist quick acceptance of information systems. They are particularly wary about what anyone in the field knows - the legendary failure of many organizational change initiatives on a large scale.

It is important to emphasize the strength of this very human resistance to change because the advantages of our new connected world cannot be taken for granted, and are by no means obvious to everyone. Utilizing the potential of globalizing e-HRM is very often acutely constrained by the complexities of people dynamics such as managing user acceptance when adapting new e-HRM systems (Grant et al., 2009). Problematical communication and misunderstanding between human resource personnel and IT staff have been found to prevent successful e-HRM implementations (Wilson-Evered \& Hartel, 2009). A further, somewhat more opaque obstacle was documented by Gardner et al. (2003) who found that in practice the implementation of e-HRM -- rather than freeing up time for HR practitioners -- can simply lead to the replacement of administrative duties with technologyrelated work, with no visible improvement in HRM services. Other studies report numerous cases where HR professionals were unsuccessful in using technology to initiate and support strategic decisions (Dery \& Wailes, 2005), or e-HRM technology was primarily used to simply support routine administrative HR tasks (Ball, 2001; Haines \& Lafleur, 2008; Hussain et al. 2007).

Despite a literal torrent of organizations that proudly advertise their e-HRM achievements, it cannot be denied that some companies have abandoned e-HRM after years of experimenting with it. Wounded but staying alive, they have retreated back to traditional practices (Lee, 2011). These companies typically suffered from a host of critical issues centered on the complex expertise required for the management of huge volumes of data created by their e-HRM systems. The cost of data storage and management offset the expected cost savings from -HRM implementation, and they were unable to leverage the data into useable business intelligence (Furtmueller et al., 2011). For example, Chapman and Webster's (2003) report only $25 \%$ of organizations using e-Recruitment regard its implementation as successful.

Organizations are now aware that e-HRM activities -- in order to take full advantage of emerging technologies -- need to be integrated seamlessly along a central or global HRM strategy. In the research literature it is well established that IT is not an autonomous island 
and does not per se generate value (Peppard \& Ward, 2004). To the contrary, keen observers have found that in order to generate value investments in IT require complementary investments in a host of non-IT processes, structures and organizational resources (Melville, 2004). There is no doubt whatsoever that the effects of investment in IT resources on human resources performance parameters only result from a continuous dynamic interplay with other complementary resources (Teece et al., 1997).

The potential value of IT is subject to being overcompensated by negative influences due to a profound mismatch of long-standing organizational practices and the IT structure implemented (Brynjolfsson \& Hitt, 2000). Overcoming barriers to global IT adoption in eHRM thus requires a deeper understanding of the issues involved in such boundary-spanning implementations.

Accordingly, this paper provides insights and explanations to assist organizations in reducing unexpected negative consequences in their future global e-HRM implementations. The structure of this paper is as follows: We begin with a literature review of global approaches for HR and IT management, strategy alignment, implementation, and embedding. Next the context of the case study is briefly described. The third section then outlines the basic methodology and a discussion of the results in reference to prior literature. Finally, we present a section on theory extraction and draw out several important conclusions.

\section{Literature Review}

\section{Global approaches for HRM and IT management}

It is acknowledged that there can be local-global tensions when implementing a global strategy in regional centres (Kirsch \& Haney, 2006; Mohdzain \& Ward, 2007; Pozzebon \& Pinsonneault, 2005). At the organizational level, the question whether global management practices converge or remain different across organizations due to differences in cultural and institutional contexts remains an intriguing research field among international management scholars. This debate is evidenced in extent literature on the localization versus standardization of functional areas such as human resources practices (Birkinshaw et al., 2007; Gunnigle et al., 2002; Pudelko \& Harzing, 2008).

Even though the field of strategic information systems has attracted much research attention since the 1970s (Nolan, 1979; Galliers, 1991), few studies have focused on the experience of global IT implementation in subsidiaries (Mohdzaher \& Ward, 2007). However, 
the large volume of empirical research in multinationals in the international management literature shows that it is important to conduct such IT-oriented studies in multinationals, as entities distinct from single-nationals. Multinationals may develop their business strategies based on different goals for global integration and local responsiveness (Bartlett \& Goshal, 1986), or based on strategies for global coordination and configuration of different multinational units (Porter, 1990). A naïve perception is that a multinational environment, from an HR perspective, is purely an extension of a single-national HR environment. Extant research has shown that technical and managerial issues in global projects widely differ in institutional, cultural, political, economic, social and technological contexts (Birkinshaw, 1994; Harzing, 2000). Using standardised global IT systems in multinational organisations is increasingly seen to support rationalised and flexible operations, provide economies of scale, and reduce duplication and risk. Recently, Ghemawat (2008) identified three conceptual approaches to global strategy: adaption, aggregation, and arbitrage. Adaption seeks to boost local revenues and decentralized market share by maximizing local relevance, and may involve setting up a mini-organisation in each country, each performing a largely complete set of activities, adapted to local differences, and having many of its own information systems, including e-HRM systems. Aggregation aims to deliver economies of scale, including centralized standardising product and service offerings and grouping together development and production processes, including information technology. Arbitrage is the exploitation of differences between national and regional markets, often by locating separate parts of the supply chain in different places, or in the context of e-HRM: separate parts of the e-HRM practices (Ghemawat, 2008).

\section{Table 1}

\section{Globalizing e-HRM systems}

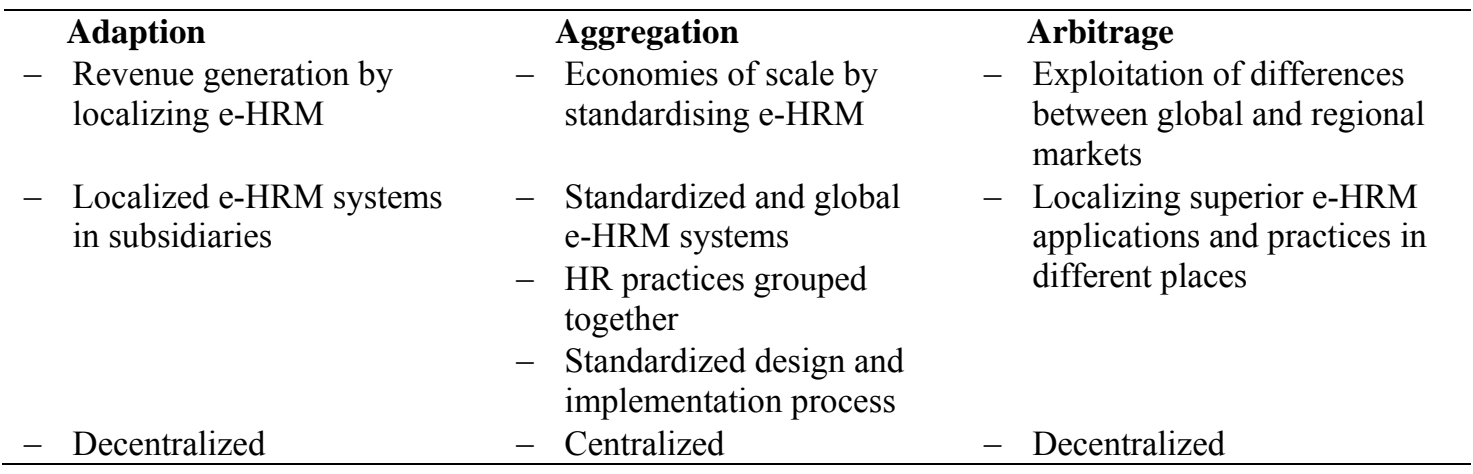

Similarly to Ghemawat's (2008) arbitrage strategy, Brewster et al. (2008) found evidence for the usefulness of duality in the HRM practices and policies in host countries of multinational 
corporations. Following trends in global IT management, firms are increasingly interested in taking a global or centralized view of their e-HRM systems (Gueutal \& Stone, 2005; Ployhart, 2006; Ruel \& Bondarouk, 2010); and they tend to centralize so that staff can be deployed flexibly and cost effectively; resource requirements can be better planned; and employees be better enabled to develop careers within the company at large. This can involve global "talent management', i.e. the ability to search within the whole organization for the availability of appropriate skills in order to avoid "the costs associated with laying off people in one group while hiring the same talent into another" (Hoffman \& Hoffman, 2007, p. 20); or alternatively, offering opportunities for employees to self-manage by scanning for upcoming vacancies and continuously up-skill to ensure they have the necessary competencies.

In the literature on global IT strategy and implementation, there have been relatively few studies that focus on the local experience of centralized global strategy implementation. It has been acknowledged that global strategies need to take account of local factors (Palvia et al., 2002). There is wide agreement that a global approach can result in tension between overall control (integration) and local autonomy and differentiation (Kirsch \& Haney, 2006; Mohdzain \& Ward, 2007; Pozzebon \& Pinsonneault, Schuler et al., 1993). Often corporate head offices and management regard local staff as simply responsible for implementation of a pre-defined strategy (Mohdzain \& Ward, 2007). Besides, the imposition of IT projects originating from the head office is often regarded as a successful implementation of strategy, without consideration of local human factors.

In the international management literature ethnocentric top-down approaches are no longer seen as sustainable in today's globalized corporate environment. Rather geocentric (Perlmutter, 1969) or transnational (Bartlett \& Goshal, 1986) strategies have gained popularity. Pudelko and Harzing (2008) argue that organizations should seek standardization and best practices wherever they originate from. In this context reverse knowledge transfer from subsidiaries to headquarters is likely. Similarly, Chakravarthy and Henderson (2007) argued that a top-down, hierarchical approach to strategy formulation is becoming obsolete, and should no-longer be driven out of the corporate office (even with a high quality set of negotiation skills). They argue that transforming global initiatives are:

"...in part about global efficiency and learning, but in part about local responsiveness...[and]...require a bottom-up adaptive planning process" (p. 649).

As an alternative to a top-down or centralized strategy, where every node is connected to the parent node, they propose a heterachy, where a node can take strategic initiatives and be 
connected to its surrounding nodes without the need to obtain permission from anywhere else (Chakravarthy \& Henderson, 2007). Such an approach appears interesting to consider in large scale IT systems management where specific applications may represent the core of e-HRM systems while separate modules can be flexible adapted to fit local needs.

However, global-local negotiation is often lacking (Kirsch \& Haney, 2006; Pozzebon $\&$ Pinsonneault). A nominally configurable enterprise system, such as (for example) SAP's human resources system; which claims at the time of writing to support forty-nine different legislative and tax requirements in its payroll system will not necessarily support the nuances of the local socio-economic environment. Achieving consensus and buy-in to a global vision, requires an extensive negotiation, communication, and willingness to compromise on e-HRM system requirements (Kirsch \& Haney, 2006). Regional differences can be genuine and important to a globally operating business (Maatman et al., 2010), as for example in some parts of the middle east that have restrictions on men and women working together (Ruel, 2010). While HR, IT, finance, management and other stakeholders involved in implementations may have divergent priorities, their complementary skills and knowledge are essential to IS project success (Kirsch, 2004). It is imperative that relationships and communication between stakeholders are effectively managed to elicit their cooperation and enable IT systems to work on a global level (Ruel \& Bondarouk, 2010). However, this assumes that if the stakeholder groups communicate with each other, differences will be easily resolved. We will suggest that there are potentially intractable, systemic local-global tensions that may arise from the implementation of global e-HRM systems, which may require a willingness by the global business to accommodate genuine strategic input from local stakeholders.

\section{IT strategy alignment, implementation and embedding}

IT strategy implementation involves "the process of completing the projects of application of information technology to assist an organisation in realizing its goals" (Gottschalk, 1999, p. 111). It is said to be complete from a time perspective when the system is installed or when changes are occurring or when benefits intended are realized. Obtaining these benefits is more easily said than done in globally operating firms.

Once a strategy is formulated, it needs to be embedded in the organisation. Embedding establishes a shared understanding of strategic objectives and priorities at all levels. This phase coordinates the flow of objectives, measures and actions; opens lines of communication, involves staff in decision making, motivates employees, adapts technology to 
assist with strategic change, avoids conflicting or overlapping development and make strategic choices to optimize business performance (Benbya \& MacElvey, 2006, Accur \& Englyst, 2006). Embedding IT requires a flow of communication and achieving consensus between different stakeholder groups (Bondarouk et al., 2009).

In order to contribute to an organization's performance over time IT alignment is a continuous co-evolutionary process. It reconciles top down designs and bottom up emergent processes and coherently interrelates all components of the business and IT requirements at the strategic, operational and individual level (Benbya \& McKelvey, 2006). IT strategic alignment deals in other words with the congruence between an organisation's global strategy and infrastructure and the organisation's IT strategy and infrastructure (Broadbent and Weill, 1993).

In this context, Ruel (2010) proposed a framework for researchers who intend to study e-HRM in a global context. Using the e-HRM model as foundation (Ruel et al. 2004) which distinguishes four phases of e-HRM adoption, he proposed an interplay between socio cultural influences (divergence) and business ideology (convergence). Based on a case study on the globalization of e-HRM systems, he argues that converging tendencies are more likely reflected in the initial e-HRM goal and policies definition phase while the diverging tendencies rather emerge in the appropriation of e-HRM systems by internal organizational members.

The model further differentiates three types of e-HRM: operational e-HRM with the salient focus on administrative services like salary administration and record-keeping; relational e-HRM with the focus on executing HRM processes, like recruitment, compensation, and training and development; and transformational e-HRM with the focus on strategic management such as knowledge management, strategic competence management, and organizational change (Ruel, 2010).

The strategic information systems literature has recognized that local-global negotiation needs to occur to effectively implement IT strategy in global organisations (Pozzebon \& Pinsonneault). This is complicated by the fact that negotiation and alignment needs to occur not only between overall strategy setting and the business and IT departments responsible for implementing strategy, but in the degree to which systems meet the requirements and needs of individuals within the organization (Benbya \& Mckelvey, 2006). A study by Kirsch and Haney (2006) examined successful negotiating requirements for global IT systems with local stakeholders: establishing a shared understanding, gaining buy-in to the global strategy, and developing lines of communication (Kirsch and Haney, 2006). Further, 
Finnegan's and Longaigh's (2002) discussed operational and environmental factors which we extended to explain the need for different approaches to planning IT in multinationals compared with single-nationals (see table 2).

Table 2

Factors influencing global IT strategic planning

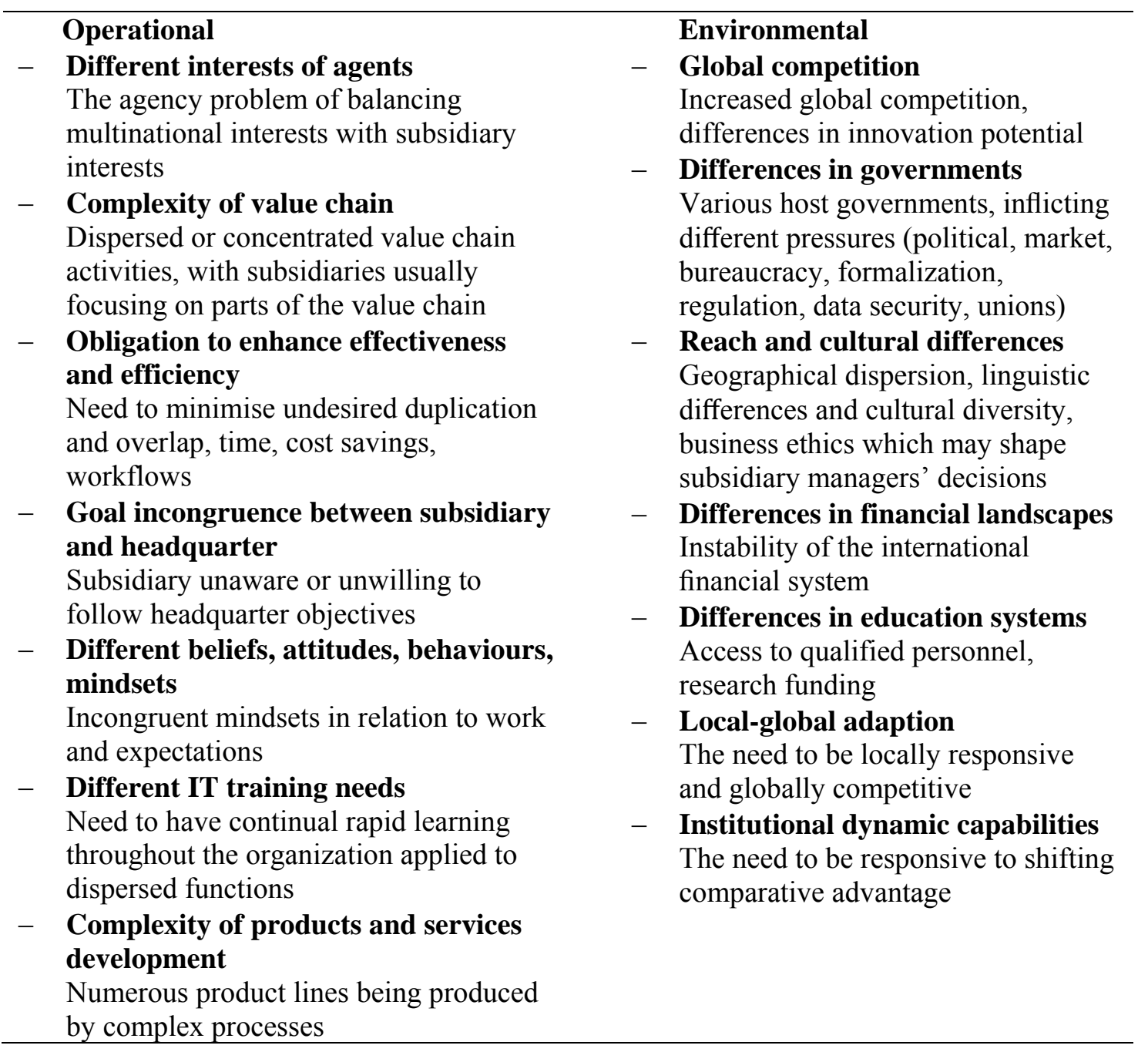

\section{Global HRM and e-HRM strategy in the case company}

The context of the study is the development and implementation of a new strategy for e-HRM systems for a large multinational professional services firm. This particular company has approximately 200,000 employees active in 35 countries, with nearly half working in the Asia-Pacific region. We zoom-in on the experiences of a regional IT group in New Zealand responsible for the implementation of a global e-HRM strategy. Due to confidentiality 
concerns details of the specific group studied in New Zealand have been concealed and replaced with non-specific references to the local region.

Dissatisfaction with the rising costs of running multiple HR platforms and IT applications, along with the lack of integrated searching and reporting, was a driving force in the growing need to integrate human resource processes. This involved the conversion of the existing, local e-HRM systems onto a single enterprise platform, and the retirement of autonomous local e-HRM systems. In a nutshell, the global HR strategy of this firm aimed at improved management of a global workforce. Previously, in each country employee supply and demand were managed locally. It was taken for granted by everyone that human resource functions were naturally delivered by the HR group in each area, and staff typically attended local training courses. Then suddenly with the new global e-HRM systems, previous processes once seen as working well for measuring employee performance became opaque and possibly inconsistent.

The new HRM strategy proposed that rather than all countries maintaining their own systems business processes and IT architectures would be aggregated at the enterprise level. The organization planned to optimize and integrate the e-HRM application portfolio. Clearly, the organization wanted to do this by centralizing the multitude of IT for HR support functions such as payroll, expense claims, pensions, training, recruiting, leave and timesheets. They wanted to manage their workforce better, including implementing a rationalized "supply chain" model for their global workforce, which involved capturing, analysing, and optimizing HR demand and supply information. At a more detailed level, global workforce management was intended to involve projecting demand for particular skill-sets. This new centralized universe - of managing applicants and supply ideally sourced from lower wage countries, and flexible deployment of staff to projects as required - depended upon the implementation of mobile and virtual work tools in a strongly connected network. This was all to be bundled together with consolidated enterprise-wide management of knowledge and online training, with the intention that staff could use training resources on a just-in-time basis to address skill gaps. The organization also aimed to devolve some functions from HR departments to a selfservice model.

\section{Method}

Everyone on the local e-HRM team in New Zealand that was tasked to implement the new global strategy became an informant in this study. In-depth interviews were conducted with those responsible for IT transformation, delivery, architecting solutions and interpreting and 
implementing the global strategy in the region, as well for the management of the local region's portfolio of HR applications. Interview questions focused on the project history and background, involved stakeholders' roles and responsibilities, strategy formation, what happened during global e-HRM implementation, alignment and embedding. The advantage of this approach is that it concentrates directly on the research topic, provides actually relevant perceived causal inferences (Yin, 2008), and allows the researcher to drill down and probe to uncover new themes based on the interviewees' personal experiences.

Our investigation provides penetrating reflection on data collected from the key project leaders: 1) The e-HRM manager who is responsible for managing the team,the relationships with the global IT group; and the internal clients of the local HR department; 2) The project manager responsible for implementing funded and approved projects; 3) The systems analysts and architects; 4) The business systems analysts responsible for requirements analysis, design and system configuration, and 5) The technical developer responsible for developing and implementing changes. Each interview lasted about 90 minutes. It should be noted here that numerous contractors and outsourcers were also involved during the implementation project to solve integration problems left unsolved by the internal IT staff. We did not interview these external consultants. We analysed extant internal documents and communications such as presentation materials, analyses, reports and memos, and made field notes during the interviews and site visits. Company material and internal strategy documents added to our understanding of the overall context in which the project was undertaken (Yin, 2008), and thus of the firm and its unfolding practical interaction in the environment.

A thematic network analysis was taken to identify, analyse and report themes in the data (Braun \& Clarke, 2006). This approach was used to organize themes into a network which summarizes the main findings (Attride-Stirling, 2001). In the first stage, the interviews were transcribed and carefully read. We became immersed with the data (Eisenhardt, 1989) which was supplemented with the collected field notes. Interview data was augmented with internal strategy documents, which was valuable for verifying project objectives, roles, responsibilities and implementation progress to date. In the second stage, themes were generated across the whole dataset, collating excerpts relevant to each theme. We adopted an inductive approach to the thematic analysis scheme, without trying to fit it into a pre-existing framework (Miles \& Huberman, 1994); we did so because we could not locate an established conceptual model for global e-HRM implementation from the perspective of a local e-HRM group (Bran \& Clarke, 2006). Accordingly, we identified themes strongly linked to the data, 
but they may be more or less unrelated to the specific questions that were in fact actually posed. In the third stage the themes were reviewed, organized and in some cases relabelled, while some codes were amalgamated. In the fourth stage the network was refined to ensure consistency of the overall analysis. Finally, the network diagram was developed, salient themes were discussed in light of previous literature and representative quotes were selected to convey the general experience of the interviewees.

\section{Results}

In this section we first present the individual themes emerging from the interviews, followed by the integrated thematic network developed from the study.

\section{Themes emerging from the interview data}

A large number of issues arose from the strategy-implementation gap, including difficulties in configuring the global system to local requirements, constraints on funding for local solutions, the need for work-arounds, and a general sense of conflicting priorities among the stakeholders involved in the global e-HRM implementation. This was clearly a sensitive topic extensively commented on by our informants.

\section{Ambiguous strategy formulation}

The top-down approach and lack of consultation resulted in a lack of detail and clarity in the strategy which meant that much of the implementation was murky and muddled in guesswork. The central strategy formulation process of how best to achieve essential goals was seen as out of touch with delivery. One of the technical developers underscored the level of confusion:

It is one thing to strategize and another to deliver. Strategy has nothing to do with delivery."

The technical developer also stressed how out of touch with reality the new program was, that it was merely at best aspirational and not realistic to develop the system in practice:

"Strategy formulation by the global team is idealistic".

The local team needed to take considerable responsibility for implementation decisions, but felt they were doing so in a vacuum. Also the business system analyst spoke out in no uncertain terms:

"The strategy formulation process does not clarify and express strategy in sufficiently clear terms to render it formally operational, most of its vapourware." 
Overall, the technical developer responsible for developing and implementing the changes summarized the discontent when he said:

"I don't think it gets done well - our attempts to operationalize strategy."

\section{Difficulties with centralized global strategy}

There was a sense that the e-HRM group had been captured by the global strategy at the expense of their local constituency. They were frequently involved in system changes originating from global strategy requirements. These added little value to the local HR group, who could not see the justification for them. The e-HRM manger pointed to the level of ignorance at work in a centralized paradigm:

[Local] "HR doesn't often understand the implications to e-HRM systems when strategic decisions are made."

The project manager commented:

"e-HRM investments are approved by the global funding committee, i.e. not locally."

This resulted in e-HRM project members having responsibility for rolling out a strategy that their local clients were not committed to, one they had little input into or a sense of ownership for. The-HRM manager underscored the failure of the rhetoric as rhetoric:

[Local] "e-HRM finds it difficult to seek commitment to a strategy that isn't convincing to [local\} HR or to [local] E-HRM itself."

This diminished credibility and lack of trust constrained their ability to respond to local requirements. The business system analyst decried the decline of proactivity:

"We mostly take direction from Global; this can also be a constraint as we are not able to proactively resolve business issues" and "[local] EHRM expends significant effort trying to fit an idealistic strategy in accordance with business needs and securing [local] HR support."

As a result, there was an acknowledged failure to meet local requirements. The region was a high-growth area, tasked with extensive new recruitment. The project manager explained:

[Local] "is unable to proactively respond to dynamic organizational change...The [strategy]..was not proactive enough to deal with the business needs of hyper growth countries in the region" and "Either they did not have a plan or it was not understood how we deal with these countries explicitly. This has a cascading impact on project delivery."

Overall, the local group were dissatisfied with the global system that was selected "Doesn't really address business requirements/priorities at the country or regional level." The local eHRM team was confident that they knew their own market and regional requirements better. The business system analyse was extremely forthright: 
"We are knowledgeable about our markets, legal and mandatory needs and workforce differences and hence the onus is on the delivery team to interpret strategy, and "It is us who have been sensitive to the needs of the regions/countries and try to fit the strategy in accordance with their needs."

The software suite selected was supposed to be an integrated, global solution which could be implemented in each region. The business system analyst found it inadequate for his job:

[Local] "e-HRM's strategy implementation focus is on Global run once solutions. Unfortunately, the system "only partially addresses business requirements and priorities at the country and regions."

\section{$\underline{\text { Responsibility and Control }}$}

Members of the local e-HRM team were given responsibility for implementation of the strategy; the IT employees were quite conscious of an explicit shift of orientation, from having had primary responsibility for servicing local HR requirements to becoming merely responsible for putting into effect a global strategy which in certain ways was at odds with local requirements. The e-HRM manager explains:

[Local] "e-HRM's strategic alignment (or lack of) with Global e-HRM, [local] HR and the CIO's strategy is part of a bigger chain of strategic alignment that occurs within the organization. A problem in this chain directly or indirectly impacts [local] e-HRM. This is evident in the issues that are manifest as a consequence of our focus being more on the Global e-HRM strategy than [local] HR strategy and requirements."

There were also issues with the strategy being lost in translation. Even though the local eHRM group had been responsible for strategy implementation, they had limited input into local strategy formulation. Although there was little if any negotiation, there was some latitude for interpretation which was seen as a potential risk to the overall success of the implementation. There was a fear of the possibility of some local hijacking. The business system analyst argues:

"When ideas are carried forward from Global to [local] the mindset does get lost. It has to do with the extent we are involved in strategy formulation. The as-is situation is that strategy provides us high level guidelines with sufficient autonomy at the regions to interpret them."

\section{Communication difficulties between local and global}

Communication between the local employees, both individually and as a group with the global e-HRM group was limited, and largely top-down. The local e-HRM group felt disempowered. One of the IT systems analyst remarked: 
"Strategy formulation is performed by a select group of individuals with limited inputs from the regions. Therefore this is not an area that we have visibility.... Now and again stuff is shared by the architecture team but as a process there is no socialization... the ability of [local] e-HRM to influence, and ideas being exchanged, is limited".

There was little two-way communication, and input from the local region did not inform global strategy:

"There are a lot of good ideas on the table; however since we do operate as silos it rarely gets past."

In addition, the e-HRM explained that there had been relatively little negotiation and that the change was clearly imposed from the top:

"Strategy was socialized amongst a select group of stakeholders who mattered to the e-HRM strategy team. [Those stakeholders] may have accepted it on the grounds that the intent of Global e-HRM's strategy is to transform and align strategic HR processes and tools by implementing best of breed solutions (buy or build) for the enterprise. This position was expected to meet little resistance and it might have been considered politically expedient to publish a strategy in the short term with the intent of making modifications later."

The e-HRM manager further noted that the push forward went straight ahead despite attempts by the local group to negotiate, as:

"At [local] e-HRM we have tried to push upwards to ensure that strategy formulation is open as possible and less prescriptive."

It was perceived that those involved in strategy formulation bypassed local authority structures in communicating the intent of the strategy. Much of the communication was delivered directly to individuals, to all staff, via presentations, or a wiki, rather than being discussed with the local e-HRM teams in order to obtain their input and bring them on board. This was perceived as being one of the contributing factors to the unexpected negative consequences of the strategy implementation. The e-HRM manager found the underlying opaqueness of the entire process highly inappropriate:

"The e-HRM strategy formulation process needs to be transparent within the [local] e-HRM team. First, the e-HRM strategy was formally publicized and it followed, months later, by an announcement of a wiki welcoming discussion and collaboration on detailed work and analysis behind the strategy. It would have been appropriate to have welcomed discussion and collaboration from the regions prior to the e-HRM strategy being publicized by global offices. The wiki announcement to all concerned was focused on individuals instead of engaging the leadership in the respective regions. It is apparent from the issues manifest that it can be traced to strategy formulation not being a social process." 


\section{Loss of confidence between local HR and local e-HRM}

A further issue was the local HR group's perception that the e-HRM group was primarily a technical group tasked with delivering technical solutions to their business requirements. The technical solutions requested by their local HR group were at odds with the architectural direction and spending guidelines they were receiving from the global e-HRM group. Since the local HR group were not heavily involved in the strategy development, and "their" IT providers had been captured by the global group, tensions broke out and rework was found necessary. The business system analyst grasped the irony of bad planning on a global scale:

"We are often called to implement technical solutions rather than solve business problems. Once technical solutions have been determined we often need to back pedal and review these decisions, which can be a source of conflict" and "[Local] HR doesn't often understand the implications to e-HRM systems when decisions are made. Once business solutions have been determined without prior engagement of e-HRM there is often a review of these decisions in terms of its feasibility and potential workarounds towards implementing them."

This resulted in a loss of confidence between the local HR department and the local e-HRM group. Fairly soon the local HR department routinely attempted to bypass the e-HRM group and go directly to their IT outsourcers, who were not subject to the same constraints and scrutiny. The e-HRM manager observed this pattern close-up:

"In a number of instances HR directly engages the AMS (outsourcer) teams instead of using [local] e-HRM's services and from a client point of view they often question [local] e-HRM value addition."

Overall, in order to roll out the strategy, e-HRM needed to have a more pro-active negotiation and consultancy role. It would be instrumental, both in terms of assisting the local HR department to conform to the global strategy, without compromising their own requirements excessively, and in informing the global group about local requirements. Currently, local eHRM was not established in either role. The local e-HRM manager was very demanding on this point:

“e-HRM requires to engage in HR proactively and to promote itself as an interested stakeholder with transformational capabilities that can be leveraged. It needs to ensure that it is part of the HR strategy formulation process both at Global and the regions to understand business problems, opportunities and priorities - taking into consideration unique business requirements of markets (country and region), workforce differences, legal and mandatory needs." 


\section{$\underline{\text { Political behaviour }}$}

These difficulties resulted in an increase in political behaviour, with the local e-HRM team effectively caught in the middle. The e-HRM manager peered into this complex political matrix:

"At [local] e-HRM the political dimension weighs more than procedural rationality in strategic decision-making. The reason being it not only needs to manage the priorities and expectations of local HR and Global e-HRM but also impacts of decisions and strategies of parties outside its sphere of influence but within the matrix structure" and "The downside to [local] e-HRM's political behaviour is that Managers take decisions that are politically expedient. Further "[Local] e-HRM Managers often distribute ownership of risks or issues to HR. This is sometimes considered as lack of ownership or not taking responsibility from a customer's perspective."

\section{Alignment and embedding of e-HRM system}

There were also problems with the configurability and constraints on legacy systems. The software was intended to be configurable. One of the technical developers stated the puzzle in plain terms:

"The challenges we have from an implementation standpoint is the extent to which these applications are configurable to meet country unique, legal and mandatory requirements."

Accordingly, the technical staff claimed that configuring the system to meet local requirements was -- for a number of reasons -- not very successful:

"Prevalent thinking is to implement best of breed solutions (buy or build); as regards how it gets implemented is another matter. The usual constraints are funding, schedule, knowledge and expertise."

Although there were difficulties with the new global solution, the local e-HRM team were also constrained by global governance and approval processes from enhancing local legacy systems. The e-HRM manager underscored the failure' true source:

"The guidance (from Global e-HRM) is to spend as little money as possible on legacy systems."

This was opposed by the local HR group, who were looking for an IT group that would be responsive to their local requirement. The business system analyst saw no limit to the confusion.

"However we are challenged by the business [local HR] on grounds that we don't enhance the legacy system. We were perceived as affecting their HR processes.” 
The system was successfully "implemented" (from the point of view of the global group) but not embedded in the local organization, who did not see it as aligned with their strategy and needs as a high-growth area aimed at flexibly supplying the HR needs of the organization.

\section{Improvisation and Work-arounds}

Work-arounds were developed as the result of limited configurability and lack of successful embedding; and yet constraints on legacy system enhancements entailed a perceived lack of responsiveness to local HR business requirements. The IT systems analysts and architects claimed the burden of blame for the fiasco was the sheer fantasy of utopian software-mania:

"The business reality is that a large extent of architected solutions only partially cater to unique business requirements of markets (country and region), workforce differences, legal and mandatory needs. There are a number of emergent business needs that [local] e-HRM does not have the means (resources, expertise, budget or time) to cope with."

The resulting residual manual processes were seen as potentially risky: Country or regional requirements that did not have global strategic solutions were forced to use use semiautomated solutions. These required manual interventions that needlessly spike business control exposure. The difficulties in configuring the global solution, and the constraint imposed on spending on local requirements, invariably resulted in conflict between the local e-HRM group and their local HR department clients

The global strategy implementation and its challenges resulted in some changes (and strains) in the roles and relationships of e-HRM and their HR clients at the local level. The local HR group has been accustomed to having autonomy over their processes and decisionmaking, and to operating IT systems that were tailored specifically to their requirements. This meant that their practice was to determine requirements independently of the e-HRM group, who would then be expected to deliver the technical solution. The business system analyst summarized the situation well:

"Most often HR puts us in a technology box and not as consultants. With late engagements we are not identified as an interested stakeholder."

\section{Thematic network}

The overall thematic network diagram is shown as Figure 1. In this diagram it is manifest that characteristics of the strategy implementation, embedding and alignment lead to unexpected results. In particular, top-down communication, limited negotiation, and communication directly to individuals which bypass the local management lead to a situation where the local e-HRM group is responsible for implementing a strategy they had not been able to discuss or 
negotiate. In addition, this pattern of pluralistic ignorance is compounded because they were given insufficient resources to localise the strategy.

The control of resources by the global group had a number of negative consequences, the foremost of which was that the local e-HRM group were seen as aligned with the global group (whether they wanted to be or not) because the global group controlled their access to resources and would not resource localisation. However since there had been very little "bottom-up" input, and the implementation details were somewhat vague, there was a significant gap between the strategy and the perceived local requirements. There were also inherent limitations in the degree to which the supposedly "configurable" global system could be effectively localised. These critical limitations were not discussable between the local and other headquarters' parties involved.

The outcome of this was that the local HR department lost confidence in their e-HRM group to meet their needs. Roles and relationships changed in a rather unmanaged way. Workarounds emerged, and the various stakeholders engaged in unproductive political behaviours. Overall, despite the overall announced success of the strategy from a global organisational perspective, at the local level there was a high level of dissatisfaction.

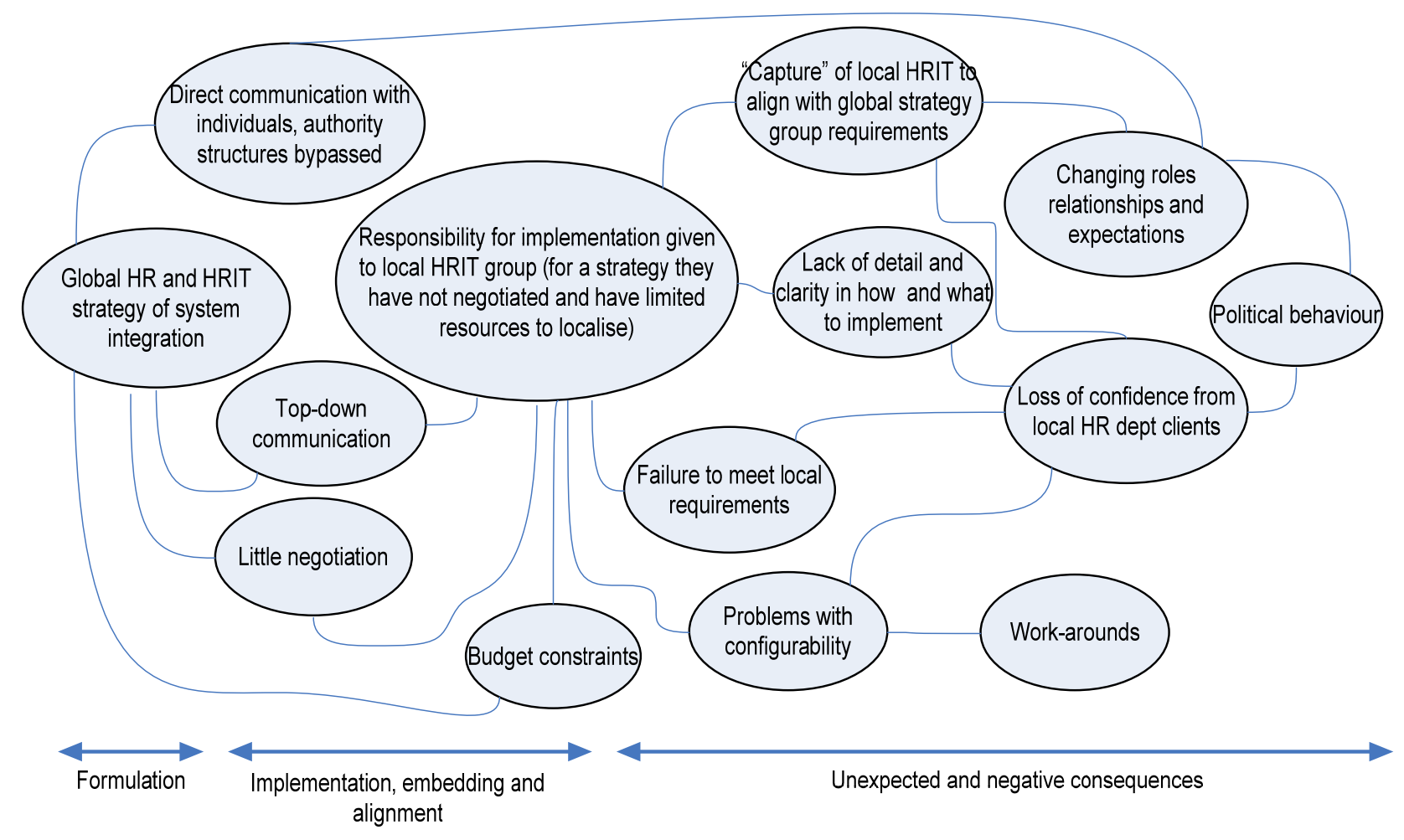

Figure 1

Thematic Analysis 


\section{Discussion}

\section{Strategy formulation and outcomes}

The approach taken by the case organization was top-down, with little communication or negotiation. It was assumed local areas would follow the lead set by the global strategy group, but there was no clear process for communicating and negotiating between local and global requirements. Although Kirsch and Haney (2006) claim the most powerful group in the negotiation will not always get its way, this appears to have happened in this case. The global headquarter group was able to exercise control over budgets and resources, largely blocking any initiatives not in conformance with their direction. The internal communications of the corporate offices suggest the strategy was generally seen as a "success." It appeared from the perspective of headquarters to be progressing steadily and satisfactorily when measured against its stated goals. However, local issues were not solved at the same time, which of course led to numerous unexpected and negative outcomes.

\section{Implementation, embedding and alignment}

The blunt approach to alignment taken by the central strategy group did not conform to the standard best practices in the IS strategy and alignment literature. It is most certainly an understatement to say shared understanding of strategic objectives/priorities at all levels was conspicuously lacking. At the workplace the local e-HRM team routinely described the strategy as "vapourware". The objectives at a global level were clear, but when they conflicted with local priorities and there was no effective mechanism to resolve differences they escalated. Local e-HRM staff often talked about poor lines of communication and a lack of their own involvement in central and even their own decision-making. This malaise of acceptance meant that - rather than feeling committed and championing the strategy - they sought distance and avoided responsibility as much as possible. The software suite selected was nominally configurable, but there was widespread perception that it did not fully support all the various specific local requirements. This was doubly difficult as the region was a highgrowth region, tasked with extensive recruiting to supply qualified knowledge workers to demanding posts. They had to be able to make the detached judgment that new hires had the competence had to satisfy the pressing and evolving requirements of the global organization.

The insufficient support for the local organization responsible for implementation and alignment led to multiple political and organizational issues. Overall this study underscores the importance of local-global negotiation and communication, and top-down/bottom-up 
negotiation (Benbya \& Mckelvey, 2006; Kirsch \& Haney, 2006; Pozzebon \& Pinsonneault, 2005) which in this case appear to have been sorely lacking. It is arguable that a heterachical approach (Chakravarthy \& Handerson, 2007) would have been desirable from an HR point of view. The local organisation was in a strategic growth area and under a less top-down regime, well placed to drive strategic recruiting initiatives. However, it is far from unambiguous whether even an agile and outgoing centralised e-HRM system would easily support this approach.

\section{Unexpected and negative outcomes}

Failure to explicitly address organizational issues resulted in a number of unexpected emergent outcomes (Benbya \& Mckelvey, 2006). The local HR was accustomed to considerable autonomy, and to treating their local e-HRM group and outsourcers as technical resources who were responsible for implementing their business decisions. This often meant the tardy involvement of the e-HRM staff in the planning cycle, when global or HR management's important business decisions were already made. The local HR team felt disempowered and frustrated by the move to a global approach to HR sourcing and the central control of resources for e-HRM. They were now responsible for implementing a global strategy, but were anxious to be involved earlier in the decision-making process and on a more strategic basis. They saw themselves as consultants in configuring the new system, and utilising it for planning, forecasting and estimating costs. However, the tight control of resources by the central group, in conjunction with the historic perception of the local e-HRM group as technical providers, meant the local HR group did not embrace this role change by "their" e-HRM group. In the aftermath of the change HR came to regard the e-HRM team as an obstacle to be worked around. To the extent HR was able to fly under the radar of global scrutiny they developed work-arounds. These alternative pathways sometimes involved local IT outsourcers who were not subject to the same restrictions as the in-house e-HRM group.

\section{The case in a wider context}

If we consider the global models of aggregation, arbitrage adaption as outlined by Ghemawat (2007), we can see that the organisation prior to the development of the global strategy was running an adaption strategy for human resource management, overall IT management and eHRM management. The organisation had national presences in many countries, each with their own IT systems. There were more than 40 separate national e-HRM systems. Local HR departments were in this restricted sense autonomous, not only able to but encouraged to 
source their own IT solutions and implement working modifications and progressive enhancements.

The organisation most recently was moving in line with global trends for multinational organisations towards an arbitrage model of HR management. This global strategy involved exploiting regional opportunities, particularly the economies of scale, expertise and estimating costs offered by hyper growth countries. For example, it was projected that in approximately two years the number of professional services staff employed in India (where wages are lower than North America and Europe) would increase five-fold.

In tandem, the organisation was pursuing a strategy to globally integrate support functions. While this was intended to support an arbitrage model of human resource management, at an information technology level it more closely represented an aggregation model. This created tension at the headquarter level between the HR business strategy and the e-HRM strategy that supports. Aggregating the IT systems, especially without adequate support for localization, tended to restrict the agility required to support rapid growth and satisfy the recruitment needs of the local regions. This also created issues for the local HR managers. Their ability to meet their local information technology requirements was reduced by system aggregation, tight central control, budget constraints, and limited communication. Further, since the regional area was targeted for significant HR growth, this caused a great deal of frustration. The HR managers in the region (which included emerging, lower-wage countries) ended up with increased responsibility as incubators for global workforce planning, while their ability to access the specific IT support they needed was increasingly constrained.

\section{Theory Extraction}

This study suggests that globalizing e-HRM systems can become a flashpoint for organizational issues associated with changing organizational strategy. Apparently, the flexibility sought in an arbitrage model can be extraordinarily difficult to enact in global eHRM systems. Cost reduction and consolidation of HR software systems and hardware platforms, along with the requirements of global planning and business intelligence - tend towards an aggregation model. Although many integrated enterprise HR systems such as $\mathrm{SAP} / \mathrm{R} 3$ are nominally configurable, this is often more at the level of merely supporting local legislation and administration such as payroll requirements, rather than genuinely supporting local business practices, strategy and culture. The global HR strategy of arbitrage in the 
studied case company was initiated and developed without a realistic view of the need of IT systems to accommodate local ways of life and complex considerations it entails.

A major theme emerging in this research is the local impact on the taken for granted trust and working relationships among local stakeholders involved in e-HRM implementations. The local HR managers were visibly frustrated and dissatisfied, while the local e-HRM group felt seriously hobbled. It is unlikely under these circumstances that local groups could provide an ideal environment for effectively implementing the strategic recruiting arbitrage model that the headquarter organisation desired. Accordingly, if organizations do not align global e-HRM strategies to local needs, i.e. "if they don't get it right on the local level”, they risk getting work-around which are costly and destroy trust among previously well-working local units.

In line with recent recommendations (Bondarouk \& Furtmueller, 2012), e-HRM implementation projects should be termed as HR rather than IT projects and project authority should be given to those who best know human resources practices and processes. Employee resistance needs to be continuously diagnosed and responded to. If organizations enforce global e-HRM strategy implementation heavy-handedly, and from the perspective of technical consolidation, work-arounds are likely to evolve and local HR is unlikely to improve HR services globally. The study of organizational change and managing employee resistance will be increasingly important to enable more effective global automation of HR practices.

Further, global implementations of e-HRM services require various types of coordination mechanisms. Besides the prevalent focus on coordination between corporate and local IT departments, Mohdzaher \& Ward (2007) suggest that multinationals need to consider three types of co-ordination in global IT planning: (1) vertical co-ordination from the subsidiaries to headquarter, (2) horizontal co-ordination across subsidiaries, and (3) cross domain co-ordination between IT and the business (i.e. HR departments). This will assist with identifying those requirements that are truly local, and those that may be shared by multiple subsidiaries, and also with integrating these requirements into the wider strategy.

Overall, in retrospect it is abundantly clear that desired corporate IT outcomes such as consolidation, cost reduction and improved data sharing and business intelligence should not be pursued at the expense of flexibility in local HR strategy initiatives. Especially in doing strategic e-HRM, significant autonomy in strategy formulation along with responsibility for strategy implementation should be delegated. This recognition of bottom up feedback should always be paramount, even if the organisation cannot move to a fully heterarchical model 
without losing the advantages of aggregating IT. It is a vital goal to maintain the trust and buy-in of local staff; to that end, workarounds and requests for additional expenditure should be investigated as opportunities rather than being blocked or suppressed. The relatively inflexible, top-down approach to aggregating e-HRM systems, involving setting standards for IT architecture, data-sharing, and core administrative HR systems that can be standardised must at the same time allow flexibility for e-HRM systems to exploit local knowledge and opportunities. In this context, Segars et al. (1998) proposed a "rational adaptation” approach for strategic information systems planning combining the need to have a formal structure in IT planning with the need to adapt to change and learning.

This work also aims to inform academics and practitioners, especially HRM, International Management and IS scholars to seek more nuanced explanations of the factors influencing global e-HRM implementation success, and not to dismiss legitimate tensions between HR and e-HRM strategies merely as communication failures. Globalizing e-HRM practices impacts HR and other professionals' work practices and job requirements (e.g. technical HR skills) and the readiness for such changes needs to be analyzed beforehand. The value in implementing global e-HRM systems needs to be convincing and clearly articulated to users working with such systems.

Overall, in our view, the organization was pursuing conflicting organisational and IT strategies: on the one hand wanting the HR arbitrage that recruitment in hyper-growth countries provide, but on the other hand the system economies in actual fact being enabled by e-HRM systems aggregation. This implies that the heterachy model of strategy proposed by Chakravarthy and Henderson (2007) may be highly desireable, but difficult to enact well at a global IT level. It appears that too often the focus of globalizing IT systems is more on what kind of system corporate headquarters are willing to offer to subsidiaries rather than the information systems local personnel department needs. Unfortunately, headquarters tend to place more emphasis on how to control IT costs and reduce problems due to the lack of systems integration or duplication than on aligning technology with the business (i.e.HR) requirements in order to gain and sustain competitive advantage. 


\section{Conclusion}

Is it already difficult to effectively implement e-HRM systems in a single organization context. This paper has taken the issue a step further and has reflected upon and theorized about the dynamics of globalizing e-HRM services. Based on a case study in a subsidiary, we identified systemic problems resulting from a tension between an arbitrage strategy for HRM management, and an aggregation strategy for e-HRM management. At the local level the human resources function, and e-HRM in particular, were caught in the middle, with unexpected and counterproductive results. Many of the complex issues we discovered emerged from poor communication and a relatively high-handed approach from corporate offices and in particular global IT management. That being said, it is critical to recognize that at a systemic level, we tapped into inherent tensions between corporate and local e-HRM strategies that almost certainly are not unique to this particular organization.

Arbitrage strategies are popular for global organizations; they make it possible to take advantage of differences in regional business environments and exploit local advantages by locating various parts of the supply chain in the regions where they can most effectively be accomplished. For instance, the emergence of a skilled workforce in low-wage countries such as India has clearly encouraged an "arbitrage" model of HR management. Simultaneously, many global organizations aiming to lower their considerable IT costs are aggregating and consolidating their IT systems. They accomplish this by reducing the number of vendors and platforms, gaining dramatically improved data integration for searching and business intelligence purposes. For effective global e-HRM implementation, headquarters need to define standardized requirements for e-HRM systems, while allowing subsidiaries flexibility in maintaining locally superior HR practices. Importantly, desired corporate outcomes should not be pursued at the expense of flexibility in local HR strategy initiatives since enforced systems are likely to result in work-arounds practices of local HR staff.

We found that the heterachy model of strategy (Chakravarthy \& Henderson, 2007) is difficult to enact. Nevertheless, in principle, delegating authority for strategic initiatives to local nodes (regions), and empowering them to collaborate with other regions seems highly desirable, so long as the global organization can maintain the standards, data integration, and interoperability it requires. Such an approach appears interesting to consider in large scale IT systems management where specific applications may represent the core of e-HRM systems 
while separate modules can be flexible adapted to fit local needs. This could point to the desirability of standardising on IT architectures rather than specific e-HRM applications.

Evidently, HRM and IS scholars and practitioners are known for having different mind-sets about how to effectively implement and use information systems to automate human resource departments. This paper reinforced the conviction about living on the edge about the deep need to continue building all sorts of bridges between technical and social sciences researchers on a global level. Our research suggests that local implementation issues for global e-HRM strategies have multiple, complex socio-technical origins that often reflect genuine tensions and do not lend themselves to simple solutions. We recommend several areas of future enquiry for deepening our understanding of globalizing e-HRM systems. The more technically-oriented academics are challenged to finding solutions which may include 1) developing business and IT processes for supporting "arbitrage-based" human resources practices and management in a global setting 2) supporting these with workflow technologies and applications, and 3) the non-trivial issue of identifying global information system integration and interaction standards that support integrated global information management, but permit local flexibilities. The more social science oriented researchers should investigate 1) effective change management strategies for globalizing e-HRM, 2) studies on cultural differences during global software development and outsourcing strategies, 3) global HR knowledge management, 4) issues of IT governance and compliance across national boundaries, and 5) employee privacy, assurance and trust in a global environment. Goshal (1987) noted innovation, learning, and adaptation as being among the potential strategic objectives of multinationals whereas shared learning across organisational units in is one of the potential sources of competitive advantage for these companies (Ghoshal, 1987). Accordingly, future research taking a multiple stakeholder perspective to enable learning from those involved in global e-HRM strategy development, system design, implementation and evaluation needs to be encouraged.

The contributions of this paper include: 1) fresh insights on the localization/standardization debate with a focus on the local experience; 2) in-depth diagnosis and explanation of the socio-technical sources of tension between headquarters and regions in e-HRM implementations; 3) an evaluation of current models of strategy implementation, suggesting that the heterachy model is highly desirable, but challenging to implement in practice, while tensions may arise between conflicting organisation goals of HR arbitrage and e-HRM aggregation; and 4) some suggestions for further research advancing the issues discussed in this paper from both IT and HR perspectives. 
Future studies specifically aimed at comparing organizations where similar global eHRM strategies resulted in different levels of success both at a corporate level and across different subsidiaries are needed to more accurately understand effective globalization of HR and e-HRM practices. Such research should investigate business distinctiveness defined as how diverse activities of local HR units are in a multinational (Dunning, 1995) or how unique (or similar) value-added activities of a given subsidiary are compared with the HR activities of other subsidiaries of the same multinational.

In line with increasing global staffing needs, clearly more incisive research into the role of information technology on HRM standardization versus localization is clearly needed. Even "configurable" e-HRM systems may lack the ability for flexible localisation. There may be inherent tensions in global organisations between IT centralisation and standardisation, and HR flexibility; that are not simply and easily addressed, and cannot be dismissed as "resistance" or "communication problems". A broadly-based, socio-technical approach informed by both HR and e-HRM research is required to advance understanding of these important issues. We hope this paper will stimulate such future research. 


\section{References}

Acur, N. \& Englyst, L. 2006. Assessment of strategy formulation: How to ensure quality in process and outcome. International Journal of Operations and Production Management, 26(1): 69-91.

Attride-Stirling, J. 2001. Thematic networks: an analytic tool for qualitative research. Qualitative Research, 1(3): 385-405.

Ball, K.S. 2001. The use of human resource information systems: A survey. Personnel Review, 30(5-6): 677-693.

Bartlett, C.A. \& Ghoshal, S. 1986. Tap your subsidiaries for global reach, Harvard Business Review, 64(6): 87-94.

Benbya, H. \& McKelvey, B. 2006. Using co-evolutionary and complexity theories to improve IS alignment: a multi-level approach. Journal of Information Technology, 21: 284-298.

Bartlett, C.A. \& Sumantra, G.. 1986. Tap your subsidiaries for global reach. Harvard Business Review, 64(6): 87-94.

Bjorkman, I. \& Lu, Y. 1999. The Management of Human Resources in Chinese-Western Joint Ventures. Journal of World Business, 34: 306-24.

Birkinshaw, J.M. 1994. Approaching heterarchy: A review of the literature on multinational strategy and structure. Advances in Comparative Management, 9: 111-44.

Bondarouk, T., Ruël, H.J.M. \& van der Heijden, B. 2009. E-HRM effectiveness in a Dutch ministry: results of a discursive exploration. International Journal of Human Resource Management, 20(3): 578-590.

Bondarouk, T. \& Furtmueller, E. Electronic Human Resource Management: Four Decades of Empirical Evidence, Academy of Management Meetings, Boston, USA, Aug 3-7, 2012.

Braun, V. \& Clarke, V. 2006. Using thematic analysis in psychology. Qualitative Research in Psychology, 3(2): 77.

Brewster, C., Wood, G., \& Brookes, M. 2008. Similarity, isomorphism and duality? Recent survey evidence on the HRM Policies of MNCs. British Journal of Management, 19(4): 320-342.

Brynjolfsson, E. \& Lorin H. 2000. Beyond Computation: Information Technology, Organization Transformation and Business Performance. Journal of Economic Perspectives, 14: 23-48.

Chapman, D.S., \& Webster, J. 2003. The use of technologies in the recruiting, screening, and selection processes for job candidates. International Journal of Selection and Assessment, 11(2-3): 113-120.

Chakravarthy, B. \& Henderson, J. 2007. From a hierarchy to a heterarchy of strategies: adapting to a changing context. Management Decision, 45(3): 642-653.

Chen, S. \& Wilson, M. 2003. Standardization and localization of human resource management in Sino-Foreign joint ventures. Asia Pacific Journal of Management, 20: $397-408$

Dery, K. \& Wailes, N. 2005. Necessary but not Sufficient: Strategic HRM and ERPs'. Strategic Change, 14(5): 265-272.

DeSanctis, G. 1986. Human-Resource Information-Systems: A Current Assessment. MIS Quarterly, 10(1): 15-27.

Eisenhardt, K.M. 1989. Building theories from case study research. Academy of Management Review, 14(4): 532-550.

Finnegan, P. \& Longaigh, S.N. 2002. Examining the effects of information technology on control and coordination relationships: an exploratory study in subsidiaries of pan-national corporations. Journal of Information Technology, 17(3): 149-163. 
Furtmueller, E., Wilderom, C. \& Tate, M. 2011. Managing recruitment and selection in the digital age: e-HRM and resumes. Human Systems Management, 30(4): 243-259.

Galliers, R.D. 1991. Strategic information systems planning: myths, realities and guidelines for successful implementation. European Journal of Information Systems, 1(1): 55-64.

Gardner, S.D., Lepak, D.P. \& Bartol, K.M. 2003. Virtual HR: The impact of information technology on the human resource professional. Journal of Vocational Behavior, 63(2): $159-179$.

Gueutal H.G. \& Stone, D.L. 2005. The Brave New World of e-HR. San Francisco, CA: Jossey-Bass.

Ghemawat, P. 2008. Reconceptualising International Strategy and Organisation. Strategic Organization, 6(2): 195-206.

Gottschalk, P. 1998. Content characteristics of formal information technology strategy as implementation predictors. Norway: Tano Aschehaug Publishing.

Haines, V.Y. \& Petit, A. 1997. Conditions for successful human resource information systems. Human Resource Management, 36(2): 261-275.

Hoffmann, C. \& Hoffmann, K. 2007. HR Can do Business! Delivering the Right Workforce. International Human Resource Information Management Journal, 11(5): 19-33.

Hussain, Z., Wallace, J. \& Cornelius, N.E. 2007. The use and impact of human resource information systems on human resource management professionals. Information and Management, 44(1): 74-89.

Huo, Y.P., Huang, H.J. \& Napier, N.K. 2002. Divergence or convergence: A cross-national comparison of personnel selection practices. Human Resource Management, 41: 31-44.

Ives, B. \& Jarvenpaa, S. 1991. Applications of Global Information Technology: Key Issues for Management. MIS Quarterly, 15(1): 33-49.

Kirsch, L. \& Haney, M. 2006. Requirements determination for common systems: turning a global vision into a local reality. Journal of Strategic Information Systems, 15(2): 79-104.

Lee. I. 2011. Modeling the benefit of e-Recruiting process integration. Decision Support Systems, 51(1): 230-239.

Maatman, M., Bondarouk, T. \& Looise, J.C. 2010. Conceptualizing the Capabilities and Value Creation of HRM Shared Service Models. Human Resource Management Review, 327-339.

Marler, J. 2009. Making human resources strategic by going to the Net: reality or myth? International Journal of Human Resource Management, 20: 515-527.

Mayer, S.J. 1971. EDP Personnel Systems - What Areas Are Being Automated. Personnel, 48(4): 29-36.

Melville, N., Kraemer, K. \& Gurbaxani, V. 2004. Review: information technology and organizational performance: an integrative model of IT business value. MIS Quarterly, 28(2): 283-322.

Mentzas, G. 1997. Implementing an IS Strategy - A Team Approach. Long Range Planning, 30(1): 84-95.

Miles, M. B. \& Huberman, A. M. 1994. Qualitative data analysis: An expanded sourcebook. (2nd Ed.) Thousand Oaks, CA: Sage.

Mohdzain, M. \& Ward, J. 2007. A study of subsidiaries' views of information systems strategic planning in multinational organizations. Journal of Strategic Information Systems, 16(4): 324-352.

Nolan, R.L. 1979. Managing the crises in data processing. Harvard Business Review, 57(2): $115-126$.

Palvia, P.C., Jain Palvia, S.C. \& Whitworth, J.E. 2002. Global information technology: a meta-analysis of key issues. Information and Management, 39: 403-414. 
Peppard, J., Ward, J. \& Daniel, E. 2007. Managing the realization of business benefits from IT investments. MIS Quarterly Executive, 6(1): 1-11.

Perlmutter, H.V. 1969. The tortuous evolution of the multinational corporation. Columbia Journal of World Business, 4: 9-18.

Ployhart, R.E. 2006. Staffing in the 21st century: New challenges and strategic opportunities. Journal of Management, 32: 868-897.

Porter, M.E. 1990. The Competitive Advantage of Nations. New York: Free Press.

Pozzebon, M. \& Pinsonneault, A. 2005. Global-local negotiations for implementing configurable packages: The power of initial organizational decisions. Journal of Strategic Information Systems, 14(2): 121-145.

Pudelko, M. \& Harzing, A. 2007. Country-of-origin, localization, or dominance effect? An empirical investigation of HRM practices in foreign subsidiaries. Human Resource Management. 46(4): 535-559.

Ruel, H.J.M., Bondarouk, T. \& Looise, J.K. 2004. E-HRM: Innovation or Irritation: An Explorative Empirical Study in Five Large Companies on Web-based HRM. Management Revue, 15(3): 364-381.

Ruel, H.J.M. \& Bondarouk, T.V. 2010. The Intersection of IT and workforce management Framing e-HRM in an international context, Guest editorial. International Journal of Technology and Human Interaction, 6(4): 1-9.

Ruel, H.J.M. 2010. The role of IT in the HR policies convergence: A process model based on evidence from the middle east. Academy of Management Meetings, Montreal, Aug 6-10.

Schuler, R., Dowling, P. \& De Cieri, H. 1993. An integrative framework of strategic international human resource management. International Journal of Human Resource Management, 4(4): 419-459.

Teece, D., Pisano, G. \& Shuen, A. 1997. Dynamic capabilities and strategic management, Journal of Strategic Management, 18(7): 509-533

Tomeski, E.A. \& Lazarus, H. 1974. Computerized Information Systems in Personnel. Academy of Management Journal, 17(1): 168-172.

Wilson-Evered, E. \& Hartel, C.E.J. 2009. Measuring attitudes to HRIS implementation: A field study to inform implementation methodology. Asia Pacific Journal of Human Resources, 47(3): 374-384.

Yin, R. 2008. Case Study Research: Design and Method. (4th Ed.) London: Sage. 


\section{CHAPTER 10}

\section{Synthesis \& What Future Online Career Services Research Needs to Solve}

Despite many organizations that proudly advertise their success with e-Recruiting services, it cannot be denied that some of these organizations - after years of experimenting with it have already abandoned e-Recruiting, retreating to timeworn routine recruiting techniques such as newspaper ads, career fairs and employee referrals (Smale \& Heikkilä, 2009; Martin \& Reddington, 2010). This dissertation has revealed that e-Recruiting systems frequently suffer from sustainability issues, involving ineffective resume storage, problematic sorting of large volumes of digital applications and communication problems with HR and IS scholars and practitioners. The cost of the latter can be determined to offset the expected and projected cost savings (Gardner et al. 2003; Furtmueller et al., 2011). The range of the e-Recruiting sustainability problem is evidenced in a report by Parry and Tyson (2008). They found that less than a quarter of the studied organizations saw their online career services as successful. It is extraordinarily easy for applicants with digital resumes to send their resumes to many different organizations with little effort and cost (Srinivasan et al., 2002).

Given the surge in demand and accelerating competitiveness among online career services to attract job seekers, it is no wonder more scholars increasingly call for a sharper understanding of the factors leading to applicant commitment to specific online career services (Feldman \& Klaas, 2002; Bauer et al., 2004; Furtmueller et al., 2010). Some of the chapters in this book have suggested that site features such as 'implementing skill competitions' and 'enabling applicants to rank their qualifications compared to others' enhances applicant commitment (Furtmueller et al., 2009). Besides, regularly asking applicants to confirm if their details are correct and if they are currently (again) job-hunting, is important. Further, requiring applicants to invest time to fill in very detailed profiles may enhance commitment to a specific career site. Moreover, the selection of a group of applicants, as part of a specific high talent pool has been found to motivate applicants to stay actively committed to a specific career service (Furtmueller et al., 2011). 
Studying applicants' commitment in an online career services context is an innovative contribution to social science because commitment is difficult to develop in e-commerce. Empirical evidence shows that increasingly applicants' use the Internet to search for information about potential employers and to apply for jobs online (Ployhart, 2006). Thus, given the importance of commitment in maintaining long-term relationships (Morgan \& Hunt, 1994), and since no previous study has examined building commitment specifically individuals in an online career services context, future research on this topic needs to break new ground and provide greater understanding and empirical validation of these behaviours. Building on the foundations of e-HRM, relationship marketing, organizational commitment and the investment model, I propose a future research agenda to develop a conceptual model that explains how applicants develop commitment to online career services.

My proposal for theorizing future e-Recruiting research is structured as follows: I first present research goals aimed at advancing the field, the theoretical background and the relation and relevance of my proposed research agenda in light of the international literature. I then describe various methodological approaches to answer the research questions.

\section{Future Research Goals}

The more we understand factors that enhance commitment to online career services, the more productive the delivered service can be (Cober et al., 2004; Fensel et al., 2011). Future research needs to contribute to this general field of knowledge, one that is inherently interdisciplinary since online commitment is a new phenomenon that is increasingly in demand. Online services such as e-Recruiting sites depend on the voluntary participation of applicants, in sharing resume data, applying to job ads, participating in skill tests, re-visiting, and using and contributing to page content (Gueutal \& Stone, 2005).

The recent e-HRM literature predicts a change from exchange-based general job boards towards niche career services, arranged around a branch, professional group, skills, or region: a relatively well-identified community. But there is scant theoretical grounding about this transformation (Smith \& Rupp, 2004; Furtmueller et al., 2008). If this prediction proves to be right - that users feel a need to stay committed to a particular online career service - we need to find out what precisely sustains a high level of users' interest. Accordingly, the central question of future online career services research is: What factors may enhance applicants' commitment to online career services? 
In order to address this question, I propose three study designs.

1. The first design aims to provide through a rigorous analyses of the relevant literatures, an integrative, explanatory overview of the factors that may enhance or retard user commitment in online services contexts.

2. With this critical analysis of archival wisdom in hand, various qualitative studies should be conducting using in-depth interviews with two types of users who are registered on career services: active job seekers and latent job seekers, i.e., those at the moment not eager to find a new job but nevertheless registered with the service. This exploratory approach will purposively gather up a large sample of applicants. It is only a wide net that can conceivably capture genuine in-depth knowledge of the full range of possible factors which from the applicants' perspective may enhance their commitment to online career services. In addition, besides working this broad crosssection of users, we need to spread the net to encompass the relatively inactive people on the site. They should be probed about what actually it is that would further interest them in a site like this. The resulting analyses, a tightly reasoned synthesis of combination of the archival wisdom on the issue of commitment and the so-to-speak eye-witness insights of the interviewees, will provide fresh input for the (re-)design of more effective and sustainable online career services. The summary and interpretation of such insights will represent a much needed contribution to the e-HRM literature (Bondarouk \& Furtmueller, 2012 $2^{14}$ ).

3. As third follow-up study component I propose a quantitative study design. Leaning on the model derived thus far, future researcher should test the earlier derived conceptual framework in a rigorous quantitative way and examine a set of hypothesized predictors of applicants' high commitment to such an online career service. This investigation will put forth the dominant path leading to commitment by addressing the following research questions:

a. What are the predictors of applicants' high-commitment to online career services?

b. What are the essential differences in this commitment between those applicants who have an immediate need for a job and those who do not foresee a strong need, in the short term, for an online career service?

\footnotetext{
${ }^{14}$ Bondarouk, T. \& Furtmueller, E. Keynote Presentation. E-HRM Promises and Empirical Findings: Four Decades of Research, Keynote Presentation. International HRM Conference: Innovation, Creativity and e-HRM, Nottingham Business School, UK, March 28-29, 2012.
} 


\section{Positioning Future Research Contributions}

Most studies to date view continued use of information systems as an extension of acceptance behaviours (i.e., they employ the same set of pre-acceptance variables to explain both acceptance and committed usage); implicitly assuming that continued usage co-varies with acceptance (Davis et al. 1989). Accordingly, research is needed to explain why some internet users discontinue using an online service after accepting it initially (the acceptancediscontinuance anomaly). There is at present scant research that elaborates upon users' psychological motivations emerging after their initial acceptance of systems. Current acceptance models may provide a limited explanation of, and may sometimes contradict, observed committed usage. Understanding users' initial acceptance of career sites is an important first step toward realizing information systems success (DeLone \& McLean, 2004). However, as innumerable internet services failures have shown, long-term sustainability depends on continued committed use rather than first-time acceptance.

Without a doubt there are several dominant paradigms and a rich literature in psychology, organizational behaviour and marketing that help us understand how people interact with computers. Yet the bonding of applicants to career sites is unlike playing games on mobiles rather than on computers (i.e. technology acceptance model), and commitment to a site which compiles resumes of competitive applicants (i.e. brand consumer relationship model) is difficult to enact on career sites. Importantly, the technology acceptance model (Davis et al. 1989), and the theory of planned behaviour (Ajzen, 1991) and a subsequent rich research tradition have examined the full range of variables that motivate individuals to accept a new information system (such as career sites). While such understanding of initial acceptance of career sites is an important first step toward realizing information systems success (DeLone \& McLean, 2004), long-term sustainability of information systems depends on its continued use rather than first-time use.

Understanding sustained use and commitment is important for future research. The study of committed usage at the individual user level is of course also central to the competitive survival of many other electronic commerce services, such as online retailers, banks, travel agencies, and the like. In our project the effective subscriber base, market share, and revenues of these firms depend on both the number of initial adopters (new registered job applicants) and the number of long-term committed users (applicant database). The vital 
importance of commitment, vis-a-vis acceptance, is further evident from the fact that acquiring new customers may cost as much as five times more than retaining existing ones (Gustaffson et al., 2005).

Such research requires integrative and cross-disciplinary thinking, building on insights from theories in psychology, marketing, HRM and information systems. In particular, the theoretical foundations for the critical quantitative study need to be grounded in a deep reading of the e-HRM and relationship management literature, and will benefit from theoretical foundation such as the investment model (Rusbult, 1983) and organizational commitment theory (Allen \& Meyer, 1990). These latter two theories give sharpness to the explanation of why applicants may commit to a relationship with an online career service.

While there has been ample research into the nature of relationship commitment in offline contexts (e.g., Morgan \& Hunt, 1994), very little is known about the bonding mechanisms in online environments that make the providing organizations more sustainable. Future research needs to offer an account that answers the growing calls from the interdisciplinary field of e-HRM (Electronic Human Resource Management) for inquiries into sustainable online career services (Lee, 2011; Bondarouk \& Furtmueller, 2012). The depth of the contemporary sustainability issue of career services is compounded by a global pattern of shorter and temporary job contracts and increasing job switches (CedarCrestone, 2011). Ever more applicants turn for advice and queries about their prospective career moves to online career services (Ployhart, 2006). Organizations progressively use online career services as a means to building relationships with applicants, including those who have an interest in a specific organization, job type or field, but who are currently not available for recruitment (Stone, Stone-Romero \& Lukaszewski, 2006). Nearly all Fortune 500 companies use some kind of online career services, many increasingly relying in turn on sophisticated external recruiting services,

The scope of such future e-research is thus innovative and considerable. No prior study has examined the building of commitment of applicants towards online career services; and future research is challenged to provide a greater conceptual understanding and empirical validation of such relational behaviour. An empirically grounded analysis of antecedents of user commitment will fill a major gap in our theoretical understanding of how job seekers 
perceive the universe of alternative jobs, and all too frequently switch costly strategies in their job-search efforts.

Although academics have proposed ways to design the architectures of sustainable online services, e.g., social networks (Preece, 2000), scholars have only recently begun to harvest the insights available from social psychology and marketing theory (e.g. Szmigin, Canning \& Reppel, 2005). In particular, future research needs to show how these disparate theories can be fruitfully deployed for the purpose of explaining how applicants develop commitment to online career services. This investigation will provide an interdisciplinary and integrative picture of the complex nature of antecedents of attachments in a growing industry. This kind of research will not just add to the knowledge base, but bring order to a research area where confusion now prevails.

\section{Building bridges between technical and social sciences}

As discovered in this dissertation, researchers from technical disciplines (Information Systems, Computer Science) and social sciences (Human Resource Management, Psychology) have for a long time worked independently from each other. Only in the past decade have e-HRM scholars started to undertake joint interdisciplinary efforts to understand the phenomenon and its multilevel implications within and across organizations. From Slovenia to Taiwan to California cross-disciplinary departments of information systems have sprung up, along with a plentitude of special e-HRM issues in international academic journals

In June 2011 Emerald Publishing group asked its members to propose new journals aimed at publishing research on e-HRM and its functional areas such as e-Recruiting services. I believe there is a deep need to build such bridges between technical and social sciences researchers. My own future research agenda should contribute to the bridging of the e-HRM, commitment and marketing relationship literature.

Tanya Bondarouk and I have been bestowed the honour of being invited to give the keynote presentations at the 2012 International HRM conference at Nottingham Trent University (March 2012). The title of our talk is "E-HRM Research - Four Decades of Empirical Evidence: Promises, Hopes, Facts and Paths Forward”. 


\section{Future Research on Sustainable Online Career Services}

The theoretical foundations for my proposed research agenda are based on e-HRM and relationship management literature, the investment model (Rusbult, 1983) and organizational commitment theory (Allen \& Meyer, 1990). These two latter theories are essential for the quantitative part of my research project, giving precision to my explanation of why applicants commit to a relationship with an online career service.

\section{The investment model}

The investment model provides rich theoretical foundations for understanding how human beings actually build and maintain relationships (Rusbult, 1983). Commitment to a relationship, defined as one's intent to persist in a relationship, including long-term involvement and feelings of psychological attachment, is a central construct in this model. Three antecedents to commitment are predefined.

The first antecedent, satisfaction, is conceptualized as the extent to which customers are satisfied when a relationship offers high rewards and low costs. Rewards are attributes of a relationship that are preferred by an individual in that relationship. Costs are characteristics of a relationship that are disliked by an individual e.g. financial burden.

The second antecedent, quality of alternatives concerns the perceived desirability of the best available alternative to a relationship. Alternatives refer to an individual's comparative assessment of the rewards and costs that could be obtained through another partner apart from the current relationship. For instance, customers may decide to terminate the current relationship with an online career service and try a new one if they think it may be more useful in terms of the level of technologies and services.

The third antecedent in the investment model is the investment size, which refers to how much customers have already invested in a relationship (Rusbult, 1983). This investment may be financial, temporal and/or emotional. The greater the investment in a current relationship, the stronger the tendencies toward commitment and reduced likelihood of exiting. In so many words, in some ways similar to the classic Gestalt notion of Einstellung (Luchins \& Luchins, 1959) or fixation (Duncker, 1945), higher levels of investment help in locking individuals into a relationship ( $\mathrm{Li}$ et al., 2006). The model emphasizes the "traditional" path of going forward for certain customers; those highly satisfied and invested substantially in a relationship, and without experience of an appealing alternative will tend to be highly committed to their current relationship. 


\section{Commitment theory}

A half century ago Becker presented his initial account of commitment theory, defining commitment as an inclination to engage in consistent lines of activity based on an individual's recognition of the costs associated with terminating a relationship (Becker, 1960). This elementary notion has been extensively studied within organizational contexts, for example the employee-employer relationship (Allen \& Meyer, 1990), but in fact commitment is a very broad construct that extends to a wider range of other relationships. Some examples include the romantic relationship (Rusbult, 1980), the relationship between organizations (Anderson \& Weitz, 1992), the manufacturer-distributor relationship (Geyskens et al., 1996), the customer-retailer relationship (Bettencourt, 1997), and the business-to-customer relationship (Fullerton, 2003); These studies have led to a variety of definitions of commitment including its elaboration as a multi-dimensional construct made up of several components.

Allen and Meyer (1990) defined organizational commitment as a psychological state that binds the individual to the organization in terms of three dimensions: affective, calculative, and normative. Affective commitment concerns the desire to belong to an organization, while calculative commitment is based on a belief that leaving an organization is costly and normative commitment is the extent a person is morally obligated to stay with an organization. Theoretically, these forms of commitment are distinct ways for bonding with an organization or other grouping (Bergman, 2006).

Let us zoom-in on normative commitment, the underlying explanatory factors are moral obligations, social norms and one's obligation to the other party in a relationship (Allen \& Meyer, 1990). It has been found that people feel a normative commitment to online sites when they have a pre-existing commitment to the purpose the site serves. For example, online health support groups where patients or survivors - say cancer or amputation - feel obliged to provide advice to others; advocacy communities; hobbyist communities; or open source software development communities where users experience a moral obligation to help each other (Ren et al., 2007). None of this appears relevant to the sustainability of online career services (Furtmueller et al., 2010). Building on Li, Browne \& Chau (2006) argued that normative commitment and its implications are more relevant to the study of business-tobusiness relationships. Since this study's focus is on studying customer relationships, who are in fact competitors for scarce jobs, the proposed quantitative research model concentrates strictly on the issue of affective and calculative commitment. 
Studying high commitment is especially intriguing in revealing profound paradoxes regarding exchange-based online services. On the one hand, anyone who engages in a sustained survey of a broad range of portals will recognize they are not designed to be leveraged on users' bonds. On the other hand, organizations progressively use online career services as a means to building relationships with applicants, including potential candidates having an interest or skill in a specific organization or field but presently unavailable (Stone, Stone-Romero \& Lukaszewski, 2006). Since almost all large companies use some form of online career services, the scope of the study's contribution in exploring the subtle issue of online commitment is considerable. Online career services represent one of the most widely utilized e-business areas in organizations, and the reported and proposed research will provide in-depth understanding into career services' capacity for relationship building with applicants.

Concerning economic relevance, a strong bond is desirable for almost every online service: returning customers contribute to the organizations' profitability. It is highly relevant for niche career services to develop strong bonds to users because they can benefit from identity-based and common bond based attachments (Meyer, et al., 2006). Recent studies suggest career services should include design elements that enhance a user's commitment to a shared concern (i.e., career move), industry field (IT, chemistry, biotech, entertainment, etc.) or promise and deliver superior services besides fostering bond-based attachments among applicants and organizations (Furtmueller et al., 2010). Accordingly, such research provides insights on relationship management with applicants. This is relevant for various types of online career services such as organizations' e-HRM career sections, niche career services and general job boards. Other stakeholders potentially benefiting from such future research would include industry clusters, professional associations, trade schools, institutes and universities that wish to maintain lasting bonds with their members, students or alumni.

Reflecting upon societal relevance, the latent job seekers need to become easier to reach, and future online career services need to foster relationships prior to start up. This is relevant not only for the design and architecture of general job boards (e.g. monster.com) and organizations' online career sections; social and business network services can also learn from latent job seekers' long-term intentions to use career services. Concerning technological relevance, information systems researchers would need to gain insights into effectively designing innovative and practical online career services to bind users. Further, the time required for specification and development of information systems that aim to build 
sustainable services will be reduced when we genuinely gain a better understanding of user commitment to such services (see Table 1 for an overview of the proposed constructs for future research).

Table 1: Examples of constructs to be utilized for the quantitative part of a future study

\begin{tabular}{|c|c|c|}
\hline Theory & Construct & Definition \\
\hline \multirow[t]{2}{*}{$\begin{array}{l}\text { Organizational } \\
\text { commitment }\end{array}$} & Affective commitment & $\begin{array}{l}\text { Refers to a situation in which an applicant } \\
\text { demonstrates an affective and emotional attachment } \\
\text { to their relationship with an online career service. }\end{array}$ \\
\hline & $\begin{array}{l}\text { Calculative } \\
\text { commitment }\end{array}$ & $\begin{array}{l}\text { Refers to a situation where an applicant recognizes } \\
\text { the rewards and benefits associated with continuing to } \\
\text { use and maintaining a relationship with an online } \\
\text { career service. }\end{array}$ \\
\hline \multirow[t]{3}{*}{ Investment model } & Quality of alternatives & $\begin{array}{l}\text { Refers to the perceived desirability of alternatives to } \\
\text { the present relationship with the current career } \\
\text { service. }\end{array}$ \\
\hline & Investment size & $\begin{array}{l}\text { Refers to how much applicants have already invested } \\
\text { in the relationship. Investments can be financial, } \\
\text { temporal or emotional. }\end{array}$ \\
\hline & Satisfaction & Refers to the relative satisfaction level of applicants. \\
\hline $\begin{array}{l}\text { User network } \\
\text { communication }\end{array}$ & $\begin{array}{l}\text { Word-of-mouth } \\
\text { (WOM) }\end{array}$ & $\begin{array}{l}\text { Post-purchase user communication about an online } \\
\text { career service: to potential other users. }\end{array}$ \\
\hline
\end{tabular}

\section{Method}

My methodological future research agenda aims to articulate an empirically grounded explanatory model of applicant commitment to online career services based on a (1) systematic literature analyses; (2) in-depth interviews with applicants who are active users of online career services; and (3) a quantitative survey with registered applicants of the same career services.

Empirical data should be collected in order to extend (with the qualitative research design) as well as examine (with the quantitative research design) prior theory. While this mixed methods approach is time-consuming, it can potentially lead to penetrating explanatory insights into e-services design for career services. This approach should overcome wellknown shortcomings of choosing a sole method to study the posed research questions (Bardhan et al., 2010).

The proposed methods are in line with recent guidelines from social engineering research. For instance, Davis et al. (2011) argued that the logic of online services design, which attempts to manage trade-offs among many parameters that can influence an individuals' behaviour, is at odds with the logic of social sciences research. 
Usually social sciences scholars attempt to examine the influence of a small set of variables ceteris paribus, i.e., holding everything else equal while attempting to hold other variables constant in regression models or short-lived experiments. This paradigm for developing and testing online commitment produces theories that normally are too simple for the purpose of social engineering, i.e. optimizing online career services design (Furtmueller et al., 2011).

In contrast, the study of commitment to online career services requires theory emergence that explains the behaviour of a large set of interconnected factors. Theory-driven information systems design requires a broad navigation map that synthesizes insights from multiple (interdisciplinary) theories to identify alternative pathways through which particular design choices may have positive and negative effects on online services outcomes. Such investigations require the mixed synthetic methods approach I have outlined.

\section{Stage 1: Literature Review}

First, researchers should conduct a comprehensive analysis of the literature where user commitment has been of focal interest. Commitment has been extensively studied in sociology, psychology, marketing and economics; it increasingly gains relevance in social network theory, information systems, e-HRM and internet research literature. The increasing diversity of disciplines in commitment research calls for a comprehensive synthesis of the chief insights in the scattered studies. Suitable information sources to find relevant articles could be a database search on ISI Web of Science and Scopus. Colleagues in the related research disciplines should review an initial list of specific article search keywords before starting to systematically mine the research databases.

The grounded theory literature review method (Wolfswinkel, Furtmueller \& Wilderom, 2012) provides a systematic way to analyse dispersed literature (this literature review method integrates principles from grounded theory, see Strauss \& Corbin, 1998). It assures finding and integrating only solidly legitimized, in-depth analyses of empirical facts and related insights beyond traditional meta-analysis review studies. By applying our recently published Grounded Theory Literature Review Method ${ }^{15}$, other researcher can point to new themes in the study of applicants' online commitment to career services, interrelationships and dependencies, as well as review and avoid possible inconsistencies in the literatures.

\footnotetext{
15 see Wolfswinkel, J., Furtmueller, E. \& Wilderom, C. (2012). Using grounded theory as a method for rigorously reviewing literature, European Journal of Information Systems, in press (doi: 10.1057/ejis.2011.51).
} 
Beyond synthesizing factors that enable and constrain individuals' commitment in an e-services environment, this grounded theory type review should present fresh insights for a more theory-based study of sustainable online services. Scholars should analyse the various conceptualisations of the related research fields to arrive at an integrative understanding of the antecedents of job-applicants commitment.

\section{Stage 2: Qualitative Study}

Following the literature analyses, researchers may use various types of qualitative approaches such as in-depth interviewing with various types of job-applicants. This explorative part of the research project aims to contribute additional insights on factors that are described from the perspective of applicants as strengthening or reducing their commitment to online career services. Interviews should uncover the interviewees' job search behaviour, navigational wisdom, choice and use of jobs services. In line with general guidelines for doing qualitative research, these sessions should be audio-recorded and subsequently transcribed verbatim. Comprehensive field notes should be taken as well and interpretative validity should be strengthened by returning each written interview transcript to the interviewee, in order to give them an opportunity to comment upon and/or correct the transcript.

In order to analyse such qualitative data, the critical incident technique (CIT) (Flanagan, 1954) is useful. This method has been extensively used in service management and marketing research for several decades (Bitner, 1990; Edvardsson \& Roos, 2001). Critical incidents are defined as interaction incidents the customer (i.e. young professional) perceives or remembers as unusually positive or negative when asked about them. Customers recall them and tell others about them as stories (Flanagan, 1954). Critical-incident studies can be conducted in different ways, and mostly involve personal interviews, focus group interviews, and direct or participatory observation. For example, Olsen's (1992) variant of the CIT method involves recording opinions of how an incident affects the respondents' relationships with an organization. Scholars may draft an interview guide which will encompass inquiries into young applicants' positive and negative experiences with the online career service, exploring their perceptions and explanations of their relationship commitment to the site. Personal interviews will enable to improvise and inject penetrating follow-up questions to help probe and digest the meaning of what has been said regarding these critical incidents.

For analyzing the data, one first needs to read and re-read all transcripts, listen to all audio recordings, categorize and then analyse the most frequently mentioned themes and crucial details, using traditional content analysis (Miles \& Huberman, 1994). The qualitative 
software program Nvivo 2.0 could be used to categorize the raw data. At least two should independently code the transcripts, field notes, and themes created by Nvivo 2.0. The results should be compressed into a codebook containing a list of well-defined emerging factors for strengthening or reducing online commitment.

In accordance with the methodology of Strauss \& Corbin (1998), the emerging factors will be rigorously refined by repeated iterations among: (i) the data; (ii) the concepts emerging in the field notes, memos, and discussions among coders; and (iii) the relevant literature. Future researchers need to make sure to achieve all-inclusive non-overlapping sets, i.e., factors that are mutually exclusive. This could be done by coding tests on at least two randomly extended snippets from each interview. Coders need to get trained to use the coding guidelines and the set of factors before being asked to code each of the randomly selected texts. Coding tests should continue until an inter-coder reliability of $95 \%$ is achieved.

It is also important to control code saturation. Denzin and Lincoln (2000) suggested a rather low figure of six interviews for reaching code saturation in qualitative studies. I find this far too low based on my experience in qualitative research (see e.g. Furtmueller et al., 2011), and especially inadequate with reference to the topic at hand. For a serious qualitative inquiry, one needs to interview a minimum of 40 applicants, and interviewing needs to continue until no new themes emerge, following the now classic theoretical sampling approach of Glaser \& Strauss (1967).

The goal of such qualitative research is not only to compare the two randomly selected groups of applicants (latent and urgent job seekers). This kind of future research will create rich insights into the factors relevant for online commitment on career services.

\section{Stage 3: Quantitative Study}

\section{Model development and hypotheses}

Given the importance of commitment in the development of customer relationships, it is vital to examine the factors that are the antecedents and outcome of commitment. A tentative general model for explaining why applicants commit to online career services is shown in Fig. 1. I present the nature of constructs such as quality of alternatives, investment size, and satisfaction as the currently derived examples of antecedents to customer commitment and sustainable use of an online job site. Other prospective variables may well result from the qualitative study and be incorporated in the full survey model finalized right before the surveying starts. Potential variables include the nature and the frequency of interaction 
between exchange partners, technical quality of various online career services, information quality, usefulness, ease of use, perceived risk, switching costs and opportunistic behaviour.

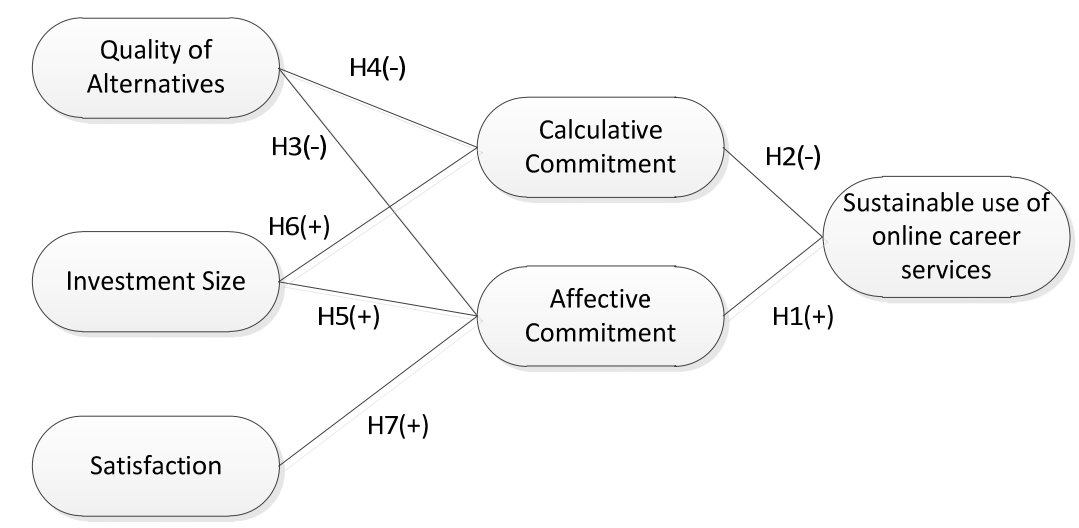

Figure 1. Research model for sustainable use of online career services

\section{Commitment}

Scholars have recognized that commitment is inherently multi-level and deeply contextual, and is expressed in many ways; yet only two kinds of commitment have been dominant in the literature. First, calculative commitment indicates that commitment is economic in its structure and rooted in switching costs, sacrifice, and lack of attractive alternatives Second, affective commitment is very different - it is emotional in nature and is based on a sense of liking the partner. It is rooted in shared values, identification, and emotional attachment (Bansal, Irving \& Taylor, 2004); the affective attachment and involvement an individual feels toward a relationship (Allen \& Meyer, 1990). Analogously, it would seem that applicants who are career oriented would stay in a relationship with an online service that helps them to advance their career and accordingly supports their career moves (Cichy, Cha \& Kim, 2009).

It is not unreasonable to believe applicants affectively committed to an online career service have a favourable attitude toward that site, and as a consequence use it much more. This rather obvious yet extremely subtle point leads to proposing the following hypothesis:

\section{H1: Applicants' affective commitment to an online career site is positively related to the sustainable use of the service.}

Geyskens et al. (1996) view the calculative dimension of commitment ass the degree to which partners experience the need to maintain a relationship, given the significant anticipated costs associated with leaving, terminating or switching out of a relationship. In other words, applicants may realize the rewards and benefits associated with continuing to use a particular 
career service. When applicants experience calculative commitment they are bound to the career service because it is economically difficult to terminate the relationship, or they perceive few alternative career services. As explained by Mowday et al. (1982), those who feel compelled to remain with a vendor to avoid financial or other costs may do little more than the minimum required. Further, Fullerton (2005) found that calculative commitment has a negative impact on WOM communications. Consequently, the following hypothesis is suggested:

\section{H2: Applicants' calculative commitment to an online career site is negatively related to sustainable use of the service.}

\section{Investment model}

The investment model claims individuals should be more satisfied with relationships that are perceived as having more rewards than costs. Commitment is a key component of Rusbult's (1983) investment model; it represents the intent to persist in a relationship, including longterm orientation toward the involvement as well as feelings of psychological attachment (Rusbult et al., 1998). The model implies that applicants' commitment to online career services should be affected by three factors: quality of alternatives, investment size, and satisfaction. Let us develop these dimensions seriatim: Quality of alternatives can be taken to refer to the perceived desirability of the best available alternative web sites that provides similar technologies and services, as compared to the web site currently used by applicants. Rusbult (1983) noted that the presence of an attractive alternative could threaten a relationship. The presence of good quality alternatives appears to be associated with diminished probability of commitment (Rusbult, 1980).

It is invaluable to translate this impressionistic view into a clear, more formal hypothesis:

\section{H3: Quality of Alternatives is negatively associated with applicants' affective commitment to online career services.}

Likewise, if customers are aware of many appealing alternative career websites they may be attracted by their relative advantages and simultaneously deemphasize the costs/rewards with their current web site (Li et al., 2006). This leads to proposing the following relationship: 
H4: Quality of alternatives is negatively associated with applicants' calculative commitment to online career services.

When applicants invest time, money and/or effort in a career service, investment size may function as a psychological inducement to maintain a relationship. Customers heavily invested in a relationship (e.g., time to fill in detailed resume data, online knowledge tests) with a vendor have much to lose should the relationship end (Farrell \& Rusbult, 1992). As stated earlier, greater investment size is associated with stronger tendencies toward commitment and reduced probability of breaking the current relationship. As a result, increased investment in relationships should be positively associated with affective commitment (Rusbult, 1983).

Accordingly, H5: Investment size is positively associated with applicants' affective commitment to online career services.

Likewise, according to Becker (1960) investment size helps in developing calculative commitment. Hence, it is hypothesized:

H6: Investment size is positively associated with applicants' calculative commitment to online career services.

\section{Satisfaction}

Customer satisfaction is highly important for maintaining long-term relationships because it provides high rewards and low costs (Sirdeshmukh et al., 2002). It represents an overall evaluation based on the total purchase and consumption experience with a good or service over time (Anderson et al., 1994). Satisfaction is one of the most studied constructs in the history of marketing scholarship (Szymanski \& Henard, 2001). Satisfaction is strongly related to affective commitment (Nusair \& Hua, 2009). In other words, a customer who is satisfied with an online career service tends to be emotionally attached to that relationship. The following hypothesis is therefore proposed.

H7: Satisfaction is positively associated with applicants' affective commitment to online career services. 


\section{Measures}

All research constructs will be measured using multiple-item seven-point Likert scales (mostly, with strongly disagree and strongly agree type anchoring scales). As much as is possible, these scales will have already been reliably and validly used in numerous published studies. Minor modifications will invariably be needed to fit the context of online career services. In my future research, I will measure affective commitment using a three-item scale measure and calculative commitment using a four-item scale measure adapted from Allen and Meyer (1990). Investment size will be measured using a four-item scale; satisfaction a fouritem scale and quality of alternatives a three-item scale measure. These three scales will be adapted from Rusbult et al. (1998), see Table 2.

Table 2. A sample set of prospective questionnaire items(to be refined in the first phases of the proposed research).

\begin{tabular}{|c|c|c|}
\hline Constructs & Authors & Questionnaire items \\
\hline $\begin{array}{l}\text { Affective } \\
\text { commitment }\end{array}$ & $\begin{array}{l}\text { Allen \& Meyer, } \\
1990\end{array}$ & $\begin{array}{l}\text { 1. It is easy to become attached to this career service. } \\
\text { 2. This career service has a great deal of personal meaning for me. }\end{array}$ \\
\hline $\begin{array}{l}\text { Calculative } \\
\text { commitment }\end{array}$ & $\begin{array}{l}\text { Allen \& Meyer, } \\
1990\end{array}$ & $\begin{array}{l}\text { 1. I am afraid something will be lost if I stop using this career } \\
\text { service. } \\
\text { 2. To stop using this career service would require considerable } \\
\text { personal sacrifice. } \\
\text { 3. Some aspects of my life would be affected if I stop using this } \\
\text { career service. } \\
\text { 4. One of the few serious consequences of stopping use of this } \\
\text { career service would be the scarcity of available alternatives. }\end{array}$ \\
\hline $\begin{array}{l}\text { Quality of } \\
\text { alternatives }\end{array}$ & $\begin{array}{l}\text { Rusbult, Martz } \\
\text { \& Agnew, } 1998\end{array}$ & $\begin{array}{l}\text { 1. An alternative career service is appealing. } \\
\text { 2. To my knowledge, another career service is close to ideal. } \\
\text { 3. An alternative career service is attractive to me. }\end{array}$ \\
\hline Investment size & $\begin{array}{l}\text { Rusbult, Martz } \\
\text { \& Agnew, } 1998\end{array}$ & $\begin{array}{l}\text { 1. Many aspects of my life have become linked to this career } \\
\text { service. } \\
\text { 2. I have invested a lot in learning how to use this career service. } \\
\text { 3. The time I have spent on this career service is significant. }\end{array}$ \\
\hline Satisfaction & $\begin{array}{l}\text { Rusbult, Martz } \\
\text { \& Agnew, } 1998\end{array}$ & $\begin{array}{l}\text { 1. I feel satisfied with this career service. } \\
\text { 2. My experience with this career service is very pleasing. } \\
\text { 3. This career service makes me happy. } \\
\text { 4. This career service does a satisfactory job of fulfilling my needs. }\end{array}$ \\
\hline
\end{tabular}

Moreover, I will have the option available of various objective as well as perceptual assessments of the dependent variable "sustainable use of an online job site." This mode of verification will occur through user click tracking, time spent on the career site, log files and other registrations of online user behaviour. The non-perceptual measures of online usage will prevent common-method bias user. Studying user behaviour by using subjective and objective measures should better reflect the complexity of user interactions with a website (Brooks et al., 2010). 
The survey research instrument will be pre-tested twice with smaller groups of applicants. After implementing the suggestions from the first and second pre-test (and eventually further testing), all constructs will need to achieve reliability coefficients greater than 0.70 (Hair et al., 2005). Data will be analysed using SPSS 16 and Lisrel 8.

A confirmatory factor analysis (CFA) will be used to measure the adequacy of the proposed measurement model. As proposed by Khattree and Naik (2000), the multivariate normality assumption will be evaluated. If the results indicate that the multivariate normality assumption is not violated, the maximum likelihood method of estimation will be used. Next, goodness-of-fit measures will be used to assess the overall model fit.

The measurement model will be further evaluated for its reliability, convergent validity and discriminant validity. The reliabilities of the constructs need to be above the threshold value of 0.70 (Chen \& Hitt, 2002). In addition, the average variance extracted (AVE), as suggested by Garbarino \& Johnson (1999), will be used to assess convergent validity. The AVE values need to exceed the 0.50 threshold value. I will also compare the inter-construct correlations with the square root of AVE, and aim to get positive support for discriminant validity (Fornell \& Larcker, 1981).

In the next analytical step, the structural model will be evaluated. The overall model fit in both measurement and structural models will be evaluated using the following goodnessof-fit indices: Chi-Square/df ratio, CFI, GFA, AGFA, NFI, PNFI, RFI, IFI and RMSEA (Schumacker \& Lomax, 2010). The goodness-of-fit measures will be used to assess the overall structural model correspondence.

All in all, the research proposal outlined in the above addresses what I consider one of the most pressing issues in e-Recruiting research. This sketch of the needed research is only part of the scope of the research reported in this entire book. For summaries of each chapter, I refer to the beginning and end of each of the foregoing chapters and also to the overall summary of the book (both in English and in Dutch). 


\section{Concluding Remarks}

Bringing the virtues of the best explanatory theories of HRM/OB and IS together was challenging, mirroring the real life difficulty of persuading traditional personnel departments of the genuine working value of computerized information systems. Overcoming barriers to IT adoption in recruiting requires a deeper understanding of the requirements of e-Recruiting systems. The dissertation has shown that poorly designed and ineffective recruiting services discourage job applicants from submitting and updating profiles (Lee, 2011). Recruiters, in the business of screening job applicants, are increasingly dependent on information systems especially digital resume databases. They were found to be frustrated about wasting their time on digital applicants in outdated resume profile databases (Furtmueller et al., 2010). Consequently, this thesis took a service engineering approach by studying the diverse requirements of applicants, recruiters, system designers, and developers as well as managers of e-Recruiting systems, in order to innovate services and make e-Recruiting services more dynamic and thus sustainable. Recruiting is a natural candidate for service development as recruiting services exemplify the service dominated logic of business. However much of this potential is yet to be realized.

The theoretical implications of this dissertation are to bring together the concepts of eRecruiting services architecture and the options that are inherent in the dynamic design and operation of market structures, processes and workflows for strategic human resources sourcing. These solutions are innovative and offer a way forward for known issues identified by e-HRM researchers, such as: developing and maintaining a consistent, extensible, and learning vocabulary of resume data and matching process; bridging the boundaries between researchers, developers, recruiters and applicants; managing the long-life of digital resumes and leveraging this into a dialogue between recruiters and applicants; crowdsourcing local knowledge of skills and qualifications; and offering the potential for greater automation of many currently manual functions.

This dissertation is useful for organizations to more effectively coordinate recruiting processes; internationally-oriented strategists who need to optimize global recruiting services; designers and developers of service-oriented staffing systems; and academics engaged in strategic e-HRM type research. We also offer some general insights based on our experience 
of a large service development project, for methodologies for IT service development, and areas of future research in managing service development projects.

Apparently, e-Recruiting services require not only useful information sections on careers and continuing education, but can also encourage social exchanges of their users if they perceive that doing so might contribute to advancing their careers. The future is likely to belong to those providers who rethink the elusive nature of loyalty in hyperspace, and to best understand their users' shared social identity. Once they grasp this they should strive to provide semantic technologies that genuinely enhance users' online experiences in terms of social exchange, self-esteem, privacy, sense of control and playfulness.

I hope this research will stimulate knowledge sharing across organizations, industries, cultural boundaries and disciplines for more innovative and sustainable e-Recruiting services design. 


\section{References}

Ajzen, I. 1991. The Theory of Planned Behavior. Organizational Behavior and Human Decision Processes, 50: 179-211.

Allen, N.J. \& Meyer, J.P. 1990. The Measurement and Antecedents of Affective, Continuance and Normative Commitment to the Organisation. Journal of Occupational Psychology, 63: $1-18$

Anderson, E. \& Weitz, B. 1992. The use of pledges to build and sustain commitment in distribution channels. Journal of Marketing Research, 29: 18-43

Anderson, E., Fornell, C. \& Lehmann, D. 1994. Customer satisfaction, market share, and profitability: findings from Sweden. Journal of Marketing, 58(3): 53-66.

Bansal, H., Irving, P. \& Taylor, S. 2004. A three-component model of customer commitment to service providers. Journal of Academy of Marketing Science, 32(3): 109-250.

Bardhan, I., Demirkan, H., Kannan, P.K., Kauffman, R.J. \& Sougstad, R. 2010. An Interdisciplinary Perspective on IT Services Management and Services Science. Journal of Management Information Systems, 26 (4): 13-65.

Bauer, T.N., Truxillo, D.M., Paronto, M.E., Weekley, J.A. \& Campion, M.A. 2004. Applicant Reactions to Different Selection Technology: Face-to-Face, Interactive Voice Response, and Computer-Assisted Telephone Screening Interviews. International Journal of Selection and Assessment, 12: 135-148.

Becker, H. 1960. Notes on the concept of commitment. Journal of Sociology, 66: 32-42.

Bergman, M. 2006. The relationship between affective and normative commitment: review and research agenda. Journal of Organization Behavior, 27(5): 645-663.

Bettencourt, L. 1997. Customer voluntary performance: customers as partners in service delivery. Journal of Retailing, 73(3): 383-406.

Bitner, M.J. 1990. Evaluating service encounters: the effects of physical surroundings and employee responses. Journal of Marketing, 54: 69-82.

Bondarouk, T. \& Furtmueller, E. 2012. e-HRM Promises and Empirical Findings: Four Decades of Research. International HRM Conference: Innovation, Creativity and eHRM. Nottingham Business School, UK, March. 28-29.

CedarCrestone, 2011-2012. HR Systems Survey: HR Technologies, Deployment Approaches, Value, and Metrics. 14th Annual Edition (http://www.cedarcrestone.com).

Chen, P., \& Hitt, L. 2002. Measuring switching costs and the determinants of customer retention in Internet-enabled businesses: a study of the online brokerage industry. Information Systems Research, 13(3): 255-274.

Cichy, R., Cha, J. \& Kim, S. 2009. The relationship between organizational commitment and contextual performance among private club leaders. International Journal of Hospitality Management, 28(1): 53-62.

Cober, R.T., Brown, D.J., Keeping, L.M. \& Levy, P.E. 2004. Recruitment on the Net: How do Organizational Web Site Characteristics Influence Applicant Perceptions? Journal of Management, 30: 623-646.

Davis, F.D., Bagozzi, R.P. \& Warshaw, P.R. 1989. User Acceptance of Computer Technology: A Comparison of Two Theoretical Models. Management Science, 35(8): 982-1003.

Davis, M.D., Spohrer, J.C. \& Maglio, P.P. 2011. How technology is changing the design and delivery of Services. Operations Management Research, 4: 1-5.

DeLone, W.H. \& McLean, E.R. 2004. Measuring e-commerce success: applying the DeLone $\&$ McLean information systems success model. International Journal of Electronic Commerce 9(1): 31-47. 
Denzin, N.K. \& Lincoln, Y.S. 2000. Handbook of qualitative research, Thousand Oaks, CA: Sage.

Duncker, 1945. On problem solving. Psychological Monographs, 58(5): No. 270.

Edvardsson, B. \& Roos, I. 2001. Critical incident techniques.Towards a framework for analysing the criticality of critical incidents. International Journal of Service Industry Management, 12 (3): 251-268.

Farrell, D. \& Rusbult, C. 1992. Exploring the exit, voice, loyalty, and neglect typology: the influence of job satisfaction, quality of alternatives, and investment size. Employee Responsibilities and Rights Journal, 5(3): 201-218.

Feldman, D. \& Klaas, B. 2002. Internet Job Hunting: A Field Study of Applicant Experiences with Online Recruitment. Human Resource Management, 41(2): 175-201.

Fensel, D., Facca, F.M., Simperl, E. \& Toma, J. 2011. Semantic Web Services. Springer: Heidelberg.

Flanagan, J.C. 1954. The critical incident technique. Psychological Bulletin, 51(4): 327-58.

Fornell, C. \& Larcker, D. 1981. Evaluating structural equation models with unobservable variables and measurement error. Journal of Marketing Research, 18(1): 39-50.

Fullerton, G. 2005. The service quality e-loyalty relationship in retail services; does commitment matter? Journal of Retailing and Consumer Services, 12(2): 99-111.

Furtmueller, E., Wilderom, C. \& van Dick, R. 2008. Transforming Exchange-based Job Boards into Lasting Career Communities. Business Information Systems Conference Social Aspects of the Web, Innsbruck, Austria, May 5-7.

Furtmueller, E., Wilderom, C. \& van Dick, R. 2009. Utilizing the Lead User Method for promoting Innovation in e-Recruiting. In Handbook of Research on E-Transformation and Human Resources Management Technologies, 251-273. (Eds). T.V. Bondarouk, H.J.M. Ruël, E. Oiry and K. Guiderdoni-Jourdan, Information Science Reference, New York.

Furtmueller, E., Wilderom, C. \& van Dick, R. 2010. Sustainable e-recruiting portals: How to motivate applicants to stay connected throughout their careers? International Journal of Technology and Human Interaction. 6(3): 1-20.

Furtmueller, E., Wilderom, C. \& Tate, M. 2011. Managing recruitment and selection in the digital age: e-HRM and resumes. Human Systems Management, (4)30: 1-17.

Garbarino, E. \& Johnson, M. 1999. The different roles of satisfaction, trust and commitment in customer relationships. Journal of Marketing, 63: 70-87.

Gardner, S.D., Lepak, D.P. \& Bartol, K.M. 2003. Virtual HR: The impact of information technology on the human resource professional. Journal of Vocational Behavior, 63(2): 159-179.

Geyskens, I., Steenkamp, E., Scheer, L. \& Kumar, N. 1996. The effects of trust and interdependence on relationship commitment: a trans-Atlantic study. International Journal of Research in Marketing, 13: 303-317.

Gueutal, H.G. \& Stone, D.L. 2005. The Brave New World of e-HR: Human Resources Management in the Digital Age. San Francisco: Jossey-Bass.

Gustafsson, A., Johnson, M.D. \& Roos, I. 2005. The Effects of Customer Satisfaction, Relationship.Commitment Dimensions, and Triggers on Customer Retention. Journal of Marketing, 69: 210-218.

Hair, J., Anderson, R., Tatham, R. \& Black, W. 2005. Multivariate data analysis. (6th Ed.). New Jersey: Prentice Hall.

Khattree, R. \& Naik, D.M. 2000. Multivariate data reduction and discrimination with SAS software. SAS Institute, Cary, NC.

Lee, I. 2011. Modeling the benefit of e-recruiting process integration. Decision Support Systems. 51 (1): 230-239. 
Li, D., Browne, G. \& Chau, P. 2006. An empirical investigation of web site use using a commitment-based model. Decision Sciences, 37(3): 427-444.

Luchins, A.S. \& Luchins, E.H. 1959. Rigidity of Behavior: A Variational Approach to the Effect of Einstellung (123-124), University of Oregon Books: Eugene, Oregon.

Martin, G. \& Reddington, M. 2010. Theorizing the links between e-HR and strategic HRM: a model, case illustration and reflections. International Journal of Human Resource Management, 21(10): 1553-1574.

Meyer, J.P., Becker, T.E. \& Van Dick, R. 2006. Social Identities and Commitments at Work: Toward and Integrative Model. Journal of Organizational Behavior, 27: 665-683.

Miles, M.B. \& Huberman, A.M. 1994. Qualitative Data Analysis: An Expanded Sourcebook (2nd Ed.). Thousand Oaks, CA: Sage.

Morgan, R. \& Hunt, S. 1994. The commitment-trust theory of relationship marketing. Journal of Marketing, 58: 20-38.

Nusair, K. \& Hua, N. 2009. Comparative assessment of structural equation modeling and multiple regression: e-commerce context. Tourism Management, 31(3): 314-324.

Olsen, M.J.S. 1992. Quality in retail banking: customers' perceived problems with bank services: a study using critical-incident method. Doctoral thesis, The University of Stockholm and Center for Service Research (CTF), Karlstad, Sweden.

Parry, E. \& Tyson, S. 2008. An analysis of the use and success of online recruitment methods in the UK. Human Resource Management Journal, 18 (3): 257-274.

Ployhart, R.E. 2006. Staffing in the 21st Century: New Challenges and Strategic Opportunities. Journal of Management, 32(6): 868-897.

Preece, J. 2000. Online Communities: Designing Usability, Supporting Sociability. Chichester: Wiley.

Ren, Y., Kraut, R. \& Kiesler, S. 2007. Applying Common Identity and Bond Theory to Design of Online Communities. Organization Studies, 28(3): 377-408.

Rusbult, C. 1980. Commitment and satisfaction in romantic associations: a test of the investment model. Journal of Experimental Social Psychology, 16: 172-186.

Rusbult, C. 1983. A longitudinal test of the investment model: the development (and deterioration) of satisfaction and commitment in heterosexual involvements. Journal of Personality and Social Psychology, 45: 101-117.

Rusbult, C., Martz, J. \& Agnew, C. 1998. The investment model scale: commitment level, satisfaction level, quality of alternatives, and investment size. Personal Relationships, 5: 357-391.

Schumacker, R. \& Lomax, R. 2010. A beginner's guide to structural equation modelling (3rd Ed.). New York: Routledge.

Sirdeshmukh, D., Singh, J. \& Sabol, B. 2002. Consumer trust, value, and loyalty in relational Exchanges. Journal of Marketing, 66: 15-37.

Smale, A. \& Heikkilä, J.P. 2009. IT-Based integration of HRM in a foreign MNC subsidiary: A micro-political perspective (153-170). Handbook of Research on ETransformation and Human Resources Management Technologies: Organizational Outcomes and Challenges.

Smith, A.D. \& Rupp, W.T. 2004. Managerial Challenges of e-Recruiting. Online Information Review, 28(1): 61-74.

Stone, D.L., Stone-Romero, E.F. \& Lukaszewski, K. 2006. Factors Affecting the Acceptance and Effectiveness of Electronic Human Resource Systems. Human Resource Management Review, 16(2): 229-244.

Strauss, A. \& Corbin, J. 1998. Basics of qualitative research: Techniques and procedures for developing grounded theory. (2nd Ed.), Thousand Oaks, CA: Sage. 
Szmigin, I., Canning, L. \& Reppel, A.E. 2005. Online Community: Enhancing the Relationship Marketing Concept through Customer Bonding. International Journal of Service Industry Management, 16(5): 480-496.

Szymanski, D. 2001. Henard Customer satisfaction: a meta-analysis of the empirical evidence. Journal of the Academy of Marketing Science, 29(1): 16-35.

Wolfswinkel, J., Furtmueller, E. \& Wilderom, C. 2012. Using grounded theory as a method for rigorously reviewing literature. European Journal of Information Systems, doi:10.1057, in press. 


\section{Further Reading: Publications from the Author}

\section{Journal articles, proceedings, book chapters and presentations}

1. Furtmueller, E. \& Tate, M. "Technology as a service in global talent recruitment", Academy of Management Meetings, Boston, USA, Aug 3-7, 2012.

2. Bondarouk, T. \& Furtmueller, E. "Electronic Human Resource Management: Four Decades of Empirical Evidence", Academy of Management Meetings, Boston, USA, Aug 3-7, 2012 (Best Paper Proceedings in the Human Resource Management Division).

3. Furtmueller, E. "Digital resumes for recruitment and selection: e-HRM's achilles heel", Academy of Management Meetings, Boston, USA, Aug 3-7, 2012.

4. Furtmueller, E., Tate, M. \& Wilderom, C. "Strategic Human Resource Management Systems: The service-dominant logic", Journal of Strategic Information Systems, (second revision).

5. Furtmueller, E., Wilderom, C. \& van Dick, R. "Sustainable e-Recruiting portals", In Human interaction with technology for working, communicating and learning: Advancements (66-86). (Ed). Mesquita, A., Information Science Reference: Hershey, PA, 2012.

6. Bondarouk, T. \& Furtmueller, E. "E-HRM Promises and Empirical Findings: Four Decades of Research", Keynote Presentation, International HRM Conference: Innovation, Creativity and e-HRM, Nottingham Business School, UK, March 28-29, 2012.

7. Wolfswinkel, J., Furtmueller, E., Wilderom C. \& Tate. M. "How to rigorously review literature using Grounded Theory", International Conference of Information Systems, AIS Special Interest Group on Grounded Theory Methodology, Shanghai, China, Dec 4-7, 2011.

8. Furtmueller, E. Wilderom, C. \& Tate, M. "Managing recruitment and selection in the digital age: e-HRM and resumes", Human Systems Management, 2011, 30(4): 243-259.

9. Wolfswinkel, J., Furtmueller, E. \& Wilderom, C. "Using grounded theory as a method for rigorously reviewing literature", European Journal of Information Systems, doi:10.1057 (in press).

10. Furtmueller, E., van Dick, R. \& Wilderom, C. "Service behaviour of highly committed financial consultants", Journal of Service Management, 2011, 22(3): 317-343.

11. Furtmueller. E., Wilderom C. \& Rao, P. "Young IT professionals preferred recruiting modes in the contemporary economy", European Journal of Management, 2011, 11(1):119.

12. Furtmueller. E., van Dick, R. \& Wilderom, C. "On the illusion of organizational commitment among finance professionals", Team Performance Management, 2011, 17, 5(6): 255-278.

13. Furtmueller, E., Wilderom, C. \& Tate, M. "Recruiters and the dilemma of finding the right match in our flat world", Academy of Management Meetings, San Antonio, USA, Aug 12-16, 2011.

14. Furtmueller. E. Rao, P. \& Wilderom C. "Traditional versus web 2.0 recruiting practices", International Academy of Business and Economics, Barcelona, Spain, June 3-5, 2011.

15. Furtmueller, E., van Dick, R. \& Wilderom, C. "Professionals' Balancing of Customer and Firm Interests: On Finance Professionals' Foci of Commitment", in Talent Management of Knowledge Employees: Embracing Non-traditional Workforce, 163-179, (Ed). V. Vaiman, Palgrave Macmillan: UK, 2010.

16. Furtmueller, E., Wilderom, C. \& van Dick, R. "Sustainable e-Recruiting portals: How to motivate applicants to stay connected throughout their careers?", International Journal of Technology and Human Interaction, 2010, 6(3): 1-20. 
17. Furtmueller, E., Wilderom, C. \& Mueller, R. "Online Resumes: Optimizing Design to Service Recruiters", Proceedings of the European Conference on Information Systems, June 7-9, 2010, Pretoria, South Africa.

18. Wolfswinkel, J., Furtmueller, E. \& Wilderom, C. "Reflecting on e-Recruiting Research Using Grounded Theory", Proceedings of the European Conference on Information Systems, June 7-9, 2010, Pretoria, South Africa.

19. Jansen, C., Furtmueller, E. \& Wilderom, C. "Usability Study on Dutch e-Recruiting Services - Limitations and possibilities from the applicants' perspective", Proceedings of the International Conference on Enterprise Information Systems, track HRIS, May 6-10, 2009, Milan.

20. Furtmueller, E. \& Kijl, B. "Service Innovation in Online Recruiting", Communications of IBIMA, 10(23): 174-185, 2009 (presented at 11th International Business Information Management Association, Jan 4-6, 2009, Cairo, Egypt).

21. Furtmueller, E., Wilderom, C. \& Ruel, H. "Web recruiters service quality criteria: a content analysis", Proceedings of the International Conference on System Science, Jan 58, 2009, Hawaii.

22. Furtmueller, E., Wilderom, C. \& van Dick, R. "Utilizing the Lead User Method for promoting Innovation in e-Recruiting", In Handbook of Research on E-Transformation and Human Resources Management Technologies, 251-273, (Eds). T.V. Bondarouk, H.J.M. Ruël, E. Oiry \& K. Guiderdoni-Jourdan, Information Science Reference, Hershey: New York, 2009.

23. Furtmueller, E. "Innovating e-Recruiting Services", Research Seminar, December 10, 2008, Department of Information Systems \& Change Management, University of Twente, the Netherlands.

24. de Vries, K., Furtmueller, E., Schaefer, M.T. Andersen, C. \& Rieder, B. "Community, Privacy, and Power: The Complex Relationships of Web 2.0", Panel presentation, Association of Internet Researchers Conference, October 16-18, 2008, IT University Copenhagen, Denmark.

25. Furtmueller, E., Wilderom, C. \& van Dick, R. "Transforming Exchange-based Job boards into Lasting Career Communities, in Fleitjer, D. et al. Business Information Systems 2008, 109-116, ISBN 978-83-916842-5-2.

26. Furtmueller, E., Wilderom, C., van Dick, R. \& Kent, T. "Innovating Online Career Services: The Role of User Involvement", Association of Internet Researchers Conference, October 16-18, 2008, IT University Copenhagen, Denmark.

27. Furtmueller, E., van Dick, R. \& Wilderom, C. "Tapping and mapping financial consultants' high commitment behaviour", Academy of Management Meetings, Anaheim, CA, USA, August 10-13, 2008.

28. Furtmueller, E. "Participative Online Career Communities", OCIS Consortium, Academy of Management Meetings, Anaheim, CA, USA, August 8-9, 2008.

29. Furtmueller, E. \& Wilderom, C., "Innovations in e-Recruiting: Empirical Findings on the Lead User Method", Annual Workshop on Open and User Innovation, Harvard Business School, Boston, USA, August 4-6, 2008.

30. Furtmueller, E. (2008) "Learning through Serving", Journal of Human Resource Education, 2 (3):1-2.

31. Furtmueller, E. "How Online Career Communities Transform Work", ASA Communication \& Information Technologies Workshop, Worlds of Work: Communication \& ICT, Massachusetts Institute of Technology, Boston, USA, July 31, 2008. 
32. Furtmueller, E., Wilderom, C., van Dick, R. \& Young-Hee Hur, S. "Outcomes of Professionals High Commitment Behavior in Service Contents", Annual Professional Service Conference, Saïd Business School, University of Oxford, England, July 6-8, 2008.

33. Young-Hee Hur, S., Wilderom, C. \& Furtmueller, E. "Leadership style, emotional intelligence and performance: Evidence and challenges reviewed". Proceedings of the International Research Seminar in Service Management, La Londe les Maures, France, May 27-30, 2008.

34. Furtmueller, E., Wilderom, C. \& van Dick, R., "Transforming Exchange-based Job Boards into Lasting Career Communities", Business Information Systems Conference Social Aspects of the Web, Innsbruck, Austria, May 5-7, 2008.

35. Furtmueller, E., Wilderom, C. \& Kent, T. "Service Innovation in sustainable recruiting platforms: Optimizing User Involvement", Innovation Workshop, April 4, 2008, Utrecht, in Eerste Nederlandse Diensteninnovatie, Telematica Institute, University of Twente.

36. Furtmueller, E., van Dick, R., Kent, T., \& Lehner, J. "The meaning of financial consultants' commitment behaviours, foci and motives", Academy of Management Meetings, Philadelphia, PA, USA, August 3-8, 2007.

37. Furtmueller, E., van Dick, R., Lehner, J. \& Kent, T. "Does it pay off to employ committed financial consultants?", European Group for Organization Studies Conference, Vienna, Austria, July 5-7, 2007.

38. Furtmueller, E. "Students' commitment to high performance is not a matter of chance", Young Teacher's Excellence Conference, Bratislava, Jan 15-16, 2007, in Gregušová, Gabriela (ed.): How to Teach Political Science? The Experience of First-time University Teachers, Nr. 5, 2007, Bratislava: epsNet Teaching Political Science series.

39. Furtmueller, E. Rethinking Commitment and Identification of Finance Professionals, Research Colloquium, University of Frankfurt, Department of Social Psychology, Germany, November 07, 2006.

40. Furtmueller, E. "Conference Summary: Commitment in Organizations", Journal of Personnel Psychology, 5(3): 142-143, 2006, Hogrefe: Göttingen.

41. Furtmueller, E. "Creativity in Service Delivery", Berkeley Annual Leadership Symposium, University of California, Berkeley, USA, February 4-5, 2006.

\section{Books}

42. Furtmueller, E. (forewords by Rolf van Dick, David J. Teece \& Tom Kent) "Highly Effective Behaviors of Financial Consultants", ISBN 978-3-8349-1272-5, Gabler Verlag: Wiesbaden, 2008.

43. Furtmueller, E. "Innovative Developments in Human Resource Management due to Retention Management of High Potentials", ISBN 978-3-85487-546-8, 2004, $\underline{\text { Trauner }}$ Verlag: Linz, 2003.

44. Furtmueller, E. “Technology as a Service in Global Talent Recruitment”, PhysicaSpringer, in prep.

\section{Invited presentations}

45. Furtmueller, E. Innovating e-Recruiting Services, Research Seminar, December 10, 2008, Department of Information Systems \& Change Management, University of Twente, the Netherlands.

46. Furtmueller, E. Utilizing Semantic Technologies for Developing Online Career Portals, September 19, 2007, techCenter Linz, Austria.

47. Furtmueller, E. Commitment Foci, Behaviours and Motives: A Means-end Chain Analyses among Finance Professionals, June 21, 2006, Research Colloquium, Institute of Organization and Innovation, University of Linz, Austria. 
48. Furtmueller, E. Rethinking Commitment and Identification of Finance Professionals, November 07, 2006, Research Colloquium, Department of Social Psychology, University of Frankfurt, Germany.

49. Furtmueller, E. The Meaning of Professionals' Commitment, Doctoral Research Colloquium in Organizational Behaviour, Oct 6, 2005, University of California, Berkeley, Haas School of Business, USA.

\section{Research reports}

50. Austrian Business Services Reports, Fund No. 11/22277. Development of Innovative Career Portals, 2006-2008, research end report, 2008.

51. Austrian Research Promotion Agency FFG, Fund No. 813.190. Innovating eRecruiting Services by Semantic Technologies, research progress mid report, 20052007.

52. Austrian Research Promotion Agency FFG, Fund No. 815.547, research end report, 2007.

\section{Research in progress}

53. Tate, M., Furtmueller, E. \& Wilderom, C. "Globalizing e-HRM Services: Localization versus Standardization of HRM Practices", European Journal of International Management, first revision.

54. Wolfswinkel, J., Furtmueller, E. \& Wilderom, C. "Reviewing e-Recruiting Literature Using Grounded Theory", European Journal of Information Systems, under review.

55. Bondarouk, T. \& Furtmueller, E. "Electronic Human Resource Management: Four Decades of Empirical Evidence", Journal of Management, to be submitted to the Annual Review Special Issue in June 2012.

56. Furtmueller, E., van Dick, R. \& Wilderom, C. "Tapping and mapping financial consultants' high commitment behaviour", Journal of Management Studies, in prep.

57. Furtmueller, E. Wolfswinkel, J. \& Wilderom, C. "A conceptual e-service quality model for career sites", Journal of Service Marketing, in prep.

58. Furtmueller, E., van Dick, R. \& Wilderom, C. "The meaning of financial consultants' commitment behaviours, foci and motives", Journal of Management Inquiry, in prep.

59. Furtmueller, E. \& Wilderom, C. "Effective service provision in the retail car industry: Sales agent perspectives", Journal of Business Research, in prep.

60. Furtmueller, E. \& Wilderom, C. "Service delivery on e-Recruiting sites: Limitations and possibilities from the applicants' perspective", International Journal of Business and Systems Research, in prep.

61. Bondarouk, T., Furtmueller, E., \& Wilderom, C. "Learning from an e-Recruiting implementation in a multinational organization", Journal of Organizational Change Management, in prep. 


\section{Nederlandse Samenvatting}

Dit proefschrift draagt bij aan de Electronic Human Resource Management (e-HRM) literatuur en is specifiek gericht op het vergroten van inzicht over het ontwerpen en innoveren van e-Recruiting technologieën. Ondanks de vele organisaties die trots hun succes met eRecruiting diensten verkondigen, kan niet worden ontkend dat veel van deze organisaties - na er jaren mee geëxperimenteerd te hebben - e-Recruiting al opgegeven hebben en terugtrekken naar ouderwetse routinematige wervingstechnieken, zoals advertenties in kranten, carrière beurzen en persoonlijke doorverwijzingen. Dit proefschrift laat zien dat e-Recruiting systemen regelmatig lijden onder duurzaamheidsproblemen met betrekking tot niet effectieve curriculum vitae opslag, problematiek bij het sorteren van grote hoeveelheden digitale sollicitatiebrieven en communicatieproblemen met HR / OB en IS wetenschappers en mensen uit de praktijk.

Het is uitdagend om de best-verklarende theorieën op het gebied van human resource management/gedrag in organisaties en informatiesystemen samen te brengen rondom eRecruiting issues. Het weerspiegelt de moeilijkheden die men typisch heeft om traditionele afdelingen Personeelszaken te overtuigen van de werkelijke arbeidswaarde van geautomatiseerde informatiesystemen. Het kan niet genoeg worden benadrukt hoe diep geworteld de loyaliteit is aan ouderwetse normale middelen van werving - waar persoonlijk contact en recruiters' individuele beoordeling van vaardigheden van sollicitanten (b.v. voorafgaande screening, selectiegesprekken, assessment centers) lang werden gezien als een integraal deel van de taak van recruiters. Recruiters zijn natuurlijk nog steeds belangrijk in het totale wervingsproces, dit omdat ze een fundamentele rol vervullen bij het verwoorden van informatie over de functie en de wervende organisatie. Dat gezegd hebbende, e-Recruitment zou recruiters moeten helpen om het matchen van werkgevers en werknemers naar een hoger niveau te brengen. Bijvoorbeeld organisaties die corporate carrière secties gebruiken, kunnen sollicitanten overduidelijk betere informatie bieden over de organisatie, de bedrijfscultuur, de baan en carrièreperspectieven.

Wanneer investeringen in technologie naïef gemaakt worden - zonder een overeenkomstige evolutie in de organisatorische competenties en routines, kan dit leiden tot een significant productiviteitsverlies. De potentiële waarde van IT is onderhevig aan overcompensatie door negatieve invloeden als gevolg van een diepgaande discrepantie tussen lang bestaande organisatorische werkwijzen en de geïmplementeerde IT-structuur. 
Het overwinnen van barrières voor adoptie van IT in de werving van personeel vereist dus een dieper inzicht in de eisen voor e-Recruiting systemen. Het proefschrift laat zien dat slecht ontworpen en ineffectieve wervingsdiensten sollicitanten ontmoedigen om profielen in te dienen en bij te werken. Recruiters, belast met het screenen van sollicitanten, zijn in toenemende mate afhankelijk van informatiesystemen, in het bijzonder digitale cv databases. Ze bleken gefrustreerd te zijn over het verspillen van hun tijd met digitale sollicitanten in verouderde databases met cv profielen.

Derhalve heeft dit proefschrift een Service Engineering benadering genomen door de uiteenlopende behoeften van de eindgebruikers van dergelijke systemen (aanvragers, recruiters, werknemer branding professionals), systeem ontwerpers, ontwikkelaars en beheerders van e-Recruiting systemen te bestuderen, om te innoveren en om e-Recruiting diensten dynamischer en dus duurzaam te maken.

De theoretische implicaties van dit proefschrift zijn het samenbrengen van de concepten en inzichten van e-Recruiting dienstenarchitectuur ten behoeve van de mogelijkheden die inherent zijn aan de dynamische opzet en de werking van markt structuren, processen en workflows voor strategische human resource toelevering. Om ten volle te profiteren van opkomende technologieën moeten elektronische wervingsactiviteiten naadloos worden geïntegreerd in het gehele wervingsproces. Belangrijk is dat effectieve e-Recruiting diensten niet alleen nuttige informatie secties vereisen over carrières en voortdurende bijscholing, ook kunnen zij bevorderlijk zijn voor de sociale uitwisselingen van hun gebruikers, zeker als zij ervaren dat dit zou kunnen bijdragen aan het bevorderen van hun carrière. De toekomst behoort daarom waarschijnlijk tot die loopbaan dienstverleners die goed nagedacht hebben over de ongrijpbare aard van loyaliteit in hyperspace, en zij die het beste de gedeelde sociale identiteit van hun gebruikers begrijpen. Als we dit eenmaal beter begrijpen, zouden we moeten streven naar semantische technologieën die de online ervaringen van gebruikers verbeteren in termen van sociale uitwisseling, het gevoel van eigenwaarde, privacy, gevoel van controle en speelsheid.

Dit boek is nuttig voor organisaties die hun wervingsprocessen effectiever willen coördineren: voor internationaal georiënteerde strategen die wereldwijde wervingsdiensten moeten optimaliseren, voor ontwerpers en ontwikkelaars van service-georiënteerde personeel systemen; en voor academici die zich bezighouden met strategisch e-HRM onderzoek. We bieden ook een aantal cross-culturele inzichten voor het beheer van e-Recruiting ontwikkelprojecten op basis van ons empirisch onderzoek in Oostenrijk, Nederland en NieuwZeeland. 

Research is all a matter of building bridges...

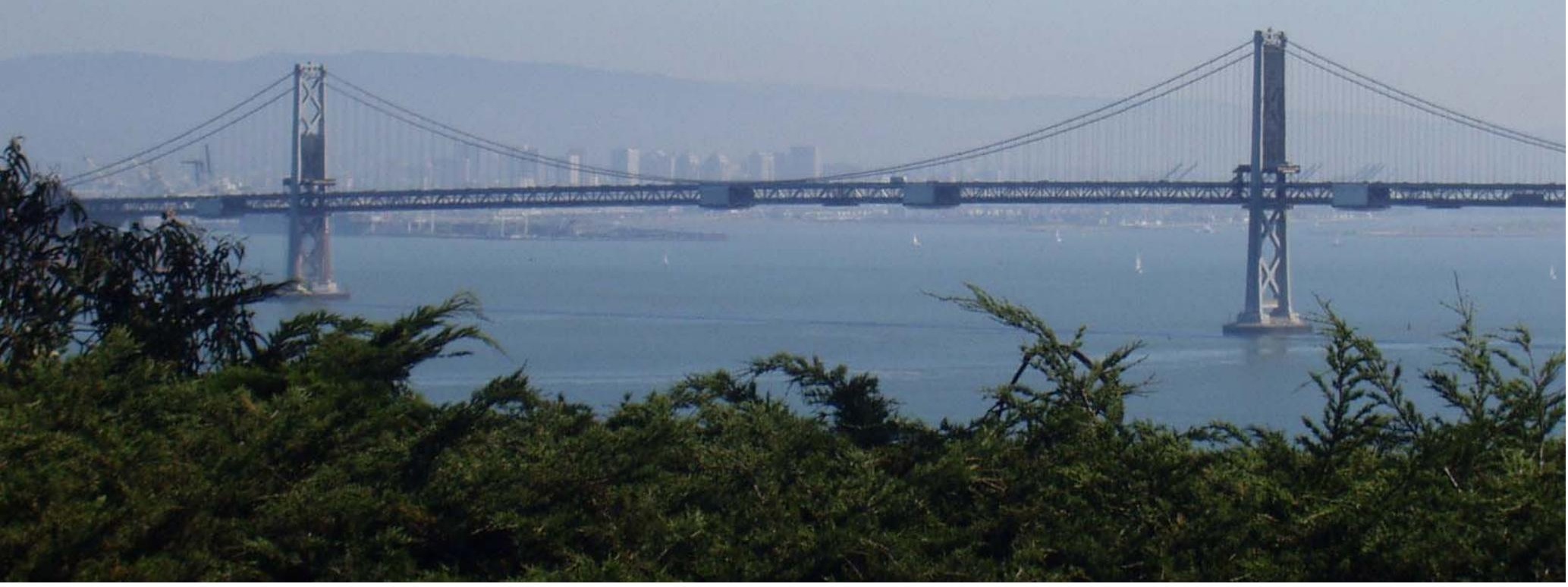

Elfi Furtmueller 